Carolina Angélica Araújo de Azevedo

\title{
Diversidade e Filogenia da ordem Halymeniales (Rhodophyta) no litoral do Brasil
}

Diversity and Phylogeny of the Order Halymeniales (Rhodophyta) on the Brazilian Coast

Versão corrigida

São Paulo - SP 


\section{Diversidade e Filogenia da ordem Halymeniales (Rhodophyta) no litoral do Brasil}

Diversity and Phylogeny of the Order Halymeniales (Rhodophyta) on the Brazilian Coast

Tese apresentada ao Instituto de Biociências da Universidade de São Paulo, para obtenção do Título de Doutor em Ciências, na Área de Botânica.

Orientadora: Mariana Cabral de Oliveira Co-orientadora: Valéria Cassano 


\section{Azevedo, Carolina}

Diversidade e Filogenia da Ordem Halymeniales (Rhodophyta) no litoral do Brasil. 217 p.

Tese (Doutorado) - Instituto de Biociências da Universidade de São Paulo. Departamento de Botânica.

1. Halymeniales. 2. 3. 4. Universidade de São Paulo. Instituto de Biociências. Departamento de Botânica.

Comissão Julgadora:

Prof $^{a}$. Dr ${ }^{\mathrm{a}}$. Estela Maria Plastino

Prof $^{\mathrm{a}}$. Dr ${ }^{\mathrm{a}}$. Mutue Toyota Fujii

Prof $^{a}$. Dr ${ }^{\mathrm{a}}$. Silvia Maria Pita de Beauclair Guimarães

Prof. Dr. José Marcos de Castro Nunes

Prof $^{a}$. Dr ${ }^{\mathrm{a}}$. Mariana Cabral de Oliveira 


\section{AGRADECIMENTOS}

À FAPESP, pela concessão das bolsas referentes aos processos DR 2011/19225-7 e BEPE 2013/25409-9.

Às orientadoras Mariana e Valéria, pela tão agradável parceria.

Àqueles que forneceram amostras e que auxiliaram durante as coletas.

Aos técnicos e professores do Laboratório de Algas Marinhas.

Ao Dr. Gary W. Saunders e aos membros de seu laboratório, pela assistência durante a realização do estágio no exterior.

Aos herbários de Harvard (Farlow Herbarium - FH) e da Universidade Federal de Santa Catarina (FLOR), pelos empréstimos de material.

À família.

Aos amigos. 


\section{ÍNDICE}

1. Introdução Geral .......................................................................................... 1

1.1 A taxonomia de algas vermelhas e a ferramenta molecular .................................. 1

1.2 A ordem Halymeniales (Rhodophyta) - histórico e cenário atual............................... 4

1.3 Importância ecológica e econômica das algas pertencentes à ordem Halymeniales .. 14

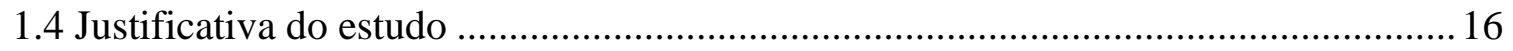

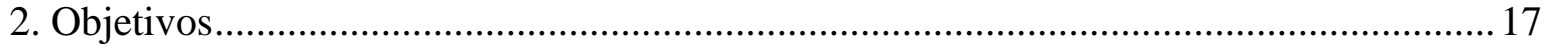

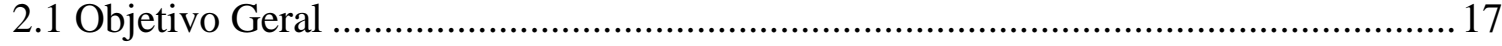

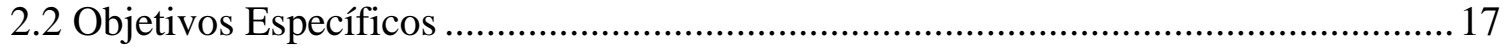

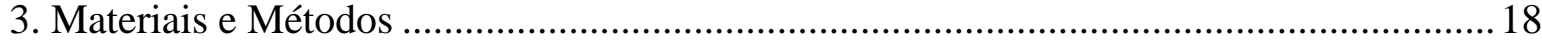

3.1 Obtenção de Amostras .................................................................................... 18

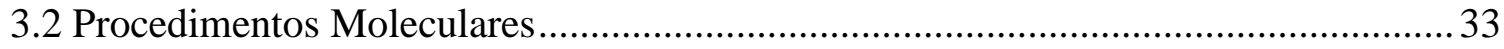

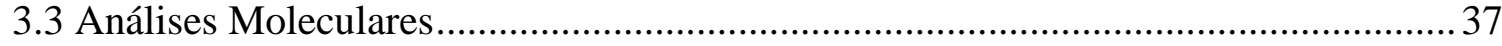

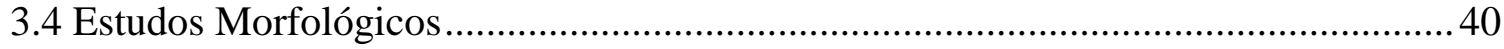

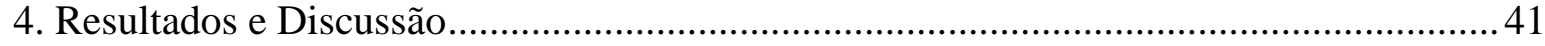

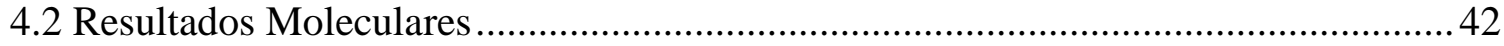

4.2 Distribuiçãa geográfica de espécies .................................................................55

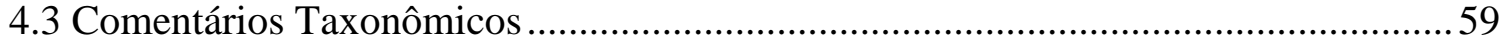

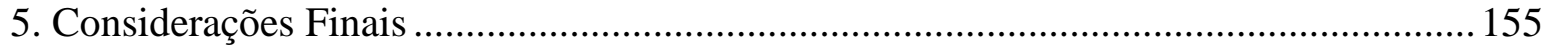

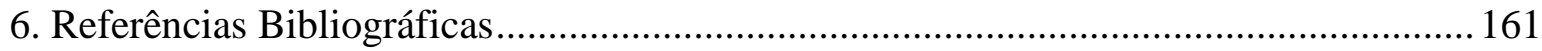

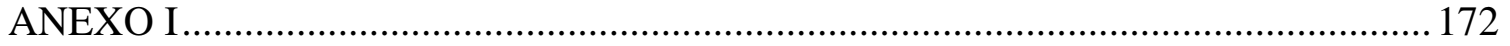

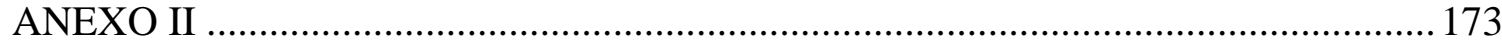

ANEXO III................................................................. 174

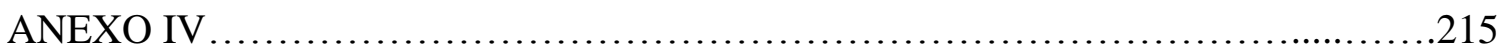




\section{LISTA DE TABELAS}

Tabela 1. Espécies de Halymeniales registradas no litoral do Brasil....................................8

Tabela 2. Dados de coleta das amostras incluídas neste estudo, para as quais foram gerados dados moleculares. A coluna "SPF" se refere ao número de tombamento para espécimes já incorporados ao Herbário da Universidade de São Paulo. A coluna "Marcadores Moleculares" se refere ao número de acesso no GenBank das sequências já depositadas, enquanto que "x" corresponde a sequências geradas que serão depositadas após a submissão dos artigos

Tabela 3. Primers utilizados para amplificação e sequenciamento de cada marcador molecular. .35

Tabela 4. Combinações de primers testados para o marcador COI-5P que não resultaram em amplificação. 36

Tabela 5. Números de acesso para sequências utilizadas na análise concatenada. A sequência obtida no banco de dados BOLD está indicada. As demais sequências foram obtidas no banco de dados GenBank. 39

Tabela 6. Valores de divergência intraespecífica (\%) nos grupos genéticos obtidos com os marcadores UPA e COI-5P. n.a.: não se aplica

Tabela 7. Valores de divergência interespecífica nos grupos genéticos obtidos com os marcadores UPA (abaixo da diagonal indicada por -) e COI-5P (acima da diagonal). n.a.: não se aplica.

Tabela 8. Valores de divergência (\%) de $r b c \mathrm{~L}$ entre amostras de "Cryptonemia" crenulata. .71

Tabela 9. Valores de divergência (\%) de $r b c \mathrm{~L}$ para amostras de Cryptonemia seminervis..81

Tabela 10. Valores de divergência (\%) de $r b c \mathrm{~L}$ para amostras de Grateloupia gibbesii.

Tabela 11. Cenário atual do conhecimento da diversidade de Halymeniales no litoral do Brasil.

Tabela 12. Comparação das características vegetativas dos principais gêneros encontrados neste estudo. 


\section{LISTA DE FIGURAS}

Figura 1. Número de amostras obtidas neste estudo, em cada estado do litoral brasileiro, conforme as zonas de diversidade de algas de acordo com Horta et al. (2001). .18

Figura 2. Árvore de agrupamento para sequências de UPA, gerada através do algoritmo Neighbor-joining. Os números nos nós representam os valores de Bootstrap para 1000 réplicas. Valores abaixo de 50 não são mostrados. Todas as sequências foram geradas neste estudo e são precedidas pelo código institucional (IBC) .................................................48

Figura 3. Árvore de agrupamento para sequências de COI-5P, gerada através do algoritmo Neighbor-joining. Os números nos nós representam os valores de Bootstrap para 1000 réplicas. Valores abaixo de 50 não são mostrados. Todas as sequências foram geradas neste estudo e são precedidas pelo código institucional (IBC).

Figura 4. Árvore filogenética com sequências de $r b c \mathrm{~L}$, gerada através do algoritmo de Máxima Verossimilhança. Os números nos nós representam valores de Bootstrap para 100 réplicas. Valores de bootstrap inferiores a 50 não apresentados. . Espécies-tipo de gêneros em negrito. Sequências geradas neste estudo precedidas pelo código institucional (IBC). Os números de acesso para as sequências obtidas no BOLD e no GenBank estão na Tabela 4 .53

Figura 5. Árvore filogenética com sequências concatenadas de COI-5P e $r b c \mathrm{~L}$, gerada através do algoritmo de Máxima Verossimilhança. Os números nos nós representam valores de Bootstrap para 100 réplicas. Valores de bootstrap inferiores a 50 não apresentados. Espécies-tipo de gêneros em negrito. Sequências geradas neste estudo precedidas pelo código institucional (IBC). Os números de acesso para as sequências obtidas no BOLD e no GenBank estão na Tabela 4. As áreas sombreadas indicam os cinco principais clados obtidos (numerados de 1 a 5), que refletem dados de distribuição geográfica. .54

Figura 6. Distribuição geográfica de espécies encontradas neste estudo, de acordo com o estado da federação brasileira. As áreas sombreadas indicam as zonas de diversidade de algas de acordo com Horta et al. (2001).

Figura 7. Distribuição global dos táxons representados na análise filogenética concatenada apresentada na Figura 5. Os números nos círculos indicam a ocorrência dos cinco clados principais. As zonas coloridas indicam a temperatura da superfície do mar. Imagem obtida no dia 26 de junho de 2015 e adaptada de http://www.ospo.noaa.gov .58

Figuras 8-9. Imagens de Corynomorpha cf. clavata...............................................61/63

Figuras 10-11. Imagens de "Cryptonemia” bengryi.................................................66/68

Figuras 12-13. Imagens de “Cryptonemia” crenulata .............................................69/73

Figuras 14-15. Imagens de “Cryptonemia” delicatula ..............................................75/78 
Figuras 16-20. Imagens do Complexo Cryptonemia seminervis. $.82 / 85 / 87 / 89 / 91$

Figuras 21-22. Imagens de "Halymenia” elongata ....................................................93/95

Figuras 23-24. Imagens de "Halymenia” floridana ...............................................97/100

Figuras 25-26. Imagens de Halymenia sp. 1....................................................103/105

Figuras 27-29. Imagens de Halymenia sp. 2..................................................106/108/109

Figuras 30-31. Imagens de Grateloupia cf. dichotoma.......................................112/114

Figuras 32-35. Imagens do Complexo Grateloupia filicina.........................117/119/120/121

Figuras 36-37. Imagens de Grateloupia filiformis..............................................122/124

Figuras 38-39. Imagens de Grateloupia gibbesii..................................................125/130

Figuras 40-41. Imagens de Grateloupia orientalis...............................................132/134

Figuras 42-43. Imagens de Grateloupia yangjiangensis.......................................137/139

Figuras 44-45. Imagens de Halymeniales sp. 1.................................................141/142

Figuras 46-47. Imagens de Halymeniales sp. 2 ...............................................143/144

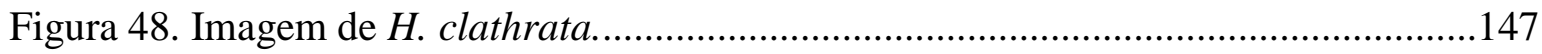

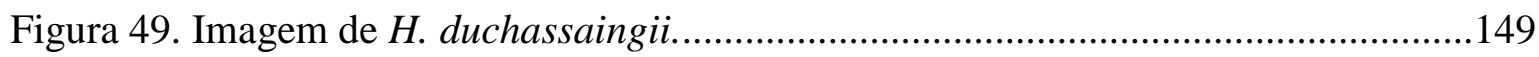

Figura 50. Materais-tipo de H. vinacea, $H$. integra e $H$. rosea.......................................153 


\section{ABREVIATURAS}

BOLD: Barcode of Life Database Systems.

COI-5P: região 5' do gene que codifica para a enzima citocromo c oxidase subunidade 1 .

GTR+G+I: General Time Reversible + Gamma Distribution + Proportion of Invariable Sites.

ML: Maximum Likelihood ou Máxima Verossimilhança.

NJ: Neighbor-joining.

pb: pares de base.

PCR: Polymerase Chain Reaction ou Reação em cadeia da polimerase.

$r b c \mathrm{~L}$ : gene codificante da subunidade grande da ribulose-1, 5-bifosfato carboxilaseoxigenase (Rubisco).

SPF: Herbário da Universidade de São Paulo.

UPA: Universal Plastid Amplicon, domínio V do gene 23S. 


\section{RESUMO}

As algas da ordem Halymeniales (Rhodophyta) apresentam grande importância ecológica e econômica como produtores primários e de compostos bioativos, além de incluírem espécies invasoras em várias localidades do mundo. A taxonomia do grupo é bastante problemática, com vários registros de identificações equivocadas e mudanças nomenclaturais. Em virtude disso, diversos estudos têm incluído ferramentas moleculares como auxílio à taxonomia morfológica do grupo. O objetivo deste estudo é investigar por meio de técnicas moleculares e morfológicas a diversidade da ordem Halymeniales no litoral do Brasil de forma, a contribuir para o conhecimento da flora marinha do país. Para isso, foram sequenciados três marcadores moleculares, UPA, COI-5P e $r b c \mathrm{~L}$, cujos dados, combinados com a observação de caracteres morfológicos, resultaram na delimitação de 26 espécies. Dessas, 11 são espécies novas para a ciência: Corynomorpha cf. clavata, dois táxons morfologicamente identificados como "Cryptonemia" crenulata, dois táxons morfologicamente identificados como Cryptonemia seminervis, Halymenia ignifera, Halymenia pinnatifida, Halymenia silviae, Grateloupia cf. dichotoma, Grateloupia cf. filicina 1 e Grateloupia cf. filicina 2. Pelo menos sete gêneros novos foram encontrados, representados pelos táxons: "Cryptonemia" bengryi, integrantes do complexo "Cryptonemia" crenulata, "Cryptonemia" delicatula, "Halymenia" elongata, "Halymenia" floridana, Halymeniales sp. 1 e Halymeniales sp. 2. Foram encontradas três espécies cuja localidade-tipo é a Ásia: Grateloupia orientalis, Grateloupia turuturu e Grateloupia yangjiangensis. Entre os táxons previamente citados para a costa brasileira, nove não foram encontrados. Se os táxons não encontrados constituírem espécies válidas, a diversidade da ordem no Brasil será de 35 espécies. As análises filogenéticas mostraram que os gêneros Cryptonemia, Halymenia e Grateloupia constituem grupos nãomonofiléticos. Os resultados demonstraram a existência de ampla diversidade críptica e pseudo-críptica e de espécies e gêneros novos para a ciência, além de revelarem a ocorrência de espécies não nativas. Este estudo contribui substancialmente para o conhecimento da diversidade de algas marinhas na costa brasileira.

Palavras-chave: Algas marinhas, Brasil, COI-5P, DNA-barcoding, filogenia, Halymeniales, morfologia, $r b c \mathrm{~L}$, UPA. 


\section{ABSTRACT}

Algae of Halymeniales (Rhodophyta) present a wide ecological and economic importance, as primary producers and bioactive compounds producers, and include invasive species worldwide. Its taxonomy is quite problematic, with reports of misidentifications and nomenclatural changes. Therefore, studies have included molecular tools to assist the morphological taxonomy of this order. This study aims to investigate through molecular and morphological techniques the diversity of Halymeniales along the Brazilian coast, in order to contribute to the knowledge of native marine flora. Three molecular markers were sequenced, UPA, COI-5P and $r b c \mathrm{~L}$, whose data were allied to morphological characters and resulted in 26 delimited species. There are 11 new species to science: Corynomorpha cf. clavata, two taxa morphologically identified as "Cryptonemia" crenulata, two taxa morphologically identified as Cryptonemia seminervis, Halymenia ignifera, Halymenia pinnatifida, Halymenia silviae, Grateloupia cf. dichotoma, Grateloupia cf. filicina 1 and Grateloupia cf. filicina 2. At least seven new genera were found, represented by the following taxa: "Cryptonemia" bengryi, representatives of "Cryptonemia" crenulata complex, "Cryptonemia" delicatula, "Halymenia" elongata, "Halymenia" floridana, Halymeniales sp. 1 and Halymeniales sp. 2. Three species whose type locality is Asia were detected: Grateloupia orientalis, Grateloupia turuturu and Grateloupia yangjiangensis. Among taxa previously recorded to Brazilian coast, nine were not found. If those taxa constitute valid species, the diversity of the order in Brazil will be represented by 35 species. Phylogenetic analyses showed that Cryptonemia, Halymenia and Grateloupia constitute non-monophyletic groups. Results demonstrated the existence of wide cryptic and pseudo-cryptic diversity as well as novel species and genera, and revealed the presence of non-native species.

Keywords: Brazil, COI-5P, DNA barcoding, Halymeniales, marine algae, morphology, phylogeny, $r b c \mathrm{~L}$, UPA. 


\section{Introdução Geral}

\subsection{A taxonomia de algas vermelhas e a ferramenta molecular}

A taxonomia alpha consiste na atividade de descrever e nomear adequadamente os seres vivos, e sua importância não se restringe à catalogação da diversidade (De Clerck et al. 2013). O uso de nomes corretos para as entidades biológicas tem importância fundamental em diferentes áreas do conhecimento, tais como, química, genética, medicina, microbiologia, farmacologia e farmácia, isto é, a taxonomia produz o conhecimento básico necessário para pesquisas científicas que refletem os interesses humanos (De Clerck et al. 2013; Bennett \& Balick 2014). O nome de uma espécie está associado às similaridades e diferenças entre organismos e aos aspectos evolutivos de classificação dos objetos de estudo de todos os ramos da Biologia (Calisher 2007), o que proporciona um melhor entendimento sobre biologia da conservação, serviços ecossistêmicos, mudanças climáticas e modelagem ecológica (De Clerck et al. 2013).

A taxonomia de algas foi, durante muito tempo, conduzida com base no conceito morfológico de espécie, segundo o qual as espécies são diferenciadas de acordo com suas variações morfológicas, seguido do conceito biológico, que estabelece que espécies correspondem a um grupo de populações com fluxo reprodutivo entre si, mas com isolamento reprodutivo em relação a outras populações de espécies diferentes (Mayr \& Ashlock 1991; John \& Maggs 1997; Leliaert et al. 2014). No entanto, diversos fatores se constituem em limitações à aplicação desses conceitos, tais como existência de variação morfológica intraespecífica, ausência de diferenças morfológicas em linhagens que divergiram recentemente e ocorrência de espécies crípticas, inexistência de um critério sólido para definição de isolamento reprodutivo, ocorrência de híbridos e de reprodução assexuada (Leliaert et al. 2014). Já o conceito filogenético, que considera que espécies correspondem às menores entidades biológicas diagnosticáveis e/ou monofiléticas, passou a ser bastante aplicado na sistemática de algas após a inclusão de técnicas moleculares (Mayden 1997; John \& Maggs 1997; Leliaert et al. 2014). 
As algas pertencentes ao filo Rhodophyta, também chamadas algas vermelhas, constituem um grupo bastante diverso, que inclui aproximadamente 7100 espécies descritas em todo o mundo (Guiry \& Guiry 2016). Os estudos tradicionais de taxonomia de Rhodophyta são realizados com base em caracteres anatômicos de reprodução, desenvolvimento pós-fertilização, padrões de histórico de vida e anatomia vegetativa (Saunders \& Hommersand 2004). Porém, esses organismos podem apresentar elevada plasticidade fenotípica e alta incidência de espécies crípticas, o que contribui para que sua sistemática seja bastante problemática (Saunders 2005; Robba et al. 2006; Maggs et al. 2007; Verbruggen et al. 2010). Além disso, espécimes estéreis ou fragmentados também são muito difíceis de serem identificados.

Em virtude disso, inúmeros estudos sobre biodiversidade de algas têm utilizado ferramentas morfológicas e moleculares para resolução de problemas taxonômicos, o que consiste na Molecular-Assisted Alpha Taxonomy Technique (Saunders 2008; Cianciola et al. 2010). A técnica chamada DNA barcoding, por sua vez, consiste na utilização de regiões genômicas curtas e padronizadas, chamadas DNA barcodes, amplificadas através do método de PCR (Polymerase Chain Reaction) e sequenciadas com um mesmo par de primers. As sequências obtidas são então associadas a entidades taxonômicas, de forma semelhante à utilização de códigos de barra associados aos produtos comerciais (Stoeckle 2003). A técnica DNA barcoding é considerada uma ferramenta rápida, confiável, de baixo custo e bastante útil para a identificação de amostras biológicas ao nível de espécie (Radulovici et al. 2010). Um marcador molecular selecionado como DNA barcode para identificação de espécies pode auxiliar no descobrimento e delimitação de espécies, o que constitui a taxonomia baseada em sequências genômicas, também chamada DNA-based taxonomy (Leliaert et al. 2014). A aplicação da técnica está aumentando em áreas como biologia da conservação, ecologia, medicina, farmacêutica e biologia de sistemas (Pečnikar \& Buzan 2014).

Vários estudos que buscam associar sequências genômicas a entidades taxonômicas de algas têm resultado em comparações entre marcadores moleculares quanto à sua adequabilidade para uso como DNA barcodes. Para algas vermelhas, dois marcadores bastante analisados são o marcador mitocondrial COI-5P (região 5' do gene que codifica para a enzima citocromo c oxidase subunidade 1) (Saunders 2005) e o marcador plastidial 
UPA (Universal Plastid Amplicon, domínio V do gene 23S) (Sherwood \& Presting, 2007). $\mathrm{O}$ marcador mitocondrial COI-5P foi eleito pelo Consortium for the Barcode of Life (CBOL; http://www.barcoding.si.edu/) como DNA barcode teoricamente útil para a maior parte dos grupos de organismos eucarióticos. O COI-5P foi aplicado em algas pela primeira vez por Saunders (2005) e desde então diversos estudos têm considerado esse marcador adequado para discriminação de espécies, mesmo para táxons proximamente relacionados, evidenciando espécies crípticas e contribuindo para uma melhor compreensão sobre a plasticidade fenotípica e as distribuições geográficas de espécies (Clarkston \& Saunders 2010; Costa et al. 2012; Milstein et al. 2012; Milstein \& Saunders 2012; Saunders \& Millar 2014; Machín-Sánchez et al. 2014). No entanto, diversos estudos relatam dificuldades na amplificação e no sequenciamento do marcador COI-5P, incluindo ocorrência de contaminação, necessidade de várias combinações de pares de primers e desenvolvimento de primers específicos para certos grupos de algas (Clarkston \& Saunders 2010; Milstein et al. 2012).

Por outro lado, apesar de ser de fácil amplificação e sequenciamento, o marcador UPA tem sido considerado uma região muito conservada que exibe baixos valores de divergência entre táxons, o que pode conduzir à subestimação da diversidade de espécies (Clarkston \& Saunders 2010; Clarkston \& Saunders 2013). Estudos também demonstraram que para o UPA, os valores de divergência intraespecífica e interespecífica se sobrepõem, o que o torna inadequado para discriminação de espécies (Yang \& Kim 2014b). Porém, o marcador UPA pode ser útil para gerar agrupamentos de táxons proximamente relacionados, que na maioria dos casos correspondem aos mesmos clados obtidos com o marcador COI-5P, o que pode auxiliar a seleção de combinações de primers para a amplificação do COI-5P (Milstein et al. 2012; Costa et al. 2012; Iha et al. 2015).

Recentemente, as investigações sobre diversidade de algas têm utilizado mais de uma região genômica para obtenção de inferências filogenéticas, o que é chamado multilocus assessment (Payo et al. 2013; Schneider et al. 2014; Manghisi et al. 2014). Entre os marcadores moleculares utilizados em estudos filogenéticos, o gene $r b c \mathrm{~L}$, localizado no genoma do cloroplasto e codificante da subunidade grande da ribulose-1, 5-bifosfato carboxilase-oxigenase (Rubisco), é amplamente aceito como uma região de alta resolução filogenética tanto a nível de gênero quanto de espécie (Freshwater et al. 1994). 
Consequentemente, esse gene é o marcador molecular mais utilizado em estudos sobre filogenia e diversidade de Rhodophyta, incluindo a ordem Halymeniales (Maggs et al. 2007; Calderon et al. 2014a; Manghisi et al. 2014).

\subsection{A ordem Halymeniales (Rhodophyta) - histórico e cenário atual}

As espécies que hoje integram a ordem Halymeniales foram organizadas em agrupamentos pela primeira vez na obra Algae Maris Mediterranei et Adriatici, de J. Agardh (1842). No estudo, o autor chamou o grupo de tribo Cryptonemeae, a qual era caracterizada por "fronde celular-fibrosa, cistocarpo imerso, tetrasporângios inclusos". A tribo Cryptonemeae incluía táxons como Halymenia C.Agardh, Grateloupia C.Agardh e Cryptonemia J.Agardh, além de outros gêneros posteriormente acomodados em outras ordens. O gênero Halymenia foi classificado na sub-tribo Gasterocarpeae, juntamente com os gêneros Dumontia J.V.Lamouroux e Kallymenia J.Agardh, que atualmente pertencem à ordem Gigartinales. Os gêneros Cryptonemia e Grateloupia, por sua vez, integravam a subtribo Coccocarpeae, bem como Gelidium J.V.Lamouroux, Gigartina Stackhouse e Chrysymenia J.Agardh, atuais componentes das ordens Gelidiales, Gigartinales e Rhodymeniales, respectivamente.

O uso de características da ontogenia do carposporófito na classificação de Florideophycidae foi iniciado por Schmitz (1883). Esse autor levou em consideração se o carposporófito se desenvolvia a partir do carpogônio fertilizado ou a partir de uma célula auxiliar generativa. No caso da existência de uma célula auxiliar, Schmitz (1883) também observou se a célula era acessória ou uma célula vegetativa modificada, e ainda se era formada antes ou após a fertilização.

No esquema de Schmitz (1889) para a classe Florideophyceae, também baseado no desenvolvimento do carposporófito, as algas vermelhas foram classificadas em quatro grandes grupos: Nemalioninae, Gigarininae, Rhodymeninae e Cryptoneminae. Cryptoneminae constituía o único grupo caracterizado por desenvolvimento nãoprocárpico, no qual a célula auxiliar e o carpogônio se encontram em sistemas diferentes de ramos, e, portanto, não estão proximamente associados. Cryptoneminae estava dividida em sete famílias: Gloiosiphoniaceae, Grateloupiaceae, Dumontiaceae, Nemastomaceae, 
Rhizophyllidaceae, Squamariaceae e Corallinaceae. Grateloupiaceae acomodava alguns integrantes da atual ordem Halymeniales, tais como Halymenia, Grateloupia, Cryptonemia, Aeodes J.Agardh, Pachymenia J.Agardh, Corynomorpha J.Agardh, Dermocorynus P.Crouan \& H.Crouan, Prionitis J.Agardh, Polyopes J.Agardh, Carpopeltis F.Schmitz e Thamnoclonium Kützing. Schmitz (1892) classificou as mesmas famílias de Schmitz (1889) como integrantes de Cryptonemiales, e considerou esse grupo distinto de Gigartinales. Segundo Schmitz \& Hauptfleisch (1897), a família Grateloupiaceae era composta pelos mesmos gêneros considerados por Schmitz (1889), com adição de Cyrtymenia F.Schmitz, atualmente sinônimo de Grateloupia e Codiophyllum J.E.Gray.

Kylin (1932), ao avaliar a natureza da célula auxiliar, propôs a separação de Cryptonemiales, grupo em que a célula auxiliar é acessória, de Gigartinales, que apresenta célula auxiliar intercalar. Kylin (1956), por sua vez, organizou a ordem Cryptonemiales em 12 famílias, levando em consideração os seguintes caracteres: fusão de filamentos conectivos com células auxiliares ou com células nutritivas do ramo carpogonial, presença ou ausência de nematécios, presença ou ausência de procarpos, célula sustentadora atuando ou não como célula auxiliar e tipo de talo (uniaxial, multiaxial, crostoso ou ereto). Dentre essas famílias, a que incluía os membros atuais da ordem Halymeniales era chamada Grateloupiaceae. Essa família era composta por 19 gêneros: Halymenia, Grateloupia, Corynomorpha, Cryptonemia, Aeodes, Pachymenia, Dermocorynus, Prionitis, Phyllymenia J.Agardh, Polyopes, Codiophyllum, Thamnoclonium, Carpopeltis, Lobocolax M.Howe (incertae sedis - ordem e família atualmente desconhecidas), Acrodiscus Zanardini, Gelinaria Sonder, Epiphloea J.Agardh, Blastophye J.Agardh (atualmente considerado sinônimo de Cryptonemia) e Estebania Setchell \& N.L.Gardner (atual sinônimo de Gloiocladia J.Agardh, integrante da ordem Rhodymeniales).

Balakrishnan (1962) sugeriu a criação da família Corynomorphaceae para acomodação do gênero Corynomorpha, considerando o desenvolvimento procárpico do carposporófito e a existência de ampolas policarpogoniais. Chiang (1970) investigou a anatomia vegetativa e reprodutiva de diversos gêneros da família Cryptonemiaceae, e observou que os membros dessa família apresentavam ramos carpogoniais e células auxiliares produzidas em sistemas separados, chamados ampolas, as quais eram produzidas pelas células da região subcortical. Além disso, o autor destacou que as ampolas 
carpogoniais eram quase exclusivamente monocarpogoniais, com exceção de Aeodes, em que os ramos carpogoniais eram compostos por duas células e, ainda, que a ampola carpogonial era menor e menos ramificada que a ampola da célula auxiliar. Com isso, Chiang (1970) considerou que a anatomia da ampola da célula auxiliar seria de utilidade na taxonomia da então família Cryptonemiaceae, as quais foram classificadas pelo autor em cinco tipos:

a) Tipo Grateloupia: ampola com filamento ampolar primário e 2-3 filamentos ampolares secundários, de forma cônica quando madura. Inclui os gêneros Prionitis, Phyllymenia e Pachymeniopsis Yamada ex Kawabata;

b) Tipo Thamnoclonium: ampola com um filamento ampolar primário e 3-5 filamentos ampolares secundários curtos, com 2-5 células. Ampola madura com formato irregular. Apenas o gênero Thamnoclonium;

c) Tipo Halymenia: ampola com filamento ampolar primário com células inferiores longas e estreitas, a partir das quais, orginam-se um ou dois filamentos secundários simples. Ampola madura achatada e expandida. É considerada intermediária entre as ampolas do tipo Grateloupia e Cryptonemia;

d) Tipo Aeodes: ampola com filamentos ampolares de até quarta ordem, muito densa, com formato de cálice. Inclui também Pachymenia, Dermocorynus e Polyopes;

e) Tipo Cryptonemia: ampola com filamentos ampolares de até quarta ordem, muito densa, de formato cônico. Inclui também Codiophyllum.

Chiang (1970) também sugeriu que o ancestral de Cryptonemiaceae teria ampola com muitos filamentos, de maneira que as ampolas do tipo Grateloupia seriam as mais recentes na família.

Pueschel \& Cole (1982) propuseram que a família Hildenbrandiaceae, até então posicionada em Cryptonemiales, fosse elevada à categoria de ordem, chamada Hildenbrandiales. Para isso, os autores utilizaram a ultraestrutura do pit-plug e características reprodutivas. A família Corallinaceae também foi elevada à categoria de ordem (Corallinales) pelos mesmos autores, de acordo com tipo de crescimento, estruturas reprodutivas, talo com impregnação de calcita e ultraestrutura do pit-plug.

A ordem Halymeniales foi criada por Saunders \& Kraft (1996) com base em estudos moleculares, sendo Halymeniaceae a família-tipo. Os mesmos autores propuseram que as 
famílias Halymeniaceae e Sebdeniaceae, até então posicionadas nas ordens Cryptonemiales e Gigartinales, respectivamente, integrassem a ordem Halymeniales. Com exceção de Halymeniaceae, os demais integrantes de Cryptonemiales foram transferidos para Gigartinales, com a extinção da ordem Cryptonemiales. Posteriormente, a família Tsengiaceae, que até então pertencia à família Nemastomataceae (ordem Nemastomatales), foi adicionada à ordem Halymeniales (Saunders \& Kraft 2002). Após observarem diferenças anatômicas e moleculares entre Sebdeniaceae e Halymeniaceae, Withall \& Saunders (2006) propuseram a remoção da família Sebdeniaceae da ordem Halymeniales, e criaram a ordem Sebdeniales para acomodar esses organismos.

Halymeniales é caracterizada por apresentar algas de talos rastejantes ou eretos, estreitos ou expandidos, ramificados ou não; organização multiaxial; Região medular filamentosa e córtex pseudoparenquimatoso; histórico de vida trifásico com gametófitos e tetrasporófitos isomórficos; procarpos ausentes em todos os gêneros exceto em Corynomorpha; células auxiliares intercalares ou subsidiárias; ramo carpogonial com orientação exterior, com 2-4 células; após a fecundação, ocorre transferência do núcleo do zigoto a partir do carpogônio até as células auxiliares através de filamentos conectivos; desenvolvimento dos gonimoblastos em direção à superfície do talo, a partir de uma única célula inicial (Halymeniaceae) ou diretamente a partir da célula auxiliar (Tsengiaceae); o carposporófito tem um ou mais lobos; e tetrasporângios cruciados ou cruciado-decussados (Saunders \& Kraft 1996; Saunders \& Kraft 2002).

Atualmente, a ordem inclui 314 espécies descritas, distribuídas em duas famílias: Halymeniaceae Kützing, com 31 gêneros e 303 espécies; e Tsengiaceae G. W. Saunders \& Kraft, com um gênero e nove espécies (Guiry \& Guiry 2016). As duas famílias são diferenciadas pela presença em Halymeniaceae de pit connections secundárias entre as células do córtex e da Região medular e pela presença de filamentos ampolares em torno das estruturas femininas de reprodução. Ambas as características estão ausentes em Tsengiaceae (Saunders \& Kraft 2002).

Para o litoral brasileiro, há registros de 24 espécies (Tabela 1), que representam cinco gêneros: Corynomorpha, Cryptonemia, Grateloupia, Halymenia e Tsengia K.C.Fan \& Y.P.Fan (Guimarães 1990; Guimarães 2006; Amado-Filho et al. 2010; Pacheco 2011). As primeiras citações de representantes de Halymeniales no litoral brasileiro foram de Joly 
(1957), para a região Sudeste, Taylor (1960), que encontrou quatro espécies no litoral do Brasil e Joly et al. (1965a), para a região Sul. Entre os principais estudos no país, Guimarães (1990) investigou no litoral do Espírito Santo a ordem até então chamada Cryptonemiales, e identificou aproximadamente 13 espécies do grupo atualmente chamado Halymeniales. Guimarães (2006) abordou novamente o Estado do Espírito Santo e citou 21 espécies de Halymeniales.

Tabela 1. Espécies de Halymeniales registradas no litoral do Brasil antes do início deste estudo.

\begin{tabular}{|c|c|c|c|}
\hline Espécie & $\begin{array}{c}\text { Localidade } \\
\text { tipo }\end{array}$ & Ocorrência $^{1}$ & Referências \\
\hline Corynomorpha clavata & \multirow{5}{*}{ EUA, Flórida } & BA & Nunes (2005) \\
\hline \multirow[t]{4}{*}{ (Harvey) J.Agardh } & & $\mathrm{CE}$ & $\begin{array}{l}\text { Pinheiro-Joventino et al. (1998); Soares } \\
\text { (2015) }\end{array}$ \\
\hline & & ES & Guimarães (1990); Guimarães (2006) \\
\hline & & PE & Pereira et al. (2002) \\
\hline & & $\mathrm{RN}$ & Pereira et al. (1981); Silva (2010) \\
\hline Cryptonemia bengryi & Jamaica, & BA & $\begin{array}{l}\text { Nunes, 2005; Lyra et al. (2007) } \\
\text { http://www.algaemarisbrasilis.ccb.ufsc.br, }\end{array}$ \\
\hline \multirow[t]{5}{*}{ W.R.Taylor } & $\begin{array}{l}\text { Alligator Pond } \\
\text { Bay, }\end{array}$ & $\mathrm{CE}$ & Soares, 2015 \\
\hline & Manchester & ES & Guimarães (1990); Guimarães (2006) \\
\hline & & PB & http://www.algaemarisbrasilis.ccb.ufsc.br \\
\hline & & $\mathrm{PE}$ & http://www.algaemarisbrasilis.ccb.ufsc.br \\
\hline & & $\mathrm{RN}$ & Silva (2006) \\
\hline
\end{tabular}

\section{Cryptonemia crenulata}

(J.Agardh) J.Agardh

Sin.: Phyllophora crenulata

J. Agardh
Brasil - BA

Arq. F.N.

BA

CE

ES

MA

PB

$\mathrm{PE}$

RJ

RN

SP http://www.algaemarisbrasilis.ccb.ufsc.br Nunes (1998); Nunes (2005); Lyra et al. (2007) Pinheiro-Joventino et al. (1998), Soares Guimarães (1990); Guimarães (2006)

Creed et al. (2015)

Lucena et al. (2007);

Pereira et al. (2002);

Creed et al. (2015)

Silva (2006); Silva (2010)

Creed et al. (2015) 
Tabela 1. Continuação.

\begin{tabular}{|c|c|c|c|}
\hline Espécie & $\begin{array}{c}\begin{array}{c}\text { Localidade } \\
\text { tipo }\end{array} \\
\end{array}$ & Ocorrência $^{1}$ & Referências \\
\hline $\begin{array}{l}\text { Cryptonemia delicatula } \\
\text { A.B. Joly \& M. Cordeiro }\end{array}$ & $\begin{array}{l}\text { Brasil - SP, } \\
\text { Praia do } \\
\text { Lázaro, } \\
\text { Ubatuba }\end{array}$ & $\begin{array}{l}\text { BA } \\
\text { CE } \\
\text { ES } \\
\text { RJ } \\
\text { RN } \\
\text { RS } \\
\text { SC } \\
\text { SP }\end{array}$ & $\begin{array}{l}\text { Nunes (2005) } \\
\text { http://www.algaemarisbrasilis.ccb.ufsc.br } \\
\text { Guimarães (1990); Guimarães (2006) } \\
\text { Horta (2000) } \\
\text { Silva (2010) } \\
\text { Horta (2000) } \\
\text { Horta (2000) } \\
\text { Joly (1964) }\end{array}$ \\
\hline $\begin{array}{l}\text { Cryptonemia flabellifolia } \\
\text { Pinheiro-Joventino \& } \\
\text { E.C.Oliveira }\end{array}$ & $\begin{array}{c}\text { Brasil - CE, } \\
\text { Acaraú }\end{array}$ & $\begin{array}{l}\text { ES } \\
\text { RJ }\end{array}$ & $\begin{array}{l}\text { Pinheiro-Joventino \& Oliveira-Filho } \\
\text { (1977); Creed } \text { et al. (2015) } \\
\text { Guimarães (2006); Creed } \text { et al. (2010) } \\
\text { Creed } \text { et al. (2010) }\end{array}$ \\
\hline $\begin{array}{l}\text { Cryptonemia limensis } \\
\text { (Kützing) J.A.Lewis } \\
\text { Sin.: Cryptonemia guaymasensis } \\
\text { (E.Y. Dawson) E.Y. Dawson }\end{array}$ & Peru, Callao & $\begin{array}{l}\mathrm{CE} \\
\mathrm{ES}\end{array}$ & $\begin{array}{l}\text { Creed } \text { et al (2015) } \\
\text { Guimarães (1990); Guimarães (2006) } \\
\text { Creed } \text { et al. (2015) } \\
\text { Creed } \text { et al. (2015) }\end{array}$ \\
\hline $\begin{array}{l}\text { Cryptonemia seminervis } \\
\text { (C. Agardh) J. Agardh } \\
\text { Sin.: Cryptonemia luxurians } \\
\text { (C.Agardh) J.Agardh }\end{array}$ & Espanha, Cádiz & $\begin{array}{l}\text { BA } \\
\text { CE } \\
\text { ES } \\
\text { MA } \\
\text { PB } \\
\text { PE } \\
\\
\text { RJ } \\
\text { RN }\end{array}$ & $\begin{array}{l}\text { Lyra et al. (2007); Nunes (1998); Nunes } \\
\text { (2005) } \\
\text { Pinheiro-Joventino et al. (1998), Soares } \\
\text { (2015) } \\
\text { Guimarães (1990); Guimarães (2006) } \\
\text { Ferreira-Correia (1987) } \\
\text { Lucena et al. (2007) } \\
\text { Pereira } \text { et al. (1981); Pereira et al. (2002) } \\
\text { Pereira } \text { et al. (2007) } \\
\text { Yoneshigue-Valentin et al. (2008) } \\
\text { Silva (2010) }\end{array}$ \\
\hline $\begin{array}{l}\text { Dermocorynus dichotomus } \\
\text { (J.Agardh) Gargiulo, } \\
\text { M.Morabito } \\
\text { \& Manghisi } \\
\text { Sin.: Grateloupia dichotoma } \\
\text { J. Agardh }\end{array}$ & França, Nice & $\begin{array}{l}\text { CE } \\
\text { ES } \\
\text { SC }\end{array}$ & $\begin{array}{l}\text { Soares (2015) } \\
\text { Guimarães (1990); Guimarães (2006) } \\
\text { http://www.algaemarisbrasilis.ccb.ufsc.br }\end{array}$ \\
\hline
\end{tabular}


Tabela 1. Continuação.

\begin{tabular}{|c|c|c|c|}
\hline Espécie & $\begin{array}{l}\text { Localidade } \\
\text { tipo }\end{array}$ & Ocorrência $^{1}$ & Referências \\
\hline \multirow[t]{2}{*}{$\begin{array}{l}\text { Grateloupia cuneifolia } \\
\text { J.Agardh }\end{array}$} & \multirow[t]{2}{*}{$\begin{array}{l}\text { Venezuela, } \\
\text { La Guayra }\end{array}$} & $\mathrm{RJ}$ & $\begin{array}{l}\text { Széchy \& Nassar (2005) } \\
\text { Yoneshigue-Valentin et al. (2008) }\end{array}$ \\
\hline & & SP & Joly $(1957)$ \\
\hline \multirow{7}{*}{$\begin{array}{l}\text { Grateloupia doryphora } \\
\text { (Montagne) M.A.Howe }\end{array}$} & \multirow{7}{*}{$\begin{array}{l}\text { Peru, } \\
\text { Callao }\end{array}$} & ES & Guimarães (2006) \\
\hline & & PR & $\begin{array}{l}\text { http://www.algaemarisbrasilis.ccb.ufsc.br } \\
\text { Pedrini et al. (1998); Taouil \& }\end{array}$ \\
\hline & & RJ & Yoneshigue-Valentin (2002) \\
\hline & & & Amado Filho et al. (2003) \\
\hline & & $\mathrm{RS}$ & http://www.algaemarisbrasilis.ccb.ufsc.br \\
\hline & & $\mathrm{SC}$ & http://www.algaemarisbrasilis.ccb.ufsc.br \\
\hline & & SP & http://www.algaemarisbrasilis.ccb.ufsc.br \\
\hline \multirow{12}{*}{$\begin{array}{l}\text { Grateloupia filicina } \\
\text { (J.V.Lamouroux) C.Agardh }\end{array}$} & \multirow[t]{12}{*}{ Itália, Trieste } & $\begin{array}{l}\text { Arq. T. e } \\
\text { M.V. }\end{array}$ & Yoneshigue-Valentin et al. (2005) \\
\hline & & $\mathrm{BA}$ & $\begin{array}{l}\text { Nunes (1998); Nunes (1999); Nunes } \\
(2005)\end{array}$ \\
\hline & & $\mathrm{CE}$ & Soares $(2015)$ \\
\hline & & ES & Guimarães (2006) \\
\hline & & PB & http://www.algaemarisbrasilis.ccb.ufsc.br \\
\hline & & PR & http://www.algaemarisbrasilis.ccb.ufsc.br \\
\hline & & $\mathrm{RJ}$ & Amado Filho et al. (2003) \\
\hline & & & Yoneshigue-Valentin et al. (2008) \\
\hline & & $\mathrm{RN}$ & http://www.algaemarisbrasilis.ccb.ufsc.br \\
\hline & & $\mathrm{RS}$ & http://www.algaemarisbrasilis.ccb.ufsc.br \\
\hline & & $\mathrm{SC}$ & http://www.algaemarisbrasilis.ccb.ufsc.br \\
\hline & & SP & Joly (1957) \\
\hline \multirow[t]{5}{*}{ Grateloupia filiformis Kützing } & \multirow[t]{5}{*}{ Peru } & MA & Guimarães (1990) \\
\hline & & $\mathrm{CE}$ & Soares $(2015)$ \\
\hline & & ES & Guimarães (1990) \\
\hline & & SP & Guimarães (1990) \\
\hline & & $\mathrm{SC}$ & Guimarães (1990) \\
\hline Grateloupia subpectinata & \multirow[t]{5}{*}{ Japão } & \multirow[t]{5}{*}{ ES } & \multirow[t]{5}{*}{ Guimarães (2006) } \\
\hline Holmes & & & \\
\hline Sin.: Grateloupia luxurians & & & \\
\hline (A.Gepp \& E.S.Gepp) & & & \\
\hline $\begin{array}{l}\text { R.J.Wilkes, L.M.McIvor \& } \\
\text { Guiry }\end{array}$ & & & \\
\hline
\end{tabular}


Tabela 1. Continuação.

\begin{tabular}{|c|c|c|c|}
\hline Espécie & $\begin{array}{l}\text { Localidade } \\
\text { tipo }\end{array}$ & Ocorrência $^{1}$ & Referências \\
\hline $\begin{array}{l}\text { Grateloupia turuturu } \\
\text { Yamada } \\
\text { Nome mal aplicado para o } \\
\text { Brasil: Grateloupia doryphora } \\
\text { (Montagne) M.Howe sensu } \\
\text { Guimarães (2006) }\end{array}$ & $\begin{array}{l}\text { Japão, } \\
\text { Muroran }\end{array}$ & $\mathrm{ES}$ & Guimarães (2006) \\
\hline $\begin{array}{l}\text { Halymenia brasiliana } \\
\text { S.M.P.B.Guimarães \& }\end{array}$ & Brasil - ES, & $\mathrm{CE}$ & Soares (2015) \\
\hline M.T.Fujii & $\begin{array}{c}\text { Itaipava, } \\
\text { Itapemirim }\end{array}$ & $\begin{array}{l}\text { BA } \\
\text { ES }\end{array}$ & $\begin{array}{l}\text { Nunes (2005) } \\
\text { Guimarães (2006) }\end{array}$ \\
\hline $\begin{array}{l}\text { Halymenia clathrata } \\
\text { E.C.Oliveira, Pinheiro-Vieira } \\
\text { \& R.E.Norris }\end{array}$ & $\begin{array}{c}\text { Brasil - ES, } \\
\text { Praia de } \\
\text { Piabanha,Piúma }\end{array}$ & ES & Guimarães (1990); Guimarães (2006) \\
\hline $\begin{array}{l}\text { Halymenia duchassaingii } \\
\text { (J.Agardh) Kylin }\end{array}$ & $\begin{array}{l}\text { Guadalupe, } \\
\text { West Indies }\end{array}$ & $\begin{array}{l}\mathrm{BA} \\
\mathrm{CE} \\
\mathrm{PB}\end{array}$ & $\begin{array}{l}\text { Nunes (1998); Nunes (2005) } \\
\text { Soares, } 2015 \\
\text { Lucena et al. (2007) }\end{array}$ \\
\hline $\begin{array}{l}\text { Halymenia elongata C.Agardh } \\
\text { Sin.: Halymenia agardhii } \\
\text { sensu Joly (1964) }\end{array}$ & $\begin{array}{c}\text { Espanha, } \\
\text { Baía de Cádiz }\end{array}$ & $\begin{array}{l}\text { CE } \\
\text { ES } \\
\text { PB } \\
\text { PE } \\
\text { RJ } \\
\text { RN } \\
\text { SP } \\
\text { SC }\end{array}$ & $\begin{array}{l}\text { Pinheiro-Joventino et al. (1998) } \\
\text { Guimarães (1990); Guimarães (2006) } \\
\text { Oliveira-Filho (1977) } \\
\text { Pereira et al. (1981); Pereira et al. (2002) } \\
\text { Amado Filho et al. (2003); Amado Filho } \\
\text { \& Bahia (2007) } \\
\text { Pereira et al. (1981); Pereira et al. (2002); } \\
\text { Silva (2010) } \\
\text { Joly et al. (1965a) } \\
\text { Cordeiro-Marino (1978) }\end{array}$ \\
\hline $\begin{array}{l}\text { Halymenia floresii } \\
\text { (Clemente) C.Agardh }\end{array}$ & $\begin{array}{c}\text { Espanha, } \\
\text { Baía de Cádiz }\end{array}$ & $\begin{array}{l}\mathrm{BA} \\
\mathrm{CE} \\
\mathrm{ES} \\
\mathrm{PB} \\
\mathrm{RJ} \\
\mathrm{RN}\end{array}$ & $\begin{array}{l}\text { Nunes (1998); Nunes (2005) } \\
\text { http://www.algaemarisbrasilis.ccb.ufsc.br } \\
\text { Guimarães (1990); Guimarães (2006) } \\
\text { Lucena et al. (2007) } \\
\text { Amado Filho \& Bahia (2007) } \\
\text { Câmara-Neto (1971) }\end{array}$ \\
\hline
\end{tabular}


Tabela 1. Continuação.

\begin{tabular}{|c|c|c|c|}
\hline Espécie & $\begin{array}{c}\text { Localidade } \\
\text { tipo }\end{array}$ & Ocorrência $^{1}$ & Referências \\
\hline Halymenia floridana & EUA, & BA & Nunes (2005) \\
\hline J.Agardh & Flórida & $\mathrm{CE}$ & http://www.algaemarisbrasilis.ccb.ufsc.br \\
\hline Sin.: Halymenia bermudensis & & & Guimarães (1990); Guimarães \& Fujii \\
\hline Collins \& M. Howe & & ES & (1998); Guimarães (2006) \\
\hline Halymenia gelinaria & & RJ & Yoneshigue (1985) \\
\hline Collins \& M. Howe & & $\mathrm{RN}$ & Silva (2010) \\
\hline & & SP & Joly (1957) \\
\hline
\end{tabular}

Halymenia integra

M.A.Howe \& W.R.Taylor

Halymenia pseudofloresii

F.S.Collins \& M.A.Howe

Halymenia rosea

M.A.Howe \& W.R.Taylor

Halymenia vinacea

M.A.Howe \& W.R.Taylor

Tsengia sp.
Brasil - RJ,

Cabo Frio

Bermuda

Walsingham

Grotto,

Walsingham

Park,

Bermuda Island

Brasil - RJ,

Cabo Frio

Brasil - RJ,

Cabo Frio
AL http://www.algaemarisbrasilis.ccb.ufsc.br

CE Joly et al. (1967)

ES Guimarães (1990); Guimarães (2006)

PE http://www.algaemarisbrasilis.ccb.ufsc.br

RN http://www.algaemarisbrasilis.ccb.ufsc.br

CE http://www.algaemarisbrasilis.ccb.ufsc.br

RJ Amado Filho et al. (2003)

SP Joly (1957)

Guimarães \& Fujii (1998); Guimarães

ES (2006)

Yoneshigue-Valentin et al. (2005)

RJ http://www.algaemarisbrasilis.ccb.ufsc.br

ES Amado-Filho et al. (2010); Pacheco

(2011)

\footnotetext{
${ }^{1}$ Estados da Federação Brasileira. AL: Alagoas, BA: Bahia, CE: Ceará, ES: Espírito Santo, MA: Maranhão, PB: Paraíba, PE: Pernambuco, PR: Paraná, RJ: Rio de Janeiro, RN: Rio Grande do Norte, RS: Rio Grande do Sul, SC: Santa Catarina, SP: São Paulo.

Arquipélagos. Arq. F.N.: Arquipélago de Fernando de Noronha, Arq. T. e M.V.: Arquipélago de Trindade e Martim Vaz.
} 
Assim como os demais grupos de algas vermelhas, a ordem Halymeniales possui um histórico taxonômico conflituoso, que inclui registros de mudanças nomenclaturais e identificações equivocadas (De Smedt et al. 2001; Gavio \& Fredericq 2002; De Clerck et al. 2005a; Figueroa et al. 2007; Lin \& Liang 2011; Boo et al. 2013; Kim et al. 2013). Em todo o mundo, pesquisadores têm investigado a sistemática da ordem Halymeniales conciliando técnicas morfológicas e moleculares, o que tem promovido o reconhecimento de novos gêneros e espécies, a ressurreição de gêneros, a correção de identificações taxonômicas e a descoberta de ampla diversidade críptica no grupo (De Clerck et al. 2005b; Figueroa et al. 2007; Calderon et al. 2014a).

Wang et al. (2001), com base em dados moleculares e características morfológicas vegetativas e da ampola da célula auxiliar, defenderam a sinonimização do gênero Prionitis com Grateloupia. Posteriormente, os gêneros Phyllymenia e Dermocorynus também foram colocados em sinonímia com Grateloupia, por meio de estudos moleculares (De Clerck et al. 2005a; Wilkes et al. 2005). No entanto, Gargiulo et al. (2013) combinaram dados moleculares e anatômicos da estrutura das ampolas carpogoniais e da célula auxiliar, bem como desenvolvimento pós-fertilização, e propuseram a ressurreição dos gêneros Prionitis, Phyllymenia, Dermocorynus e Pachymeniopsis. Pachymeniopsis, por sua vez, havia sido sinonimizado com Grateloupia por Kawaguchi (1997), considerando apenas características vegetativas e reprodutivas. Hommersand et al. (2010) criaram o gênero Glaphyrosiphon Hommersand \& Leister para acomodar a espécie Grateloupia intestinalis (Harvey) Setchell ex P.G. Parkinson, registrada na Nova Zelândia. O gênero Neorubra (Montagne) M.S.Calderon, G.H.Boo \& S.M.Boo, descrito por Calderon et al. (2014b), abrange as espécies Neorubra decipiens (Montagne) M.S.Calderon, G.H.Boo \& S.M.Boo e Neorubra denticulata (Montagne) M.S.Calderon, G.H.Boo \& S.M.Boo, previamente atribuídas a Prionitis decipiens (Montagne) J.Agardh e Grateloupia denticulata Montagne, respectivamente.

Em relação às espécies crípticas, algumas espécies de Halymeniales que já foram consideradas de ampla distribuição geográfica são atualmente reconhecidas como complexos de espécies. De Clerck et al. (2005b) constataram que a espécie Grateloupia filicina (C.Agardh) Lamouroux, até então considerada cosmopolita, possuía distribuição restrita ao Mediterrâneo, e que os numerosos registros dessa espécie para outras regiões do 
mundo correspondiam a espécies crípticas. Hernández-Kantún et al. (2012), ao analisarem espécies de Halymenia do Indo-Pacífico, verificaram que espécimes atribuídos a Halymenia durvillei Bory de Saint-Vincent constituíam um complexo de cinco espécies crípticas. Os mesmos autores também observaram que Halymenia floresii subsp. harveyana (J.Agardh) Womersley \& Lewis, originalmente referida para Austrállia, constituía uma espécie válida, e por isso ressuscitaram a espécie Halymenia harveyana J.Agardh. A espécie Cryptonemia asiatica M.Y.Yang \& M.S.Kim foi descrita por Yang \& Kim (2014a) para acomodar indivíduos atribuídos a Cryptonemia seminervis (C.Agardh) J.Agardh na Ásia.

Além disso, estudos também demonstraram que diversos gêneros da ordem Halymeniales constituem grupos não-monofiléticos (Schneider et al. 2010; HernándezKantún et al. 2012; Kraft \& Saunders 2013; Tan et al. 2015). Em algumas reconstruções

filogenéticas de estudos anteriores, as espécies (os gêneros) Gelinaria ulvoidea Sonder e Epiphloea bullosa (Harvey) De Toni pertencem ao mesmo clado que contém Halymenia floresii (Clemente) C.Agardh, espécie-tipo do gênero Halymenia (Hernández-Kantún et al. 2012; Tan et al. 2015). Além de Halymenia, outros gêneros já reconhecidos como polifiléticos incluem Cryptonemia, Thamnoclonium e Phyllymenia (Schneider et al. 2010; Kim et al. 2012; Manghisi et al. 2014; Calderon et al. 2014b), o que evidencia a necessidade de estudos filogenéticos para essas algas.

\subsection{Importância ecológica e econômica das algas pertencentes à ordem Halymeniales}

As algas da ordem Halymeniales ocorrem no infra e mesolitoral de regiões temperadas e tropicais, sobre substrato rochoso ou biogênico, e expostas a uma grande variedade de condições hidrodinâmicas, como áreas protegidas ou expostas ao embate de ondas (Figueroa et al. 2007; Hernández-Kantun et al. 2009).

Do ponto de vista ecológico, além de sua importância como produtores primários, espécies de Halymeniales têm sido reportadas em eventos de introdução de espécies exóticas em diversas regiões do mundo. Halymeniaceae é uma das famílias de Rhodophyta com maior número de espécies registradas em eventos de invasão de macroalgas (Williams \& Smith 2007). Entre as espécies já referidas na literatura em eventos de introdução de 
espécies não-nativas, tem-se como exemplo Grateloupia imbricata Holmes, G. asiatica S.Kawaguchi \& H.W.Wang, G. patens (Okamura) S.Kawaguchi \& H.W.Wang, G. subpectinata Holmes, G. yinggehaiensis H.W.Wang et R.X.Luan e G. turuturu Yamada (Verlaque et al. 2005; García-Jiménez et al. 2008; Wolf et al. 2014; Azevedo et al. 2015). Algumas vezes, a identificação taxonômica incorreta das algas retarda a constatação da presença e identidade de espécies exóticas. Como exemplo, tem-se o caso de Grateloupia turuturu, espécie nativa do Japão e erroneamente identificada como Grateloupia doryphora (Montagne) M.A.Howe, cuja presença foi observada nos litorais dos Estados Unidos, França e Inglaterra (Gavio \& Fredericq 2002). Verlaque et al. (2005) confirmaram a identificação incorreta de Grateloupia turuturu como Grateloupia doryphora e de G. asiatica citada como G. filicina (J.V.Lamouroux) C.Agardh em estudos anteriores realizados na França. Posteriormente, a espécie Polyopes lancifolius (Harvey) Kawaguchi \& Wang, proveniente do Japão, também foi encontrada no litoral da França formando uma pequena população (Mineur et al. 2010). Recentemente, a presença de G. turuturu no litoral do sul do Brasil foi confirmada por meio de dados moleculares e morfológicos (Azevedo et al. 2015).

Além de sua importância ecológica, alguns gêneros de Halymeniales apresentam importância econômica, especialmente Grateloupia e Halymenia que são componentes da alimentação humana, principalmente em países orientais (Zemke-White \& Ohno 1999). O gênero Halymenia também é utilizado na agricultura, como fertilizante (Zemke-White \& Ohno 1999). Além disso, as algas do grupo Halymeniales sintetizam galactanas sulfatadas, também conhecidas como ficocolóides, que são compostos de ampla aplicação industrial (Zibetti 2005).

As galactanas produzidas por Halymeniales apresentam estrutura química intermediária entre a carragenana e o ágar, denominada de carrágar por Chopin et al. (1999). Diversos estudos comprovam que esses polissacarídeos também atuam como substâncias bioativas, o que demonstra o potencial de aplicação dessas algas na produção de fármacos e cosméticos. Sen et al. (1994) constataram a atividade anticoagulante de uma galactana sulfatada extraída da alga Grateloupia indica Børgesen. Athukorala et al. (2003) detectaram importante atividade antioxidante de extratos de Grateloupia filicina. Algumas espécies de Halymeniales que ocorrem na costa brasileira tiveram seu potencial bioativo 
investigado e demonstraram resultados promissores, tais como Cryptonemia spp. que produzem compostos contra os vírus da herpes (Talarico et al. 2004), dengue (Talarico et al. 2007) e metapneumovírus humano (Mendes et al. 2014).

\subsection{Justificativa do estudo}

Apesar das Halymeniales apresentarem significativa importância ecológica e econômica, o conhecimento de sua diversidade no Brasil é considerado insuficiente, o que leva à hipótese de que a diversidade do grupo esteja subestimada. De Clerck et al. (2013) afirmam que o ato de descrever e nomear espécies, chamado "taxonomia alfa", tem uma importância que ultrapassa a simples catalogação da diversidade. A "taxonomia alfa" produz o conhecimento necessário para pesquisas científicas que refletem interesses humanos, além de promover um melhor entendimento sobre conservação da biodiversidade, serviços ecossistêmicos, mudanças climáticas e modelagem ecológica (Payo et al. 2013; De Clerck et al. 2013). Neste contexto, abordagens taxonômicas sobre a ordem Halymeniales são consideradas indispensáveis ao conhecimento e à conservação da biodiversidade marinha brasileira, além de serem necessárias para viabilizar a utilização racional dos recursos naturais marinhos do país. 


\section{Objetivos}

\subsection{Objetivo Geral}

Investigar a diversidade e a filogenia das algas pertencentes ao grupo Halymeniales no litoral brasileiro, de forma a contribuir para o conhecimento da flora marinha do país e para a filogenia da ordem.

\subsection{Objetivos Específicos}

- Identificar e descrever a diversidade da ordem Halymeniales no Brasil;

- Utilizar as ferramentas morfológicas e moleculares no estudo da taxonomia das espécies de Halymeniales existentes no país;

- Testar a viabilidade de uso dos marcadores moleculares COI-5P e UPA como ferramentas na identificação de Halymeniales;

- Obter inferências filogenéticas sobre o grupo através da aplicação do marcador molecular $r b c \mathrm{~L}$. 


\section{Materiais e Métodos}

\subsection{Obtenção de Amostras}

As amostras utilizadas neste estudo foram coletadas manualmente em pontos georeferenciados ao longo do litoral brasileiro (Figura 1). Foram coletados espécimes nas regiões de mesolitoral e infralitoral, assim como indivíduos arribados. Foram obtidas 256 amostras no total, sendo que foram obtidos dados moleculares para 152 amostras (Tabela 2).

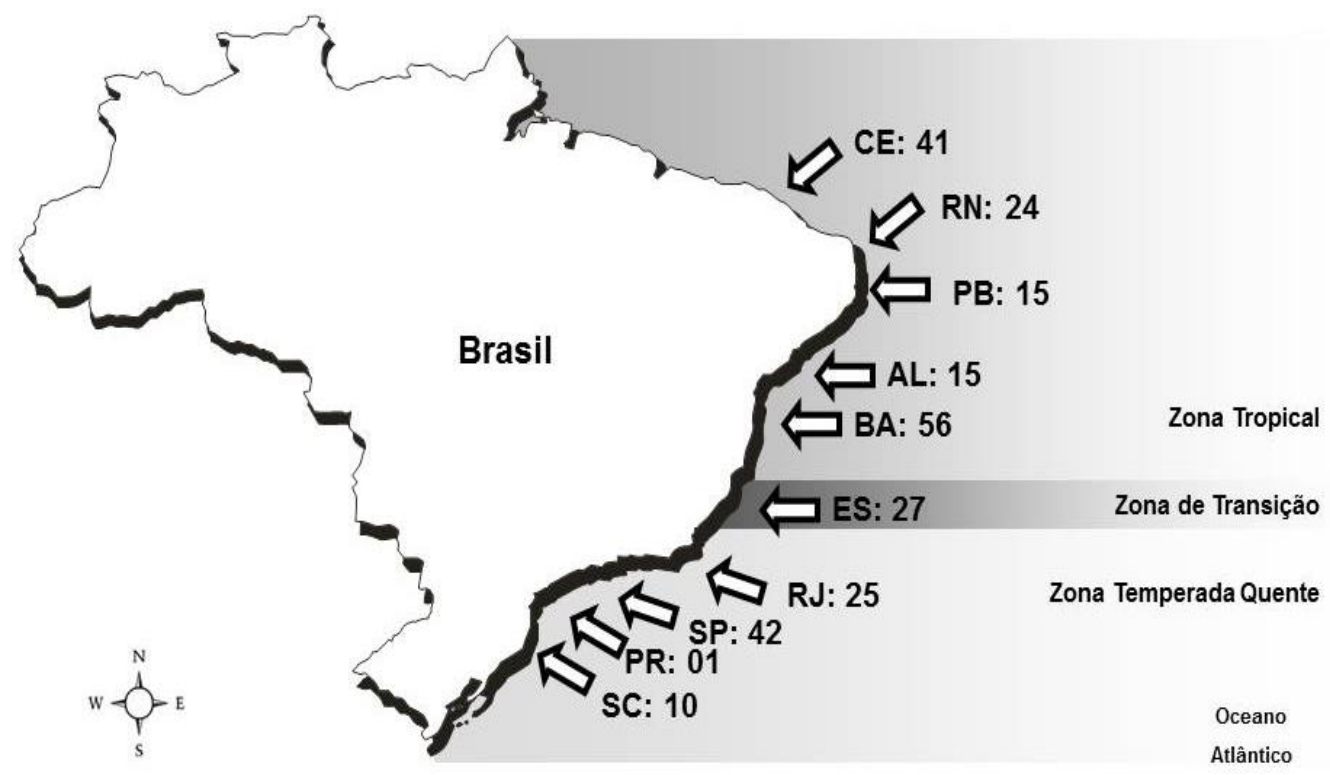

Figura 1. Número de amostras obtidas neste estudo, em cada estado do litoral brasileiro, conforme as zonas de diversidade de algas de acordo com Horta et al. (2001). 
Tabela 2. Dados de coleta das amostras incluídas neste estudo, para as quais foram gerados dados moleculares. A coluna "SPF" se refere ao número de tombamento para espécimes já incorporados ao Herbário da Universidade de São Paulo. A coluna "Marcadores Moleculares" se refere ao número de acesso no GenBank das sequências já depositadas, enquanto que "x" corresponde a sequências geradas que serão depositadas após a submissão dos artigos.

\begin{tabular}{|c|c|c|c|c|c|c|c|c|c|}
\hline \multirow{2}{*}{$\begin{array}{l}\text { Código } \\
\text { de Coleta }\end{array}$} & \multirow{2}{*}{ Espécie } & \multirow{2}{*}{ Local de coleta } & \multirow{2}{*}{ Latitude/Longitude } & \multirow{2}{*}{ Coletor (s) } & \multirow{2}{*}{ Data } & \multirow{2}{*}{ SPF } & \multicolumn{3}{|c|}{ Marcadores Moleculares } \\
\hline & & & & & & & UPA & COI-5P & $r b c \mathbf{L}$ \\
\hline IBT 0228 & Grateloupia cf. filicina 2 & $\begin{array}{l}\text { Praia Domingas Dias, Ubatuba, } \\
\mathrm{SP}\end{array}$ & $23^{\circ} 29^{\prime} 45^{\prime \prime} \mathrm{S} ; 45^{\circ} 08^{\prime} 46^{\prime \prime O}$ & M. T. Fujii & 04/09/2009 & & $\mathrm{X}$ & & $\mathrm{x}$ \\
\hline IBC0054 & "Halymenia" floridana & $\begin{array}{l}\text { Praia Dura,costão esquerdo, } \\
\text { Ubatuba, SP }\end{array}$ & $23^{\circ} 49^{\prime} 51.59^{\prime \prime} \mathrm{S} ; 45^{\circ} 16^{\prime} 50.38^{\prime \prime O}$ & $\begin{array}{l}\text { E.C. Oliveira e } \\
\text { M. C. Oliveira }\end{array}$ & $14 / 10 / 2008$ & 57820 & $\begin{array}{l}X \\
X\end{array}$ & & $\mathrm{x}$ \\
\hline IBC0055 & "Halymenia" floridana & $\begin{array}{l}\text { Praia Dura,costão esquerdo, } \\
\text { Ubatuba, SP }\end{array}$ & $23^{\circ} 49^{\prime} 51.59^{\prime \prime} \mathrm{S} ; 45^{\circ} 16^{\prime} 50.38^{\prime \prime O}$ & $\begin{array}{l}\text { E.C. Oliveira e } \\
\text { M. C. Oliveira }\end{array}$ & $14 / 10 / 2008$ & & $\begin{array}{l}X \\
X\end{array}$ & & \\
\hline IBC 0161 & "Halymenia" floridana & $\begin{array}{l}\text { Praia da Lagoinha, Ubatuba, } \\
\text { SP }\end{array}$ & $23^{\circ} 52^{\prime} 30,77^{\prime \prime S} ; 45^{\circ} 19^{\prime} 11.30^{\prime \prime O}$ & $\begin{array}{l}\text { E.C. Oliveira e } \\
\text { F. Nauer }\end{array}$ & 23/07/2009 & & $\mathrm{X}$ & & \\
\hline IBC 0295 & Cryptonemia seminervis 1 & Praia da Cruz, Marataízes, ES & $21^{\circ} 01^{\prime} 58.2^{\prime \prime} \mathrm{S} ; 40^{\circ} 48^{\prime} 43.9^{\prime \prime O}$ & M. C. Oliveira & 07/05/2012 & 57823 & $\mathrm{X}$ & & $\mathrm{x}$ \\
\hline IBC 0506 & Grateloupia cf. filicina 2 & $\begin{array}{l}\text { Praia da Ferradura, costão } \\
\text { esquerdo, Armação dos Búzios, } \\
\text { RJ }\end{array}$ & $22^{\circ} 46^{\prime} 12.8^{\prime \prime} \mathrm{S} ; 41^{\circ} 53^{\prime} 00.1^{\prime \prime O}$ & $\begin{array}{l}\text { C. Tha, B. Torrano- } \\
\text { Silva e F. Nauer }\end{array}$ & $25 / 09 / 2011$ & 57781 & $\mathrm{X}$ & & $\mathrm{x}$ \\
\hline IBC 2000 & "Grateloupia" gibbesii & $\begin{array}{l}\text { Prainha, costão direito, } \\
\text { Florianópolis, SC }\end{array}$ & $27^{\circ} 34^{\prime} 36.20^{\prime \prime} \mathrm{S} ; 48^{\circ} 25^{\prime} 14.51^{\prime \prime O}$ & $\begin{array}{l}\text { E.C. Oliveira e } \\
\text { M. C. Oliveira }\end{array}$ & $17 / 10 / 2011$ & & $\mathrm{X}$ & & \\
\hline IBC 2001 & "Grateloupia" gibbesii & $\begin{array}{l}\text { Prainha, costão direito, } \\
\text { Florianópolis, SC }\end{array}$ & $27^{\circ} 34^{\prime} 36.20^{\prime \prime} \mathrm{S} ; 48^{\circ} 25^{\prime} 14.51^{\prime \prime O}$ & $\begin{array}{l}\text { E.C. Oliveira e } \\
\text { M. C. Oliveira }\end{array}$ & $17 / 10 / 2011$ & & $\mathrm{X}$ & $\mathrm{x}$ & $\mathrm{x}$ \\
\hline IBC 2002 & "Grateloupia" gibbesii & $\begin{array}{l}\text { Praia Moçambique, } \\
\text { Florianópolis, SC }\end{array}$ & $27^{\circ} 34^{\prime} 25.64^{\prime \prime S} ; 48^{\circ} 25^{\prime} 21.27^{\prime \prime O}$ & $\begin{array}{l}\text { E.C. Oliveira e } \\
\text { M. C. Oliveira }\end{array}$ & $19 / 10 / 2011$ & & $\mathrm{X}$ & $\mathrm{x}$ & \\
\hline IBC 2003 & "Cryptonemia" crenulata & $\begin{array}{l}\text { Praia de Pirambúzios, } \\
\text { Parnamirim, RN }\end{array}$ & $5^{\circ} 59^{\prime} 12.35^{\prime \prime} ; 35^{\circ} 06^{\prime} 49.544^{\prime \prime O}$ & C. A. A. Azevedo & $25 / 01 / 2012$ & 57788 & $\mathrm{X}$ & & $\mathrm{x}$ \\
\hline IBC 2004 & "Cryptonemia" crenulata & Praia de Pirambúzios, & $5^{\circ} 59^{\prime} 12.35^{\prime \prime} ; 35^{\circ} 06^{\prime} 49.544^{\prime \prime O}$ & C. A. A. Azevedo & $25 / 01 / 2012$ & & $\mathrm{X}$ & & \\
\hline
\end{tabular}


Tabela 2. Continuação

\begin{tabular}{|c|c|c|c|c|c|c|c|c|c|}
\hline \multirow{2}{*}{$\begin{array}{l}\text { Código } \\
\text { de Coleta }\end{array}$} & \multirow{2}{*}{ Espécie } & \multirow{2}{*}{ Local de coleta } & \multirow{2}{*}{ Latitude/Longitude } & \multirow{2}{*}{ Coletor (s) } & \multirow{2}{*}{ Data } & \multirow{2}{*}{ SPF } & \multicolumn{3}{|c|}{ Marcadores Moleculares } \\
\hline & & & & & & & UPA & COI-5P & $r b c \mathrm{~L}$ \\
\hline & & Parnamirim, RN & & & & & & & \\
\hline \multirow[t]{2}{*}{ IBC 2005} & "Cryptonemia" crenulata & Praia de Pirambúzios, & $5^{\circ} 59^{\prime} 12.35^{\prime \prime} ; 35^{\circ} 06^{\prime} 49.544^{\prime \prime} \mathrm{O}$ & C. A. A. Azevedo & $25 / 01 / 2012$ & & $\mathrm{X}$ & & \\
\hline & & Parnamirim, RN & & & & & & & \\
\hline IBC 2006 & "Cryptonemia" crenulata & $\begin{array}{l}\text { Praia de Paracuru, Paracuru, } \\
\text { CE }\end{array}$ & $3^{\circ} 40^{\prime} 00.00^{\prime \prime} \mathrm{S} ; 39^{\circ} 07^{\prime} 00.00^{\prime \prime O}$ & E. M. Plastino e & $11 / 02 / 2012$ & 57818 & $\mathrm{X}$ & & $\mathrm{x}$ \\
\hline \multirow[t]{2}{*}{ IBC 2008} & Grateloupia turuturu & $\begin{array}{l}\text { Praia da Armação, } \\
\text { Florianópolis, }\end{array}$ & $27^{\circ} 45^{\prime} 01.10^{\prime \prime} \mathrm{S} ; 48^{\circ} 30^{\prime} 02.28^{\prime \prime O}$ & $\begin{array}{l}\text { L. Ayres-Ostrock } \\
\text { C. A. A. Azevedo, B. }\end{array}$ & 26/02/2012 & 57787 & $\mathrm{X}$ & KP976170 & KP976173 \\
\hline & & $\mathrm{SC}$ & & Torrano-Silva, F. Nauer & & & & & \\
\hline \multirow[t]{2}{*}{ IBC 2009} & Grateloupia orientalis & Prainha da Ponte Pênsil, São & $23^{\circ} 58^{\prime} 36.32^{\prime \prime} \mathrm{S} ; 46^{\circ} 23^{\prime} 15.93^{\prime \prime O}$ & E.C. Oliveira & $21 / 03 / 2011$ & 57822 & $\mathrm{X}$ & $\mathrm{x}$ & $\mathrm{x}$ \\
\hline & & Vicente, SP & & & & & & & \\
\hline \multirow[t]{2}{*}{ IBC 2010} & Grateloupia orientalis & Prainha da Ponte Pênsil, São & $23^{\circ} 58^{\prime} 36.32^{\prime \prime} \mathrm{S} ; 46^{\circ} 23^{\prime} 15.93^{\prime \prime O}$ & E.C. Oliveira & 21/03/2011 & 57807 & $\mathrm{X}$ & $\mathrm{x}$ & \\
\hline & & Vicente, SP & & & & & & & \\
\hline \multirow[t]{2}{*}{ IBC 2011} & "Grateloupia" gibbesii & Prainha da Ponte Pênsil, São & $23^{\circ} 58^{\prime} 36.32^{\prime \prime} \mathrm{S} ; 46^{\circ} 23^{\prime} 15.93^{\prime \prime O}$ & E.C. Oliveira & $21 / 03 / 2011$ & 57819 & $\mathrm{X}$ & $\mathrm{x}$ & \\
\hline & & Vicente, SP & & & & & & & \\
\hline \multirow[t]{2}{*}{ IBC 2012} & $\begin{array}{l}\text { Grateloupia } \mathrm{cf} . \\
\text { dichotoma }\end{array}$ & Prainha da Ponte Pênsil, São & $23^{\circ} 58^{\prime} 36.32^{\prime \prime S} ; 46^{\circ} 23^{\prime} 15.93^{\prime \prime O}$ & E.C. Oliveira & 21/03/2011 & 57821 & $\mathrm{X}$ & $\mathrm{x}$ & \\
\hline & & Vicente, SP & & & & & & & \\
\hline IBC 2013 & Grateloupia orientalis & Ilha Porchat, São Vicente, SP & $23^{\circ} 58^{\prime} 38.32^{\prime \prime} \mathrm{S} ; 46^{\circ} 22^{\prime} 18.82^{\prime \prime O}$ & E.C. Oliveira & 21/03/2011 & 57806 & $\mathrm{X}$ & $\mathrm{x}$ & \\
\hline IBC 2014 & "Grateloupia" gibbesii & $\begin{array}{l}\text { Praia de Areia Preta, } \\
\text { Guarapari, }\end{array}$ & $20^{\circ} 40^{\prime} 38.4^{\prime \prime} \mathrm{S} ; 40^{\circ} 30^{\prime} 06.0^{\prime \prime} \mathrm{O}$ & B. Torrano-Silva e & 05/04/2012 & & $\mathrm{X}$ & $\mathrm{x}$ & $\mathrm{x}$ \\
\hline & & ES & & C. E. Amâncio & & & & & \\
\hline IBC 2017 & "Halymenia" elongata & $\begin{array}{l}\text { Iriri, } 20 \mathrm{~m} \text { de profundidade, } \\
\text { Anchieta ES }\end{array}$ & 2050'24"S; 40³9'58"O & $\begin{array}{l}\text { B. Torrano-Silva e } \\
\text { C. E. Amâncio }\end{array}$ & 07/04/2012 & & $X$ & & $\mathrm{x}$ \\
\hline IBC 2029 & "Grateloupia" gibbesii & $\begin{array}{l}\text { Ponta da Lagoinha, Armação } \\
\text { dos Búzios, RJ }\end{array}$ & $22^{\circ} 45^{\prime} 53^{\prime \prime} \mathrm{S} ; 41^{\circ} 52^{\prime} 41^{\prime \prime O}$ & V. Cassano & 05/05/2012 & & $\mathrm{X}$ & $\mathrm{x}$ & \\
\hline IBC 2030 & "Grateloupia" gibbesii & Ponta da Lagoinha, Armação & $22^{\circ} 45^{\prime} 53^{\prime \prime} \mathrm{S} ; 41^{\circ} 52^{\prime} 41^{\prime \prime O}$ & V. Cassano & 05/05/2012 & 57804 & $\mathrm{X}$ & $\mathrm{x}$ & $\mathrm{x}$ \\
\hline
\end{tabular}


Tabela 2. Continuação.

\begin{tabular}{|c|c|c|c|c|c|c|c|c|c|}
\hline \multirow{2}{*}{$\begin{array}{c}\text { Código } \\
\text { de Coleta }\end{array}$} & \multirow{2}{*}{ Espécie } & \multirow{2}{*}{ Local de coleta } & \multirow{2}{*}{ Latitude/Longitude } & \multirow{2}{*}{ Coletor (s) } & \multirow{2}{*}{ Data } & \multirow{2}{*}{ SPF } & \multicolumn{3}{|c|}{ Marcadores Moleculares } \\
\hline & & & & & & & UPA & COI-5P & $r b c \mathbf{L}$ \\
\hline & & dos Búzios, RJ & & & & & & & \\
\hline IBC 2032 & "Grateloupia" gibbesii & Praia de Itaoca, Itapemirim, ES & $20^{\circ} 54^{\prime} 16.0^{\prime \prime} \mathrm{S} ; 40^{\circ} 46^{\prime} 37.4^{\prime \prime O}$ & $\begin{array}{l}\text { B. Torrano-Silva, C. } \\
\text { Iha }\end{array}$ & $06 / 05 / 2012$ & & $\mathrm{X}$ & $\mathrm{x}$ & \\
\hline IBC 2033 & Halymenia ignifera & Praia de Itaoca, Itapemirim, ES & $20^{\circ} 54^{\prime} 16.0^{\prime \prime} \mathrm{S} ; 40^{\circ} 46^{\prime} 37.4^{\prime \prime O}$ & $\begin{array}{l}\text { e F. Nauer } \\
\text { B. Torrano-Silva, C. } \\
\text { Iha }\end{array}$ & $06 / 05 / 2012$ & 57784 & $\mathrm{X}$ & KT807819 & KT807830 \\
\hline IBC 2037 & "Grateloupia" gibbesii & Praia da Cruz, Marataízes, ES & $21^{\circ} 01^{\prime} 58.2^{\prime \prime S} ; 40^{\circ} 48^{\prime} 43.9^{\prime \prime O}$ & $\begin{array}{l}\text { e F. Nauer } \\
\text { B. Torrano-Silva, C. } \\
\text { Iha }\end{array}$ & $07 / 05 / 2012$ & & & $\mathrm{x}$ & \\
\hline IBC 2038 & $\begin{array}{l}\text { Grateloupia cf. } \\
\text { dichotoma }\end{array}$ & Praia da Cruz, Marataízes, ES & $21^{\circ} 01^{\prime} 58.2^{\prime \prime} \mathrm{S} ; 40^{\circ} 48^{\prime} 43.9^{\prime \prime} \mathrm{O}$ & $\begin{array}{l}\text { F. Nauer e M. C. Oliveire } \\
\text { B. Torrano-Silva, C. } \\
\text { Iha }\end{array}$ & 07/05/2012 & 57799 & $X$ & $\mathrm{x}$ & $\mathrm{x}$ \\
\hline IBC 2040 & "Grateloupia" gibbesii & $\begin{array}{l}\text { Praia dos Namorados, } \\
\text { Guarapari, } \\
\text { ES }\end{array}$ & $20^{\circ} 40^{\prime} 19.7^{\prime \prime} \mathrm{S} ; 40^{\circ} 29^{\prime} 41.9^{\prime \prime O}$ & $\begin{array}{l}\text { F. Nauer e M. C. Oliveira } \\
\text { B. Torrano-Silva, C. } \\
\text { Iha } \\
\text { F. Nauer e M. C. Oliveire }\end{array}$ & 08/05/2012 & 57803 & $\mathrm{X}$ & $\mathrm{x}$ & \\
\hline IBC 2041 & Cryptonemia seminervis 1 & Praia de Carapibus, Conde, PB & $7^{\circ} 17^{\prime} 58.2^{\prime \prime} \mathrm{S} ; 34^{\circ} 47^{\prime} 56.0^{\prime \prime O}$ & $\begin{array}{l}\text { C. A. A. Azevedo e } \\
\text { F. Nauer }\end{array}$ & $20 / 07 / 2012$ & & $\mathrm{X}$ & $\mathrm{x}$ & \\
\hline IBC 2047 & Cryptonemia seminervis 1 & Praia de Tabatinga, Conde, PB & $7^{\circ} 18^{\prime} 51.6^{\prime \prime} \mathrm{S} ; 34^{\circ} 48^{\prime} 07.0^{\prime \prime O}$ & $\begin{array}{l}\text { C. A. A. Azevedo, F. } \\
\text { Nauer e R. Perez }\end{array}$ & $21 / 07 / 2012$ & 57792 & $\mathrm{X}$ & & \\
\hline IBC 2050 & Cryptonemia seminervis 1 & Praia de Tabatinga, Conde, PB & $7^{\circ} 18^{\prime} 51.6^{\prime \prime} \mathrm{S} ; 34^{\circ} 48^{\prime} 07.0^{\prime \prime O}$ & $\begin{array}{l}\text { C. A. A. Azevedo, F. } \\
\text { Nauer e R. Perez }\end{array}$ & $21 / 07 / 2012$ & & $\mathrm{X}$ & $\mathrm{x}$ & \\
\hline IBC 2051 & Cryptonemia seminervis 1 & $\begin{array}{l}\text { Praia de Coqueirinho, Conde, } \\
\text { PB }\end{array}$ & $7^{\circ} 19^{\prime} 41.2^{\prime \prime} \mathrm{S} ; 34^{\circ} 47^{\prime} 42.6^{\prime \prime O}$ & C. A. A. Azevedo, F. & $21 / 07 / 2012$ & & $\mathrm{X}$ & & \\
\hline IBC 2052 & Cryptonemia seminervis 1 & Praia de Tambaba, Conde, $\mathrm{PB}$ & $7^{\circ} 21^{\prime} 56.1^{\prime \prime} \mathrm{S} ; 34^{\circ} 47^{\prime} 51.4^{\prime \prime O}$ & $\begin{array}{l}\text { Nauer e R. Perez } \\
\text { C. A. A. Azevedo e } \\
\text { F. Nauer }\end{array}$ & $23 / 07 / 2012$ & & $\mathrm{X}$ & & \\
\hline IBC 2055 & Cryptonemia seminervis 1 & Praia de Tambaba, Conde, PB & $7^{\circ} 21^{\prime} 56.1^{\prime \prime} \mathrm{S} ; 34^{\circ} 47^{\prime} 51.4^{\prime \prime O}$ & $\begin{array}{l}\text { C. A. A. Azevedo e } \\
\text { F. Nauer }\end{array}$ & $23 / 07 / 2012$ & 57797 & $X$ & & $\mathrm{x}$ \\
\hline IBC 2057 & $\begin{array}{l}\text { Grateloupia cf. } \\
\text { dichotoma }\end{array}$ & Praia de Cibratel, Itanhaém, SP & $24^{\circ} 12^{\prime} 06.5^{\prime \prime} \mathrm{S} ; 46^{\circ} 48^{\prime} 40.1^{\prime \prime O}$ & $\begin{array}{l}\text { B. Torrano-Silva, B. } \\
\text { Vieira e W. Oliveira }\end{array}$ & $20 / 07 / 2012$ & & $\mathrm{X}$ & $\mathrm{x}$ & \\
\hline
\end{tabular}


Tabela 2. Continuação.

\begin{tabular}{|c|c|c|c|c|c|c|c|c|c|}
\hline \multirow{2}{*}{$\begin{array}{c}\text { Código } \\
\text { de Coleta } \\
\end{array}$} & \multirow{2}{*}{ Espécie } & \multirow{2}{*}{ Local de coleta } & \multirow{2}{*}{ Latitude/Longitude } & \multirow{2}{*}{ Coletor (s) } & \multirow{2}{*}{ Data } & \multirow{2}{*}{ SPF } & \multicolumn{3}{|c|}{ Marcadores Moleculares } \\
\hline & & & & & & & UPA & COI-5P & $r b c \mathrm{~L}$ \\
\hline IBC 2060 & Grateloupia filiformis & Praia do Pedrão, Itacaré, BA & $14^{\circ} 17^{\prime} 09.5^{\prime \prime} \mathrm{S} ; 38^{\circ} 59^{\prime} 06.2^{\prime \prime O}$ & V. Cassano & $02 / 08 / 2012$ & 57798 & $\mathrm{X}$ & & $\mathrm{x}$ \\
\hline IBC 2070 & Cryptonemia seminervis 1 & $\begin{array}{l}\text { Praia de Tartarugas, Santa Cruz } \\
\text { Cabrália, BA }\end{array}$ & $16^{\circ} 17^{\prime} 05.4^{\prime \prime} \mathrm{S} ; 39^{\circ} 01^{\prime} 18.1^{\prime \prime O}$ & $\begin{array}{l}\text { C. A. A. Azevedo e } \\
\text { F. Nauer }\end{array}$ & $17 / 09 / 2012$ & 57791 & $\mathrm{X}$ & & $\mathrm{x}$ \\
\hline IBC 2071 & Cryptonemia seminervis 1 & $\begin{array}{l}\text { Praia de Tartarugas, Santa Cruz } \\
\text { Cabrália, BA }\end{array}$ & $16^{\circ} 17^{\prime} 05.4^{\prime \prime S} ; 39^{\circ} 01^{\prime} 18.1 " \mathrm{O}$ & $\begin{array}{l}\text { C. A. A. Azevedo e } \\
\text { F. Nauer }\end{array}$ & $17 / 09 / 2012$ & & $\mathrm{X}$ & & \\
\hline IBC 2072 & Cryptonemia seminervis 1 & $\begin{array}{l}\text { Praia de Tartarugas, Santa Cruz } \\
\text { Cabrália, BA }\end{array}$ & $16^{\circ} 17^{\prime} 05.4^{\prime \prime} \mathrm{S} ; 39^{\circ} 01^{\prime} 18.1^{\prime \prime O}$ & $\begin{array}{l}\text { C. A. A. Azevedo e } \\
\text { F. Nauer }\end{array}$ & $17 / 09 / 2012$ & & $\mathrm{X}$ & & \\
\hline IBC 2076 & Cryptonemia seminervis 1 & $\begin{array}{l}\text { Praia de Apuã, Santa Cruz } \\
\text { Cabrália, BA }\end{array}$ & $16^{\circ} 16^{\prime} 45.0^{\prime \prime} \mathrm{S} ; 39^{\circ} 01^{\prime} 11.0^{\prime \prime} \mathrm{O}$ & $\begin{array}{l}\text { C. A. A. Azevedo e } \\
\text { F. Nauer }\end{array}$ & $17 / 09 / 2012$ & & $\mathrm{X}$ & & \\
\hline IBC 2078 & Cryptonemia seminervis 1 & $\begin{array}{l}\text { Praia de Apuã, Santa Cruz } \\
\text { Cabrália, BA }\end{array}$ & $16^{\circ} 16^{\prime} 45.0^{\prime \prime S} ; 39^{\circ} 01^{\prime} 11.0^{\prime \prime O}$ & $\begin{array}{l}\text { C. A. A. Azevedo e } \\
\text { F. Nauer }\end{array}$ & $17 / 09 / 2012$ & & $\mathrm{X}$ & & \\
\hline IBC 2079 & Grateloupia cf. filicina 1 & $\begin{array}{l}\text { Praia de Vilas do Atlântico, } \\
\text { Lauro de Freitas, BA }\end{array}$ & $12^{\circ} 53^{\prime} 11^{\prime \prime} \mathrm{S} ; 38^{\circ} 16^{\prime} 58^{\prime \prime O}$ & V. Cassano & $15 / 10 / 2012$ & 57786 & $\mathrm{X}$ & $\mathrm{x}$ & $\mathrm{x}$ \\
\hline IBC 2080 & Grateloupia filiformis & Praia dos Padres, Aracruz, ES & $19^{\circ} 55^{\prime} 55^{\prime \prime} \mathrm{S} ; 40^{\circ} 07^{\prime} 10^{\prime \prime O}$ & M. T. Fujii & $14 / 11 / 2012$ & 57789 & $\mathrm{X}$ & $\mathrm{x}$ & $\mathrm{x}$ \\
\hline IBC 2082 & "Cryptonemia" bengryi & $\begin{array}{l}\text { Praia de Tabatinga, Nísia } \\
\text { Floresta, RN }\end{array}$ & $6^{\circ} 04^{\prime} 30^{\prime \prime} \mathrm{S} ; 35^{\circ} 06^{\prime} 01^{\prime \prime O}$ & $\begin{array}{l}\text { C. A. A. Azevedo e } \\
\text { R. F. Menezes }\end{array}$ & $12 / 01 / 2013$ & 57778 & $\mathrm{X}$ & $\mathrm{x}$ & \\
\hline IBC 2083 & "Cryptonemia" crenulata & $\begin{array}{l}\text { Praia de Tabatinga, Nísia } \\
\text { Floresta, RN }\end{array}$ & $6^{\circ} 04^{\prime} 30^{\prime \prime} \mathrm{S} ; 35^{\circ} 06^{\prime} 01^{\prime \prime O}$ & $\begin{array}{l}\text { C. A. A. Azevedo e } \\
\text { R. F. Menezes }\end{array}$ & $12 / 01 / 2013$ & & $\mathrm{X}$ & & \\
\hline IBC 2085 & Halymenia ignifera & $\begin{array}{l}\text { Praia de Rio do Fogo, Rio do } \\
\text { Fogo, RN }\end{array}$ & $5^{\circ} 15^{\prime} 56^{\prime \prime} \mathrm{S} ; 35^{\circ} 23^{\prime} 05^{\prime \prime O}$ & $\begin{array}{l}\text { C. A. A. Azevedo e } \\
\text { R. F. Menezes }\end{array}$ & $13 / 01 / 2013$ & 57865 & $\mathrm{X}$ & KT807810 & \\
\hline IBC 2086 & Halymenia pinnatifida & $\begin{array}{l}\text { Praia de Rio do Fogo, Rio do } \\
\text { Fogo, RN }\end{array}$ & $5^{\circ} 15^{\prime} 56^{\prime \prime} \mathrm{S} ; 35^{\circ} 23^{\prime} 05^{\prime \prime O}$ & $\begin{array}{l}\text { C. A. A. Azevedo e } \\
\text { R. F. Menezes }\end{array}$ & $13 / 01 / 2013$ & 57871 & $\mathrm{X}$ & KT807811 & KT807828 \\
\hline IBC 2087 & Halymenia pinnatifida & $\begin{array}{l}\text { Praia de Rio do Fogo, Rio do } \\
\text { Fogo, RN }\end{array}$ & $5^{\circ} 15^{\prime} 56^{\prime \prime} \mathrm{S} ; 35^{\circ} 23^{\prime} 05^{\prime \prime O}$ & $\begin{array}{l}\text { C. A. A. Azevedo e } \\
\text { R. F. Menezes }\end{array}$ & $13 / 01 / 2013$ & 57872 & & KT807816 & \\
\hline IBC 2088 & Halymenia ignifera & $\begin{array}{l}\text { Praia de Rio do Fogo, Rio do } \\
\text { Fogo, RN }\end{array}$ & $5^{\circ} 15^{\prime} 56^{\prime \prime} \mathrm{S} ; 35^{\circ} 23^{\prime} 05^{\prime \prime O}$ & $\begin{array}{l}\text { C. A. A. Azevedo e } \\
\text { R. F. Menezes }\end{array}$ & $13 / 01 / 2013$ & 57866 & $\mathrm{X}$ & KT807815 & \\
\hline IBC 2089 & Halymenia silviae & $\begin{array}{l}\text { Praia de Rio do Fogo, Rio do } \\
\text { Fogo, RN }\end{array}$ & $5^{\circ} 15^{\prime} 56^{\prime \prime} \mathrm{S} ; 35^{\circ} 23^{\prime} 05^{\prime \prime O}$ & $\begin{array}{l}\text { C. A. A. Azevedo e } \\
\text { R. F. Menezes }\end{array}$ & $13 / 01 / 2013$ & 57873 & $\mathrm{X}$ & KT807818 & \\
\hline
\end{tabular}


Tabela 2. Continuação.

\begin{tabular}{|c|c|c|c|c|c|c|c|c|c|}
\hline \multirow{2}{*}{$\begin{array}{c}\text { Código } \\
\text { de Coleta } \\
\end{array}$} & \multirow{2}{*}{ Espécie } & \multirow{2}{*}{ Local de coleta } & \multirow{2}{*}{ Latitude/Longitude } & \multirow{2}{*}{ Coletor (s) } & \multirow{2}{*}{ Data } & \multirow{2}{*}{ SPF } & \multicolumn{3}{|c|}{ Marcadores Moleculares } \\
\hline & & & & & & & UPA & COI-5P & $r b c \mathrm{~L}$ \\
\hline IBC 2090 & Halymenia ignifera & $\begin{array}{l}\text { Praia de Rio do Fogo, Rio do } \\
\text { Fogo, RN }\end{array}$ & $5^{\circ} 15^{\prime} 56^{\prime \prime} \mathrm{S} ; 35^{\circ} 23^{\prime} 05^{\prime \prime O}$ & $\begin{array}{l}\text { C. A. A. Azevedo e } \\
\text { R. F. Menezes }\end{array}$ & $13 / 01 / 2013$ & 57867 & $\mathrm{X}$ & KT807821 & \\
\hline IBC 2094 & "Halymenia" elongata & $\begin{array}{l}\text { Praia de Rio do Fogo, Rio do } \\
\text { Fogo, RN }\end{array}$ & $5^{\circ} 15^{\prime} 56^{\prime \prime} \mathrm{S} ; 35^{\circ} 23^{\prime} 05^{\prime \prime O}$ & $\begin{array}{l}\text { C. A. A. Azevedo e } \\
\text { R. F. Menezes }\end{array}$ & $13 / 01 / 2013$ & 57785 & $\mathrm{X}$ & $\mathrm{x}$ & $\mathrm{x}$ \\
\hline IBC 2095 & "Halymenia" elongata & $\begin{array}{l}\text { Praia de Rio do Fogo, Rio do } \\
\text { Fogo, RN }\end{array}$ & $5^{\circ} 15^{\prime} 56^{\prime \prime} \mathrm{S} ; 35^{\circ} 23^{\prime} 05^{\prime \prime O}$ & $\begin{array}{l}\text { C. A. A. Azevedo e } \\
\text { R. F. Menezes }\end{array}$ & $13 / 01 / 2013$ & 57816 & $\mathrm{X}$ & & $\mathrm{x}$ \\
\hline IBC 2096 & Halymenia silviae & $\begin{array}{l}\text { Praia de Rio do Fogo, Rio do } \\
\text { Fogo, RN }\end{array}$ & $5^{\circ} 15^{\prime} 56^{\prime \prime} \mathrm{S} ; 35^{\circ} 23^{\prime} 05^{\prime \prime O}$ & $\begin{array}{l}\text { C. A. A. Azevedo e } \\
\text { R. F. Menezes }\end{array}$ & $13 / 01 / 2013$ & & $\mathrm{X}$ & & \\
\hline IBC 2097 & Halymenia ignifera & $\begin{array}{l}\text { Praia de Rio do Fogo, Rio do } \\
\text { Fogo, RN }\end{array}$ & $5^{\circ} 15^{\prime} 56^{\prime \prime} \mathrm{S} ; 35^{\circ} 23^{\prime} 05^{\prime \prime O}$ & $\begin{array}{l}\text { C. A. A. Azevedo e } \\
\text { R. F. Menezes }\end{array}$ & $13 / 01 / 2013$ & 57868 & $\mathrm{X}$ & KT807824 & \\
\hline IBC 2099 & Halymenia ignifera & $\begin{array}{l}\text { Praia de Rio do Fogo, Rio do } \\
\text { Fogo, RN }\end{array}$ & $5^{\circ} 15^{\prime} 56^{\prime \prime} \mathrm{S} ; 35^{\circ} 23^{\prime} 05^{\prime \prime O}$ & $\begin{array}{l}\text { C. A. A. Azevedo e } \\
\text { R. F. Menezes }\end{array}$ & $13 / 01 / 2013$ & 57817 & $\mathrm{X}$ & KT807817 & KT807829 \\
\hline IBC 2100 & Halymenia ignifera & $\begin{array}{l}\text { Praia de Rio do Fogo, Rio do } \\
\text { Fogo, RN }\end{array}$ & $5^{\circ} 15^{\prime} 56^{\prime \prime} \mathrm{S} ; 35^{\circ} 23^{\prime} 05^{\prime \prime O}$ & $\begin{array}{l}\text { C. A. A. Azevedo e } \\
\text { R. F. Menezes }\end{array}$ & $13 / 01 / 2013$ & 57815 & $\mathrm{X}$ & KT807808 & KT807826 \\
\hline IBC 2101 & Halymenia silviae & $\begin{array}{l}\text { Praia de Rio do Fogo, Rio do } \\
\text { Fogo, RN }\end{array}$ & $5^{\circ} 15^{\prime} 56^{\prime \prime} \mathrm{S} ; 35^{\circ} 23^{\prime} 05^{\prime \prime O}$ & $\begin{array}{l}\text { C. A. A. Azevedo e } \\
\text { R. F. Menezes }\end{array}$ & $13 / 01 / 2013$ & 57814 & $\mathrm{X}$ & KT807809 & KT807827 \\
\hline IBC 2102 & Halymenia ignifera & $\begin{array}{l}\text { Praia de Rio do Fogo, Rio do } \\
\text { Fogo, RN }\end{array}$ & $5^{\circ} 15^{\prime} 56^{\prime \prime} \mathrm{S} ; 35^{\circ} 23^{\prime} 05^{\prime \prime} \mathrm{O}$ & $\begin{array}{l}\text { C. A. A. Azevedo e } \\
\text { R. F. Menezes }\end{array}$ & $13 / 01 / 2013$ & 57869 & $\mathrm{X}$ & KT807825 & \\
\hline IBC 2103 & Halymenia silviae & $\begin{array}{l}\text { Praia de Ponta Verde, Maceió, } \\
\text { AL }\end{array}$ & $9^{\circ} 39^{\prime} 54^{\prime \prime} \mathrm{S} ; 35^{\circ} 41^{\prime} 42^{\prime \prime} \mathrm{O}$ & $\begin{array}{l}\text { C. A. A. Azevedo, T. } \\
\text { Vieira-Pinto e B. } \\
\text { Torrano-Silva }\end{array}$ & $10 / 03 / 2013$ & 57813 & $\mathrm{X}$ & KT807812 & \\
\hline IBC 2105 & "Cryptonemia" crenulata & $\begin{array}{l}\text { Praia de Pontal do Peba, } \\
\text { Piaçabuçu, AL }\end{array}$ & $10^{\circ} 21^{\prime} 28^{\prime \prime} \mathrm{S} ; 36^{\circ} 17^{\prime} 44^{\prime \prime O}$ & $\begin{array}{l}\text { C. A. A. Azevedo, T. } \\
\text { Vieira-Pinto e B. } \\
\text { Torrano-Silva }\end{array}$ & $11 / 03 / 2013$ & & & $\mathrm{x}$ & \\
\hline IBC 2106 & Halymenia silviae & $\begin{array}{l}\text { Praia de Pontal do Peba, } \\
\text { Piaçabuçu, AL }\end{array}$ & $10^{\circ} 21^{\prime} 28^{\prime \prime S} ; 36^{\circ} 17^{\prime} 44^{\prime \prime O}$ & $\begin{array}{l}\text { C. A. A. Azevedo, T. } \\
\text { Vieira-Pinto e B. } \\
\text { Torrano-Silva }\end{array}$ & $11 / 03 / 2013$ & 57874 & $\mathrm{X}$ & KT807820 & \\
\hline IBC 2108 & "Cryptonemia" crenulata & Praia de Pontal do Peba, & $10^{\circ} 21^{\prime} 28^{\prime \prime S} ; 36^{\circ} 17^{\prime} 44^{\prime \prime O}$ & C. A. A. Azevedo, T. & $11 / 03 / 2013$ & 57782 & & & $\mathrm{x}$ \\
\hline
\end{tabular}


Tabela 2. Continuação.

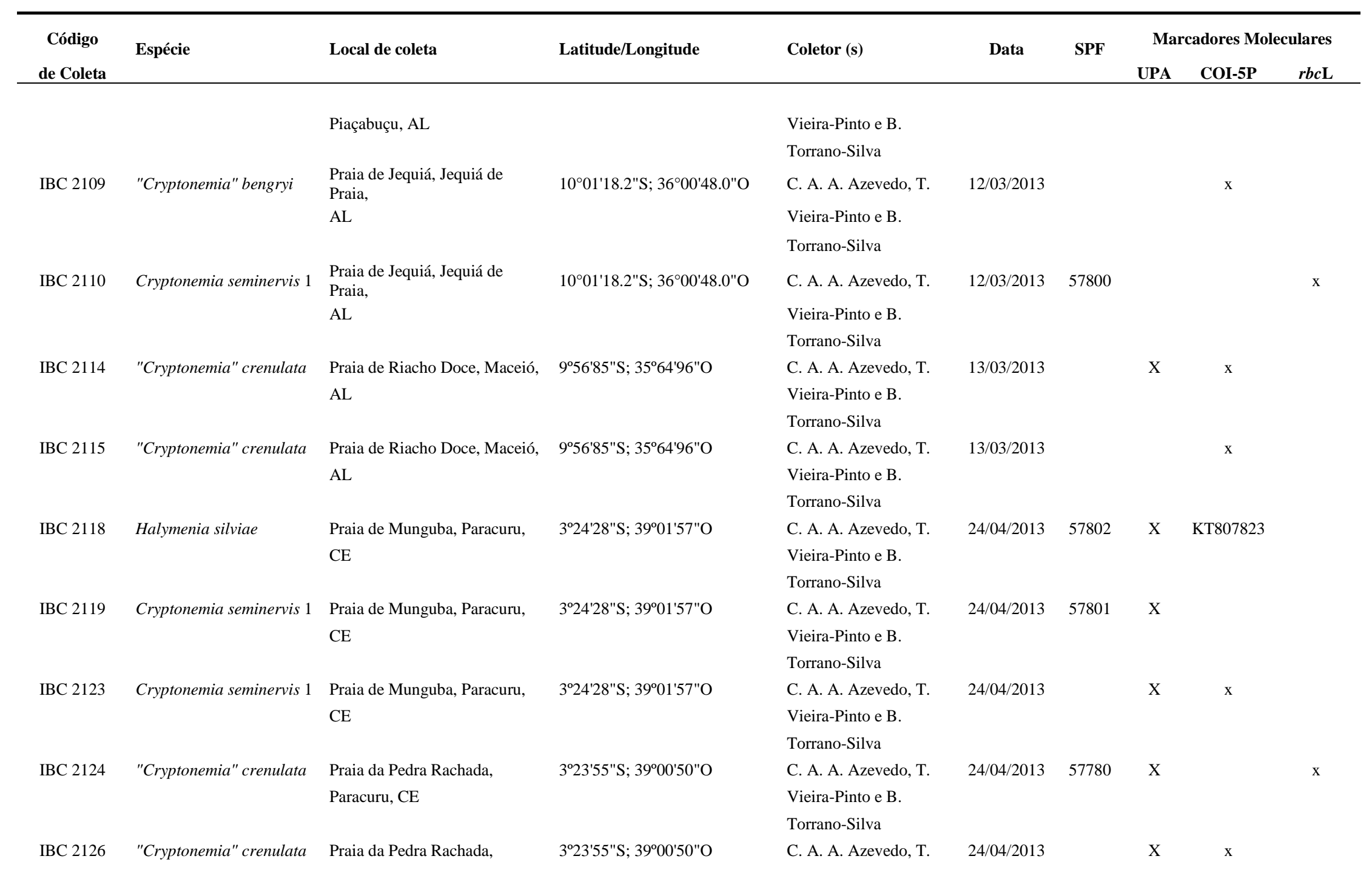


Tabela 2. Continuação.

\begin{tabular}{|c|c|c|c|c|c|c|c|c|c|}
\hline \multirow{2}{*}{$\begin{array}{c}\text { Código } \\
\text { de Coleta }\end{array}$} & \multirow{2}{*}{ Espécie } & \multirow{2}{*}{ Local de coleta } & \multirow{2}{*}{ Latitude/Longitude } & \multirow{2}{*}{ Coletor (s) } & \multirow{2}{*}{ Data } & \multirow{2}{*}{ SPF } & \multicolumn{3}{|c|}{ Marcadores Moleculares } \\
\hline & & & & & & & UPA & COI-5P & $r b c \mathrm{~L}$ \\
\hline & & Paracuru, CE & & Vieira-Pinto e B. & & & & & \\
\hline & & & & Torrano-Silva & & & & & \\
\hline \multirow[t]{3}{*}{ IBC 2127} & "Cryptonemia" crenulata & Praia da Pedra Rachada, & $3^{\circ} 23^{\prime} 55^{\prime \prime} \mathrm{S} ; 39^{\circ} 00^{\prime} 50^{\prime \prime O}$ & C. A. A. Azevedo, T. & $24 / 04 / 2013$ & & $\mathrm{X}$ & $\mathrm{x}$ & $\mathrm{x}$ \\
\hline & & Paracuru, CE & & Vieira-Pinto e B. & & & & & \\
\hline & & & & Torrano-Silva & & & & & \\
\hline \multirow[t]{3}{*}{ IBC 2128} & "Cryptonemia" crenulata & Praia da Pedra Rachada, & $3^{\circ} 23^{\prime} 55^{\prime \prime} \mathrm{S} ; 39^{\circ} 00^{\prime} 50^{\prime \prime} \mathrm{O}$ & C. A. A. Azevedo, T. & $24 / 04 / 2013$ & & $\mathrm{X}$ & $\mathrm{x}$ & \\
\hline & & Paracuru, CE & & Vieira-Pinto e B. & & & & & \\
\hline & & & & Torrano-Silva & & & & & \\
\hline \multirow[t]{3}{*}{ IBC 2129} & Halymenia sp. 2 & Praia de Guajiru, Trairi, CE & $3^{\circ} 14^{\prime} 20^{\prime \prime} \mathrm{S} ; 39^{\circ} 13^{\prime} 41^{\prime \prime O}$ & C. A. A. Azevedo, T. & $25 / 04 / 2013$ & & $\mathrm{X}$ & $\mathrm{x}$ & \\
\hline & & & & Vieira-Pinto e B. & & & & & \\
\hline & & & & Torrano-Silva & & & & & \\
\hline \multirow[t]{3}{*}{ IBC 2132} & Halymenia sp. 2 & Praia de Guajiru, Trairi, CE & $3^{\circ} 14^{\prime} 20^{\prime \prime} \mathrm{S} ; 39^{\circ} 13^{\prime} 41^{\prime \prime O}$ & C. A. A. Azevedo, T. & $25 / 04 / 2013$ & & $\mathrm{X}$ & $\mathrm{x}$ & \\
\hline & & & & Vieira-Pinto e B. & & & & & \\
\hline & & & & Torrano-Silva & & & & & \\
\hline \multirow[t]{3}{*}{ IBC 2133} & Halymenia sp. 2 & Praia de Guajiru, Trairi, CE & $3^{\circ} 14^{\prime} 20^{\prime \prime} \mathrm{S} ; 39^{\circ} 13^{\prime} 41^{\prime \prime O}$ & C. A. A. Azevedo, T. & $25 / 04 / 2013$ & & $\mathrm{X}$ & $\mathrm{x}$ & \\
\hline & & & & Vieira-Pinto e B. & & & & & \\
\hline & & & & Torrano-Silva & & & & & \\
\hline \multirow[t]{3}{*}{ IBC 2136} & "Halymenia" elongata & Praia de Guajiru, Trairi, CE & $3^{\circ} 14^{\prime} 20^{\prime \prime} \mathrm{S} ; 39^{\circ} 13^{\prime} 41^{\prime \prime O}$ & C. A. A. Azevedo, T. & $25 / 04 / 2013$ & & $\mathrm{X}$ & $\mathrm{x}$ & \\
\hline & & & & Vieira-Pinto e B. & & & & & \\
\hline & & & & Torrano-Silva & & & & & \\
\hline \multirow[t]{3}{*}{ IBC 2137} & Halymenia sp. 2 & Praia de Guajiru, Trairi, CE & $3^{\circ} 14^{\prime} 20^{\prime \prime} \mathrm{S} ; 39^{\circ} 13^{\prime} 41^{\prime \prime O}$ & C. A. A. Azevedo, T. & $25 / 04 / 2013$ & & $\mathrm{X}$ & $\mathrm{x}$ & \\
\hline & & & & Vieira-Pinto e B. & & & & & \\
\hline & & & & Torrano-Silva & & & & & \\
\hline \multirow[t]{3}{*}{ IBC 2138} & Halymenia sp. 1 & Praia de Guajiru, Trairi, CE & $3^{\circ} 14^{\prime} 20^{\prime \prime} \mathrm{S} ; 39^{\circ} 13^{\prime} 41^{\prime \prime O}$ & C. A. A. Azevedo, T. & $25 / 04 / 2013$ & 57795 & $\mathrm{X}$ & $\mathrm{x}$ & $\mathrm{x}$ \\
\hline & & & & Vieira-Pinto e B. & & & & & \\
\hline & & & & Torrano-Silva & & & & & \\
\hline \multirow[t]{2}{*}{ IBC 2139} & Halymenia sp. 2 & Praia de Guajiru, Trairi, CE & $3^{\circ} 14^{\prime} 20^{\prime \prime} \mathrm{S} ; 39^{\circ} 13^{\prime} 41^{\prime \prime O}$ & C. A. A. Azevedo, T. & $25 / 04 / 2013$ & & $X$ & $\mathrm{x}$ & \\
\hline & & & & Vieira-Pinto e B. & & & & & \\
\hline
\end{tabular}


Tabela 2. Continuação.

\begin{tabular}{|c|c|c|c|c|c|c|c|c|c|}
\hline \multirow{2}{*}{$\begin{array}{c}\text { Código } \\
\text { de Coleta }\end{array}$} & \multirow{2}{*}{ Espécie } & \multirow{2}{*}{ Local de coleta } & \multirow{2}{*}{ Latitude/Longitude } & \multirow{2}{*}{ Coletor (s) } & \multirow{2}{*}{ Data } & \multirow{2}{*}{ SPF } & \multicolumn{3}{|c|}{ Marcadores Moleculares } \\
\hline & & & & & & & UPA & COI-5P & $r b c \mathrm{~L}$ \\
\hline IBC 2140 & Halymenia sp. 2 & Praia de Guajiru, Trairi, CE & $3^{\circ} 14^{\prime} 20^{\prime \prime} \mathrm{S} ; 39^{\circ} 13^{\prime} 41^{\prime \prime O}$ & $\begin{array}{l}\text { Torrano-Silva } \\
\text { C. A. A. Azevedo, T. } \\
\text { Vieira-Pinto e B. } \\
\text { Torrano-Silva }\end{array}$ & $25 / 04 / 2013$ & & $\mathrm{X}$ & $\mathrm{x}$ & \\
\hline IBC 2141 & Halymenia sp. 2 & Praia de Guajiru, Trairi, CE & $3^{\circ} 14^{\prime} 20^{\prime \prime} \mathrm{S} ; 39^{\circ} 13^{\prime} 41^{\prime \prime O}$ & $\begin{array}{l}\text { C. A. A. Azevedo, T. } \\
\text { Vieira-Pinto e B. } \\
\text { Torrano-Silva }\end{array}$ & $25 / 04 / 2013$ & & $\mathrm{X}$ & $\mathrm{x}$ & \\
\hline IBC 2142 & Halymenia sp. 2 & Praia de Guajiru, Trairi, CE & $3^{\circ} 14^{\prime} 20^{\prime \prime} \mathrm{S} ; 39^{\circ} 13^{\prime} 41^{\prime \prime O}$ & $\begin{array}{l}\text { C. A. A. Azevedo, T. } \\
\text { Vieira-Pinto e B. } \\
\text { Torrano-Silva }\end{array}$ & $25 / 04 / 2013$ & & $\mathrm{X}$ & $\mathrm{x}$ & \\
\hline IBC 2143 & Halymenia sp. 2 & Praia do Pacheco, Caucaia, CE & $3^{\circ} 41^{\prime} 09^{\prime \prime} \mathrm{S} ; 38^{\circ} 38^{\prime} 01^{\prime \prime O}$ & $\begin{array}{l}\text { C. A. A. Azevedo, P. B. } \\
\text { Carneiro, T. Vieira-Pinto } \\
\text { e B. Torrano-Silva }\end{array}$ & $26 / 04 / 2013$ & 57794 & $\mathrm{X}$ & $\mathrm{x}$ & $\mathrm{x}$ \\
\hline IBC 2144 & "Cryptonemia" crenulata & Praia do Pacheco, Caucaia, CE & $3^{\circ} 41^{\prime} 09^{\prime \prime} \mathrm{S} ; 38^{\circ} 38^{\prime} 01^{\prime \prime O}$ & $\begin{array}{l}\text { C. A. A. Azevedo, P. B. } \\
\text { Carneiro, T. Vieira-Pinto } \\
\text { e B. Torrano-Silva }\end{array}$ & $26 / 04 / 2013$ & & $\mathrm{X}$ & $\mathrm{x}$ & \\
\hline IBC 2145 & "Cryptonemia" crenulata & Praia do Pacheco, Caucaia, CE & $3^{\circ} 41^{\prime} 09^{\prime \prime} \mathrm{S} ; 38^{\circ} 38^{\prime} 01^{\prime \prime O}$ & $\begin{array}{l}\text { C. A. A. Azevedo, P. B. } \\
\text { Carneiro, T. Vieira-Pinto } \\
\text { e B. Torrano-Silva }\end{array}$ & $26 / 04 / 2013$ & & & $\mathrm{x}$ & \\
\hline IBC 2146 & Cryptonemia seminervis 1 & Praia do Pacheco, Caucaia, CE & $3^{\circ} 41^{\prime} 09^{\prime \prime} \mathrm{S} ; 38^{\circ} 38^{\prime} 01^{\prime \prime O}$ & $\begin{array}{l}\text { C. A. A. Azevedo, P. B. } \\
\text { Carneiro, T. Vieira-Pinto } \\
\text { e B. Torrano-Silva }\end{array}$ & $26 / 04 / 2013$ & & $\mathrm{X}$ & & \\
\hline IBC 2147 & Halymenia sp. 2 & Praia do Pacheco, Caucaia, CE & $3^{\circ} 41^{\prime} 09^{\prime \prime} \mathrm{S} ; 38^{\circ} 38^{\prime} 01^{\prime \prime O}$ & $\begin{array}{l}\text { C. A. A. Azevedo, P. B. } \\
\text { Carneiro, T. Vieira-Pinto } \\
\text { e B. Torrano-Silva }\end{array}$ & $26 / 04 / 2013$ & 57793 & $\mathrm{X}$ & $\mathrm{x}$ & \\
\hline IBC 2148 & Halymenia sp. 2 & Praia do Pacheco, Caucaia, CE & $3^{\circ} 41^{\prime} 09^{\prime \prime} \mathrm{S} ; 38^{\circ} 38^{\prime} 01^{\prime \prime O}$ & $\begin{array}{l}\text { C. A. A. Azevedo, P. B. } \\
\text { Carneiro, T. Vieira-Pinto } \\
\text { e B. Torrano-Silva }\end{array}$ & $26 / 04 / 2013$ & 57779 & $\mathrm{X}$ & $\mathrm{x}$ & \\
\hline
\end{tabular}


Tabela 2. Continuação.

\begin{tabular}{|c|c|c|c|c|c|c|c|c|c|}
\hline \multirow{2}{*}{$\begin{array}{c}\text { Código } \\
\text { de Coleta }\end{array}$} & \multirow{2}{*}{ Espécie } & \multirow{2}{*}{ Local de coleta } & \multirow{2}{*}{ Latitude/Longitude } & \multirow{2}{*}{ Coletor (s) } & \multirow{2}{*}{ Data } & \multirow{2}{*}{ SPF } & \multicolumn{3}{|c|}{ Marcadores Moleculares } \\
\hline & & & & & & & UPA & COI-5P & $r b c \mathbf{L}$ \\
\hline IBC 2149 & Halymenia sp. 2 & Praia do Pacheco, Caucaia, CE & $3^{\circ} 41^{\prime} 09^{\prime \prime} \mathrm{S} ; 38^{\circ} 38^{\prime} 01^{\prime \prime O}$ & $\begin{array}{l}\text { C. A. A. Azevedo, P. B. } \\
\text { Carneiro, T. Vieira-Pinto } \\
\text { e B. Torrano-Silva }\end{array}$ & 26/04/2013 & & & $\mathrm{x}$ & \\
\hline IBC 2150 & "Cryptonemia" bengryi & Praia do Pacheco, Caucaia, CE & $3^{\circ} 41^{\prime} 09^{\prime \prime} \mathrm{S} ; 38^{\circ} 38^{\prime} 01^{\prime \prime O}$ & $\begin{array}{l}\text { C. A. A. Azevedo, P. B. } \\
\text { Carneiro, T. Vieira-Pinto } \\
\text { e B. Torrano-Silva }\end{array}$ & $26 / 04 / 2013$ & & $\mathrm{X}$ & $\mathrm{x}$ & \\
\hline IBC 2151 & Halymenia sp. 2 & Praia do Pacheco, Caucaia, CE & $3^{\circ} 41^{\prime} 09^{\prime \prime} \mathrm{S} ; 38^{\circ} 38^{\prime} 01^{\prime \prime O}$ & $\begin{array}{l}\text { C. A. A. Azevedo, P. B. } \\
\text { Carneiro, T. Vieira-Pinto } \\
\text { e B. Torrano-Silva }\end{array}$ & $26 / 04 / 2013$ & & $\mathrm{X}$ & $\mathrm{x}$ & \\
\hline IBC 2152 & Cryptonemia seminervis 1 & $\begin{array}{l}\text { Praia de Ponta Grossa, Icapuí, } \\
\text { CE }\end{array}$ & $4^{\circ} 37^{\prime} 37.6^{\prime \prime} \mathrm{S} ; 37^{\circ} 30^{\prime} 16.0^{\prime \prime O}$ & $\begin{array}{l}\text { C. A. A. Azevedo e T. } \\
\text { Vieira-Pinto }\end{array}$ & $27 / 04 / 2013$ & & $\mathrm{X}$ & & \\
\hline IBC 2153 & Halymenia ignifera & $\begin{array}{l}\text { Praia de Ponta Grossa, Icapuí, } \\
\text { CE }\end{array}$ & $4^{\circ} 37^{\prime} 37.6^{\prime \prime} \mathrm{S} ; 37^{\circ} 30^{\prime} 16.0^{\prime \prime O}$ & $\begin{array}{l}\text { C. A. A. Azevedo e T. } \\
\text { Vieira-Pinto }\end{array}$ & $27 / 04 / 2013$ & 57870 & $\mathrm{X}$ & KT807813 & \\
\hline IBC 2154 & "Cryptonemia" bengryi & $\begin{array}{l}\text { Praia de Ponta Grossa, Icapuí, } \\
\mathrm{CE}\end{array}$ & $4^{\circ} 37^{\prime} 37.6^{\prime \prime} \mathrm{S} ; 37^{\circ} 30^{\prime} 16.0^{\prime \prime O}$ & $\begin{array}{l}\text { C. A. A. Azevedo e T. } \\
\text { Vieira-Pinto }\end{array}$ & $27 / 04 / 2013$ & & $\mathrm{X}$ & $\mathrm{x}$ & \\
\hline IBC 2157 & "Cryptonemia" bengryi & $\begin{array}{l}\text { Praia da Caponga, Cascavel, } \\
\text { CE }\end{array}$ & $4^{\circ} 02^{\prime 2} 23^{\prime \prime} \mathrm{S} ; 38^{\circ} 11^{\prime} 32^{\prime \prime} \mathrm{O}$ & $\begin{array}{l}\text { C. A. A. Azevedo e T. } \\
\text { Vieira-Pinto }\end{array}$ & $28 / 04 / 2013$ & 57805 & $\mathrm{X}$ & $\mathrm{x}$ & $\mathrm{x}$ \\
\hline IBC 2158 & "Cryptonemia" bengryi & $\begin{array}{l}\text { Praia da Caponga, Cascavel, } \\
\text { CE }\end{array}$ & $4^{\circ} 02^{\prime 2} 23^{\prime \prime} \mathrm{S} ; 38^{\circ} 11^{\prime} 32^{\prime \prime} \mathrm{O}$ & $\begin{array}{l}\text { C. A. A. Azevedo e T. } \\
\text { Vieira-Pinto }\end{array}$ & $28 / 04 / 2013$ & & $\mathrm{X}$ & $\mathrm{x}$ & \\
\hline IBC 2159 & Cryptonemia seminervis 1 & $\begin{array}{l}\text { Praia de Stella Maris, Salvador, } \\
\text { BA }\end{array}$ & $12^{\circ} 56^{\prime} 41.5^{\prime \prime} \mathrm{S} ; 38^{\circ} 20^{\prime} 04.7^{\prime \prime O}$ & $\begin{array}{l}\text { C. A. A. Azevedo e T. } \\
\text { Vieira-Pinto }\end{array}$ & $22 / 05 / 2013$ & & & $\mathrm{x}$ & \\
\hline IBC 2160 & Cryptonemia seminervis 1 & $\begin{array}{l}\text { Praia de Stella Maris, Salvador, } \\
\text { BA }\end{array}$ & $12^{\circ} 56^{\prime} 41.5^{\prime \prime} \mathrm{S} ; 38^{\circ} 20^{\prime} 04.7^{\prime \prime O}$ & $\begin{array}{l}\text { C. A. A. Azevedo e T. } \\
\text { Vieira-Pinto }\end{array}$ & $22 / 05 / 2013$ & 57808 & $\mathrm{X}$ & & \\
\hline IBC 2161 & Halymeniales sp. 1 & Banco da Panela, Salvador, BA & $12^{\circ} 57^{\prime} 59^{\prime \prime} \mathrm{S} ; 38^{\circ} 31^{\prime} 37^{\prime \prime O}$ & $\begin{array}{l}\text { B. Torrano-Silva e M. } \\
\text { Jamas }\end{array}$ & $22 / 05 / 2013$ & 57811 & $\mathrm{X}$ & $\mathrm{x}$ & $\mathrm{x}$ \\
\hline IBC 2164 & Halymeniales sp. 1 & Banco da Panela, Salvador, BA & $12^{\circ} 57^{\prime} 59^{\prime \prime} \mathrm{S} ; 38^{\circ} 31^{\prime} 37^{\prime \prime O}$ & $\begin{array}{l}\text { B. Torrano-Silva e M. } \\
\text { Jamas }\end{array}$ & $22 / 05 / 2013$ & & $\mathrm{X}$ & $\mathrm{x}$ & \\
\hline
\end{tabular}


Tabela 2. Continuação.

\begin{tabular}{|c|c|c|c|c|c|c|c|c|c|}
\hline \multirow{2}{*}{$\begin{array}{c}\text { Código } \\
\text { de Coleta } \\
\end{array}$} & \multirow{2}{*}{ Espécie } & \multirow{2}{*}{ Local de coleta } & \multirow{2}{*}{ Latitude/Longitude } & \multirow{2}{*}{ Coletor (s) } & \multirow{2}{*}{ Data } & \multirow{2}{*}{ SPF } & \multicolumn{3}{|c|}{ Marcadores Moleculares } \\
\hline & & & & & & & UPA & COI-5P & $r b c \mathbf{L}$ \\
\hline IBC 2165 & Halymeniales sp. 2 & Banco da Panela, Salvador, BA & $12^{\circ} 57^{\prime} 59^{\prime \prime} \mathrm{S} ; 38^{\circ} 31^{\prime} 37^{\prime \prime O}$ & $\begin{array}{l}\text { B. Torrano-Silva e M. } \\
\text { Jamas }\end{array}$ & $22 / 05 / 2013$ & & & $\mathrm{x}$ & $\mathrm{x}$ \\
\hline IBC 2170 & Cryptonemia seminervis 1 & Praia de Jauá, Camaçari, BA & $12^{\circ} 44^{\prime} \mathrm{S} ; 38^{\circ} 08^{\prime} \mathrm{O}$ & $\begin{array}{l}\text { B. Torrano-Silva e M. } \\
\text { Jamas }\end{array}$ & $22 / 05 / 2013$ & & $\mathrm{X}$ & $\mathrm{x}$ & \\
\hline IBC 2173 & Cryptonemia seminervis 1 & $\begin{array}{l}\text { Praia da Coroa, Ilha de } \\
\text { Itaparica, } \\
\text { Vera Cruz, BA }\end{array}$ & $13^{\circ} 00^{\prime} 39.7^{\prime \prime S} ; 38^{\circ} 38^{\prime} 26.6^{\prime \prime O}$ & $\begin{array}{l}\text { C. A. A. Azevedo, T. } \\
\text { Vieira-Pinto, B. Torrano- } \\
\text { Silva e M. Jamas }\end{array}$ & $23 / 05 / 2013$ & 57809 & $\mathrm{X}$ & & $\mathrm{x}$ \\
\hline IBC 2175 & "Halymenia" floridana & $\begin{array}{l}\text { Praia de Guarajuba, Camaçari, } \\
\text { BA }\end{array}$ & $12^{\circ} 38^{\prime} 58^{\prime \prime} \mathrm{S} ; 38^{\circ} 03^{\prime} 37^{\prime \prime} \mathrm{O}$ & $\begin{array}{l}\text { C. A. A. Azevedo, T. } \\
\text { Vieira-Pinto e B. Torrano- } \\
\text { Silva }\end{array}$ & $26 / 05 / 2013$ & 57812 & $\mathrm{X}$ & & $\mathrm{x}$ \\
\hline IBC 2176 & "Cryptonemia" crenulata & $\begin{array}{l}\text { Praia de Guarajuba, Camaçari, } \\
\text { BA }\end{array}$ & $12^{\circ} 38^{\prime} 58^{\prime \prime} \mathrm{S} ; 38^{\circ} 03^{\prime} 37^{\prime \prime O}$ & $\begin{array}{l}\text { C. A. A. Azevedo, T. } \\
\text { Vieira-Pinto e B. Torrano- } \\
\text { Silva }\end{array}$ & $26 / 05 / 2013$ & 57810 & $\mathrm{X}$ & & $\mathrm{x}$ \\
\hline IBC 2177 & "Cryptonemia" crenulata & $\begin{array}{l}\text { Praia de Guarajuba, Camaçari, } \\
\text { BA }\end{array}$ & $12^{\circ} 38^{\prime} 58^{\prime \prime} \mathrm{S} ; 38^{\circ} 03^{\prime} 37^{\prime \prime O}$ & $\begin{array}{l}\text { C. A. A. Azevedo, T. } \\
\text { Vieira-Pinto e B. Torrano- } \\
\text { Silva }\end{array}$ & $26 / 05 / 2013$ & & $\mathrm{X}$ & $\mathrm{x}$ & \\
\hline IBC 2178 & "Cryptonemia" crenulata & $\begin{array}{l}\text { Praia de Guarajuba, Camaçari, } \\
\text { BA }\end{array}$ & $12^{\circ} 38^{\prime} 58^{\prime \prime} \mathrm{S} ; 38^{\circ} 03^{\prime} 37^{\prime \prime O}$ & $\begin{array}{l}\text { C. A. A. Azevedo, T. } \\
\text { Vieira-Pinto e B. Torrano- } \\
\text { Silva }\end{array}$ & $26 / 05 / 2013$ & & $\mathrm{X}$ & $\mathrm{x}$ & \\
\hline IBC 2179 & "Cryptonemia" crenulata & $\begin{array}{l}\text { Praia de Guarajuba, Camaçari, } \\
\text { BA }\end{array}$ & $12^{\circ} 38^{\prime} 58^{\prime \prime} \mathrm{S} ; 38^{\circ} 03^{\prime} 37^{\prime \prime} \mathrm{O}$ & $\begin{array}{l}\text { C. A. A. Azevedo, T. } \\
\text { Vieira-Pinto e B. Torrano- } \\
\text { Silva }\end{array}$ & $26 / 05 / 2013$ & & $\mathrm{X}$ & $\mathrm{x}$ & $\mathrm{x}$ \\
\hline IBC 2180 & "Cryptonemia" delicatula & $\begin{array}{l}\text { Praia de Subaúma, Entre Rios, } \\
\text { BA }\end{array}$ & $12^{\circ} 13^{\prime} 57^{\prime \prime} \mathrm{S} ; 37^{\circ} 45^{\prime} 59^{\prime \prime O}$ & $\begin{array}{l}\text { C. A. A. Azevedo, T. } \\
\text { Vieira-Pinto e B. Torrano- } \\
\text { Silva }\end{array}$ & $27 / 05 / 2013$ & 57783 & $\mathrm{X}$ & $\mathrm{x}$ & $\mathrm{x}$ \\
\hline IBC 2181 & "Cryptonemia" delicatula & $\begin{array}{l}\text { Praia de Subaúma, Entre Rios, } \\
\text { BA }\end{array}$ & $12^{\circ} 13^{\prime} 57^{\prime \prime} \mathrm{S} ; 37^{\circ} 45^{\prime} 59^{\prime \prime O}$ & $\begin{array}{l}\text { C. A. A. Azevedo, T. } \\
\text { Vieira-Pinto e B. Torrano- } \\
\text { Silva }\end{array}$ & $27 / 05 / 2013$ & & $\mathrm{X}$ & & \\
\hline
\end{tabular}


Tabela 2. Continuação.

\begin{tabular}{|c|c|c|c|c|c|c|c|c|c|}
\hline \multirow{2}{*}{$\begin{array}{l}\text { Código } \\
\text { de Coleta } \\
\end{array}$} & \multirow{2}{*}{ Espécie } & \multirow{2}{*}{ Local de coleta } & \multirow{2}{*}{ Latitude/Longitude } & \multirow{2}{*}{ Coletor (s) } & \multirow{2}{*}{ Data } & \multirow{2}{*}{ SPF } & \multicolumn{3}{|c|}{ Marcadores Moleculares } \\
\hline & & & & & & & UPA & COI-5P & $r b c \mathrm{~L}$ \\
\hline IBC 2182 & "Cryptonemia" delicatula & $\begin{array}{l}\text { Praia de Subaúma, Entre Rios, } \\
\text { BA }\end{array}$ & $12^{\circ} 13^{\prime} 57^{\prime \prime S} ; 37^{\circ} 45^{\prime} 59^{\prime \prime O}$ & $\begin{array}{l}\text { C. A. A. Azevedo, T. } \\
\text { Vieira-Pinto e B. Torrano- } \\
\text { Silva }\end{array}$ & $27 / 05 / 2013$ & & & & \\
\hline IBC 2183 & Corynomorpha cf. clavata & $\begin{array}{l}\text { Praia de Subaúma, Entre Rios, } \\
\text { BA }\end{array}$ & $12^{\circ} 13^{\prime} 57^{\prime \prime S} ; 37^{\circ} 45^{\prime} 59^{\prime \prime O}$ & $\begin{array}{l}\text { C. A. A. Azevedo, T. } \\
\text { Vieira-Pinto e B. Torrano- } \\
\text { Silva }\end{array}$ & $27 / 05 / 2013$ & 57790 & $\mathrm{X}$ & $\mathrm{x}$ & $\mathrm{x}$ \\
\hline IBC 2184 & Corynomorpha cf. clavata & $\begin{array}{l}\text { Praia de Subaúma, Entre Rios, } \\
\text { BA }\end{array}$ & $12^{\circ} 13^{\prime} 57^{\prime \prime S} ; 37^{\circ} 45^{\prime} 59^{\prime \prime O}$ & $\begin{array}{l}\text { C. A. A. Azevedo, T. } \\
\text { Vieira-Pinto e B. Torrano- } \\
\text { Silva }\end{array}$ & $27 / 05 / 2013$ & & $\mathrm{X}$ & & \\
\hline IBC 2190 & "Cryptonemia" crenulata & $\begin{array}{l}\text { Praia de Subaúma, Entre Rios, } \\
\text { BA }\end{array}$ & $12^{\circ} 13^{\prime} 57^{\prime \prime S} ; 37^{\circ} 45^{\prime} 59^{\prime \prime O}$ & $\begin{array}{l}\text { C. A. A. Azevedo, T. } \\
\text { Vieira-Pinto e B. Torrano- } \\
\text { Silva }\end{array}$ & $27 / 05 / 2013$ & & $\mathrm{X}$ & $\mathrm{x}$ & \\
\hline IBC 2191 & Corynomorpha cf. clavata & $\begin{array}{l}\text { Praia de Subaúma, Entre Rios, } \\
\text { BA }\end{array}$ & $12^{\circ} 13^{\prime} 57^{\prime \prime} \mathrm{S} ; 37^{\circ} 45^{\prime} 59^{\prime \prime O}$ & $\begin{array}{l}\text { C. A. A. Azevedo, T. } \\
\text { Vieira-Pinto e B. Torrano- } \\
\text { Silva }\end{array}$ & $27 / 05 / 2013$ & & $\mathrm{X}$ & $\mathrm{x}$ & \\
\hline IBC 2193 & Grateloupia filiformis & Praia Vermelha, Ubatuba, SP & $23^{\circ} 30^{\prime} 23.7^{\prime \prime S} ; 45^{\circ} 10^{\prime} 22.2^{\prime \prime} \mathrm{O}$ & $\begin{array}{l}\text { M. C. Oliveira e E. C. } \\
\text { Oliveira }\end{array}$ & $17 / 10 / 2013$ & & $\mathrm{X}$ & $\mathrm{x}$ & \\
\hline IBC 2194 & Cryptonemia seminervis 2 & $\begin{array}{l}\text { Praia da Foca, Armação dos } \\
\text { Búzios, RJ }\end{array}$ & $22^{\circ} 45^{\prime} 55^{\prime \prime} \mathrm{S} ; 41^{\circ} 52^{\prime} 43^{\prime \prime O}$ & $\begin{array}{l}\text { C. A. A. Azevedo, V. } \\
\text { Cassano e M. Mungioli }\end{array}$ & $14 / 03 / 2014$ & 57776 & & & $\mathrm{x}$ \\
\hline IBC 2195 & Cryptonemia seminervis 3 & $\begin{array}{l}\text { Praia da Foca, Armação dos } \\
\text { Búzios, RJ }\end{array}$ & $22^{\circ} 45^{\prime} 55^{\prime \prime} \mathrm{S} ; 41^{\circ} 52^{\prime} 43^{\prime \prime O}$ & $\begin{array}{l}\text { C. A. A. Azevedo, V. } \\
\text { Cassano e M. Mungioli }\end{array}$ & $14 / 03 / 2014$ & 57777 & & & $\mathrm{x}$ \\
\hline IBC 2201 & Grateloupia cf. filicina 1 & $\begin{array}{l}\text { Praia Rasa, Armação dos } \\
\text { Búzios, } \\
\text { RJ }\end{array}$ & $22^{\circ} 43^{\prime} 59.5 " \mathrm{~S} ; 41^{\circ} 57^{\prime} 26.1^{\prime \prime O}$ & $\begin{array}{l}\text { C. A. A. Azevedo, V. } \\
\text { Cassano e M. Mungioli }\end{array}$ & $17 / 03 / 2014$ & & $\mathrm{X}$ & $\mathrm{x}$ & \\
\hline IBC 2202 & "Grateloupia" gibbesii & $\begin{array}{l}\text { Praia Rasa, Armação dos } \\
\text { Búzios, } \\
\text { RJ }\end{array}$ & $22^{\circ} 43^{\prime} 59.5^{\prime \prime} \mathrm{S} ; 41^{\circ} 57^{\prime} 26.1^{\prime \prime O}$ & $\begin{array}{l}\text { C. A. A. Azevedo, V. } \\
\text { Cassano e M. Mungioli }\end{array}$ & $17 / 03 / 2014$ & & $\mathrm{X}$ & $\mathrm{x}$ & \\
\hline IBC 2203 & Grateloupia turuturu & $\begin{array}{l}\text { Praia da Armação, } \\
\text { Florianópolis, } \\
\text { SC }\end{array}$ & 27ํ4'57"S; 48²9'59"O & P. Horta & $30 / 01 / 2011$ & & & & KP976174 \\
\hline
\end{tabular}


Tabela 2. Continuação.

\begin{tabular}{|c|c|c|c|c|c|c|c|c|c|}
\hline \multirow{2}{*}{$\begin{array}{c}\text { Código } \\
\text { de Coleta } \\
\end{array}$} & \multirow{2}{*}{ Espécie } & \multirow{2}{*}{ Local de coleta } & \multirow{2}{*}{ Latitude/Longitude } & \multirow{2}{*}{ Coletor (s) } & \multirow{2}{*}{ Data } & \multirow{2}{*}{ SPF } & \multicolumn{3}{|c|}{ Marcadores Moleculares } \\
\hline & & & & & & & UPA & COI-5P & $r b c \mathbf{L}$ \\
\hline IBC 2204 & Grateloupia turuturu & $\begin{array}{l}\text { Praia do Saquinho, } \\
\text { Florianópolis, SC }\end{array}$ & $27^{\circ} 80^{\prime} 31^{\prime \prime} \mathrm{S} ; 48^{\circ} 53^{\prime} 64^{\prime \prime} \mathrm{O}$ & M. B. Batista & $13 / 09 / 2011$ & & $\mathrm{X}$ & KP976172 & KP976177 \\
\hline IBC 2205 & "Halymenia" floridana & $\begin{array}{l}\text { Praia Ponta das Canas, } \\
\text { Florianópolis, SC }\end{array}$ & $27^{\circ} 24^{\prime} 35.2^{\prime \prime S} ; 48^{\circ} 25^{\prime} 42.9^{\prime \prime O}$ & M. B. Batista & $16 / 06 / 2011$ & & & & $\mathrm{x}$ \\
\hline IBC 2206 & Grateloupia turuturu & $\begin{array}{l}\text { Praia do Saquinho, } \\
\text { Florianópolis, SC }\end{array}$ & $27^{\circ} 80^{\prime} 31^{\prime \prime S} ; 48^{\circ} 53^{\prime} 64^{\prime \prime} \mathrm{O}$ & M. B. Batista & 13/09/2011 & & & & KP976176 \\
\hline IBC 2207 & Grateloupia turuturu & $\begin{array}{l}\text { Praia da Armação, } \\
\text { Florianópolis, } \\
\text { SC }\end{array}$ & 274ㄴ'57"S; 48²9'59"O & M. B. Batista & $30 / 01 / 2011$ & & $\mathrm{X}$ & KP976171 & KP976175 \\
\hline IBC 2208 & $\begin{array}{l}\text { Grateloupia cf. } \\
\text { dichotoma }\end{array}$ & Ilha do Mel, Ilha do Mel, PR & $25^{\circ} 30 \mathrm{~S} ; 48^{\circ} 18^{\prime} \mathrm{O}$ & V. Cassano & $12 / 07 / 2014$ & & $X$ & $\mathrm{x}$ & $\mathrm{x}$ \\
\hline IBC 2209 & "Grateloupia" gibbesii & $\begin{array}{l}\text { Praia Vermelha, Rio de } \\
\text { Janeiro, } \\
\text { RJ }\end{array}$ & $22^{\circ} 57^{\prime} 23.4^{\prime \prime S} ; 43^{\circ} 09^{\prime} 51.1^{\prime \prime O}$ & J. de Paula & $11 / 08 / 2014$ & & $\mathrm{X}$ & & \\
\hline IBC 2210 & "Halymenia" floridana & $\begin{array}{l}\text { Ponta de Castelhanos, } \\
\text { Anchieta, } \\
\text { ES }\end{array}$ & $20^{\circ} 50^{\prime} 03 " \mathrm{~S} ; 40^{\circ} 37^{\prime} 20^{\prime \prime O}$ & T. Vieira-Pinto & 09/09/2014 & & $\mathrm{X}$ & & \\
\hline IBC 2211 & $\begin{array}{l}\text { Grateloupia cf. } \\
\text { dichotoma }\end{array}$ & Praia da Cruz, Marataízes, ES & $21^{\circ} 01^{\prime} 58.2^{\prime \prime} \mathrm{S} ; 40^{\circ} 48^{\prime} 43.9^{\prime \prime} \mathrm{O}$ & T. Vieira-Pinto & $10 / 09 / 2014$ & & $\mathrm{X}$ & & \\
\hline IBC 2212 & "Grateloupia" gibbesii & Praia da Cruz, Marataízes, ES & $21^{\circ} 01^{\prime} 58.2^{\prime \prime} \mathrm{S} ; 40^{\circ} 48^{\prime} 43.9^{\prime \prime O}$ & T. Vieira-Pinto & $10 / 09 / 2014$ & & $\mathrm{X}$ & & \\
\hline IBC 2213 & Grateloupia filiformis & $\begin{array}{l}\text { Praia de Japaratinga, } \\
\text { Jarapatinga, AL }\end{array}$ & $9^{\circ} 05^{\prime} 49^{\prime \prime} \mathrm{S} ; 35^{\circ} 15^{\prime} 28^{\prime \prime O}$ & V. Cassano & & & $X$ & & \\
\hline IBC 2215 & Cryptonemia seminervis 2 & Ilha do Vigia, Cabo Frio, RJ & $22^{\circ} 52^{\prime} 06.1^{\prime \prime S} ; 41^{\circ} 58^{\prime} 50.0^{\prime \prime O}$ & $\begin{array}{l}\text { C. A. A. Azevedo, V. } \\
\text { Cassano e M. Mungioli }\end{array}$ & 07/03/2015 & & $X$ & & \\
\hline IBC 2216 & Cryptonemia seminervis 3 & Ilha do Vigia, Cabo Frio, RJ & $22^{\circ} 52^{\prime} 06.1^{\prime \prime S} ; 41^{\circ} 58^{\prime} 50.0^{\prime \prime O}$ & $\begin{array}{l}\text { C. A. A. Azevedo, V. } \\
\text { Cassano e M. Mungioli }\end{array}$ & 07/03/2015 & & $\mathrm{X}$ & & \\
\hline IBC 2217 & Cryptonemia seminervis 3 & Ilha do Vigia, Cabo Frio, RJ & $22^{\circ} 52^{\prime} 06.1^{\prime \prime S} ; 41^{\circ} 58^{\prime} 50.0^{\prime \prime O}$ & $\begin{array}{l}\text { C. A. A. Azevedo, V. } \\
\text { Cassano e M. Mungioli }\end{array}$ & 07/03/2015 & & $X$ & & \\
\hline IBC 2218 & "Halymenia" floridana & $\begin{array}{l}\text { Praia Rasa, Armação dos } \\
\text { Búzios, RJ }\end{array}$ & $22^{\circ} 43^{\prime} 59.5^{\prime \prime S} ; 41^{\circ} 57^{\prime} 26.1^{\prime \prime O}$ & $\begin{array}{l}\text { C. A. A. Azevedo, V. } \\
\text { Cassano e M. Mungioli }\end{array}$ & 08/03/2015 & & & & $\mathrm{x}$ \\
\hline IBC 2219 & Cryptonemia seminervis 1 & Praia Rasa, Armação dos & $22^{\circ} 43^{\prime} 59.5^{\prime \prime} \mathrm{S} ; 41^{\circ} 57^{\prime} 26.1^{\prime \prime O}$ & C. A. A. Azevedo, V. & $08 / 03 / 2015$ & & $\mathrm{X}$ & & \\
\hline
\end{tabular}


Tabela 2. Continuação.

\begin{tabular}{|c|c|c|c|c|c|c|c|c|c|}
\hline \multirow{2}{*}{$\begin{array}{c}\text { Código } \\
\text { de Coleta } \\
\end{array}$} & \multirow{2}{*}{ Espécie } & \multirow{2}{*}{ Local de coleta } & \multirow{2}{*}{ Latitude/Longitude } & \multirow{2}{*}{ Coletor (s) } & \multirow{2}{*}{ Data } & \multirow{2}{*}{ SPF } & \multicolumn{3}{|c|}{ Marcadores Moleculares } \\
\hline & & & & & & & UPA & COI-5P & $r b c \mathbf{L}$ \\
\hline & & Búzios, RJ & & Cassano e M. Mungioli & & & & & \\
\hline \multirow[t]{2}{*}{ IBC 2220} & Cryptonemia seminervis 1 & Praia Rasa, Armação dos & $22^{\circ} 43^{\prime} 59.5^{\prime \prime} \mathrm{S} ; 41^{\circ} 57^{\prime} 26.1^{\prime \prime O}$ & C. A. A. Azevedo, V. & 08/03/2015 & & $\mathrm{X}$ & & \\
\hline & & Búzios, RJ & & Cassano e M. Mungioli & & & & & \\
\hline \multirow[t]{2}{*}{ IBC 2221} & Cryptonemia seminervis 3 & $\begin{array}{l}\text { Praia da Ferradurinha, } \\
\text { Armação }\end{array}$ & $22^{\circ} 46{ }^{\prime} 53.3^{\prime \prime} \mathrm{S} ; 41^{\circ} 53^{\prime} 59.1^{\prime \prime O}$ & & 09/03/2015 & & $\mathrm{X}$ & & $\mathrm{x}$ \\
\hline & & dos Búzios, RJ & & Cassano e M. Mungioli & & & & & \\
\hline \multirow[t]{2}{*}{ IBC 2222} & Cryptonemia seminervis 2 & $\begin{array}{l}\text { Praia da Ferradurinha, } \\
\text { Armação }\end{array}$ & $22^{\circ} 46{ }^{\prime} 53.3^{\prime \prime} \mathrm{S} ; 41^{\circ} 53^{\prime} 59.1^{\prime \prime O}$ & C. A. A. Azevedo, V. & 09/03/2015 & & $\mathrm{X}$ & & $\mathrm{x}$ \\
\hline & & dos Búzios, RJ & & Cassano e M. Mungioli & & & & & \\
\hline \multirow[t]{2}{*}{ IBC 2223} & "Grateloupia" gibbesii & Praia da Foca, Armação dos & $22^{\circ} 45^{\prime} 55.2^{\prime \prime} \mathrm{S} ; 41^{\circ} 52^{\prime} 43.6^{\prime \prime O}$ & C. A. A. Azevedo, V. & 09/03/2015 & & $\mathrm{X}$ & & $\mathrm{x}$ \\
\hline & & Búzios, RJ & & Cassano e M. Mungioli & & & & & \\
\hline \multirow[t]{2}{*}{ IBC 2224} & Cryptonemia seminervis 2 & Praia da Foca, Armação dos & $22^{\circ} 45^{\prime} 55.2^{\prime \prime} \mathrm{S} ; 41^{\circ} 52^{\prime} 43.6^{\prime \prime O}$ & C. A. A. Azevedo, V. & 09/03/2015 & & $\mathrm{X}$ & & \\
\hline & & Búzios, RJ & & Cassano e M. Mungioli & & & & & \\
\hline \multirow[t]{2}{*}{ IBC 2225} & Cryptonemia seminervis 2 & Praia da Foca, Armação dos & $22^{\circ} 45^{\prime} 55.2^{\prime \prime} \mathrm{S} ; 41^{\circ} 52^{\prime} 43.6^{\prime \prime} \mathrm{O}$ & C. A. A. Azevedo, V. & 09/03/2015 & & $\mathrm{X}$ & & \\
\hline & & Búzios, RJ & & Cassano e M. Mungioli & & & & & \\
\hline \multirow[t]{2}{*}{ IBC 2226} & "Grateloupia" gibbesii & Praia de Cibratel, Itanhaém, SP & $24^{\circ} 12^{\prime} 06.5^{\prime \prime} \mathrm{S} ; 46^{\circ} 48^{\prime} 40.1^{\prime \prime O}$ & C. A. A. Azevedo e & $20 / 03 / 2015$ & & & & $\mathrm{x}$ \\
\hline & & & & M. Mungioli & & & & & \\
\hline \multirow[t]{2}{*}{ IBC 2228} & "Grateloupia" gibbesii & Praia Desertinha, costão & $24^{\circ} 25^{\prime} 49.28^{\prime \prime S} ; 4^{\circ} 02^{\prime} 46.14^{\prime \prime O}$ & C. A. A. Azevedo e & $04 / 05 / 2015$ & & & & $\mathrm{x}$ \\
\hline & & esquerdo, Peruíbe, SP & & M. Mungioli & & & & & \\
\hline \multirow[t]{2}{*}{ IBC 2235} & $\begin{array}{l}\text { Grateloupia cf. } \\
\text { dichotoma }\end{array}$ & Praia de Guaraú, Peruíbe, SP & $24^{\circ} 22^{\prime} 01.98^{\prime \prime S} ; 4^{\circ} 00^{\prime} 32.33^{\prime \prime O}$ & C. A. A. Azevedo e & 05/05/2015 & & & & $\mathrm{x}$ \\
\hline & & & & M. Mungioli & & & & & \\
\hline \multirow[t]{2}{*}{ IBC 2247} & $\begin{array}{l}\text { Grateloupia } \\
\text { yangjiangensis }\end{array}$ & Praia do Lázaro, Ubatuba, SP & $23^{\circ} 30^{\prime} 31.12^{\prime \prime} \mathrm{S} ; 45^{\circ} 08^{\prime} 09.72^{\prime \prime O}$ & C. A. A. Azevedo e & $17 / 05 / 2015$ & & & & $\mathrm{x}$ \\
\hline & & & & M. Mungioli & & & & & \\
\hline \multirow[t]{2}{*}{ IBC 2248} & Grateloupia orientalis & Praia do Lázaro, Ubatuba, SP & $23^{\circ} 30^{\prime} 31.12^{\prime \prime} \mathrm{S} ; 45^{\circ} 08^{\prime} 09.72^{\prime \prime O}$ & C. A. A. Azevedo e & $17 / 05 / 2015$ & & & & $\mathrm{x}$ \\
\hline & & & & M. Mungioli & & & & & \\
\hline \multirow[t]{2}{*}{ IBC 2528} & Halymenia silviae & Ponta do Corumbau, Prado, BA & $16^{\circ} 54^{\prime} 05^{\prime \prime} \mathrm{S} ; 39^{\circ} 07^{\prime} 10^{\prime \prime O}$ & B. Torrano-Silva, J. & $13 / 05 / 2014$ & 57875 & \multicolumn{3}{|c|}{ КT807814 } \\
\hline & & & & Pires e A. S. Santos & & & & & \\
\hline \multirow[t]{2}{*}{ IBC 2540} & Halymenia silviae & Ponta do Corumbau, Prado, BA & $16^{\circ} 54^{\prime} 05^{\prime \prime} \mathrm{S} ; 39^{\circ} 07^{\prime} 10^{\prime \prime O}$ & B. Torrano-Silva, J. & $13 / 05 / 2014$ & 57876 & \multirow{2}{*}{\multicolumn{3}{|c|}{ KT807822 }} \\
\hline & & & & Pires e A. S. Santos & & & & & \\
\hline
\end{tabular}


Tabela 2. Continuação.

\begin{tabular}{|c|c|c|c|c|c|c|c|c|c|}
\hline \multirow{2}{*}{$\begin{array}{c}\text { Código } \\
\text { de Coleta } \\
\end{array}$} & \multirow{2}{*}{ Espécie } & \multirow{2}{*}{ Local de coleta } & \multirow{2}{*}{ Latitude/Longitude } & \multirow{2}{*}{ Coletor (s) } & \multirow{2}{*}{ Data } & \multirow{2}{*}{ SPF } & \multicolumn{3}{|c|}{ Marcadores Moleculares } \\
\hline & & & & & & & UPA & COI-5P & $r b c \mathrm{~L}$ \\
\hline IBC 2616 & Grateloupia filiformis & $\begin{array}{l}\text { Praia do Morro de } \\
\text { Pernambuco, } \\
\text { Ilhéus, BA }\end{array}$ & $14^{\circ} 48^{\prime} 21.8^{\prime \prime S} ; 39^{\circ} 01^{\prime} 24.4^{\prime \prime O}$ & $\begin{array}{l}\text { J. Pires, A. S. Santos e } \\
\text { B. Torrano-Silva }\end{array}$ & $13 / 05 / 2014$ & & & $\mathrm{x}$ & \\
\hline
\end{tabular}




\subsection{Procedimentos Moleculares}

Para os estudos moleculares, foram retiradas porções apicais dos talos, as quais foram desidratadas e armazenadas em sílica gel. O restante da alga foi colocado em solução de formol salino $4 \%$ ou diretamente herborizadas para as análises morfológicas descritas abaixo. A extração de DNA foi feita a partir do talo desidratado e macerado manualmente em nitrogênio líquido ou submetido à homogeneização em equipamento Precellys®24Dual (Bertin Technologies, Aix-em-Provence, França). A extração de DNA foi realizada através de método manual (Faugeron et al. 2001) ou com uso de resina de Chélex®100 (Bio-Rad, Hercules, EUA), segundo Goff \& Moon (1993). Depois de extraído, o DNA foi submetido à eletroforese em gel de agarose e quantificado em espectrofotômetro Nanodrop 2000 (Thermo Scientific, Waltham, EUA), para verificação da qualidade do processo de extração.

Os marcadores moleculares empregados foram UPA (Sherwood \& Presting, 2007), o marcador mitocondrial COI-5P (Saunders 2005) e o rbcL (Freshwater et al. 1994). Os primers que resultaram em amplificações e sequenciamentos bem sucedidos estão descritos na Tabela 3, de acordo com cada marcador molecular. As reações de PCR foram realizadas com kit Taq DNA Polymerase Recombinant (Invitrogen, Life Technologies, Grand Island, EUA), em volume total de $50 \mu \mathrm{L}$. Amostras que não amplificaram nessas condições foram repetidas com uso do kit Phire ${ }^{\circledR}$ Plant Direct PCR (Finnzymes, Thermo Scientific, Waltham, EUA). Os ciclos de PCR utilizados para cada marcador foram:

(i) UPA: $94^{\circ} \mathrm{C}$ por 2 min (desnaturação inicial) $/ 35$ ciclos de $94^{\circ} \mathrm{C}$ por $20 \mathrm{~s}$, $55^{\circ} \mathrm{C}$ por $30 \mathrm{~s}, 72^{\circ} \mathrm{C}$ por $30 \mathrm{~s} / 72^{\circ} \mathrm{C}$ por $10 \mathrm{~min}$ (extensão final) (Sherwood \& Presting 2007);

(ii) $\mathrm{COI}-5 \mathrm{P}: 94^{\circ} \mathrm{C}$ por 2 min (desnaturação inicial) $/ 5$ ciclos de $94^{\circ} \mathrm{C}$ por $30 \mathrm{~s}$, $45^{\circ} \mathrm{C}$ por $30 \mathrm{~s}, 72^{\circ} \mathrm{C}$ por $1 \mathrm{~min} / 35$ ciclos de $94^{\circ} \mathrm{C}$ por $30 \mathrm{~s}, 46,5^{\circ} \mathrm{C}$ por $30 \mathrm{~s}$, $72^{\circ} \mathrm{C}$ por $1 \mathrm{~min} / 72^{\circ} \mathrm{C}$ por $7 \mathrm{~min}$ (extensão final) (Saunders \& Moore 2013);

(iii) $\quad r b c \mathrm{~L}: 94^{\circ} \mathrm{C}$ por 2 min (desnaturação inicial) $/ 35$ ciclos de $94^{\circ} \mathrm{C}$ por $30 \mathrm{~s}$, $45^{\circ} \mathrm{C}$ por $1 \mathrm{~min}, 72^{\circ} \mathrm{C}$ por $2 \mathrm{~min} / 72^{\circ} \mathrm{C}$ por $4 \mathrm{~min}$ (extensão final) (Freshwater et al. 1994). 
Os produtos de PCR foram purificados com Kit IllustraTM GTXTM PCR DNA and GEL BAND PURIFICATION (GE Healthcare, Buckinghamshire, Inglaterra), segundo instruções do fabricante. As quantificações foram realizadas em espectrofotômetro Nanodrop 2000 (Thermo Scientific, Waltham, EUA). As reações de sequenciamento foram realizadas com uso do Kit de Sequenciamento BigDyeTM Terminator v3.1 (Applied Biosystems, Life Technologies, Grand Island, EUA), segundo instruções do fabricante. As amostras foram sequenciadas em equipamento Applied Biosystems 3130xl Genetic Analyzer ou Applied Biosystems 3730 DNA Analyzer.

Em relação ao marcador COI-5P, houve grande dificuldade de amplificação dessa região e várias tentativas foram realizadas até a obtenção dos dados apresentados neste estudo. As sequências de COI-5P foram obtidas durante o estágio no exterior (Bolsa BEPEFAPESP, de 23 de abril a 22 de outubro de 2014), em colaboração com o Dr. Gary Saunders, University of New Brunswick, Canadá, pesquisador de extensa experiência na amplificação e no sequenciamento da região gênica COI-5P em algas vermelhas. No total, foram testadas 16 combinações de primers, das quais 14 combinações não resultaram em amplificação (Tabela 4).

Durante a realização do estágio no exterior, as amostras foram processadas de acordo com Saunders \& McDevit (2012) para extração de DNA e conforme Saunders \& Moore (2013) para as reações de PCR. Esses procedimentos foram conduzidos no Centre for Environmental \& Molecular Algal Research, Department of Biology, University of New Brunswick, Fredericton, New Brunswick, Canadá. Nesse caso, as reações de sequenciamento foram realizadas na McGill University and Génome Québec Innovation Centre, Montréal, Canadá. 
Tabela 3. Primers utilizados para amplificação e sequenciamento de cada marcador molecular.

\begin{tabular}{|c|c|c|c|}
\hline Marcador & Primers & Direção & Referência \\
\hline \multirow[t]{2}{*}{ UPA } & p23SrV_f1 (GGACAGAAAGACCCTATGAA) & $\mathrm{F}$ & Sherwood \& Presting (2007) \\
\hline & p23SrV_r1 (TCAGCCTGTTATCCCTAGAG) & $\mathrm{R}$ & Sherwood \& Presting (2007) \\
\hline \multirow{3}{*}{ COI-5P } & M13LF3 (TGTAAAACGACGGCCAGTACHAAYCAYAARGATATHGG) & $\mathrm{F}$ & Saunders \& Moore (2013) \\
\hline & M13Rx (CAGGAAACAGCTATGACACTTCTGGRTGICCRAARAAYCA) & $\mathrm{R}$ & Saunders \& Moore (2013) \\
\hline & M13Ri (CAGGAAACAGCTATGACGGRTGICCRAARAAYCARAA) & $\mathrm{R}$ & Saunders \& Moore (2013) \\
\hline \multirow{10}{*}{$r b c \mathbf{L}$} & FrbcL-Start (ATGTCTAACTCTGTAGAAG) & $\mathrm{F}$ & Freshwater et al. (1994) \\
\hline & R753a (GCTCTTTCRTACATATCYTC) & $\mathrm{R}$ & Freshwater et al. (1994) \\
\hline & F492a (CGYATGGAYAAATTTGGACG) & $\mathrm{F}$ & Freshwater et al. (1994) \\
\hline & R1150 (GCATTTGTCCGCAGTGAATACC) & $\mathrm{R}$ & Freshwater et al. (1994) \\
\hline & F993 (GGTACTGTTGTAGGTAAATTWGAAGG) & $\mathrm{F}$ & Freshwater et al. (1994) \\
\hline & RbcS-Start (GTTCTTGTGTTAATCTCAC) & $\mathrm{R}$ & Freshwater et al. (1994) \\
\hline & F57 (GTAATTCCATATGCTAAAATGGG) & $\mathrm{F}$ & Freshwater \& Rueness (1994) \\
\hline & TLR4 (AAYTCWGCCCTTTCRTACAT) & $\mathrm{R}$ & Saunders \& Moore (2013) \\
\hline & TLF5 (TCWCARCCWTTYATGCGTTGG) & $\mathrm{F}$ & Saunders \& Moore (2013) \\
\hline & rbcLrevNew (ACATTTGCTGTTGGAGTYTC) & $\mathrm{R}$ & Saunders \& Moore (2013) \\
\hline
\end{tabular}


Tabela 4. Combinações de primers testados para o marcador COI-5P que não resultaram em amplificação.

\begin{tabular}{|c|c|c|}
\hline Primer $\mathbf{F}$ & & Primer $\mathbf{R}$ \\
\hline GazF1 (TCAACAAATCATAAAGATATTGG) & $\mathrm{x}$ & GazR1 (ACTTCTGGATGTCCAAAAAAYCA) \\
\hline Saunders (2005) & & Saunders (2005) \\
\hline GWSFn (TCAACAAAYCAYAAAGATATYGG) & $\mathrm{x}$ & GWSRn (GGRTGTCCRAARAAYCARAA) \\
\hline Yang et al. (2013) & & Yang \& Kim (2014b) \\
\hline GazF1 (TCAACAAATCATAAAGATATTGG) & $\mathrm{x}$ & COX1R1 (GTATACATATGATGHGCTCAA) \\
\hline Saunders (2005) & & Saunders (2008) \\
\hline GWSFn (TCAACAAAYCAYAAAGATATYGG) & $\mathrm{x}$ & GWSRx (ACTTCTGGRTGICCRAARAAYCA) \\
\hline Yang et al. (2013) & & Saunders \& Moore (2013) \\
\hline GWSLF2 (CAAAYCAYAARGATATHGGNAC) & $\mathrm{x}$ & GWSRi (GGRTGICCRAARAAYCARAA) \\
\hline Saunders \& Moore (2013) & & Saunders \& Moore (2013) \\
\hline GWSFn (TCAACAAAYCAYAAAGATATYGG) & $\mathrm{x}$ & GWSRi (GGRTGICCRAARAAYCARAA) \\
\hline Yang et al. (2013) & & Saunders \& Moore (2013) \\
\hline GWSLF2 (CAAAYCAYAARGATATHGGNAC) & $\mathrm{x}$ & GWSRx (ACTTCTGGRTGICCRAARAAYCA) \\
\hline Saunders \& Moore (2013) & & Saunders \& Moore (2013) \\
\hline GWSLF3 (ACHAAYCAYAARGATATHGG) & $\mathrm{x}$ & GWSRn (GGRTGTCCRAARAAYCARAA) \\
\hline Saunders \& Moore (2013) & & Yang \& Kim (2014b) \\
\hline GazF1 (TCAACAAATCATAAAGATATTGG) & $\mathrm{x}$ & GWSRx (ACTTCTGGRTGICCRAARAAYCA) \\
\hline Saunders (2005) & & Saunders \& Moore (2013) \\
\hline GWSFn (TCAACAAAYCAYAAAGATATYGG) & $\mathrm{x}$ & GazR1 (ACTTCTGGATGTCCAAAAAAYCA) \\
\hline Yang et al. (2013) & & Saunders (2005) \\
\hline GWSFn (TCAACAAAYCAYAAAGATATYGG) & $\mathrm{x}$ & GWSRx (ACTTCTGGRTGICCRAARAAYCA) \\
\hline Yang et al. (2013) & & Saunders \& Moore (2013) \\
\hline GWSLF3 (ACHAAYCAYAARGATATHGG) & $\mathrm{x}$ & GWSRx (ACTTCTGGRTGICCRAARAAYCA) \\
\hline Saunders \& Moore (2013) & & Saunders \& Moore (2013) \\
\hline $\begin{array}{l}\text { M13LF2 } \\
\text { (TGTAAAACGACGGCCAGTCAAAYCAYAARGATATHGGNAC) }\end{array}$ & $\mathrm{x}$ & $\begin{array}{r}\text { M13Rx } \\
\text { (CAGGAAACAGCTATGACACTTCTGGRTGICCRAARAAYCA) }\end{array}$ \\
\hline Saunders \& Moore (2013) & & Saunders \& Moore (2013) \\
\hline M13LF2 (TGTAAAACGACGGCCAGTCAAAYCAYAARGATATH & & M13Ri (CAGGAAACAGCTATGACGGRTGICCRAARAAYCARAA) \\
\hline Saunders \& Moore (2013) & $\mathrm{x}$ & Saunders \& Moore (2013) \\
\hline
\end{tabular}




\subsection{Análises Moleculares:}

As sequências consenso foram geradas a partir do alinhamento entre a sequência direta e a reversa, realizado nos programas computacionais BioEdit 7.0.9.0 (Hall 1999) ou Sequencher 5.0 (Gene Codes Corporation, Ann Arbor, MI). Os cromatogramas foram conferidos nas posições que apresentaram divergências. As sequências geradas neste estudo já foram incluídas no banco de dados BOLD, The Barcode of Life Data System (www.barcodinglife.org) (Ratnasingham \& Hebert 2007), e estão sendo submetidas ao banco de dados GenBank (www.ncbi.nlm.nih.gov/genbank/) à medida que os artigos científicos estão sendo produzidos. Neste estudo, foram geradas 282 sequências de Halymeniales, sendo 136 do marcador UPA, 88 de COI-5P e 58 de $r b c$ L.

As sequências de UPA foram utilizadas para geração de uma árvore de agrupamento, através da aplicação do algoritmo Neighbor-joining (NJ), no programa computacional Mega 6 (Tamura et al. 2013). A análise de UPA foi realizada com 129 sequências, com 370 pares de base. Os valores de suporte correspondem a 1000 replicações de Bootstrap. As distâncias genéticas foram calculadas utilizando o método de $p$-Distance (Nei \& Kumar 2000). As posições contendo gaps ou dados ausentes foram eliminadas para cada par de sequências (pairwise deletion).

Para o COI-5P, a análise de agrupamento também foi realizada através do algoritmo de NJ, no software MEGA 6 (Tamura et al. 2013). O alinhamento era composto por 88 sequências, com 612 pb. Os valores de Bootstrap foram inferidos a partir de 1000 réplicas. O método de p-Distance (Nei \& Kumar 2000) foi utilizado para estimar as distâncias evolutivas. As posições com ambiguidades foram removidas para cada par de sequências.

Para cada agrupamento genético obtido com os marcadores UPA e COI-5P, foram escolhidos alguns espécimes para produção de sequências de $r b c \mathrm{~L}$, de maneira a representar todas as linhagens coletadas em um contexto filogenético. Além das sequências de $r b c \mathrm{~L}$ geradas neste estudo, foram incluídas também sequências depositadas nos bancos de dados BOLD e GenBank (os números de acesso dessas sequências estão incluídos nas árvores e na Tabela 5). De acordo com a disponibilidade, foram utilizadas sequências de pelo menos um representante de cada gênero da ordem Halymeniales, e, sempre que possível, foram usadas sequências das espécies-tipo dos gêneros, de preferência 
provenientes das localidades-tipo. Além disso, foram incluídas também sequências referentes a espécies citadas para a costa brasileira.

Foram produzidas duas reconstruções filogenéticas: uma considerando apenas o marcador $r b c \mathrm{~L}$, e outra baseada em um alinhamento concatenado com sequências de COI5P e $r b c \mathrm{~L}$. A inferência filogenética apresentada neste estudo foi construída a partir de 99 sequências de $r b c \mathrm{~L}$, sendo 58 geradas neste estudo. A sequência identificada como “Cryptonemia limensis CNU067563 Peru” foi gentilmente cedida por Martha Calderón (Chungnam National University, Daejeon, Coreia). A sequência identificada como "Tsengia lanceolata AY294386 South Africa-Western Cape" foi utilizada como grupo externo. O alinhamento final, com 1392 pb de comprimento, foi submetido à análise de Máxima Verossimilhança (ML) na plataforma online RaxML Blackbox (Stamatakis et al. 2008), utilizando o modelo GTR+G+I (por padronização - by default). O alinhamento foi particionado de acordo com as posições dos códons, correspondendo, portanto, a três partições. Os valores de Bootstrap foram obtidos a partir de 100 replicações.

A análise concatenada $(\mathrm{COI}-5 \mathrm{P}+r b c \mathrm{~L})$ foi realizada utilizando apenas uma sequência representante de cada linhagem obtida até o momento. $\mathrm{O}$ alinhamento concatenado foi composto por 73 sequências, com 2053 pb. Os números de acesso referentes às sequências obtidas nos bancos de dados BOLD e GenBank estão apresentados na Tabela 5. A sequência identificada como “Tsengia sp. (2LH) GWS023643" foi gentilmente cedida pelo Dr. Gary W. Saunders e utilizada como grupo externo. O alinhamento foi então submetido à análise de ML na plataforma online RaxML Blackbox (Stamatakis et al. 2008), utilizando o modelo de substituição de nucleotídeos GTR+G+I (por padronização - by default). O alinhamento foi particionado por gene e de acordo com as posições dos códons, totalizando seis partições. Os valores de Bootstrap foram inferidos a partir de 100 replicações. 
Tabela 5. Números de acesso para sequências utilizadas na análise concatenada. A sequência obtida no banco de dados BOLD está indicada. As demais sequências foram obtidas no banco de dados GenBank.

\begin{tabular}{|c|c|c|}
\hline Espécie e Local de Coleta & COI-5P & $\operatorname{Rbc} \mathbf{L}$ \\
\hline Acrodiscus vidovichii Croácia, Mar Adriático & - & KJ594952 \\
\hline Aeodes nitidissima Nova Zelândia, Pacífico Sul & - & EU497914 \\
\hline Amalthea freemaniae Nova Zelândia, Pacífico Sul & - & KJ606651 \\
\hline Carpopeltis phyllophora Austrália, Mar da Tasmânia & - & FN908164 \\
\hline Codiophyllum natalense África do Sul, Oceano Índico & - & FN908160 \\
\hline Corynomorpha prismatica Madagascar, Canal de Moçambique & KJ594946 & KJ594955 \\
\hline Corynomorpha clavata EUA, Flórida, Atlântico Norte & - & AY294360 \\
\hline Cryptonemia bengryi Panamá, Mar do Caribe & - & AY178766 \\
\hline Cryptonemia lomation França, Mar Mediterrâneo & - & FN908155 \\
\hline Cryptonemia luxurians Brasil, RJ & - & AF488813 \\
\hline Dermocorynus dichotomus França, Mar Mediterrâneo & - & AY775387 \\
\hline Dermocorynus montagnei Irlanda, Atlântico Norte & - & AY435171 \\
\hline Epiphloea bullosa Austrália, Oceano Índico & - & FN908149 \\
\hline Felicinia marginata França, Mar Tirreno & - & KJ594954 \\
\hline Galene profundae Nova Zelândia, Mar da Tasmânia & - & KJ606645 \\
\hline Gelinaria ulvoidea Austrália, Oceano Índico & - & FN908154 \\
\hline Glaphyrosiphon intestinalis Nova Zelândia, Pacífico Sul & - & GU252163 \\
\hline "Grateloupia dichotoma" Brasil, ES & - & AF488823 \\
\hline Grateloupia doryphora Peru, Pacífico Sul & - & AF488817 \\
\hline Grateloupia filicina Itália, Mar Adriático & - & AB055472 \\
\hline Grateloupia filiformis Brasil, ES & - & AF488822 \\
\hline Grateloupia gibbesii EUA, Carolina do Sul, Atlântico Norte & - & JX645160 \\
\hline Grateloupia orientalis China, Mar da China Meridional & - & LNU092102 \\
\hline Grateloupia subpectinata Japão, Pacífico Norte & KJ648542 & KF156718 \\
\hline Grateloupia turuturu Japão, Pacífico Norte & KF475725 & AB038611 \\
\hline Grateloupia yangjiangensis China & & HQ324237 \\
\hline Halymenia floresii Península Ibérica, Atlântico Norte & GQ862071 & $\begin{array}{c}\text { AY772019 } \\
\text { (BOLD) }\end{array}$ \\
\hline Halymenia pseudofloresii Bermudas, Atlântico Norte & GQ862076 & ABMMC3746-09 \\
\hline Neorubra decipiens Peru, Pacífico Sul & - & KJ561157 \\
\hline Pachymenia carnosa África do Sul, Atlântico Sul & - & AF385640 \\
\hline Pachymeniopsis lanceolata Japão, Baía de Sagami & JX474995 & JX475042 \\
\hline Phyllymenia belangeri África do Sul, Atlântico Sul & - & AY772035 \\
\hline Polyopes constrictus Austrália, Estreito de Bass & - & AB084535 \\
\hline Prionitis lanceolata EUA, Califórnia, Pacífico Norte & GQ497308 & PLU04216 \\
\hline Ramirezia osornoensis Sul do Chile, Pacífico Sul & - & KF601433 \\
\hline Spongophloea tissotii Austrália, Oceano Índico & - & FN908162 \\
\hline Thamnoclonium dichotomum Austrália, Mar da Tasmânia & - & FN908152 \\
\hline Yonagunia tenuifolia Japão, Mar da China Oriental & - & AB116248 \\
\hline
\end{tabular}

Os índices de divergência entre linhagens correspondem a valores de $p$-Distance, calculados no software Mega 6 (Tamura et al. 2013). Foi utilizada a pairwise deletion de posições com ambiguidades, isto é, as posições com dados ausentes foram removidas para cada par de sequências. 


\subsection{Estudos Morfológicos:}

Para os estudos morfológicos, as amostras foram preservadas em solução de formol salino $4 \%$ ou diretamente herborizadas. Os exemplares herborizados foram depositados no Herbário da Universidade de São Paulo (SPF). Foram analisados cinco indivíduos de cada táxon, quando possível. Os protocolos de análise morfológica utilizados neste estudo envolvem aspectos macroscópicos e microscópicos, bem como caracteres vegetativos e reprodutivos (Anexos I e II). Entre as características macroscópicas, foram observados os seguintes aspectos do talo: cor, formato (folioso, achatado ou cilíndrico), textura, tipo de ramificação, altura do talo, largura das frondes, forma e tamanho do estipe, forma e tamanho do apressório e presença de nervura. Aspectos microscópicos foram analisados em microscópio óptico, através de cortes histológicos à mão livre, corados com azul de anilina $1 \%$ acidificada com $\mathrm{HCl} 1 \mathrm{~N}$. Os cortes histológicos foram realizados em três regiões do talo: apical (a uma distância de até $0,5 \mathrm{~cm}$ do ápice), mediana (equidistante entre o ápice e a base) e basal (na fronde, imediatamente acima do estipe). As preparações de esmagamento foram feitas após imersão em $\mathrm{HCl} 1 \%$ por 3-5 minutos. Os caracteres vegetativos analisados foram: espessura do talo, disposição das células no córtex e na Região medular, medidas das células corticais e Região medularres e presença de células ganglionares e estreladas. Para diferenciar células ganglionares e estreladas, foi adotada a definição de Guimarães \& Fujii (1998), segundo a qual células ganglionares consistem em filamentos conectados com conteúdo refringente, paralelos à superfície do talo, enquanto que células estreladas possuem conteúdo normal e são derivadas do esticamento do talo em crescimento. Já os caracteres reprodutivos foram: localização e desenvolvimento de espermatângios, aspecto das ampolas da célula auxiliar, localização e medidas dos cistocarpos e desenvolvimento e medidas dos tetrasporângios.

As imagens macroscópicas foram obtidas com câmera Panasonic Lumix DMC-TS2O (Japão) ou com Lupa ZEISS Discovery V8 (Carl Zeiss, Oberkochen, Alemanha). As imagens microscópicas, por sua vez, foram capturadas com câmera Leica DFC 420 acoplada ao microscópio Leica DM 4000B (Leica Microsystems, Wetzlar, Alemanha), ou com câmera Panasonic Lumix DMC-TS20 (Japão) acoplada ao microscópio Nikon Eclipse E200 (Tóquio, Japão). 


\section{Resultados e Discussão}

\subsection{Sinopse dos táxons encontrados}

Halymeniaceae Kützing

Corynomorpha J. Agardh

Corynomorpha cf. clavata (Harvey) J. Agardh**

Cryptonemia J. Agardh

"Cryptonemia” bengryi W.R. Taylor

"Cryptonemia" crenulata 1 (J. Agardh) J. Agardh

"Cryptonemia" crenulata 2 (J. Agardh) J. Agardh

"Cryptonemia" crenulata 3 (J. Agardh) J. Agardh

"Cryptonemia" delicatula Joly \& Cordeiro

Cryptonemia seminervis 1 (C. Agardh) J. Agardh

Cryptonemia seminervis 2 (C. Agardh) J. Agardh**

Cryptonemia seminervis 3 (C. Agardh) J. Agardh**

Halymenia C. Agardh

"Halymenia" elongata Sonder

"Halymenia" floridana J. Agardh

Halymenia ignifera C.A.A. Azevedo, Cassano \& M.C. Oliveira**

Halymenia pinnatifida C.A.A. Azevedo, Cassano \& M.C. Oliveira**

Halymenia silviae C.A.A. Azevedo, Cassano \& M.C. Oliveira**

Halymenia sp. 1

Halymenia sp. 2

Grateloupia C. Agardh

Grateloupia cf. dichotoma J. Agardh**

Grateloupia cf. filicina 1 (J.V. Lamouroux) C. Agardh**

Grateloupia cf. filicina 2 (J.V. Lamouroux) C. Agardh**

Grateloupia filiformis Kützing 


\section{"Grateloupia" gibbesii Harvey \\ Grateloupia orientalis Showe M. Ling \& H.Y. Liang* \\ "Grateloupia” turuturu Yamada* \\ Grateloupia yangjiangensis W.-X. Li \& Z.-F. Ding*}

Halymeniales sp. $1 * *$

Halymeniales sp. $2^{* *}$

\footnotetext{
2 * Indica novas citações para o Atlântico Sudoeste;

** Indica espécies novas para a ciência;

Nomes com gêneros grafados entre aspas se referem a espécies que, segundo dados moleculares, não correspondem ao gênero no qual estão atualmente incluídas.
}

Neste estudo, foram encontrados 26 táxons. Antes da realização deste estudo, havia registros de 24 espécies de Halymeniales para a costa brasileira, das quais nove não foram coletadas no presente estudo, são elas: Cryptonemia flabellifolia, Grateloupia subpectinata, Halymenia brasiliana, $H$. clathrata, $H$. duchassaingii, H. integra, H. rosea, $H$. vinacea e Tsengia sp. Três outros táxons citados anteriormente para o Brasil, Cryptonemia limensis, Grateloupia cuneifolia e G. doryphora, foram redefinidos com base em nossos dados moleculares.

Dentre as espécies citadas na "Sinopse dos táxons", três delas, Halymenia ignifera, H. pinnatifida e H. silviae foram descritas como novas para a ciência em um manuscrito submetido ao periódico Phycologia (Anexo III).

\subsection{Resultados Moleculares}

A partir da análise das árvores obtidas (Figuras 2, 3, 4 e 5) e das matrizes de divergência dos nucleotídeos (Tabelas 6 e 7), é possível observar que foram coletadas e sequenciadas pelo menos 26 espécies de Halymeniales.

\section{UPA}

Para o marcador UPA, entre as 136 sequências geradas, sete se posicionaram em clados de diferentes espécies e até diferentes gêneros, conflitantes com os outros marcadores obtidos. Por essa razão, essas amostras foram consideradas resultantes de 
contaminações e, portanto, foram excluídas da análise de NJ (Figura 2). Não foi possível obter sequências desse marcador para os táxons Grateloupia yangjiangensis e "Halymeniales sp. 2". A análise de agrupamento de UPA resultou, portanto, na delimitação de 22 grupos genéticos, dos quais a maioria apresentou elevado suporte de Bootstrap.

Espécimes de Corynomorpha cf. clavata formaram um clado de suporte máximo de Bootstrap (100\%), assim como "Cryptonemia" bengryi, "Cryptonemia" crenulata, Grateloupia cf. filicina 2 e Halymeniales sp. 1. Indivíduos de "Cryptonemia” delicatula constituíram um clado com 99\% de suporte, enquanto que amostras atribuídas a Cryptonemia seminervis estiveram divididas em três clados distintos, nomeados Cryptonemia seminervis 1, Cryptonemia seminervis 2 e Cryptonemia seminervis 3, cujos valores de Bootstrap foram, respectivamente, 93, 84 e $91 \%$.

Em relação às amostras até então atribuídas ao gênero Halymenia, "Halymenia" elongata e "Halymenia" floridana apresentaram suporte de 99 e 93\%, respectivamente. Espécimes que até a realização deste estudo eram morfologicamente atribuídos a Halymenia floresii constituíram dois clados distintos correspondentes às espécies novas Halymenia ignifera e Halymenia pinnatifida. O suporte foi inferior a 50\% no clado de UPA de Halymenia ignifera, enquanto que para Halymenia pinnatifida, apenas uma sequência de UPA foi obtida, e, portanto, o cálculo de Bootstrap não se aplica. Para as espécies Halymenia silviae e Halymenia sp. 2, esses valores foram de 97 e 99\%. H. silviae é uma nova espécie proposta para acomodar indivíduos previamente identificados como $H$. pseudofloresii.

Exemplares morfologicamente identificados como Grateloupia filicina formaram dois clados diferentes, tratados aqui como Grateloupia cf. filicina 1 e Grateloupia cf. filicina 2, cujos valores de suporte foram $88 \%$ e $100 \%$, respectivamente. Para as espécies Grateloupia cf. dichotoma, "Grateloupia” gibbesii, Grateloupia filiformis e "Grateloupia” turuturu, os valores foram de 99\%, 98\%, 95\% e 94\%, respectivamente. Grateloupia orientalis constituiu um clado com $57 \%$ de suporte de Bootstrap.

Neste estudo, a divergência intraespecífica do marcador UPA variou de $0-1,1 \%$. O maior índice de divergência intraespecífica foi registrada no táxon Halymenia ignifera, cujo valor de $p$-Distance foi de $1,1 \%$, correspondente a uma diferença de 4 pares de base (Tabela 6). Em seguida, tem-se os clados de "Halymenia" elongata e Grateloupia 
filiformis com divergência de $0,5 \%$ (diferença de $2 \mathrm{pb}$ ), enquanto que para "Cryptonemia" crenulata, Cryptonemia seminervis 1, Grateloupia cf. dichotoma e "Grateloupia” gibbesii esse valor foi de $0,3 \%$ (diferença de $1 \mathrm{pb}$ ). Para todos os outros táxons, não foi observada divergência.

Neste estudo, a divergência interespecífica do marcador UPA variou de 0,5-3,2\%. Esses valores são comparáveis aos encontrados em estudos prévios com outros gêneros de Rhodophyta, tais como, Gracilariopsis (0,8-3,7\%), Hypnea (2,5-4,4\%) e Gelidium (0,6\%) (Costa et al. 2012; Nauer et al. 2014; Iha et al. 2015). Considerando o gênero Cryptonemia, os menores valores foram observados entre Cryptonemia seminervis 1 e Cryptonemia seminervis 2 (0,8-1,1\%), Cryptonemia seminervis 2 e Cryptonemia seminervis $3(0,8 \%)$ e Cryptonemia seminervis 2 e "Halymenia" floridana (0,8\%). O maior valor ocorreu entre Cryptonemia seminervis 1 e "Halymenia” floridana (1,6-2,0\%). Os dados de rbcL que serão detalhados adiante suportam a transferência de "Halymenia" floridana para o gênero Cryptonemia. Para o gênero Halymenia, o menor valor foi de 0,8-1,6\%, entre Halymenia ignifera e Halymenia pinnatifida, e o maior foi de 3,2\%, entre Halymenia sp. 1 e Halymenia sp. 2. Em relação ao gênero Grateloupia, a menor divergência interespecífica ocorreu entre os táxons Grateloupia cf. filicina 2 e Grateloupia orientalis, que divergiram em apenas 0,5\%, enquanto que o maior valor foi de 2,4-3,0\%, entre Grateloupia cf. filicina 2 e Grateloupia filiformis (Tabela 7). Neste estudo, observa-se uma sobreposição entre os valores de divergência intra e interespecífica para o marcador UPA, o que também já foi encontrado em estudos anteriores de Halymeniaceae (Yang \& Kim 2014b).

\section{COI-5P:}

Em relação ao marcador COI-5P, observou-se grande dificuldade de amplificação dessa região gênica. Estudos relatam dificuldades na amplificação desse marcador em alguns grupos de algas vermelhas, tais como amplificação de contaminantes e necessidade de uso de várias combinações de primers ou a necessidade de desenvolver primers específicos para algumas linhagens (Clarkston \& Saunders 2010; Milstein et al. 2012).

Devido à dificuldade de amplificação do COI-5P, foi possível obter esse marcador para apenas 19 grupos genéticos, que correspoderam aos respectivos grupos obtidos com o marcador UPA. O suporte de Bootstrap foi $100 \%$ para todos os clados. Não foi possível 
obter sequências de COI-5P para cinco espécies: "Halymenia floridana", Cryptonemia seminervis 2, Cryptonemia seminervis 3, Grateloupia cf. filicina 2 e Grateloupia yangjiangensis.

Os agrupamentos de "Cryptonemia" crenulata e Cryptonemia seminervis 1 exibiram os maiores índices de divergência intraespecífica, cujos valores foram 1,2 (diferença de $7 \mathrm{pb}$ ) e 1,1 (diferença de 6 pb), respectivamente. Para Halymenia ignifera, esse valor foi de $0,5 \%$, correspondente a 4 pb de diferença. Os clados de Halymenia silviae e Grateloupia orientalis apresentaram divergência intraespecífica de 0,3\% (2 pb de diferença). $\mathrm{O}$ valor de $p$-Distance foi de $0,2 \%$ (diferença de $1 \mathrm{pb}$ ), tanto para "Cryptonemia” bengryi quanto para "Grateloupia” gibbesii. Para os demais clados, não houve divergência intraespecífica (Tabela 6).

Para o marcador COI-5P, a divergência interespecífica variou de 6,6-11,9\% (Tabela 7), que corrobora valores relatados por estudos anteriores com Gracilaria (5,8-6,5\%), Hypnea (10,1-16,3\%) e Gelidium (5,8-6,2\%) (Costa et al. 2012; Nauer et al. 2014; Iha et al. 2015). Não foi possível calcular esse parâmetro para o gênero Cryptonemia, uma vez que só foram obtidas sequências desse marcador para o táxon Cryptonemia seminervis 1. Para o gênero Halymenia, Halymenia ignifera e Halymenia sp. 2 apresentaram a menor divergência (7,4-8,4\%), enquanto que Halymenia pinnatifida e Halymenia sp. 1 apresentaram a maior (11,8-11,9\%). Em relação ao gênero Grateloupia, o menor valor foi registrado entre Grateloupia cf. filicina 1 e Grateloupia filiformis (6,6\%), e o maior entre Grateloupia cf. dichotoma e Grateloupia orientalis (6,9-7,7\%).

\section{rbcL:}

O marcador $r b c \mathrm{~L}$, por sua vez, foi de amplificação relativamente mais fácil para o grupo, de maneira que foram obtidas sequências dessa região para todos os táxons encontrados neste estudo (24 espécies). No entanto, a necessidade de aplicação de primers internos faz com que o sequenciamento desse marcador seja mais laborioso que os anteriores.

Nas árvores filogenéticas obtidas (Figuras 4 e 5), os gêneros Cryptonemia, Halymenia e Grateloupia não representam grupos monofiléticos. Halymenia e Cryptonemia constituem grupos polifiléticos, enquanto que Grateloupia é parafilético nas nossas 
análises. Outros estudos também sugerem que alguns gêneros de Halymeniales constituem grupos não-monofiléticos (Schneider et al. 2010; Hernández-Kantún et al. 2012; Kraft \& Saunders 2013). Esses resultados ressaltam a necessidade de investigações detalhadas sobre a taxonomia e a filogenia dessas algas.

Nas filogenias apresentadas neste estudo, o gênero Corynomorpha forma um clado de elevado suporte (100\%), que inclui três espécies, uma das quais era tratada no Brasil como Corynomorpha clavata.

O clado que contém a espécie-tipo do gênero Cryptonemia, Cryptonemia lomation (Bertoloni) J.Agardh, inclui também Cryptonemia seminervis 1, Cryptonemia seminervis 2, Cryptonemia seminervis 3 e é grupo irmão de "Halymenia” floridana, com suporte de Bootstrap de $66 \%$ na árvore de $r b c \mathrm{~L}$ e de $93 \%$ na análise concatenada (Figuras 4 e 5). Esse resultado demonstra a necessidade de transferência da espécie "Halymenia” floridana para um novo gênero. Espécies até então tratadas como Cryptonemia, tais como “ $C$ ”. bengryi, “C”. crenulata e “C”. delicatula não pertencem ao clado de Cryptonemia e, portanto, contituem gêneros distintos, que serão comentados com mais detalhes no item "Comentários taxonômicos".

O clado que contém a espécie-tipo (Halymenia floresii) do gênero Halymenia, por sua vez, forma um agrupamento com suporte de Bootstrap de $66 \%$ e $84 \%$ nas análises de $r b c \mathrm{~L}$ e concatenada, respectivamente (Figuras 4 e 5). Além de Halymenia ignifera, Halymenia pinnatifida, Halymenia silviae, Halymenia sp. 1 e Halymenia sp. 2, esse clado inclui também Gelinaria ulvoidea Sonder e Epiphloea bullosa (Harvey) De Toni, assim como o encontrado por estudos prévios (Hernández-Kantún et al. 2012; Yang et al. 2013; Tan et al. 2015). Yang et al. (2013) mencionaram a possibilidade de incorporação de Gelinaria Sonder e Epiphloea J.Agardh ao gênero Halymenia, e os dados obtidos aqui reforçam essa proposta. A espécie citada no Brasil como "Halymenia” elongata não pertence a esse clado que contém a espécie-tipo do gênero, e, portanto, constitui um gênero distinto.

O agrupamento que contém a espécie-tipo do gênero Grateloupia, Grateloupia filicina, inclui também $G$. cf. dichotoma, G. cf. filicina 1, G. cf. filicina 2, G. filiformis, G. orientalis e G. yangjiangensis. O suporte desse clado é de $72 \%$ na análise de $r b c \mathrm{~L}$ e $77 \%$ na 
concatenada. Os táxons "Grateloupia” gibbesii e "Grateloupia” turuturu não fazem parte do clado que contém G. filicina e, portanto, devem ser descritos como novos gêneros. 


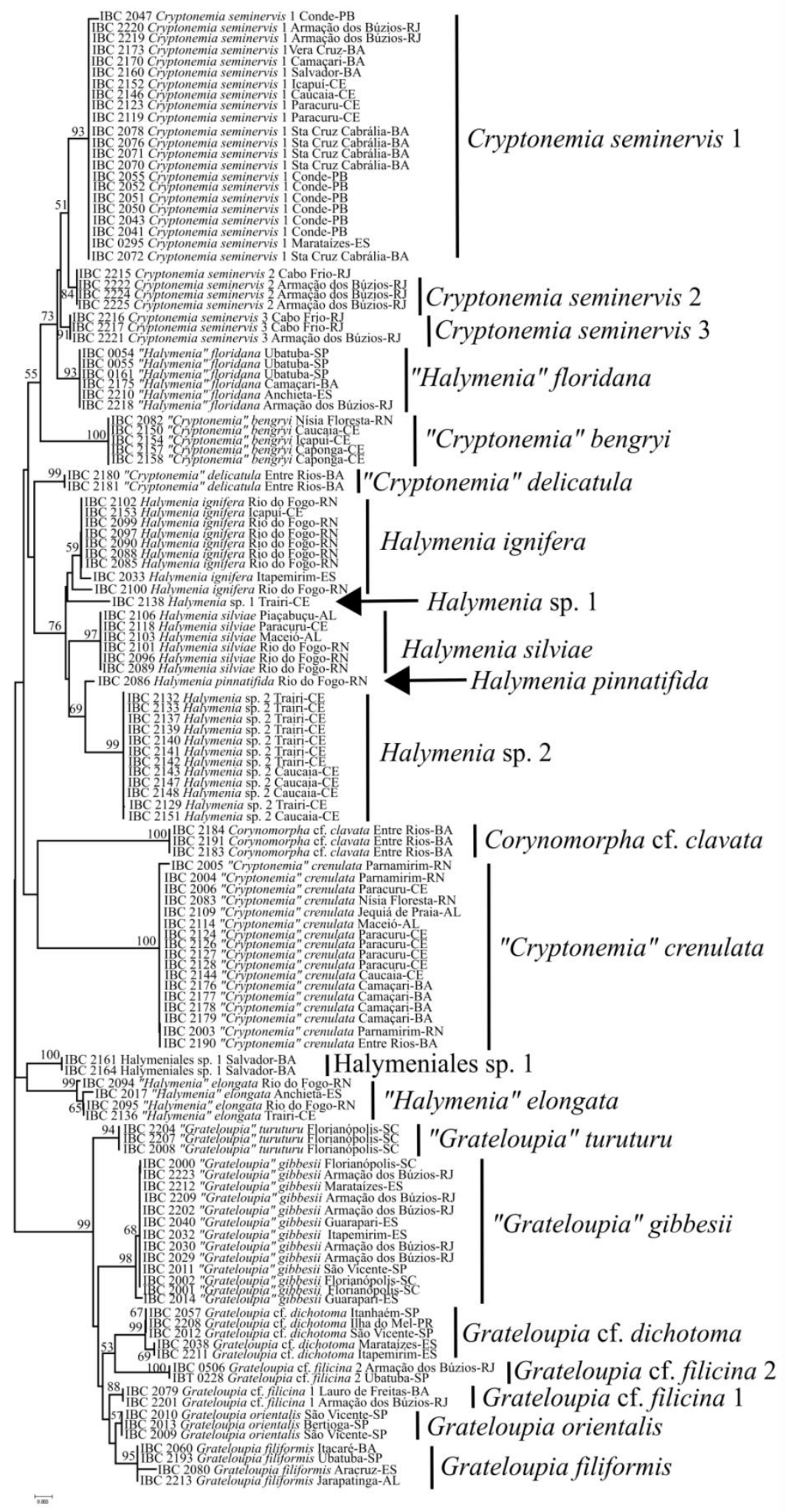

Figura 2. Árvore de agrupamento para sequências de UPA, gerada através do algoritmo Neighbor-joining. Os números nos nós representam valores de Bootstrap para 1000 réplicas. Valores abaixo de 50 não são mostrados. Todas as sequências foram geradas neste estudo e são precedidas pelo código de campo (IBC). 


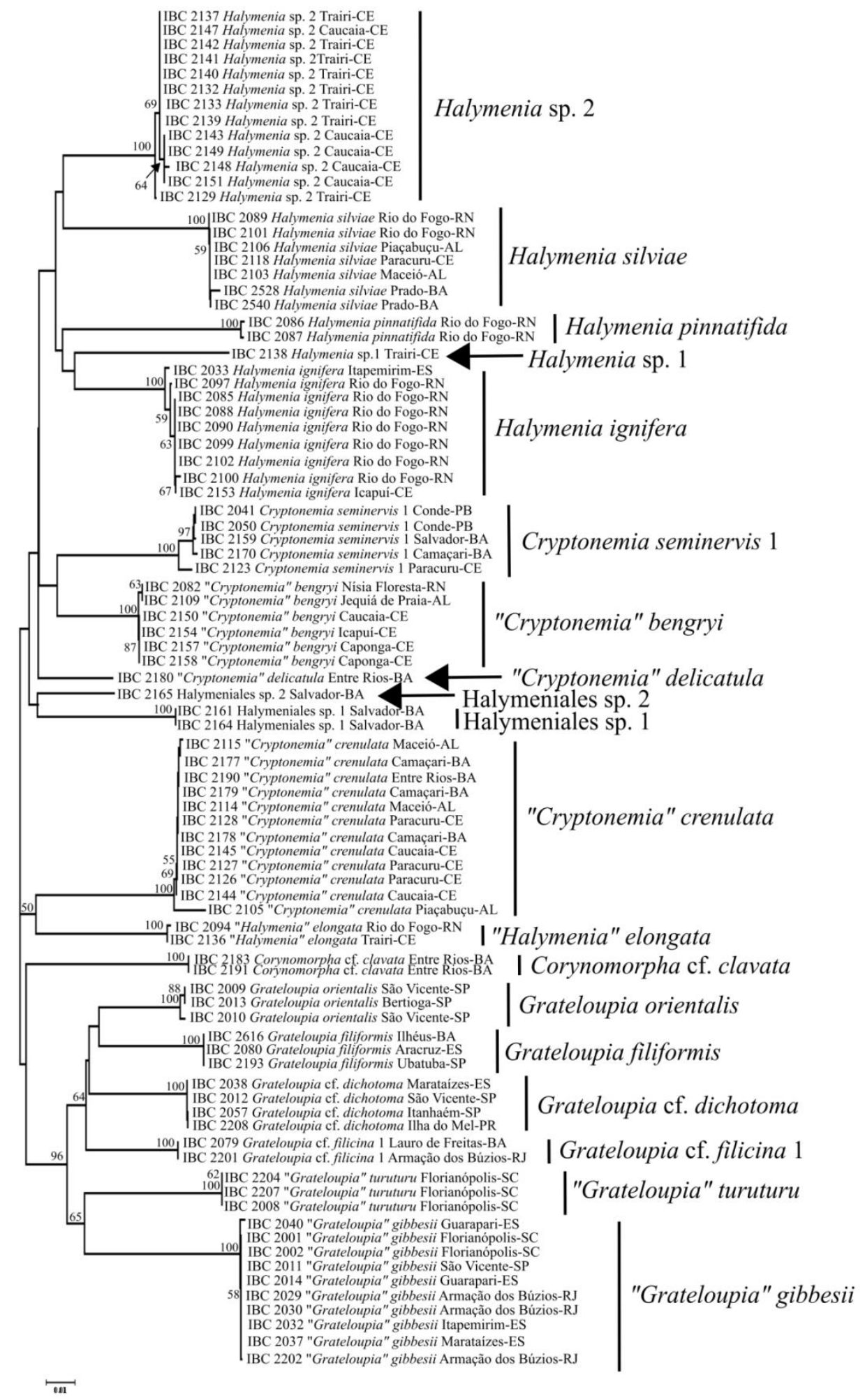

Figura 3. Árvore de agrupamento para sequências de COI-5P, gerada através do algoritmo Neighbor-joining. Os números nos nós representam valores de Bootstrap para 1000 réplicas. Valores abaixo de 50 não são mostrados. Todas as sequências foram geradas neste estudo e são precedidas pelo código de campo (IBC). 
Tabela 6. Valores de divergência intraespecífica em \% e o número de pares de base (pb) entre parênteses nos grupos genéticos obtidos com os marcadores UPA e COI-5P. n.a.: não se aplica.

\begin{tabular}{lrr}
\hline & $\mathrm{UPA}$ & $\mathrm{COI}-5 \mathrm{P}$ \\
\hline Corynomorpha cf. clavata & 0 & 0 \\
"Cryptonemia" bengryi & 0 & $0-0,2(0-1 \mathrm{pb})$ \\
"Cryptonemia" crenulata & $0-0,3(0-1 \mathrm{pb})$ & $0-1,2(0-7 \mathrm{pb})$ \\
"Cryptonemia" delicatula & 0 & $\mathrm{n} . \mathrm{a}$. \\
Cryptonemia seminervis 1 & $0-0,3(0-1 \mathrm{pb})$ & $0-1,1(0-6 \mathrm{pb})$ \\
Cryptonemia seminervis 2 & 0 & $\mathrm{n} . \mathrm{a}$. \\
Cryptonemia seminervis 3 & 0 & $\mathrm{n} . \mathrm{a}$. \\
"Halymenia" elongata & $0-0,5(0-2 \mathrm{pb})$ & 0 \\
"Halymenia" floridana & 0 & $\mathrm{n} . \mathrm{a}$. \\
Halymenia ignifera & $0-1,1(0-4 \mathrm{pb})$ & $0-0,5(0-4 \mathrm{pb})$ \\
Halymenia pinnatifida & $\mathrm{n} . \mathrm{a}$. & 0,2 \\
Halymenia silviae & 0 & $0-0,3(0-2 \mathrm{pb})$ \\
Halymenia sp. 1 & $\mathrm{n} . \mathrm{a}$. & $\mathrm{n} . \mathrm{a}$. \\
Halymenia sp. 2 & 0 & $0-0,5(0-4 \mathrm{pb})$ \\
Grateloupia cf. dichotoma & $0-0,3(0-1 \mathrm{pb})$ & 0 \\
Grateloupia cf. filicina 1 & 0 & 0 \\
Grateloupia cf. filicina 2 & 0 & $\mathrm{n} . \mathrm{a}$. \\
Grateloupia filiformis & $0-0,5(0-2 \mathrm{pb})$ & 0 \\
"Grateloupia" gibbesii & $0-0,3(0-1 \mathrm{pb})$ & $0-0,2(0-1 \mathrm{pb})$ \\
Grateloupia orientalis & 0 & $0-0,3(0-2 \mathrm{pb})$ \\
"Grateloupia" turuturu & 0 & 0 \\
Grateloupia yangjiagensis & $\mathrm{n} . \mathrm{a}$. & $\mathrm{n} . \mathrm{a}$. \\
Halymeniales sp. 1 & 0 & 0 \\
Halymeniales sp. 2 & $\mathrm{n} . \mathrm{a}$. \\
\hline & 0.9
\end{tabular}


Tabela 7. Valores de divergência interespecífica (\%) nos grupos genéticos obtidos com os marcadores UPA (abaixo da diagonal indicada por -) e COI-5P (acima da diagonal). n.a.: não se aplica.

\begin{tabular}{|c|c|c|c|c|c|c|c|c|c|c|c|c|c|}
\hline & & 1 & 2 & 3 & 4 & 5 & 6 & 7 & 8 & 9 & 10 & 11 & 12 \\
\hline 1 & Corynomorpha cf. clavata & - & $10,2-10,3$ & $11,7-12,8$ & 9,3 & $11,3-12,0$ & n.a. & n.a. & 11,3 & n.a. & $11,0-11,7$ & $12,4-12,5$ & $13,8-14,1$ \\
\hline 2 & "Cryptonemia" bengryi & 6,5 & - & $10,0-11,3$ & $6,5-6,6$ & $7,5-8,1$ & n.a. & n.a. & $8,9-9,0$ & n.a. & $9,2-9,7$ & $10,3-10,6$ & $9,3-9,9$ \\
\hline 3 & "Cryptonemia" crenulata & $7,3-7,6$ & $6,2-6,5$ & - & $7,4-8,4$ & $11,0-12,6$ & n.a. & n.a. & $9,6-10,4$ & n.a. & $10,2-11,3$ & $13,0-13,9$ & $12,0-13,3$ \\
\hline 4 & "Cryptonemia" delicatula & 5,7 & 3,2 & $5,4-5,7$ & - & $7,5-7,7$ & n.a. & n.a. & 8,1 & n.a. & $6,5-6,8$ & $10,3-10,4$ & $9,3-9,8$ \\
\hline 5 & Cryptonemia seminervis 1 & $6,2-6,9$ & $3,2-3,7$ & $5,7-6,3$ & $2,7-3,1$ & - & n.a. & n.a. & $9,8-10,3$ & n.a. & $9,3-10,0$ & $12,6-13,2$ & $11,1-12,0$ \\
\hline 6 & Cryptonemia seminervis 2 & 5,4 & 3,5 & $5,4-5,7$ & 2,7 & $0,8-1,1$ & - & n.a. & n.a. & n.a. & n.a. & n.a. & n.a. \\
\hline 7 & Cryptonemia seminervis 3 & 5,4 & 2,7 & $5,1-5,4$ & 2,2 & 1,1 & 0,8 & - & n.a. & n.a. & n.a. & n.a. & n.a. \\
\hline 8 & "Halymenia" elongata & $5,9-6,2$ & $4,3-4,6$ & $6,2-6,8$ & $2,7-3,0$ & $3,8-4,9$ & $4,1-4,6$ & $3,8-4,1$ & - & n.a. & $9,0-9,4$ & $11,8-11,9$ & $11,6-11,7$ \\
\hline 9 & "Halymenia" floridana & 5,4 & 3,2 & $5,7-5,9$ & 2,4 & $1,6-2,0$ & 0,8 & 1,1 & $3,5-4,1$ & - & n.a. & n.a. & n.a. \\
\hline 10 & Halymenia ignifera & $4,9-5,4$ & $4,1-4,3$ & $5,4-5,9$ & $2,2-2,4$ & $3,5-4,0$ & $2,7-3,0$ & $2,4-3,0$ & $3,0-3,5$ & $2,4-2,7$ & - & $10,5-11,1$ & $10,0-10,9$ \\
\hline 11 & Halymenia pinnatifida & 5,9 & 4,9 & $6,2-6,5$ & 2,7 & $3,8-4,0$ & 3,0 & 3,2 & $3,5-4,1$ & 2,7 & $0,8-1,6$ & - & $11,0-11,4$ \\
\hline 12 & Halymenia silviae & 5,7 & 4,1 & $6,5-6,8$ & 3,2 & $4,1-4,3$ & 3,2 & 3,5 & $3,2-3,8$ & 2,4 & $1,1-1,9$ & 1,4 & - \\
\hline 13 & Halymenia sp. 1 & 6,5 & 4,6 & $6,2-6,5$ & 2,7 & $4,1-4,3$ & 4,1 & 3,5 & $3,5-3,8$ & 3,8 & $1,4-2,2$ & 2,2 & 2,4 \\
\hline 14 & Halymenia sp. 2 & 6,8 & 5,4 & $7,0-7,3$ & 3,2 & $4,3-4,6$ & 4,3 & 4,3 & $4,1-4,6$ & 4,1 & $2,2-3,0$ & 1,4 & 2,7 \\
\hline 15 & Grateloupia cf. dichotoma & $7,0-7,3$ & $6,8-7,0$ & $7,0-7,6$ & $5,9-6,2$ & $5,7-6,6$ & $6,5-6,8$ & $5,9-6,2$ & $5,4-5,9$ & $5,4-5,9$ & $5,9-6,8$ & $7,0-7,3$ & $6,8-7,0$ \\
\hline 16 & Grateloupia cf. filicina 1 & 7,0 & 5,9 & $6,8-7,0$ & 4,9 & $5,1-5,7$ & 5,4 & 4,9 & $4,9-5,1$ & 4,9 & $5,7-5,9$ & 6,5 & 6,2 \\
\hline 17 & Grateloupia cf. filicina 2 & 8,4 & 7,3 & $8,9-9,2$ & 6,8 & $6,5-7,1$ & 7,3 & 6,8 & $6,2-6,5$ & 6,8 & $7,0-7,3$ & 7,8 & 6,5 \\
\hline 18 & Grateloupia filiformis & $6,8-7,3$ & $6,8-7,3$ & $7,6-8,4$ & $5,7-6,2$ & $5,4-6,6$ & $5,7-6,2$ & $5,1-5,7$ & $5,7-6,5$ & $5,1-5,7$ & $5,9-6,8$ & $6,8-7,3$ & $6,5-7,0$ \\
\hline 19 & "Grateloupia" gibbesii & $8,1-8,4$ & $5,9-6,2$ & $7,6-8,1$ & $5,4-5,7$ & $5,4-6,3$ & $5,7-5,9$ & $5,1-5,4$ & $5,4-5,9$ & $5,1-5,4$ & $6,2-6,8$ & $7,0-7,3$ & $6,8-7,0$ \\
\hline 20 & Grateloupia orientalis & 7,0 & 5,9 & $6,8-7,0$ & 4,9 & $5,1-5,7$ & 5,4 & 4,9 & $4,9-5,1$ & 4,9 & $5,7-5,9$ & 6,2 & 6,2 \\
\hline 21 & "Grateloupia" turuturu & 6,8 & 6,2 & $7,0-7,3$ & 4,6 & $4,9-5,4$ & 5,1 & 4,6 & $5,7-5,9$ & 5,1 & $5,4-5,7$ & 7,0 & 6,5 \\
\hline 22 & Grateloupia yangjiagensis & n.a. & n.a. & n.a. & n.a. & n.a. & n.a. & n.a. & n.a. & n.a. & n.a. & n.a. & n.a. \\
\hline 23 & Halymeniales sp. 1 & 6,2 & 4,1 & $6,5-6,8$ & 2,4 & $3,2-3,7$ & 3,5 & 3,0 & $2,4-2,7$ & 3,5 & $2,7-3,0$ & 3,5 & 3,2 \\
\hline 24 & Halymeniales sp. 2 & n.a. & n.a. & n.a. & n.a. & n.a. & n.a. & n.a. & n.a. & n.a. & n.a. & n.a. & n.a. \\
\hline
\end{tabular}


Tabela 7. Continuação.

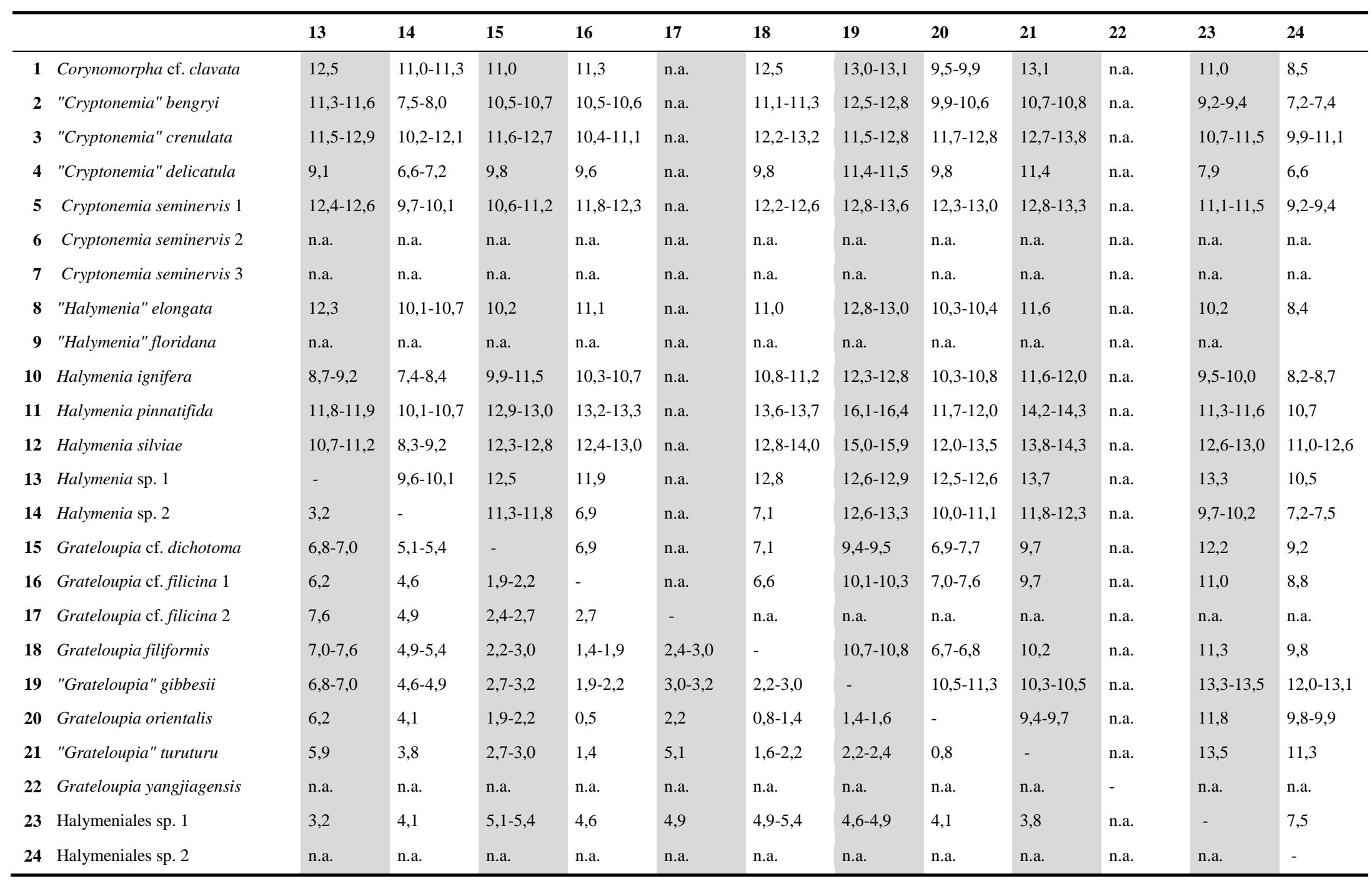




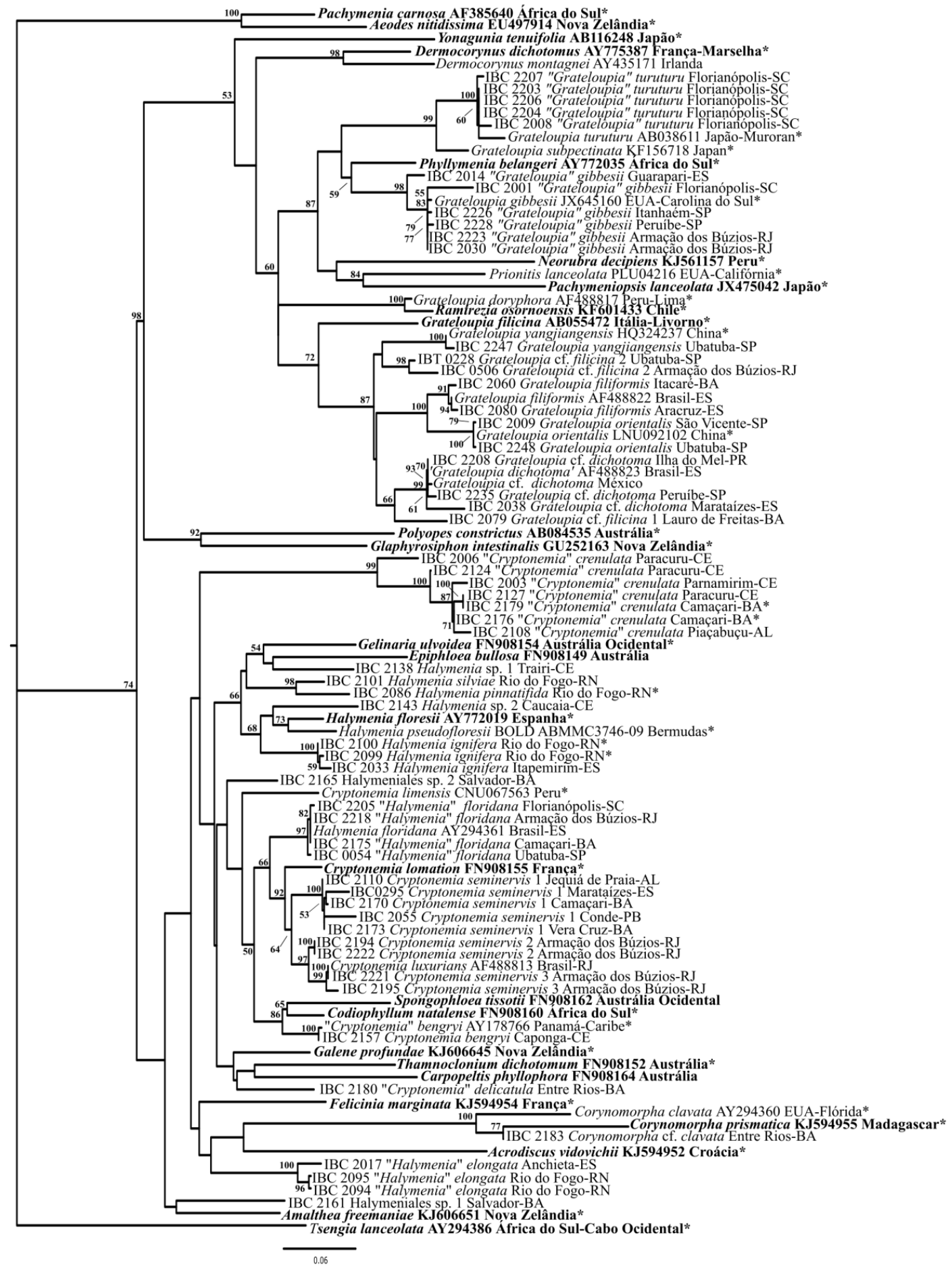

Figura 4. Árvore filogenética com sequências de $r b c \mathrm{~L}$, gerada através do algoritmo de Máxima Verossimilhança. Os números nos nós representam valores de Bootstrap para 100 réplicas. Valores de Bootstrap inferiores a 50 não apresentados. Espécies-tipo dos gêneros estão em negrito. Espécies coletadas em sua localidade-tipo estão indicadas por *. Sequências geradas neste estudo são precedidas pelo código de campo (IBC). Os números de acesso para as sequências obtidas no BOLD e no GenBank estão na Tabela 5. 


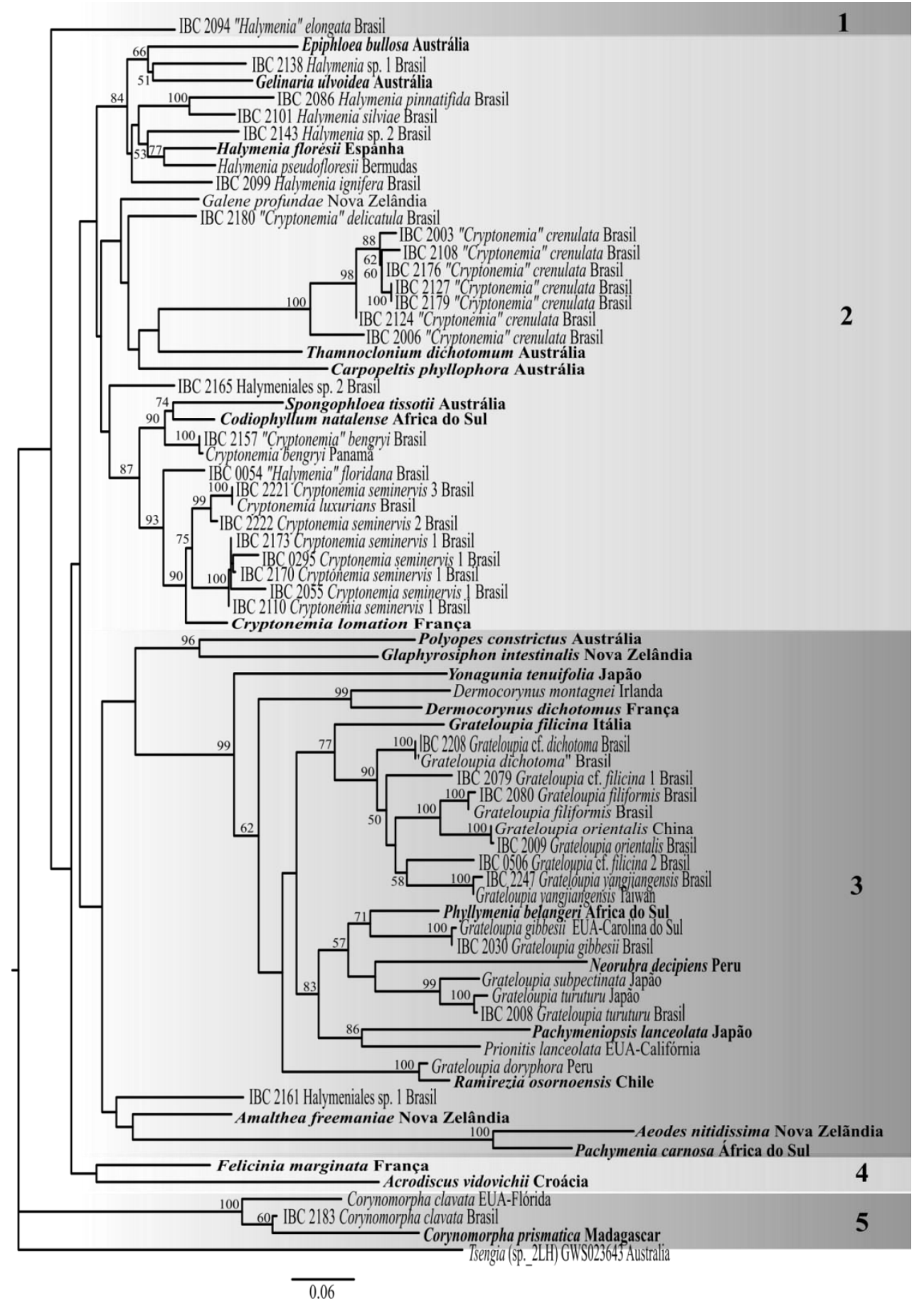

Figura 5. Árvore filogenética com sequências concatenadas de COI-5P e $r b c \mathrm{~L}$, gerada através do algoritmo de Máxima Verossimilhança. Os números nos nós representam valores de Bootstrap para 100 réplicas. Valores de Bootstrap inferiores a 50 não apresentados. Espécies-tipo dos gêneros estão em negrito. Sequências geradas neste estudo precedidas pelo código institucional (IBC). Os números de acesso para as sequências obtidas no BOLD e no GenBank estão na Tabela 5. As áreas sombreadas indicam os cinco principais clados obtidos (numerados de 1 a 5), que refletem dados de distribuição geográfica discutidos no texto. 


\subsection{Distribuição geográfica de espécies}

A Figura 6 corresponde à distribuição geográfica dos táxons encontrados neste estudo. De maneira geral, esse resultado concorda com as zonas de diversidade de algas propostas por Horta et al. (2001).

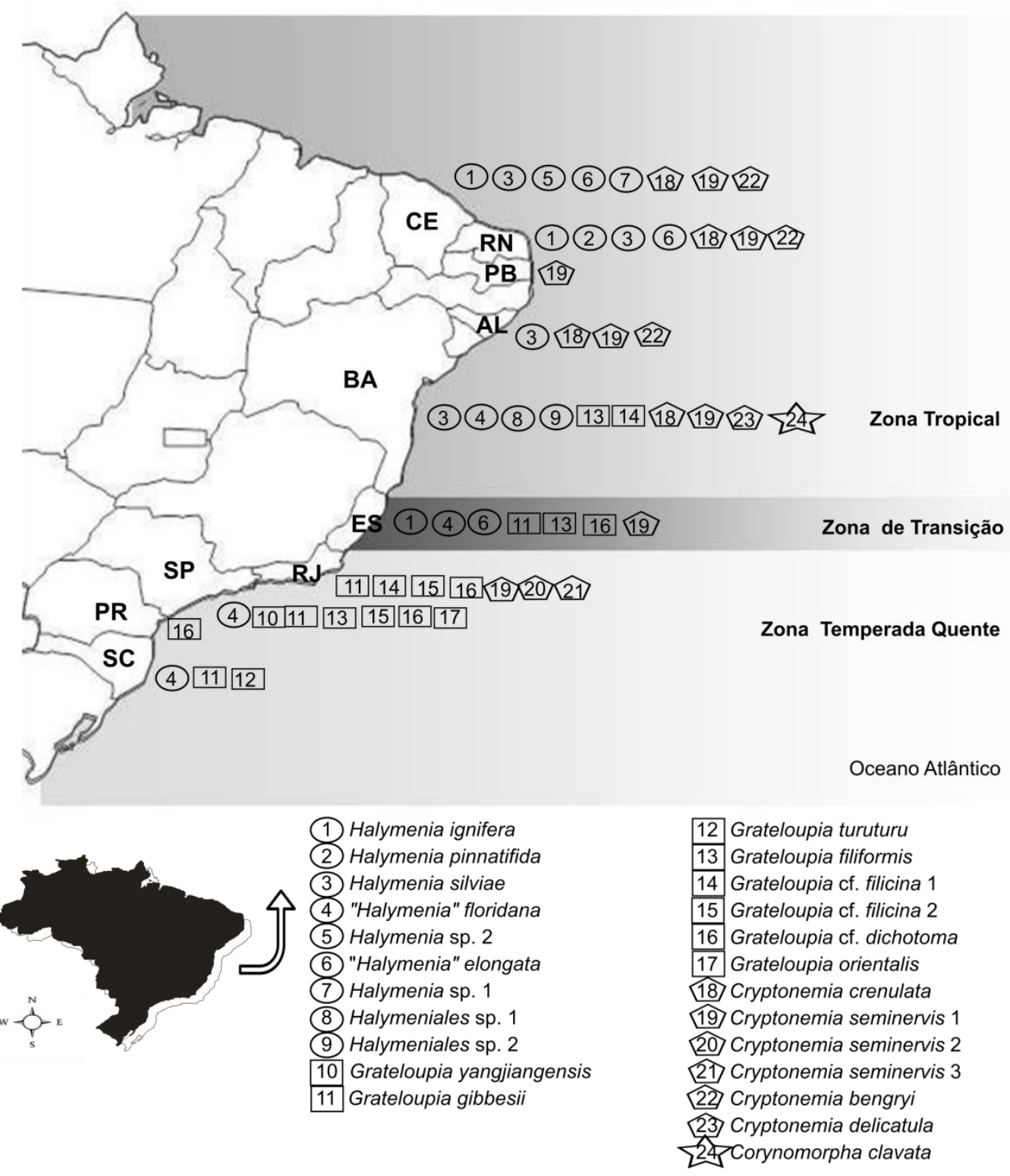

Figura 6. Distribuição geográfica de espécies encontradas neste estudo, de acordo com o estado da federação brasileira. As áreas sombreadas indicam as zonas de diversidade de algas de acordo com Horta et al. (2001). 
Algumas espécies foram registradas apenas na Zona Tropical, como é o caso de Halymenia pinnatifida, Halymenia silviae, Halymenia sp. 1, Halymenia sp. 2, Halymeniales sp. 1, Halymeniales sp. 2, "Cryptonemia” delicatula, "Cryptonemia" crenulata, "Cryptonemia" bengryi e Corynomorpha cf. clavata. Táxons exclusivos da Zona Temperada Quente incluem "Grateloupia" turuturu, Grateloupia cf. filicina 2, Grateloupia orientalis, Grateloupia yangjiangensis, Cryptonemia seminervis 2 e Cryptonemia seminervis 3. A Zona de Transição, por sua vez, não apresentou nenhum táxon exclusivo, e sim espécies comuns à Zona Tropical ou à Zona Temperada Quente. Apenas dois táxons foram encontrados nas três zonas: "Halymenia" floridana e Grateloupia filiformis. Grateloupia cf. filicina 1 foi a única espécie registrada na Zona Tropical e na Zona Temperada Quente.

É possível notar um padrão geográfico na distribuição dos gêneros. Considerando apenas os gêneros autênticos, foi observado que espécies de Halymenia ocorrem exclusivamente nas Zonas Tropical e de Transição, enquanto o gênero Grateloupia é encontrado predominantemente nas Zonas de Transição e Temperada Quente. "Halymenia" floridana, espécie registrada nas três zonas, não pertence ao gênero Halymenia, como demonstrado pelos dados moleculares encontrados neste estudo. Em relação ao gênero Cryptonemia, os dados obtidos demonstram que seus integrantes ocorrem principalmente nas Zonas Tropical e de Transição. A espécie Cryptonemia seminervis, considerada como amplamente distribuída, corresponde a três entidades distintas, de distribuição mais restrita: uma encontrada nas Zonas Tropical e de Transição (Cryptonemia seminervis 1), e outras duas que ocorrem exclusivamente na Zona Temperada Quente (Cryptonemia seminervis 2 e Cryptonemia seminervis 3), em praias de Armação dos Búzios e Cabo Frio (RJ), áreas sujeitas a influência de ressurgência.

Considerando a análise apresentada na Figura 5, é possível observar que há um sinal filogenético em relação à distribuição geográfica das espécies representadas. A análise filogenética concatenada resultou em cinco principais clados, numerados de 1 a 5 . A ocorrência desses clados está representada no mapa da Figura 7. O clado 1 é constituído pela espécie "Halymenia” elongata, coletada na zona tropical brasileira, no Rio Grande do Norte. 
Os representantes coletados na zona tropical do Brasil pertencem predominantemente ao clado 2, juntamente com espécies de locais temperados do Pacífico Sul, Oceano Índico, Atlântico Norte e Mar Mediterrâneo. Apenas três espécies da Zona Temperada Quente brasileira estão incluídas no clado 2: Cryptonemia seminervis 2, Cryptonemia seminervis 3 e "Halymenia" floridana. O clado 3, por sua vez, reúne todas as demais amostras obtidas na Zona Temperada Quente do Brasil e na Zona de Transição (Espírito Santo), além de incluir também espécimes de áreas temperadas do Atlântico Norte, Atlântico Sul, Pacífico Norte e do Pacífico Sul. O clado 3 inclui também as espécies Grateloupia cf. filicina 1 e Halymeniales sp. 1, ambas coletadas na zona tropical, no estado da Bahia. O clado 4 é composto por representantes coletados em águas temperadas dos Mares Adriático e Tirreno, enquanto que espécies pertencentes ao clado 5 são encontradas em regiões tropicais do globo. 


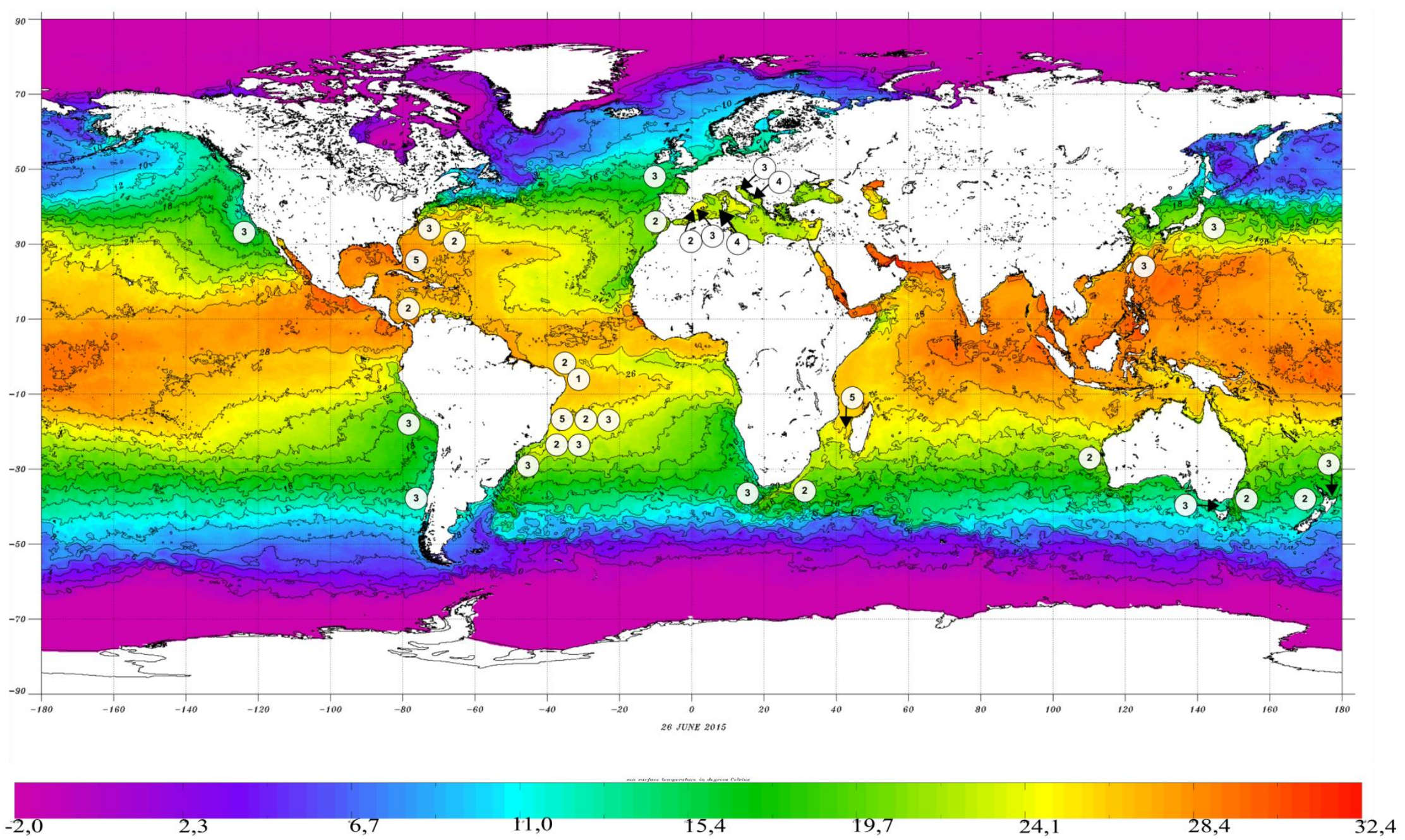

Figura 7. Distribuição global dos clados numerados de 1 a 5 e representados na análise filogenética concatenada apresentada na Figura 5 . Os números nos círculos indicam a ocorrência dos cinco clados principais segundo a Figura 5. As zonas coloridas indicam a temperatura $\left({ }^{\circ} \mathrm{C}\right)$ da superfície do mar no dia em que a imagem foi obtida (26 de junho de 2015). Imagem adaptada de http://www.ospo.noaa.gov. 


\subsection{Comentários Taxonômicos:}

A seguir, apresenta-se comentários taxonômicos sobre os táxons encontrados, considerando dados moleculares de UPA, COI-5P e $r b c \mathrm{~L}$ e observações morfológicas. 


\section{Corynomorpha J. Agardh}

\section{Do grego coryno: semelhante a uma clava + morpha: forma. \\ Espécie-tipo do gênero: Corynomorpha prismatica (J. Agardh) J. Agardh.}

Descrição: Talos cilíndricos, mas que colapsam e se tornam prismáticos quando herborizados, clavados, eretos, firmes e elásticos a sub-cartilaginosos, ramificados subdicotomicamente até quarta ordem, com estipe curto e apressório discoide pequeno. Córtex com células sub-esféricas ou elípticas, em camadas anticlinais, que aumentam de tamanho em direção à região medular. Região medular com filamentos frouxos entrelaçados e células estreladas. Células rizoidais presentes na região medular. Plantas dioicas. Estruturas reprodutivas em nematécios na região distal. Desenvolvimento procárpico. Ampola com até 10 ramos carpogoniais de duas células. A ampola também inclui célula auxiliar intercalar. O carpogônio fertilizado contacta diretamente a célula auxiliar. Uma única inicial dos gonimoblastos é cortada a partir da célula auxiliar em direção à superfície do talo, produzindo um filamento gonimoblástico axial primário unisseriado, a partir do qual se desenvolvem agrupamentos de células gonimoblásticas. Todas as células do gonimoblasto amadurecem e produzem carposporângios. Ostíolos presentes. Espermatângios formados em uma curta série catenada de células terminais de filamentos nemateciais. Tetrasporófitos e gametófitos isomórficos. Tetrasporângios cruciados irregularmente, produzidos a partir de células interiores do nematécio cortadas lateralmente.

(Guiry \& Guiry 2016) 


\section{Corynomorpha cf. clavata Harvey (J. Agardh)}

Figs 8 e 9

\section{Do latim clavata: em forma de clava.}

\section{Localidade-tipo: Estados Unidos da América, Flórida, Key West.}

Aspecto Geral: Talo de cor vermelha, firme e não mucilaginoso, com até $6 \mathrm{~cm}$ de altura e $0,5 \mathrm{~cm}$ de diâmetro. Frondes cilíndricas, claviformes, estreitas na base e mais largas na região mediana, com ápices clavados. Talo com leves constrições. Uma ou mais frondes partem de um mesmo apressório. Frondes não ramificadas. Estipe cilíndrico, com $0,7 \mathrm{~cm}$ de comprimento e $1 \mathrm{~mm}$ de diâmetro. Nervura e proliferações ausentes.

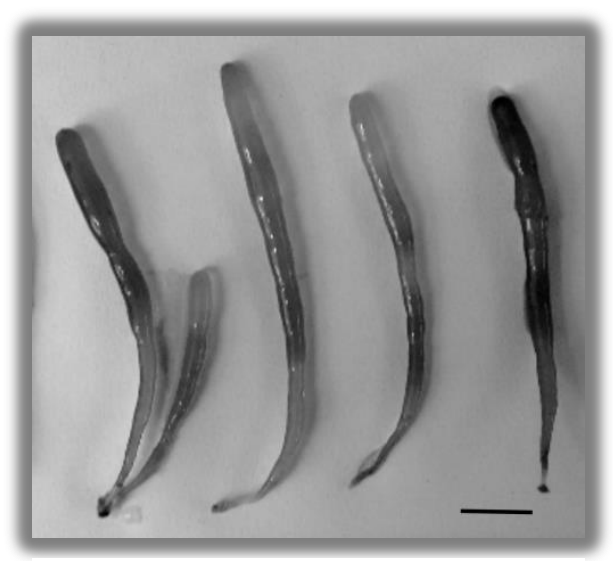

Figura 8. Aspecto geral. Barra de escala: $1 \mathrm{~cm}$.

Região Apical: Talo com 2300-2375 $\mu \mathrm{m}$ de diâmetro. Região cortical espessa, composta por aproximadamente oito camadas de células alongadas e estreitas, de 5-7 $\mu \mathrm{m}$ de altura e 2-3 $\mu \mathrm{m}$ de largura. Região medular densa, com abundantes filamentos irregularmente distribuídos, de 4-5 $\mu \mathrm{m}$ de diâmetro. Células ganglionares não observadas. Células estreladas espalhadas em toda a região medular, com 19-33 $\mu \mathrm{m}$ em sua maior medida, unindo os filamentos medulares.

Região Mediana: Talo com $5 \mathrm{~mm}$ de diâmetro. Região cortical composta por duas camadas de células alongadas, de $5 \mu \mathrm{m}$ de altura e 2,5 $\mu \mathrm{m}$ de largura. Região subcortical constituída por 3 camadas de células esféricas, de 5-7,5 $\mu \mathrm{m}$ de diâmetro. Região medular tão densa quanto na região apical, com abundantes filamentos irregulares de 6-10 $\mu \mathrm{m}$ de diâmetro. Células ganglionares não encontradas. Células estreladas próximas à região subcortical e espalhadas em toda a região medular, com 18-20 $\mu \mathrm{m}$ em sua maior medida.

Região Basal: Talo com 720-820 $\mu \mathrm{m}$ de diâmetro. Região cortical com 2-3 camadas de células alongadas, de 4-5 $\mu \mathrm{m}$ de altura e $2 \mu \mathrm{m}$ de largura. Região subcortical com 2-3 camadas esféricas de 3-5 $\mu \mathrm{m}$. Região medular bastante densa, com muitos filamentos longitudinais, semelhantes a rizines, com $5 \mu \mathrm{m}$ de diâmetro, e também 
filamentos irregulares, de 4-5 $\mu \mathrm{m}$ de diâmetro. Células ganglionares não encontradas. Células estreladas obscurecidas pelos densos filamentos.

Estruturas Reprodutivas: Ampola e cistocarpos maduros visualizados na região apical. Ampola bastante ramificada, com filamentos ramificados de aproximadamente oito células de comprimento. Ampola de formato oval, com $90 \mu \mathrm{m}$ de diâmetro. Célula auxiliar alongada, com 7,5 $\mu \mathrm{m}$ de altura e $15 \mu \mathrm{m}$ de largura. Filamento conectivo longo e bastante espesso, com aproximadamente $10 \mu \mathrm{m}$ de diâmetro. Carposporófitos envoltos por pericarpo, formando cistocarpos de formato oval, imersos no talo. Cistocarpo com 100172,5 $\mu \mathrm{m}$ de diâmetro e com 150-187,5 $\mu \mathrm{m}$ considerando o pericarpo, com um ou dois gonimolobos. Carposporângios de formato irregular, ovoides ou quadráticos, com 10-12,5 $\mu \mathrm{m}$ na maior medida. Gametófitos masculinos e tetrasporófitos não observados.

\section{Material Examinado:}

Brasil, Bahia, Entre Rios, Praia de Subaúma, 27 de maio de 2013, C.A.A. Azevedo, T. Vieira-Pinto e B. Torrano-Silva (IBC 2183; 2184; 2185- gametófito feminino; 2186 e 2191).

\section{Comentários:}

O gênero Corynomorpha atualmente compreende apenas as espécies Corynomorpha prismatica, espécie-tipo do gênero, e Corynomorpha clavata, a qual foi citada para o Brasil pela primeira vez por Joly et al. (1965b), para as costas do Ceará e do Espírito Santo. Os espécimes encontrados neste estudo estão de acordo com as ilustrações de Joly et al. (1965b) e com a descrição original de Corynomorpha clavata feita por Harvey (1853). Harvey (1853) descreve a morfologia externa dos espécimes, que são claviformes, simples ou bifurcados, que adquirem aspecto prismático quando desidratados, o que está de acordo com o material encontrado neste estudo.

As reconstruções filogenéticas mostram que a entidade coletada no Brasil se agrupa com as sequências de materiais de $C$. clavata e $C$. prismatica provenientes das respectivas localidades-tipo (Figuras 4 e 5). No entanto, a sequência de $r b c \mathrm{~L}$ do material brasileiro diverge 3,7\% em relação à primeira, e 4,1\% em relação à segunda, valores altos o suficiente para indicar que o agrupamento é composto por três espécies distintas. Por essa razão, o 
táxon é tratado neste estudo como Corynomorpha cf. clavata, mas futuramente deverá ser descrita como uma nova espécie para o gênero. Este estudo foi o primento a encontrar estruturas reprodutivas femininas dessa espécie.
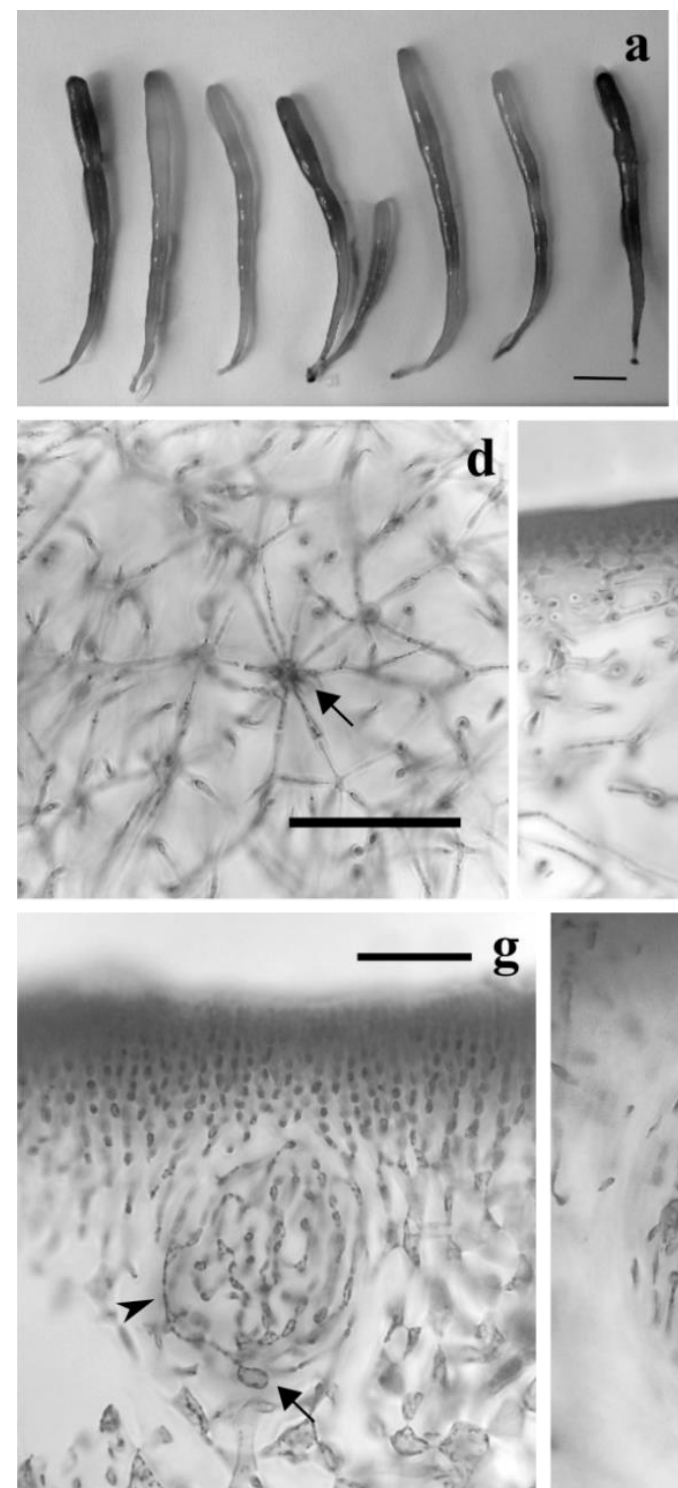

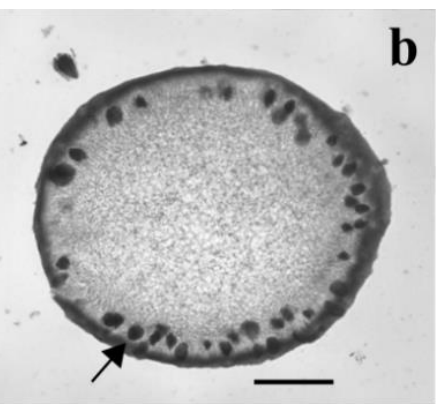

b
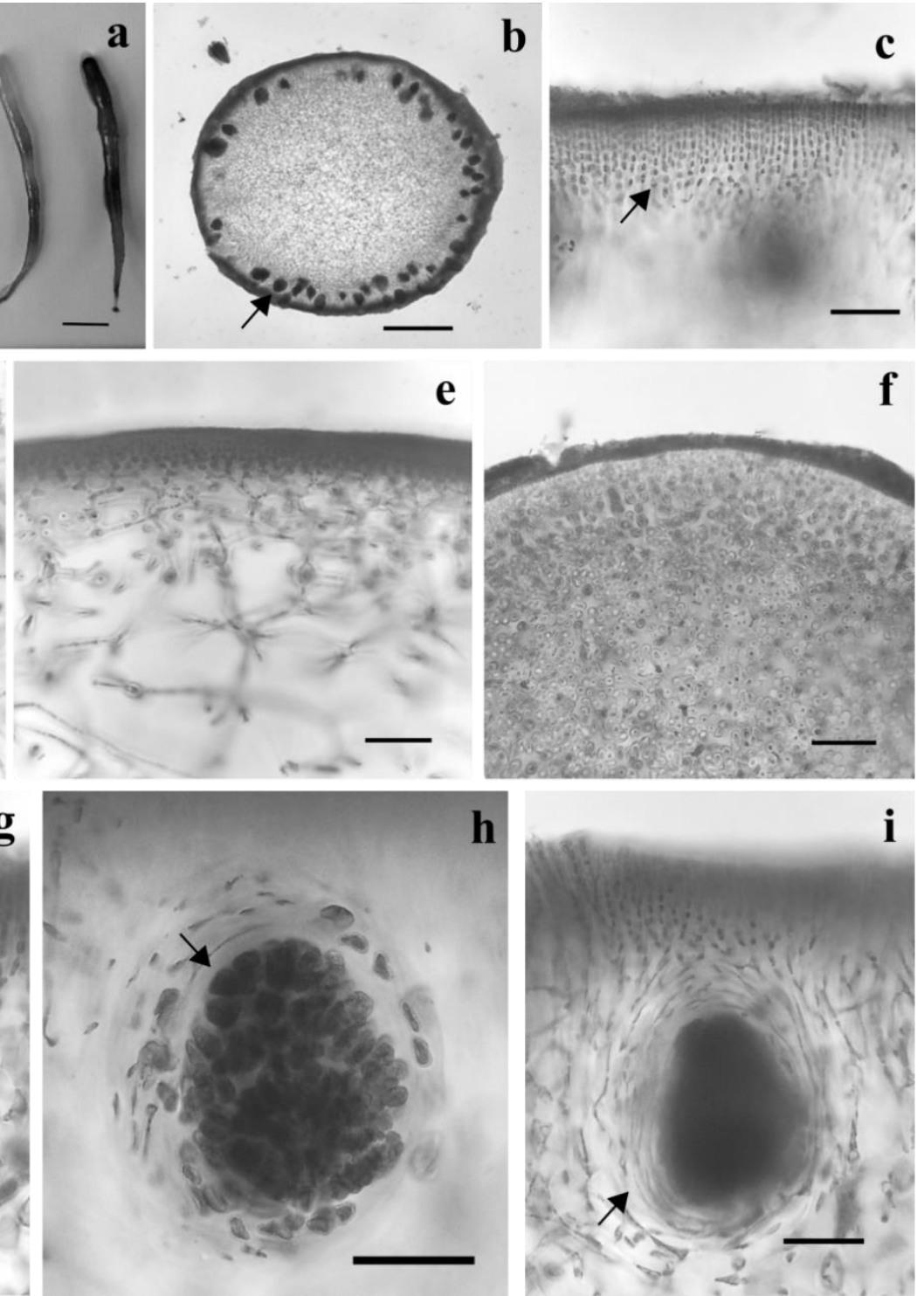

Figura 9. Corynomorpha cf. clavata. Anatomia vegetativa e reprodutiva. Todas as imagens são de IBC 2185.

(a) Aspecto geral. Barra de escala: $1 \mathrm{~cm}$;

(b) Corte transversal na região apical do talo. Seta aponta cistocarpos maduros. Barra de escala: 0,5 mm;

(c) Detalhe do corte transversal na região apical, mostrando as células do Região cortical (seta). Barra de escala: $50 \mu \mathrm{m}$;

(d) Detalhe de corte transversal na região apical, mostrando filamentos Região medularres e células estreladas na Região medular (seta). Barra de escala: $50 \mu \mathrm{m}$;

(e) Corte transversal na região mediana do talo. Barra de escala: $50 \mu \mathrm{m}$; 
(f) Corte transversal na região basal do talo. Barra de escala: $50 \mu \mathrm{m}$;

(g) Corte transversal na região apical do talo mostrando ampola. Seta e ponta de seta indicam célula auxiliar e filamento ampolar, respectivamente. Barra de escala: $50 \mu \mathrm{m}$;

(h) Corte transversal do talo, com visão longitudinal do cistocarpo maduro totalmente imerso no talo. Seta indica carposporângio. Barra de escala: $50 \mu \mathrm{m}$;

(i) Corte transversal do talo, com visão longitudinal do cistocarpo maduro totalmente imerso. Seta indica pericarpo. Barra de escala: $50 \mu \mathrm{m}$. 


\section{Cryptonemia J. Agardh}

\section{Do grego crypto: obscuro, encoberto + nema: fio. Espécie-tipo do gênero: Cryptonemia lomation (Bertoloni) J.Agardh}

Talos achatados, foliosos, lineares, lanceolados, expandidos, lobados, inteiros ou abundantemente ramificados. Râmulos marginais abundantes em alguns espécimes. Estipe geralmente bastante conspícuo e perene, que pode apresentar anéis de crescimento. Apressório discoide. Células da região cortical esféricas ou elipsoides, que diminuem de tamanho em direção à superfície do talo. Células da região subcortical arredondadas ou clavadas. Células estreladas presentes. Região medular filamentosa, com filamentos predominantemente periclinais, que podem apresentar denso conteúdo refringente. Rizoides (filamentos longitudinais) e conexões secundárias presentes. Ramos carpogoniais e células auxiliares em ampolas separadas. Estruturas reprodutivas femininas em ampolas com ramos de até quarta ordem. Ramo carpogonial com duas células, originadas em filamentos ampolares primários ou secundários. Após a fertilização, os filamentos conectivos emitidos pelo carpogônio entram em contato com as células auxiliares e uma célula auxiliar de fusão pequena é formada. Célula auxiliar é basal ou suprabasal em um filamento ampolar de segunda ou terceira ordem. A célula auxiliar diploidizada dá origem a uma única inicial dos gonimoblastos, a qual produz um cistocarpo compacto com muitos carposporângios

pequenos. O pericarpo, que envolve o cistocarpo, é composto por células ampolares alongadas. Cistocarpos imersos e espalhados, formando pequena protuberância na superfície do talo. Ostíolo presente. Espermatângios localizados na superfície do talo. Gametófitos e tetrasporófitos isomórficos. Tetrasporângios pequenos, cruciados, espalhados pelo córtex ou em soros subapicais.

(Guiry \& Guiry 2016) 


\section{“Cryptonemia” bengryi W. R. Taylor}

Figs 10 e 11

\section{Em homenagem ao coletor R. P. Bengry.}

\section{Localidade-tipo: Jamaica.}

Aspecto Geral: Talo vermelho, firme, cartilaginoso, não mucilaginoso. Frondes em forma de fitas de até $8,5 \mathrm{~cm}$ de altura e $2 \mathrm{~cm}$ de largura, irregularmente ramificadas. Base alargada, assim como a região mediana. Ápices arredondados ou de formato irregular. Proliferações marginais e apicais não estipitadas. Nervura ausente. Frondes levemente retorcidas e onduladas.

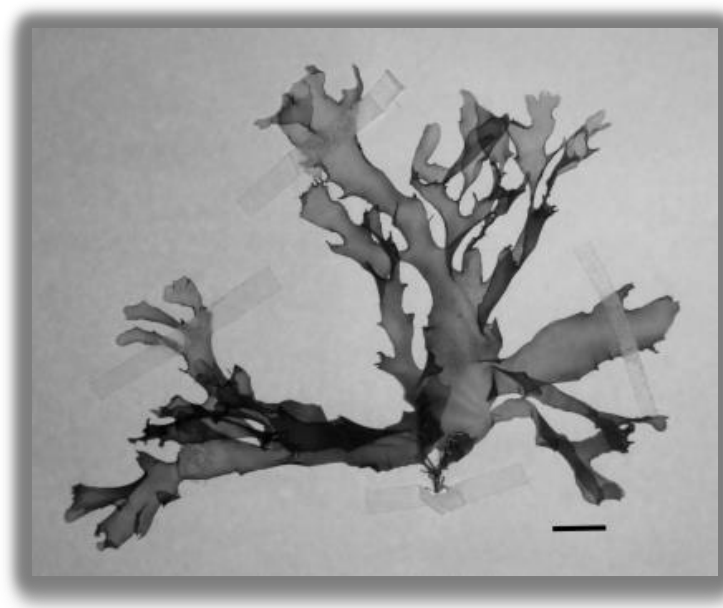

Figura 10. Aspecto geral. Barra de escala: $1 \mathrm{~cm}$. Estipe ramificado, cilíndrico, de $0,7 \mathrm{~cm}$ de comprimento e $1 \mathrm{~mm}$ de diâmetro. Apressório discoide, com $1 \mathrm{~mm}$ de diâmetro.

Região Apical: Talo com 92,5-117,5 $\mu \mathrm{m}$ de espessura. Região cortical com uma camada de células retangulares de 7-9 $\mu \mathrm{m}$ de altura e 3-4 $\mu \mathrm{m}$ de largura. Região subcortical com duas camadas de células esféricas, de 4-8 $\mu \mathrm{m}$ de diâmetro, que aumentam progressivamente de tamanho em direção à região medular. Região medular com filamentos irregulares de 2-3 $\mu \mathrm{m}$ de diâmetro. Inclusões esféricas de conteúdo refringente presentes nas células da região subcortical e nos filamentos medulares. Células ganglionares pequenas e raras. Células estreladas presentes, com 10-17 $\mu \mathrm{m}$ de largura, conectando as células da região subcortical aos filamentos medulares.

Região Mediana: Talo com 175-192,5 $\mu \mathrm{m}$ de espessura. Região cortical com uma camada de células retangulares de 5-8 $\mu \mathrm{m}$ de altura e 3-4 $\mu \mathrm{m}$ de largura. Região subcortical com 3-4 camadas de células redondas de 5-19 $\mu \mathrm{m}$ de diâmetro, que aumentam progressivamente de tamanho em direção à região medular. Região medular com filamentos irregulares de 4-9 $\mu \mathrm{m}$ de diâmetro. Inclusões esféricas de conteúdo refringente presentes nas células da região subcortical e nos filamentos medulares, mais abundantes 
que nas regiões apical e basal. Células ganglionares conspícuas e abundantes. Células estreladas presentes, com 26-35 $\mu \mathrm{m}$ de largura.

Região Basal: Talo com 330-380 $\mu \mathrm{m}$ de espessura. Região cortical com uma camada de células retangulares de 7,5-10 $\mu \mathrm{m}$ de altura e $5 \mu \mathrm{m}$ de largura. Região subcortical com 4-5 camadas de células esféricas de 7,5-27,5 $\mu \mathrm{m}$ de diâmetro. Região medular muito densa, completamente preenchida por filamentos irregulares de 5-10 $\mu \mathrm{m}$ de diâmetro. Inclusões esféricas de conteúdo refringente presentes nas células da região subcortical e nos filamentos medulares. Células incolores esféricas presentes nas regiões periféricas da região medular. Células ganglionares presentes, porém em menor número e mais discretas que na região mediana. Células estreladas obscurecidas pelos densos filamentos medulares.

Estruturas Reprodutivas: Não observadas.

\section{Material Examinado:}

Brasil, Ceará, Caponga, Praia da Caponga, 28 de abril de 2013, C.A.A. Azevedo e T. Vieira-Pinto (IBC 2157; IBC 2158). Caucaia, Praia do Pacheco, 24 de abril de 2013, C.A.A. Azevedo, P.B. Carneiro, T. Vieira-Pinto e B. Torrano-Silva (IBC 2150). Icapuí, Praia de Ponta Grossa, 27 de abril de 2013, C.A.A. Azevedo e T. Vieira-Pinto (IBC 2154).

Rio Grande do Norte, Nísia Floresta, Praia de Tabatinga, 12 de janeiro de 2013, C.A.A. Azevedo e R.F. Menezes (SPF 57778/IBC 2082). Alagoas, Jequiá de Praia, Praia de Jequiá, 12 de março de 2013, C.A.A. Azevedo, T. Vieira-Pinto e B. Torrano-Silva (IBC 2109).

\section{Comentários:}

A análise de $r b c \mathrm{~L}$ demonstra que a espécie que ocorre no Brasil corresponde à autêntica Cryptonemia bengryi, uma vez que a sequência de material brasileiro agrupa com a sequência de material coletado na localidade-tipo (Caribe) (Figura 4). A divergência entre essas duas sequências é de apenas $0,1 \%$. No entanto, segundo as filogenias aqui apresentadas (Figuras 4 e 5), os representantes de $C$. bengryi não integram o clado que contem Cryptonemia lomation, a espécie-tipo do gênero Cryptonemia, o que é um indicativo de que $C$. bengryi constitui um gênero distinto. Por essa razão, o táxon é tratado aqui como "Cryptonemia” bengryi (gênero escrito entre aspas). 
Em relação à morfologia, os indivíduos concordam com os descritos por PinheiroJoventino (1977) e Guimarães (1990) para C. bengryi. As mesmas estruturas citadas aqui como inclusões esféricas refringentes, também chamadas de conteúdo granular, foram observadas por D'Archino et al. (2014) em células corticais internas e estreladas e nos filamentos Região medularres de Galene profundae D'Archino \& Zuccarello. Galene D’Archino \& Zuccarello é um gênero recentemente descrito para a costa da Nova Zelândia (D'Archino et al. 2014), para acomodar indivíduos previamente tratados como

\section{Cryptonemia.}
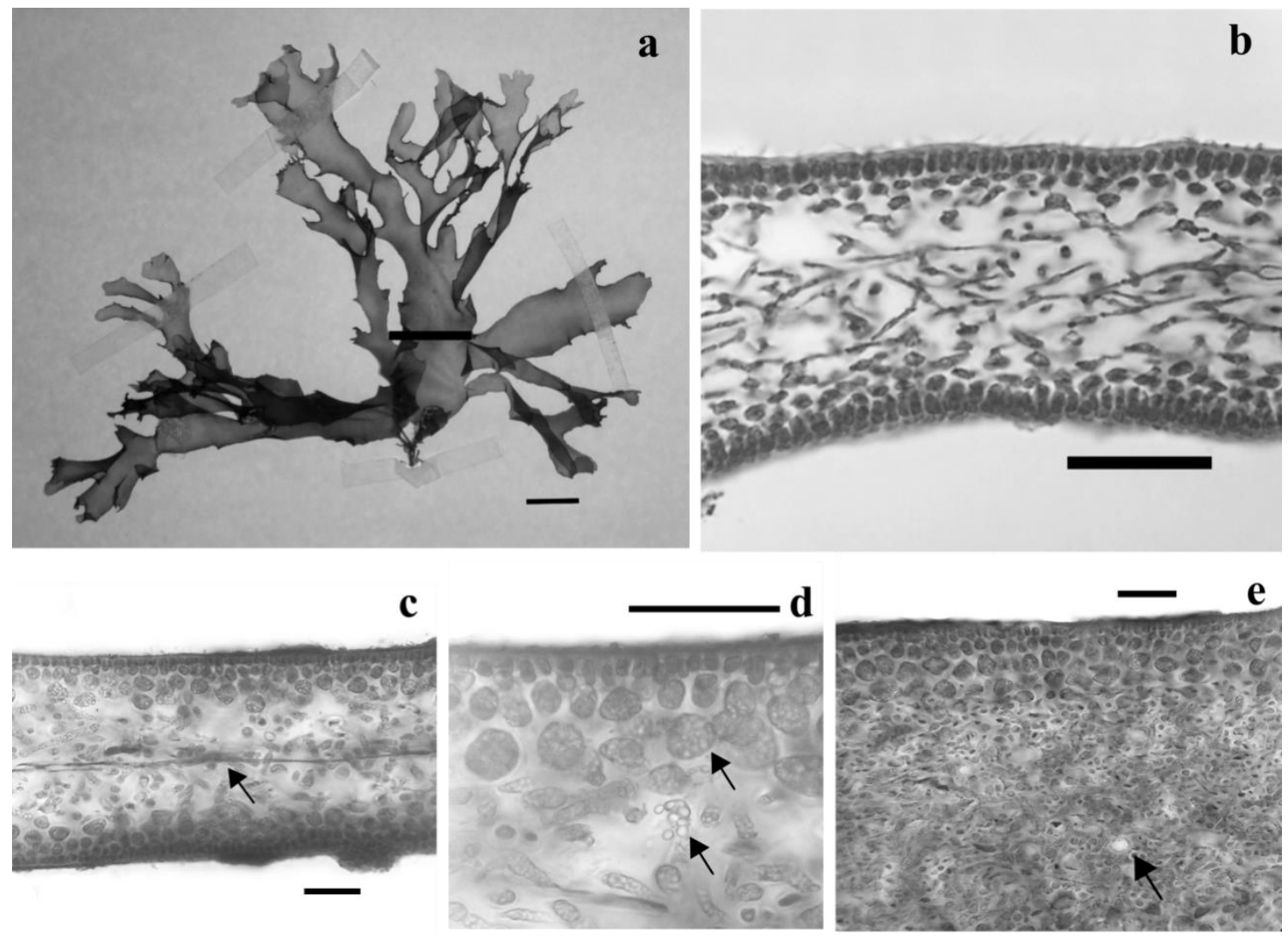

Figura 11. "Cryptonemia” bengryi. Anatomia vegetativa. Todas as imagens são de SPF 57778/IBC 2082.

(a) Aspecto geral. Barra de escala: $1 \mathrm{~cm}$;

(b) Corte transversal na região apical do talo. Barra de escala: $50 \mu \mathrm{m}$;

(c) Corte transversal na região mediana do talo. Seta indica filamento ganglionar. Barra de escala: $50 \mu \mathrm{m}$;

(d) Detalhe de corte transversal na região mediana do talo. Setas indicam inclusões esféricas no córtex e na Região medular. Barra de escala: $50 \mu \mathrm{m}$;

(e) Corte transversal na região basal do talo. Seta indica célula incolor esférica presente na Região medular. Barra de escala: $50 \mu \mathrm{m}$. 


\section{“Cryptonemia” crenulata (J. Agardh) J. Agardh}

Figs 12 e 13

\section{Do latim crenulata: denteado, serreado.}

\section{Localidade-tipo: Brasil, sul da Bahia.}

Aspecto Geral: Talo de cor rosa ou vermelha, firme, não mucilaginoso e de consistência áspera. Frondes em forma de fitas, com até $17 \mathrm{~cm}$ de altura e $4 \mathrm{~cm}$ de largura. Ramificação predominantemente dicotômica, mas também irregular. Frondes com base estreita, porém a largura aumenta em

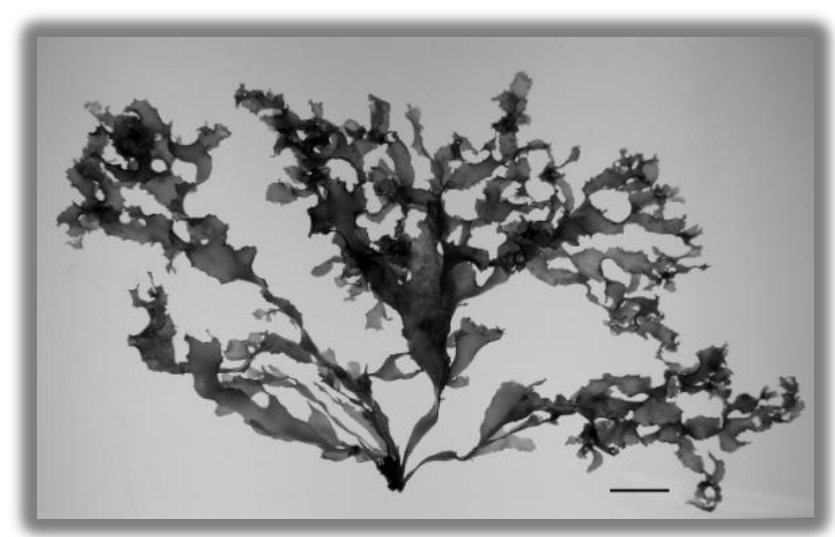

Figura 12. Aspecto geral. Barra de escala: $2 \mathrm{~cm}$ direção à região mediana. Ápices arredondados e com margens denteadas. Frondes onduladas e retorcidas. Margens lisas na região basal e denteadas a partir da região mediana em direção ao ápice. Bordas das lâminas dilatadas. Proliferações marginais, superficiais e apicais presentes em alguns espécimes e ausentes em outros. Nervura ausente. Estipe achatado, com até $0,7 \mathrm{~cm}$ de comprimento e $2 \mathrm{~mm}$ de largura. Apressório discoide, com até $3 \mathrm{~mm}$ de diâmetro.

Região Apical: Talo com 110-145,4 $\mu \mathrm{m}$ de espessura. Região cortical composta por uma camada de células quadráticas, de 4-5 $\mu \mathrm{m}$ de altura e 4-5 $\mu \mathrm{m}$ de largura. Região subcortical composta por três camadas de células esféricas, de 5-22 $\mu \mathrm{m}$ de diâmetro, que aumentam gradualmente de tamanho em direção à região medular. Região medular com filamentos predominantemente longitudinais e alguns periclinais, de 4-5 $\mu \mathrm{m}$ de diâmetro. Abundantes inclusões esféricas de conteúdo refringente, principalmente nas células da região subcortical. Raros filamentos refringentes imersos na região medular, que se assemelham a pequenas células ganglionares. Células estreladas expandidas, medindo 10$18 \mu \mathrm{m}$ em sua maior medida, conectadas apenas periclinalmente.

Região Mediana: Talo com 112,5-152,5 $\mu \mathrm{m}$ de espessura. Região cortical com 1-2 camadas de células quadráticas de 4-5 $\mu \mathrm{m}$ de altura e 3-5 $\mu \mathrm{m}$ de largura. Região subcortical 
com 2-3 camadas de células esféricas, de 4-27,5 $\mu \mathrm{m}$ de diâmetro, que aumentam de tamanho em direção à região medular. Região medular com filamentos longitudinais de 5-8 $\mu \mathrm{m}$ de diâmetro. Abundantes inclusões esféricas de conteúdo refringente, principalmente nas células da região subcortical. Células ganglionares e filamentos ganglionares presentes. Células estreladas expandidas, de 15-20 $\mu \mathrm{m}$ em sua maior medida, conectadas apenas periclinalmente.

Região Basal: Talo com 349,2-400 $\mu \mathrm{m}$ de espessura. Região cortical com 1-2 camadas de células quadráticas, de 3-5 $\mu \mathrm{m}$ de altura e 2-5 $\mu \mathrm{m}$ de largura. Região subcortical com 5-7 camadas de células esféricas, de 4-32 $\mu \mathrm{m}$ de diâmetro, que aumentam gradualmente de tamanho em direção à região medular. Região medular densa, preenchida

por filamentos longitudinais de 3-8 $\mu \mathrm{m}$ de diâmetro. Inclusões esféricas de conteúdo refringente, principalmente nas células da região subcortical, menos abundantes que nas regiões apical e mediana. Células ganglionares ou filamentos refringentes não observados. Células estreladas expandidas, com 20-25 $\mu \mathrm{m}$ em sua maior medida.

Estruturas Reprodutivas: Não observadas.

\section{Material Examinado:}

Brasil, Ceará, Paracuru, Praia da Pedra Rachada, 24 de abril de 2013, C.A.A. Azevedo, T. Vieira-Pinto e B. Torrano-Silva (SPF 57780/IBC 2124-infértil; IBC 2126; IBC 2127; IBC 2128). Paracuru, 11 de fevereiro de 2012, E. Plastino e L. Ayres-Ostrock (SPF 57818/IBC 2006). Caucaia, Praia do Pacheco, 26 de abril de 2013, C.A.A. Azevedo, P.B. Carneiro, T. Vieira-Pinto e B. Torrano-Silva (IBC 2144; IBC 2145). Rio Grande do Norte, Parnamirim, Praia de Pirambúzios, 25 de janeiro de 2012, C.A.A. Azevedo (IBC 2004; SPF 57788/IBC 2003-infértil; IBC 2005). Nísia Floresta, Praia de Tabatinga, C.A.A. Azevedo e R.F. Menezes, 12 de janeiro de 2013. Alagoas, Piaçabuçu, Praia de Pontal do Peba, 11 de março de 2013, C.A.A. Azevedo, T. Vieira-Pinto e B. Torrano-Silva (IBC 2105; SPF 57782/IBC 2108). Maceió, Praia de Riacho Doce, C.A.A. Azevedo, T. VieiraPinto e B. Torrano-Silva, 13 de março de 2013 (IBC 2114; IBC2115). Bahia, Camaçari, Praia de Guarajuba, 26 de maio de 2013, C.A.A. Azevedo, T. Vieira-Pinto e B. TorranoSilva (IBC 2176; IBC 2177; IBC 2178; IBC 2179-infértil). Entre Rios, Praia de Subaúma, 27 de maio de 2013, C.A.A. Azevedo, T. Vieira-Pinto e B. Torrano-Silva (IBC 2190). 


\section{Comentários:}

O táxon Cryptonemia crenulata é amplamente citado para a costa do Brasil, desde o estado do Maranhão até São Paulo (Guimarães 1990). De acordo com nosso conhecimento, este estudo constitui a primeira citação para o estado de Alagoas. Morfologicamente, os espécimes estão de acordo com Guimarães (1990).

Os dados filogenéticos (Figuras 4 e 5) mostram ainda que essa entidade não corresponde ao gênero Cryptonemia, uma vez que não pertence ao clado que contém a espécie-tipo do gênero, C. lomation. Os dados moleculares de UPA (Figura 2) e COI-5P (Figura 3) mostram indivíduos de "Cryptonemia" crenulata inseridos em um único clado, que possuem divergência intraespecífica de $0-0,3$ e $0-1,2 \%$, respectivamente. No entanto, as sequências de $r b c \mathrm{~L}$ (Figura 4; Tabela 8) apontam a existência de três espécies crípticas atualmente tratadas como C. crenulata:

(i) C. crenulata 1: representada pela amostra IBC 2006, ocorre no Ceará;

(ii) C. crenulata 2: representada por IBC 2124, registrada no Ceará;

(iii) C. crenulata 3: corresponde a IBC 2003 (RN), IBC 2108 (AL), IBC 2127 (CE), IBC 2176 (BA) e IBC 2179 (BA). A divergência entre os indivíduos deste grupo é de $0-1,3 \%$ (Tabela 8). Este clado representa a autêntica Cryptonemia crenulata, pois inclui sequências de amostras coletadas na localidade-tipo (Bahia).

Tabela 8. Valores de divergência de $r b c \mathrm{~L}$ em $\%$ entre amostras de "Cryptonemia" crenulata.

\begin{tabular}{|c|c|c|c|c|c|c|c|c|c|}
\hline & & & $\begin{array}{l}\text { IBC } \\
2006\end{array}$ & $\begin{array}{l}\text { IBC } \\
2124 \\
\end{array}$ & $\begin{array}{l}\text { IBC } \\
2003\end{array}$ & $\begin{array}{c}\text { IBC } \\
2108 \\
\end{array}$ & $\begin{array}{c}\text { IBC } \\
2127\end{array}$ & $\begin{array}{c}\text { IBC } \\
2176\end{array}$ & $\begin{array}{c}\text { IBC } \\
2179\end{array}$ \\
\hline $\mathrm{i}$ & "C." crenulata 1 & IBC 2006 & & & & & & & \\
\hline ii & "C." crenulata 2 & IBC 2124 & 3,1 & & & & & & \\
\hline \multirow{5}{*}{ iii } & \multirow{5}{*}{ "C." crenulata 3} & IBC 2003 & 3,3 & 1,4 & & & & & \\
\hline & & IBC 2108 & 3,9 & 1,4 & 1,3 & & & & \\
\hline & & IBC 2127 & 3,9 & 1,3 & 1 & 0,9 & & & \\
\hline & & IBC 2176 & 3,6 & 0,9 & 0,7 & 0,7 & 0,1 & & \\
\hline & & IBC 2179 & 3,8 & 1,2 & 0,9 & 0,9 & 0 & 0,1 & \\
\hline
\end{tabular}


Esses resultados indicam que Cryptonemia crenulata corresponde a um complexo de espécies, no entanto, dos três marcadores utilizados, apenas o $r b c \mathrm{~L}$ apontou uma diferenciação de linhagens. Além disso, não foram encontradas diferenças morfológicas entre essas entidades apontadas pela filogenia. Por essa razão, as aparentes três linhagens de C. crenulata são provisoriamente consideradas uma só. É necessário incluir mais estudos morfológicos e moleculares para esclarecer as relações filogenéticas e a delimitação de espécies dentro desse complexo. 

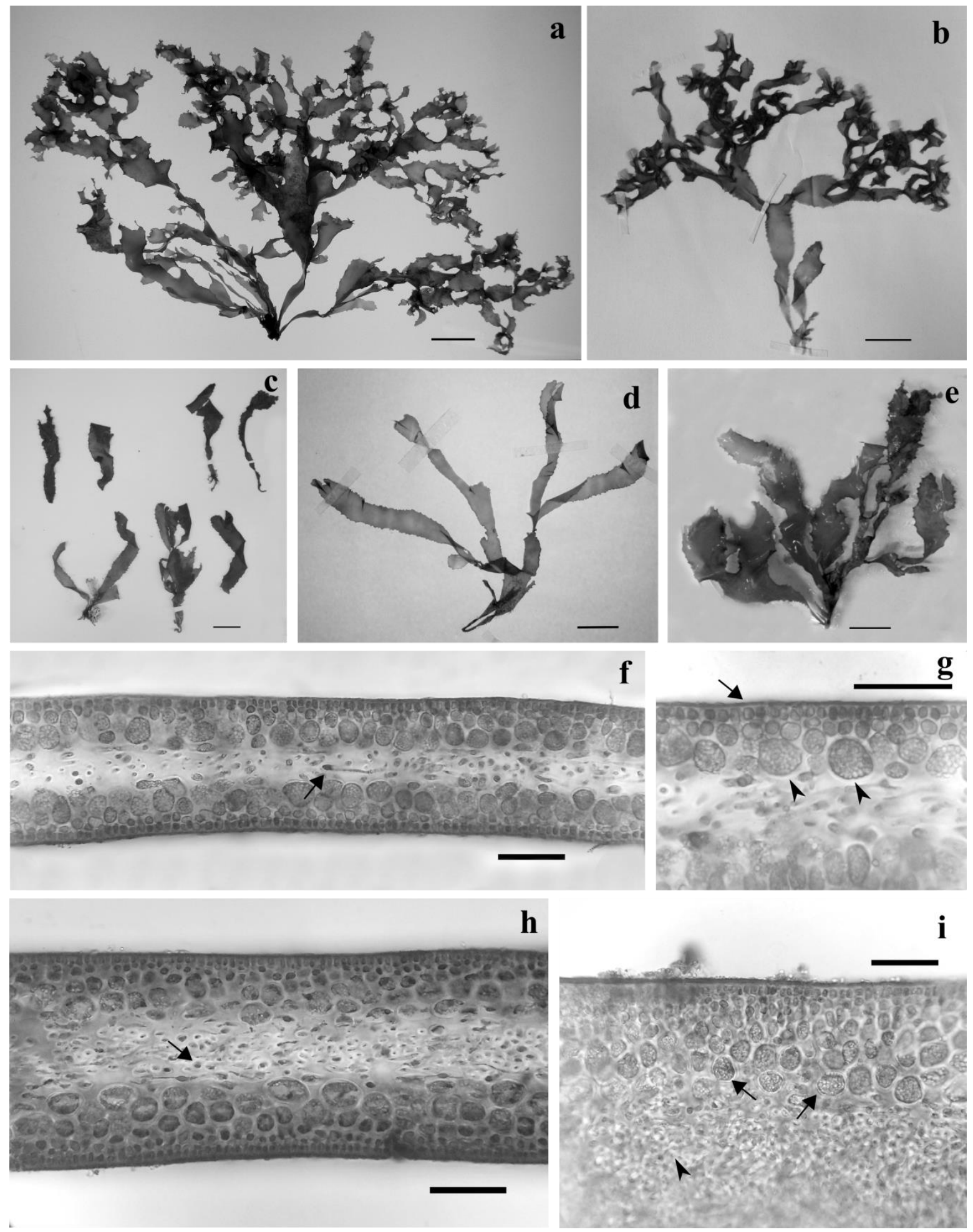

Figura 13. Complexo "Cryptonemia" crenulata. Anatomia vegetativa.

(a) C. crenulata 3. Aspecto geral. Barra de escala: $2 \mathrm{~cm}$ (IBC 2179);

(b) C. crenulata 3. Aspecto geral. Barra de escala: $2 \mathrm{~cm}$ (IBC 2108);

(c) C. crenulata 1. Aspecto geral. Barra de escala: $2 \mathrm{~cm}$ (IBC 2006); 
(d) C. crenulata 2. Aspecto geral. Barra de escala: $2 \mathrm{~cm}$ (IBC 2124);

(e) C. crenulata 3. Aspecto geral. Barra de escala: $2 \mathrm{~cm}$ (IBC 2003);

(f) Corte transversal na região apical do talo mostrando filamento ganglionar (seta). Barra de escala: $50 \mu \mathrm{m}$ (IBC 2179);

(g) Detalhe de corte transversal na região apical mostrando região cortical (seta) e células da região subcortical (pontas de seta) com abundante conteúdo granular. Barra de escala: $50 \mu \mathrm{m}$ (IBC 2179);

(h) Corte transversal na região mediana do talo mostrando filamentos medulares longitudinais (seta). Barra de escala: $50 \mu \mathrm{m}$ (IBC 2124);

(i) Corte transversal na região basal do talo mostrando células da região subcortical com abundante conteúdo granular (setas) e região medular densamente preenchida com filamentos longitudinais (pontas de seta). Barra de escala: $50 \mu \mathrm{m}$ (IBC 2179). 


\title{
“Cryptonemia” delicatula A.B. Joly \& M. Cordeiro
}

Figs 14 e 15

\section{Do latin delicatus, delicata: delicada.}

Localidade-tipo: Brasil, estado de São Paulo, Ubatuba, Praia do Lázaro.

\begin{abstract}
Aspecto Geral: Talo de cor rosa, mucilaginoso, flácido e bastante delicado. Frondes em forma de fitas de até $4,5 \mathrm{~cm}$ de altura e até $0,8 \mathrm{~cm}$ de largura, com ramificação escassa e irregular. Frondes estreitas na base, que se alargam em direção à região mediana e ao ápice. Ápices arredondados, obtusos. Frondes muito onduladas em toda a sua extensão. Algumas
\end{abstract} frondes de um mesmo espécime apresentam

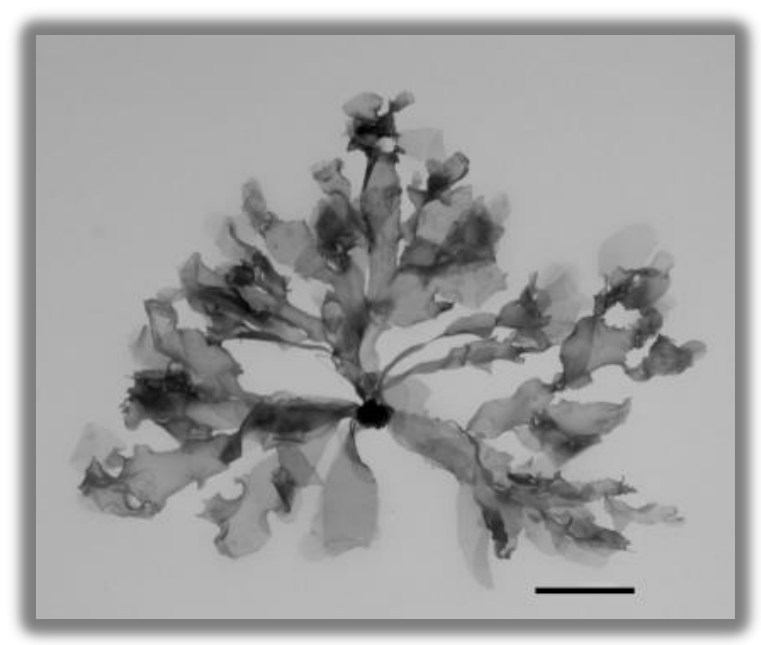

Figura 14. Aspecto geral. Barra de escala: $1 \mathrm{~cm}$. rugosidades. Abundantes proliferações superficiais, apicais e laterais. Margens levemente dilatadas, inteiras em alguns espécimes, e irregularmente e levemente denteadas em outros, visíveis apenas sob estereoscópio. Base cuneada. Nervura discreta. Estipe cilíndrico, de 0,5 $\mathrm{cm}$ de comprimento e $0,5 \mathrm{~mm}$ de diâmetro, ou ausente em alguns espécimes. Apressório discoide, com aproximadamente $1 \mathrm{~mm}$ de diâmetro.

Região Apical: Talo com 29-47,5 $\mu \mathrm{m}$ de espessura. Região cortical composta por uma camada de células de formato irregular, retangulares, quadráticas ou arredondadas, de 2-7 $\mu \mathrm{m}$ de altura e 4-8 $\mu \mathrm{m}$ de largura. Região subcortical não diferenciada, ou constituída por uma camada de células arredondadas, periclinalmente alongadas, de 8-10 $\mu \mathrm{m}$ de diâmetro, aparentemente não conectadas. Região medular muito frouxa, com aparência de vazia, com poucos filamentos periclinais de 2-3 $\mu \mathrm{m}$ de diâmetro. Células ganglionares presentes, imersas na região medular. Células estreladas não encontradas.

Região Mediana: Talo com 41-62 $\mu \mathrm{m}$ de espessura. Região cortical composta por 1-2 camadas de células de formato irregular, retangulares, quadráticas ou arredondadas, 
com 2-9 $\mu \mathrm{m}$ de altura e 2-10 $\mu \mathrm{m}$ de largura. Região subcortical constituída por uma camada não contínua de células alongadas, de 8-15 $\mu \mathrm{m}$ de diâmetro. Região medular muito estreita, com aparência de vazia, dificilmente diferenciada da região subcortical. A região medular apresenta células esféricas incolores, irregularmente distribuídas, e alguns filamentos periclinais de aproximadamente $5 \mu \mathrm{m}$ de diâmetro. Células ganglionares e estreladas não encontradas.

Região Basal: Talo com 95-167,5 $\mu \mathrm{m}$ de espessura. Região cortical composta por 3-4 camadas de células retangulares ou quadráticas, de 5-10 $\mu \mathrm{m}$ de altura e 7,5-15 $\mu \mathrm{m}$ de largura. Região subcortical pouco diferenciada, constituído por aproximadamente quatro camadas não contínuas de células alongadas, de 5-17,5 $\mu \mathrm{m}$ de diâmetro. Região medular bastante densa, com células incolores irregularmente distribuídas e filamentos longitudinais. Conteúdo granular esparso observado nas células das regiões cortical e subcortical. Células ganglionares e estreladas não encontradas.

Estruturas Reprodutivas: Cistocarpos visíveis a olho nu, formando protuberâncias em ambas as faces do talo. Em corte transversal, é possível observar o grande alargamento no talo causado pelos cistocarpos totalmente imersos. Cistocarpos com 212,5-270 $\mu \mathrm{m}$ de diâmetro. Pericarpo não diferenciado. Carposporângios de formatos variados, medindo aproximadamente 7,5-10 $\mu \mathrm{m}$ de largura. Na base do carposporófito há uma célula grande, provavelmente a célula de fusão, medindo $42,5 \mu \mathrm{m}$ de altura e $22,5 \mu \mathrm{m}$ de largura. A partir dessa célula partem minúsculos filamentos, que podem corresponder aos filamentos conectivos emitidos após a fertilização da célula auxiliar. Gametófitos masculinos e tetrasporófitos não observados.

\section{Material Examinado:}

Brasil, Bahia, Entre Rios, Praia de Subaúma, gametófito feminino, 27 de maio de 2013, C.A.A. Azevedo, T. Vieira-Pinto, B. Torrano-Silva (IBC 2180; IBC 2181 gametófito feminino; IBC 2182).

\section{Comentários:}


As árvores filogenéticas (Figuras 4 e 5) demonstram que "Cryptonemia” delicatula não pertence ao clado do gênero Cryptonemia, e que, portanto, essa entidade corresponde a um gênero distinto.

Durante as expedições de coleta realizadas neste estudo, a localidade-tipo da espécie (Praia do Lázaro, Ubatuba, São Paulo) foi visitada, porém não foram encontradas amostras. Os espécimes de "Cryptonemia" delicatula encontrados neste estudo estão de acordo com as descrições de Joly et al. (1965a), Pinheiro-Joventino (1977) e Guimarães (1990). O material examinado por esses autores apresenta margens lisas, enquanto que neste estudo foram observadas tanto margens lisas quanto levemente denteadas, em indivíduos diferentes. Guimarães (1990) descreve a presença de uma nervura tênue na base da fronde, a qual foi encontrada nos espécimes incluídos neste estudo.

Os estudos previamente citados não relatam uma distinção entre região cortical e subcortical, nem a presença de conteúdo granular nas células corticais encontrado neste estudo. Os indivíduos aqui analisados apresentam região subcortical composta por uma camada não contínua de células, dificilmente distinguida da região cortical. Células estreladas também não foram mencionadas, assim como neste estudo.

A descrição original de Joly et al. (1965a) cita a presença de filamentos altamente refringentes dispostos irregularmente na região medular, mas os autores dizem que não encontraram células ganglionares. Pinheiro-Joventino (1977) descreve que as células ganglionares são visíveis apenas em material dissociado. No entanto, neste estudo foi possível observar tais estruturas em cortes transversais na região apical, assim como Guimarães (1990), que encontrou filamentos e células ganglionares em cortes transversais e longitudinais. Os raros filamentos medulares longitudinais encontrados por Guimarães (1990) foram observados apenas na região basal das frondes neste estudo.

Em relação às estruturas reprodutivas, a protuberância no talo causada pelo cistocarpo e o pericarpo não diferenciado já foram relatados na literatura (Joly et al. 1965a; Pinheiro-Joventino 1977; Guimarães 1990). Joly et al. (1965a) descrevem que os carposporângios são unidos pela base por uma grande célula retangular. Essa célula provavelmente corresponde à célula chamada neste estudo de célula de fusão.

Cryptonemia augustata (Setchell \& N.L.Gardner) E.Y.Dawson, cuja localidade-tipo é Baja California, no México, é uma espécie de talo membranoso assim como C. delicatula. 
$\mathrm{Na}$ descrição original, C. delicatula é diferenciada de C. augustata apenas pelo fato da última incluir indivíduos maiores (Joly et al. 1965a). Ao comparar a descrição original de C. augustata com os espécimes aqui encontrados, não é possível apontar nenhuma diferença morfológica significativa entre as duas entidades (Dawson 1954). No entanto, seria precipitado sugerir coespecificidade entre os dois táxons, uma vez que neste estudo não foram examinados representantes de $C$. augustata, além de não existirem sequências moleculares disponíveis para essa espécie.
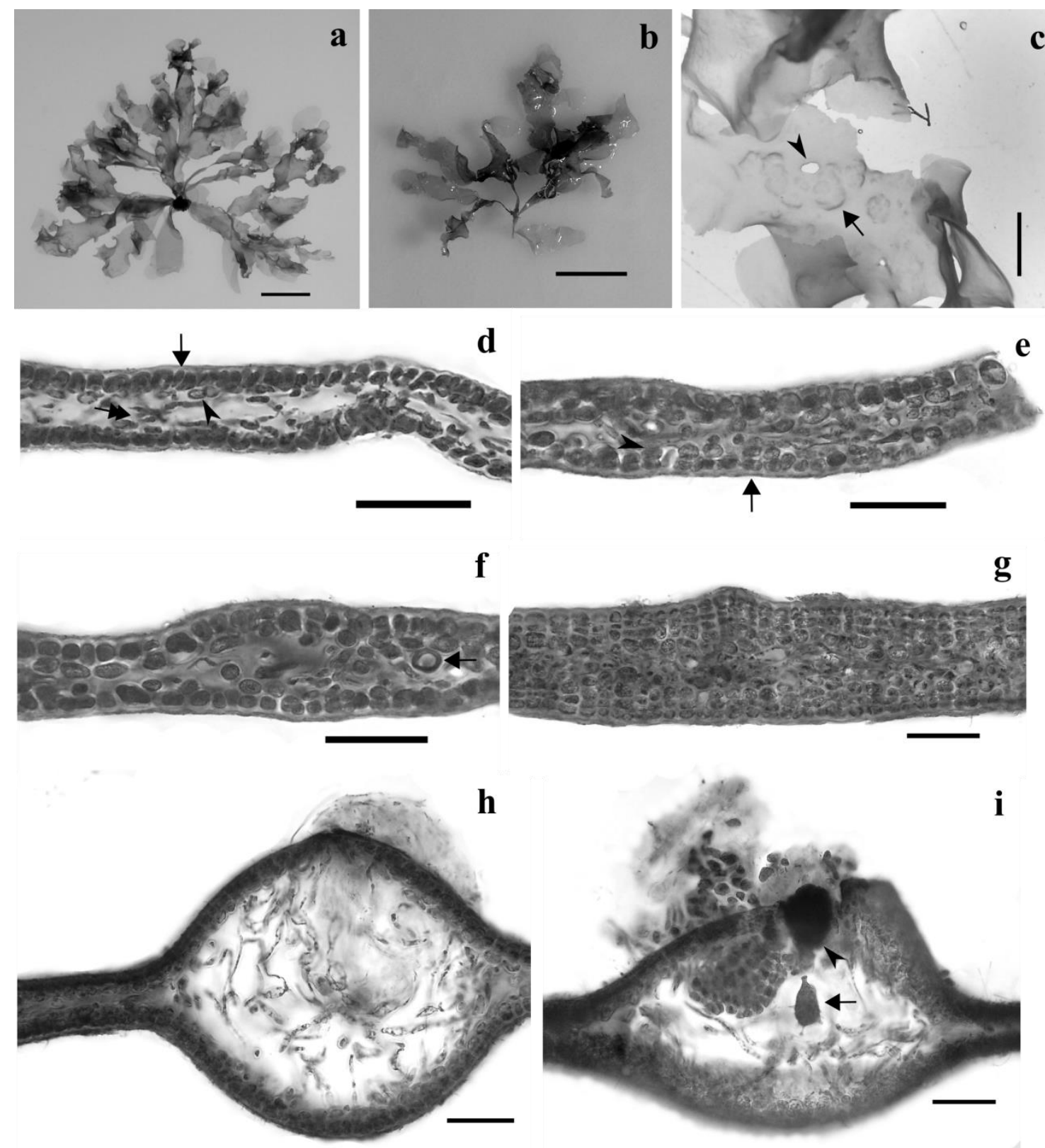

Figura 15. "Cryptonemia” delicatula. Anatomia vegetativa e reprodutiva. 
(a) Aspecto geral mostrando talo em forma de fitas que partem diretamente a partir do apressório. Barra de escala: $1 \mathrm{~cm}$ (IBC 2181);

(b) Aspecto geral mostrando talo em forma de fitas que partem a partir do estipe. Barra de escala: $1 \mathrm{~cm}$ (IBC 2182);

(c) Detalhe da superfície de uma fronde mostrando rugosidades semelhantes a bolhas (setas) e perfurações (ponta de seta). Barra de escala: 2 mm (IBC 2182);

(d) Corte transversal na região apical do talo. Seta, ponta de seta e seta dupla indicam célula da região cortical, célula da região subcortical e filamentos ganglionares, respectivamente. Barra de escala: $50 \mu \mathrm{m}$ (IBC 2182);

(e) Corte transversal na região mediana do talo mostrando conteúdo granular nas células da região cortical (seta) e região subcortical (ponta de seta). Barra de escala: $50 \mu \mathrm{m}$ (IBC 2182);

(f) Corte transversal na região mediana do talo. Seta indica célula incolor esférica imersa na região medular. Barra de escala: $50 \mu \mathrm{m}$ (IBC 2182);

(g) Corte transversal na região basal do talo, com conteúdo granular visível nas células do córtex e na região medular. Barra de escala: $50 \mu \mathrm{m}$ (IBC 2182);

(h) Corte transversal na região mediana do talo mostrando protuberância causada pelo cistocarpo (o cistocarpo acidentalmente saiu de dentro do talo durante o corte). Barra de escala: $50 \mu \mathrm{m}$ (IBC 2181);

(i) Corte transversal na região mediana do talo mostrando grande célula de fusão (seta) abaixo do gonimoblasto (ponta de seta). Barra de escala: $50 \mu \mathrm{m}$ (IBC 2181). 


\section{Complexo Cryptonemia seminervis (C.Agardh) J.Agardh}

\section{Do latim semi: parcialmente + nervis : com veias.}

\section{Localidade-tipo: Espanha, Bahia de Cádiz.}

O táxon Cryptonemia seminervis foi frequentemente referido para o litoral brasileiro como Cryptonemia luxurians, cuja localidade-tipo é o Brasil. Porém, alguns autores reconhecem C.luxurians como sinônimo de C. seminervis (Price et al. 1986; Guimarães 2006; Dawes \& Mathieson 2008). Indivíduos morfologicamente atribuídos a esse táxon foram obtidos neste estudo.

No agrupamento de UPA (Figura 2) e na filogenia inferida a partir do gene $r b c \mathrm{~L}$ (Figura 4), é possível verificar a existência de três linhagens distintas compostas por amostras que morfologicamente correspondem a $C$. seminervis. Uma das linhagens é composta por representantes provenientes das regiões Nordeste e Sudeste, enquanto que as outras duas incluem exemplares coletados na região Sudeste, no estado do Rio de Janeiro. Assim como observado para C. crenulata, C. seminervis é possivelmente um complexo de espécies crípticas.

Em relação ao marcador UPA, a divergência entre Cryptonemia seminervis $1 \mathrm{e}$ Cryptonemia seminervis 2 é de 0,8-1,1\%. Entre Cryptonemia seminervis 1 e Cryptonemia seminervis 3, o valor é de 1,1\%, enquanto que entre Cryptonemia seminervis 2 e Cryptonemia seminervis 3, a divergência é de $0,8 \%$.

Os valores de divergência para o $r b c \mathrm{~L}$ são apresentados na Tabela 9. As divergências intraespecíficas são 0,1-1,8\%, 0,0 e 0,5\% para Cryptonemia seminervis 1, Cryptonemia seminervis 2 e Cryptonemia seminervis 3, respectivamente. As divergências interespecíficas entre as linhagens são: (i) Cryptonemia seminervis 1 e Cryptonemia seminervis 2: 2,0-2,9\%; (ii) Cryptonemia seminervis 1 e Cryptonemia seminervis 3: 2,33,6\%; (iii) Cryptonemia seminervis 2 e Cryptonemia seminervis 3: 0,9-1,3\%. 
Tabela 9. Valores de divergência de $r b c \mathrm{~L}$ para amostras de Cryptonemia seminervis.

\begin{tabular}{|c|c|c|c|c|c|c|c|c|c|c|c|}
\hline & & & $\begin{array}{l}\text { IBC } \\
0295 \\
\end{array}$ & $\begin{array}{c}\text { IBC } \\
2055 \\
\end{array}$ & $\begin{array}{l}\text { IBC } \\
2110\end{array}$ & $\begin{array}{l}\text { IBC } \\
2170\end{array}$ & $\begin{array}{c}\text { IBC } \\
2173 \\
\end{array}$ & $\begin{array}{l}\text { IBC } \\
2194 \\
\end{array}$ & $\begin{array}{c}\text { IBC } \\
2222 \\
\end{array}$ & $\begin{array}{c}\text { IBC } \\
2195\end{array}$ & $\begin{array}{l}\text { IBC } \\
2221 \\
\end{array}$ \\
\hline \multirow{5}{*}{ i } & \multirow{5}{*}{ C. seminervis 1} & IBC 0295 & & & & & & & & & \\
\hline & & IBC 2055 & 1,8 & & & & & & & & \\
\hline & & IBC 2110 & 0,9 & 1,2 & & & & & & & \\
\hline & & IBC 2170 & 0,9 & 1,3 & 0,2 & & & & & & \\
\hline & & IBC 2173 & 0,9 & 1,2 & 0,1 & 0,1 & & & & & \\
\hline \multirow{2}{*}{ ii } & \multirow{2}{*}{ C. seminervis 2} & IBC 2194 & 2,8 & 2,8 & 2,0 & 2,2 & 2,1 & & & & \\
\hline & & IBC 2222 & 2,8 & 2,9 & 2,0 & 2,2 & 2,0 & 0,0 & & & \\
\hline \multirow{2}{*}{ iii } & \multirow{2}{*}{ C. seminervis 3} & IBC 2195 & 3,6 & 3,5 & 2,7 & 2,2 & 2,8 & 1,3 & 1,3 & & \\
\hline & & IBC 2221 & 3,2 & 3,3 & 2,3 & 2,6 & 2,4 & 0,9 & 0,9 & 0,5 & \\
\hline
\end{tabular}

Morfologicamente, não é possível apontar nenhuma diferença consistente entre os três táxons, uma vez que há uma sobreposição das características. Externamente, Cryptonemia seminervis 1 pode apresentar tanto talos levemente quanto intensamente ondulados, enquanto que Cryptonemia seminervis 2 inclui indivíduos de fronde bastante retorcida e ondulada. Os representantes de Cryptonemia seminervis 3, assim como Cryptonemia seminervis 1, podem ser lisos ou ondulados e retorcidos. Internamente, a estrutura é a mesma nos três táxons.

Não foi possível comparar molecularmente o material brasileiro com material da localidade-tipo, devido à inexistência de sequências deste último nos bancos de dados. É necessário realizar estudos moleculares e morfológicos mais detalhados para delimitar $C$. seminervis e $C$. luxurians. Caso seja comprovada a distinção entre esses dois táxons, o nome Cryptonemia luxurians teria que ser ressuscitado para acomodar uma das linhagens de $C$. seminervis observadas na costa do Brasil. De acordo com nosso conhecimento, esta é a primeira vez que o táxon é citado para o estado de Alagoas. 


\section{Cryptonemia seminervis 1}

Figs 16 e 17

Aspecto Geral: Talo de cor vermelha escura, firme, não mucilaginoso. Talo com até $23 \mathrm{~cm}$ de altura e frondes com até $2 \mathrm{~cm}$ de largura. Frondes em forma de fitas levemente ou intensamente onduladas, algumas retorcidas. Margens lisas em alguns espécimes ou com proliferações em outros. Ápices arredondados, com abundantes proliferações. Nervura em toda a sua extensão alcançando até a distância de $1 \mathrm{~cm}$ do ápice.

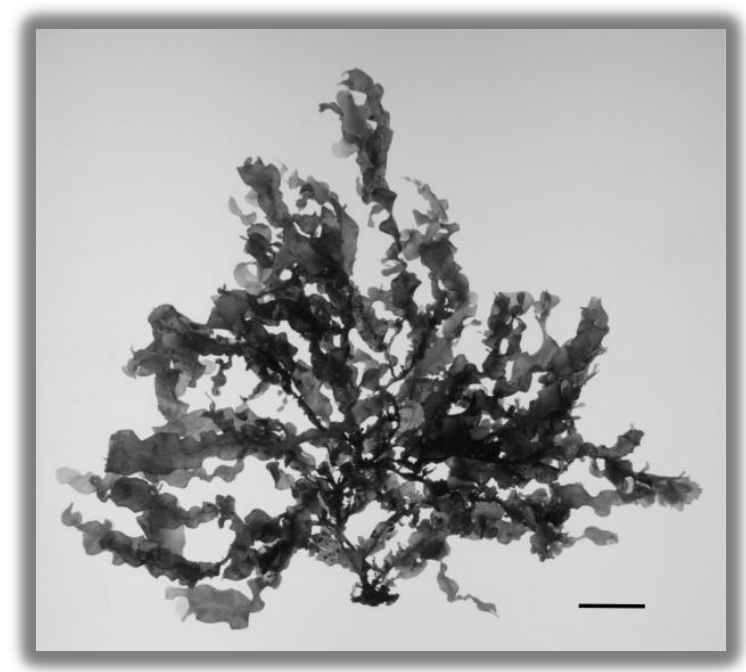

Figura 16. Aspecto geral. Barra de escala: $2 \mathrm{~cm}$. Proliferações estipitadas abundantes em ambas as faces do talo e também sobre a nervura. Ramificação irregular abundante. Estipe cilíndrico, robusto, com 0,5-2 cm de comprimento e 1-2 mm de diâmetro. Apressório discoide, com $2 \mathrm{~mm}$ de diâmetro.

Região Apical: Talo com 67,2-125 $\mu \mathrm{m}$ de espessura. Região cortical composta por uma camada de células retangulares, de 9-10 $\mu \mathrm{m}$ de altura e 2-5 $\mu \mathrm{m}$ de largura. Região subcortical constituída por 2-3 camadas de células esféricas ou periclinamente alongadas, de 4-10 $\mu \mathrm{m}$ de diâmetro ou largura. Região medular com filamentos periclinais e longitudinais, de 2-3 $\mu \mathrm{m}$ de diâmetro. Células ganglionares abundantes, orientadas paralelamente ao córtex. Células estreladas presentes, com 11-15 $\mu \mathrm{m}$ de largura.

Região Mediana: Talo com espessura de 95-135,8 $\mu$ m nas lâminas, e 223,1-440 $\mu \mathrm{m}$ na região da nervura. Bordas das lâminas dilatadas. Região cortical composta por 1-2 camadas de células quadráticas ou retangulares, de 5-10 $\mu \mathrm{m}$ de altura e 5-7,5 $\mu \mathrm{m}$ de largura. Região subcortical constituída por 2-3 camadas de células esféricas ou periclinalmente alongadas, de 5-22,5 $\mu \mathrm{m}$ de diâmetro. Região medular preenchida por densos filamentos longitudinais e periclinais, de 2,5-7,5 $\mu \mathrm{m}$ de diâmetro. Células ganglionares presentes, porém em menor número e menos evidentes que na região apical.

Região Basal: Talo com 65-100 $\mu \mathrm{m}$ de espessura na lâmina, e 400-480 $\mu \mathrm{m}$ na nervura. Região cortical composta por uma camada de células quadráticas, de 5-7,5 $\mu \mathrm{m}$ de 
altura e 5-7,5 $\mu \mathrm{m}$ de largura. Região subcortical constituída por células arredondadas, de 7,5-10 $\mu \mathrm{m}$ de diâmetro. Região medular muito densa e preenchida por filamentos longitudinais de 5-7,5 $\mu \mathrm{m}$ de diâmetro. Células ganglionares presentes, porém menos evidentes que na região mediana.

Estruturas Reprodutivas: Não observadas.

\section{Material examinado:}

Brasil, Ceará, Icapuí, Praia de Ponta Grossa, 27 de abril de 2013, C.A.A. Azevedo e T. Vieira-Pinto (IBC 2152). Caucaia, Praia do Pacheco, 26 de abril de 2013, C.A.A. Azevedo, P.B. Carneiro, T. Vieira-Pinto e B. Torrano-Silva (IBC 2146). Paracuru, Praia de Munguba, 24 de abril de 2013, C.A.A. Azevedo, T. Vieira-Pinto e B. Torrano-Silva (IBC 2119; IBC 2123). Paraíba, Conde, Praia de Tambaba, 23 de julho de 2012, C.A.A. Azevedo e F. Nauer (IBC 2052; SPF 57797/IBC 2055). Conde, Praia de Tabatinga, 21 de julho de 2012, C.A.A. Azevedo, F. Nauer e R. Perez (IBC 2047; IBC 2050). Conde, Praia de Carapibus, 20 de julho de 2012, C.A.A. Azevedo e F. Nauer (IBC 2041). Bahia, Camaçari, Praia de Jauá, 22 de maio de 2013, C.A.A. Azevedo, T. Vieira-Pinto, B. Torrano-Silva e M. Jamas (IBC 2170; IBC 2173). Salvador, Praia de Stella Maris, 22 de maio de 2013, C.A.A. Azevedo e T. Vieira-Pinto. (IBC 2159; IBC 2160). Santa Cruz Cabrália, Praia de Tartarugas, C.A.A. Azevedo e F. Nauer (IBC 2070; IBC 2071). Santa Cruz Cabrália, Praia de Apuã, 17 de setembro de 2012, C.A.A. Azevedo e F. Nauer (IBC 2072; IBC 2076; IBC 2078). Vera Cruz, Ilha de Itaparica, Praia da Coroa, 23 de maio de 2013, C.A.A. Azevedo, T. Vieira-Pinto, B. Torrano-Silva e M. Jamas (IBC 2173). Espírito Santo, Marataízes, Praia da Cruz, 07 de maio de 2012, M.C. Oliveira. Rio de Janeiro, Armação dos Búzios, Praia Rasa, 08 de março de 2015, C.A.A. Azevedo, V. Cassano e M. Mungioli (IBC 2219; IBC 2220).

\section{Comentários:}

O exemplar IBC 0295, coletado no ES, seria identificado como Cryptonemia guaymasensis (E.Y.Dawson) E.Y.Dawson seguindo Pinheiro-Joventino (1977). O exemplar coletado neste estudo é pequeno $(5,5 \mathrm{~cm})$ e apresenta nervura restrita à base e ápices arredondados. Todos os demais aspectos (número de camadas corticais, medidas de células, 
disposição dos filamentos medulares e presença de células ganglionares) concordam com C. seminervis. A filogenia (Figura 4) mostra esse espécime inserido em um clado com outras amostras identificadas como C. seminervis.

Pinheiro-Joventino (1977) foi a primeira a citar C. guaymasensis para a costa brasileira, seguida por Oliveira Filho (1977), Guimarães (1990) e Creed et al. (2015), para os estados do Ceará, Espírito Santo, Rio de Janeiro e São Paulo. Cryptonemia guaymasensis foi descrita por Dawson (1954) e sua localidade-tipo é o Pacífico Mexicano. No entanto, Lewis (1990) propôs a sinonimização de C. guaymasensis com Cryptonemia limensis, cuja localidade-tipo é o Peru.

Pinheiro-Joventino (1977) distingue Cryptonemia guaymasensis de C. seminervis (como C. luxurians) pelo menor tamanho (até $5 \mathrm{~cm}$ ) e pela nervura pouco evidente e restrita à base na primeira, enquanto que na segunda, ocorrem plantas maiores (até $28 \mathrm{~cm}$ ) e a nervura é muito evidente e está presente em toda a extensão to talo, quase alcançando o ápice. Segundo a descrição de Dawson (1954), Cryptonemia guaymasensis ocorre tanto no mesolitoral quanto no infralitoral, sendo que nas plantas do mesolitoral existe uma nervura na região basal que às vezes alcança a altura da primeira dicotomia, enquanto que no material de infralitoral a nervura é indiferenciada ou ausente. $\mathrm{O}$ material aqui encontrado concorda com Dawson (1954) em relação à nervura. As frondes são predominantemente não ramificadas, mas algumas apresentam dicotomia, concordando também com Dawson (1954).

Nós incluímos na filogenia de $r b c \mathrm{~L}$ (Figura 4), uma sequência identificada como Cryptonemia limensis que foi coletada na localidade-tipo e gentilmente cedida por Martha Calderón (Chungnam National University, Daejeon, Coreia), juntamente com imagens de exsicatas identificadas pela mesma. No entanto, o material de herbário apresenta ápices agudos, distintos dos ápices obtusos e arredondados descritos para Cryptonemia limensis. Nós suspeitamos que essa identificação possa estar equivocada. De qualquer maneira, essa sequência não agrupa com nenhuma amostra coletada no litoral brasileiro, o que nos sugere que os registros de Cryptonemia guaymasensis e Cryptonemia limensis para a costa do Brasil também são identificações equivocadas. 

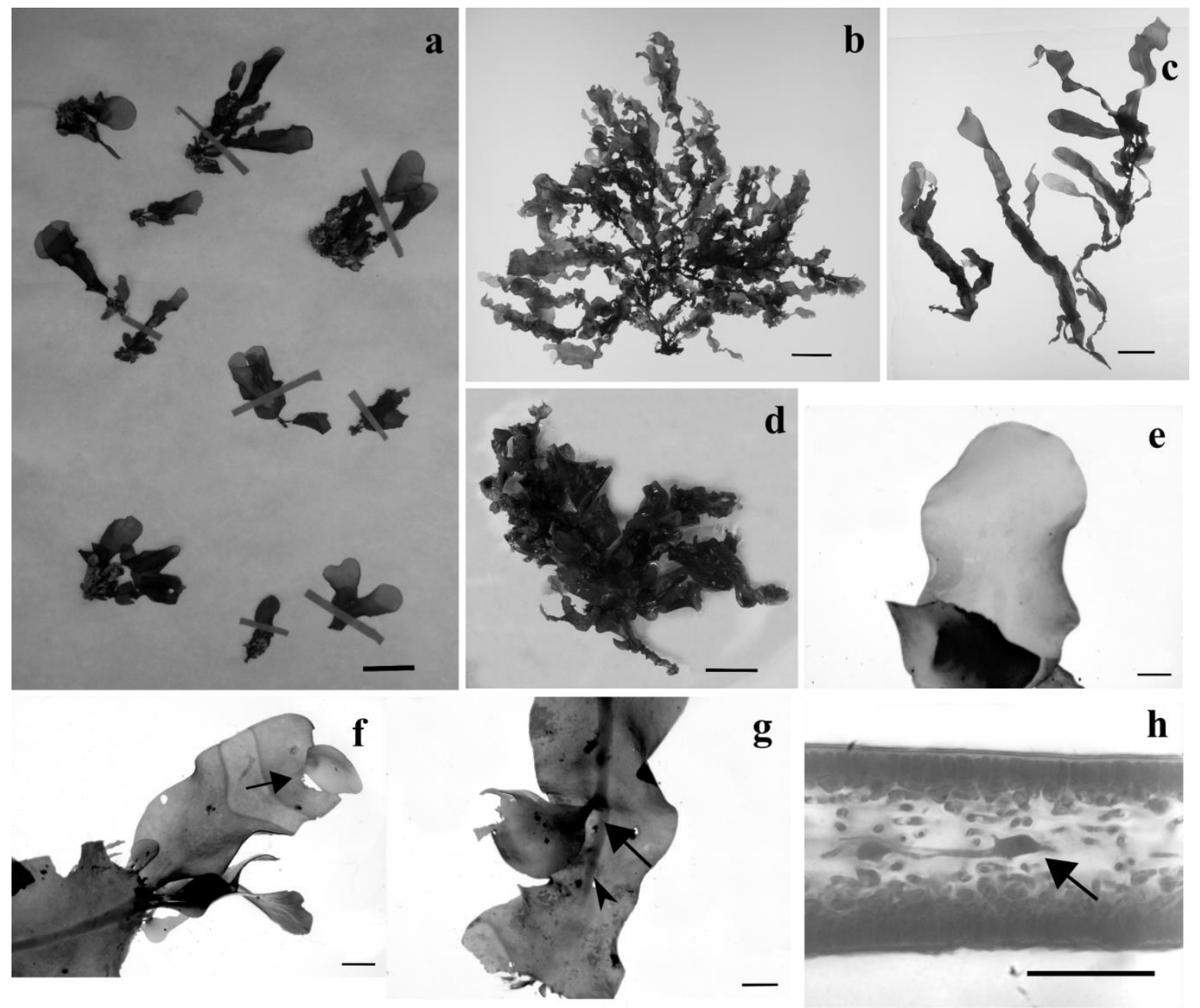

e

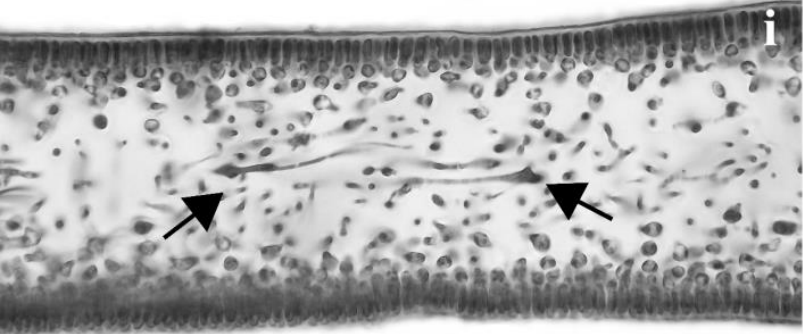

g

h
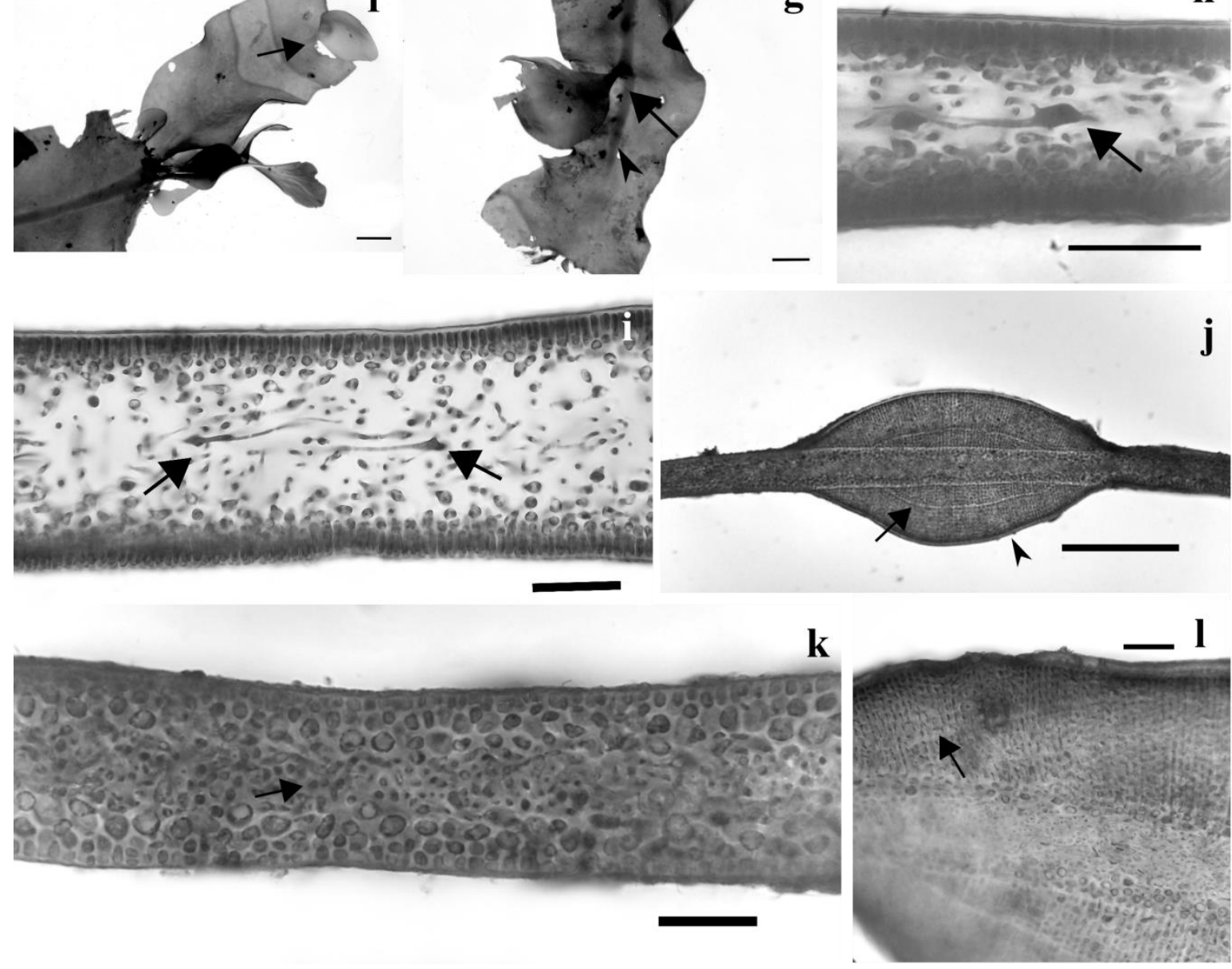

Figura 17. Cryptonemia seminervis 1. Anatomia vegetativa. 
(a) Aspecto geral. Barra de escala: $2 \mathrm{~cm}$ (IBC 0295);

(b) Aspecto geral. Barra de escala: $2 \mathrm{~cm}$ (IBC 2170);

(c) Aspecto geral. Barra de escala: $2 \mathrm{~cm}$ (IBC 2055);

(d) Aspecto geral. Barra de escala: $2 \mathrm{~cm}$ (IBC 2070);

(e) Detalhe mostrando ápice arredondado. Barra de escala: $2 \mathrm{~mm}$ (IBC 2170);

(f) Detalhe mostrando proliferação apical (seta). Barra de escala: 2 mm (IBC 2170);

(g) Detalhe mostrando proliferação superficial estipitada (seta) sobre a nervura (ponta de seta). Barra de escala: $2 \mathrm{~mm}$ (IBC 2170);

(h) Corte transversal na região apical do talo mostrando célula ganglionar (seta). Barra de escala: $50 \mu \mathrm{m}$ (IBC 2170);

(i) Corte transversal na região apical do talo mostrando filamentos ganglionares (setas). Barra de escala: 50 $\mu \mathrm{m}($ IBC 2055);

(j) Corte transversal na região mediana do talo mostrando corticação secundária (seta) e nervura (ponta de seta). Barra de escala: $300 \mu \mathrm{m}$ (IBC 2170);

(k) Corte transversal na região mediana do talo. Seta aponta filamentos medulares longitudinais. Barra de escala: $50 \mu \mathrm{m}$ (IBC 2170);

(1) Corte transversal na região basal do talo. Seta aponta nervura. Barra de escala: $50 \mu \mathrm{m}$ (IBC 0295). 


\section{Cryptonemia seminervis 2}

Figs 18 e 20

Aspecto Geral: Talo de cor vermelha, não mucilaginoso, firme e rígido. Frondes em forma de fitas bastante retorcidas e onduladas, com altura de $14 \mathrm{~cm}$ e largura de 0,8 cm. Ápices arredondados, com proliferações. Região basal alada. Ramificação irregular, dicotômica em algumas porções, alternada em outras. Nervura muito conspícua, que parte da base e alcança até aproximadamente $1 \mathrm{~cm}$ de distância do ápice. Estipe cilíndrico, com 0,5

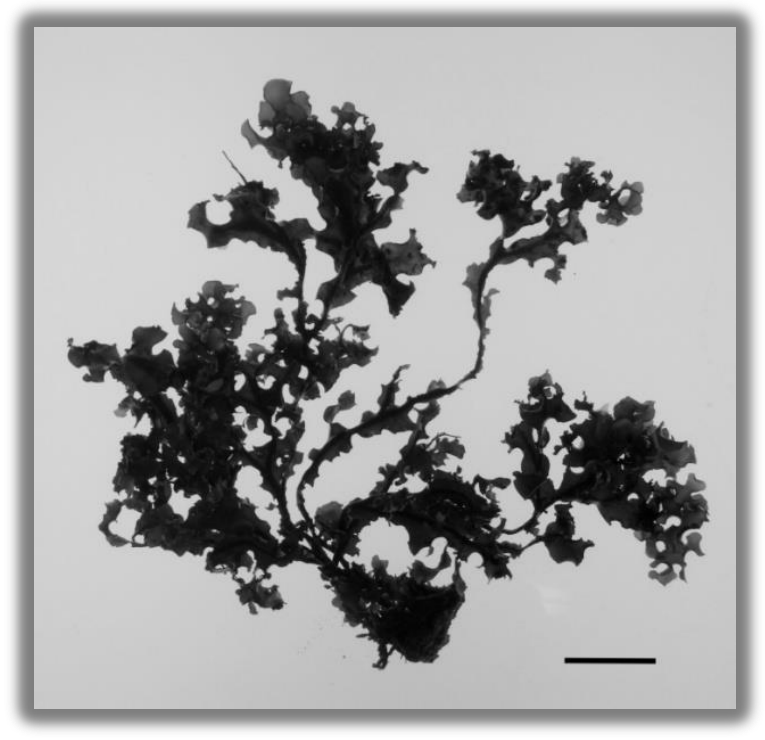

Figura 18. Aspecto geral. Barra de escala: $2 \mathrm{~cm}$ $\mathrm{cm}$ de comprimento e 1,5 mm de diâmetro. Apressório discoide, com 1,5 mm de diâmetro. Proliferações superficiais não foram encontradas.

Região Apical: Talo com 97,5-105 $\mu \mathrm{m}$ de espessura. Região cortical composta por uma camada de células quadráticas, de $5 \mu \mathrm{m}$ de altura e 2,5 $\mu \mathrm{m}$ de largura. Região subcortical constituída por 3-4 camadas de células arredondadas ou alongadas, de 5-9 $\mu \mathrm{m}$ de diâmetro. Região medular com filamentos periclinais, de 2-3 $\mu \mathrm{m}$ de diâmetro. Células ganglionares e estreladas não encontradas.

Região Mediana: Talo com 122,5-147,5 $\mu \mathrm{m}$ de espessura na lâmina e 770-790 $\mu \mathrm{m}$ na nervura. Região cortical composta por 1-2 camadas de células quadráticas ou retangulares, de 5-7,5 $\mu \mathrm{m}$ de altura e 2,5-5 $\mu \mathrm{m}$ de largura. Região subcortical constituída por 4-5 camadas de células arredondadas, de 4-14 $\mu \mathrm{m}$ de diâmetro, menores perto da região cortical e que aumentam de tamanho em direção à região medular. Região medular bastante densa, compacta. Poucas células ganglionares, pequenas e de conteúdo discreto. Células estreladas não encontradas.

Região Basal: Espessura de 1700-1875 $\mu \mathrm{m}$. Corticação secundária bastante desenvolvida, com anéis de crescimento.

Estruturas Reprodutivas: Não observadas. 


\section{Material Examinado:}

Brasil, Rio de Janeiro, Armação dos Búzios, Praia da Foca, infértil, 15 de março de 2014, C.A.A. Azevedo, V. Cassano e M. Mungioli (SPF 57776/IBC 2194; IBC 2224; IBC 2225). Praia da Ferradurinha, 09 de março de 2015, C.A.A. Azevedo, V. Cassano e M. Mungioli (IBC 2222). Cabo Frio, Ilha do Vigia, 07 de março de 2015, C.A.A. Azevedo, V. Cassano e M. Mungioli (IBC 2215). 


\section{Cryptonemia seminervis 3 (C.Agardh) J.Agardh}

Figs. 19 e 20

\section{Aspecto Geral: Talo de cor} vermelha, firme, não mucilaginoso. Frondes em forma de fitas onduladas e retorcidas, com altura de até $5,7 \mathrm{~cm} \mathrm{e}$ largura de até $1,2 \mathrm{~cm}$. Ápices arredondados. Margens levemente denteadas ou lisas. Ramificação predominantemente dicotômica, mas também com algumas ramificações laterais. Nervura parte da base e alcança a região mediana, até a distância de $3 \mathrm{~cm}$ da

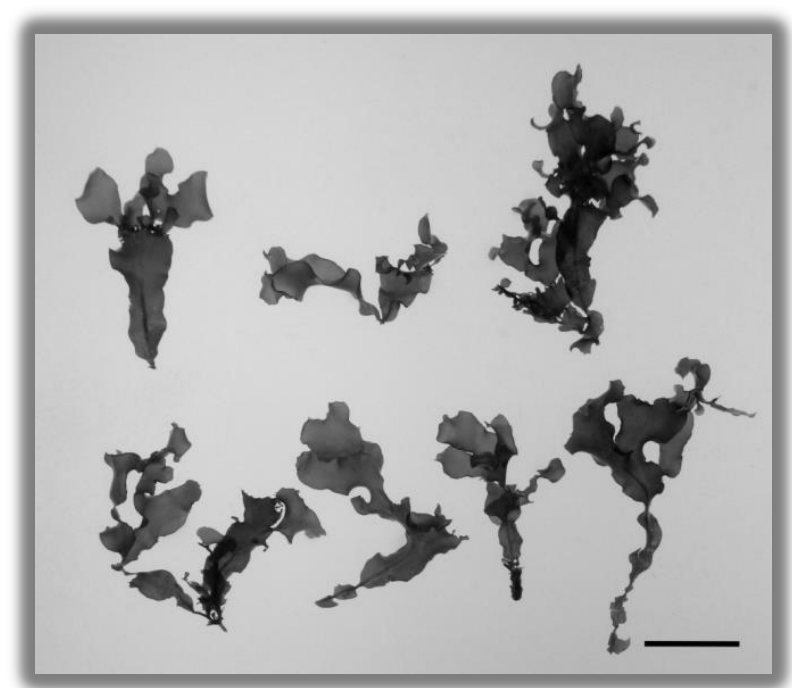

Figura 20. Aspecto geral. Barra de escala: $2 \mathrm{~cm}$ base em alguns espécimes, ou até aproximadamente $0,5 \mathrm{~cm}$ do ápice em outros. Estipe cilíndrico, com até $0,5 \mathrm{~cm}$ de comprimento e $1 \mathrm{~mm}$ de diâmetro. Proliferações superficiais ao longo da nervura podem ocorrer em alguns exemplares. Algumas proliferações foram observadas em porções aparentemente danificadas do talo. Proliferações marginais não observadas.

Região Apical: Talo com 100-115 $\mu \mathrm{m}$ de espessura. Região cortical composta por uma camada de células retangulares, de 7,5-10 $\mu \mathrm{m}$ de altura e 2,5-5 $\mu \mathrm{m}$ de largura. Região subcortical constituída por 1-2 camadas de células esféricas, de 5-7,5 $\mu \mathrm{m}$ de diâmetro. Região medular frouxa, com filamentos periclinais e alguns longitudinais. Células ganglionares grandes e abundantes. Células estreladas não encontradas.

Região Mediana: Talo com 137,5-177,5 $\mu \mathrm{m}$ de espessura na lâmina e 480-510 $\mu \mathrm{m}$ na nervura. Região cortical composta por 1-2 camadas de células quadráticas ou retangulares, de 2,5-5 $\mu \mathrm{m}$ de altura e 2,5 $\mu \mathrm{m}$ de largura. Região subcortical constituída por 3-4 camadas de células esféricas ou periclinalmente alongadas, de 5-20 $\mu \mathrm{m}$ de diâmetro, menores perto da região cortical e que aumentam de tamanho em direção à região medular. Região medular bastante densa, compacta. Poucas células ganglionares, pequenas e de 
conteúdo discreto, menos abundantes que na região apical. Células estreladas não encontradas.

Região Basal: Talo com 60-85 $\mu \mathrm{m}$ de espessura na lâmina e 600-660 $\mu \mathrm{m}$ na nervura. Região cortical com 1-2 camadas de células quadráticas ou mais largas que altas, com 2,5 $\mu \mathrm{m}$ de altura e 2,5-5 $\mu \mathrm{m}$ de largura. Região subcortical com células esféricas ou periclinalmente alongadas, de 5-15 $\mu \mathrm{m}$ de diâmetro. Região medular bastante densa, dificilmente distinguida da região subcortical, composta por pequenas células esféricas de 2,5 $\mu \mathrm{m}$ de diâmetro. Poucos filamentos ganglionares, discretos. Células estreladas não encontradas.

Estruturas Reprodutivas: Não observadas.

\section{Material Examinado:}

Brasil, Rio de Janeiro, Armação dos Búzios, Praia da Foca, 14 de março de 2014, C.A.A. Azevedo, V. Cassano e M. Mungioli (IBC 2195/SPF 57777 - infértil). Armação dos Búzios, Praia da Ferradurinha, 09 de março de 2015, C.A.A. Azevedo, V. Cassano e M. Mungioli (IBC 2221 - infértil). Cabo Frio, Ilha do Vigia, 07 de março de 2015, C.A.A. Azevedo, V. Cassano e M. Mungioli (IBC 2216 e IBC 2217 - inférteis). 

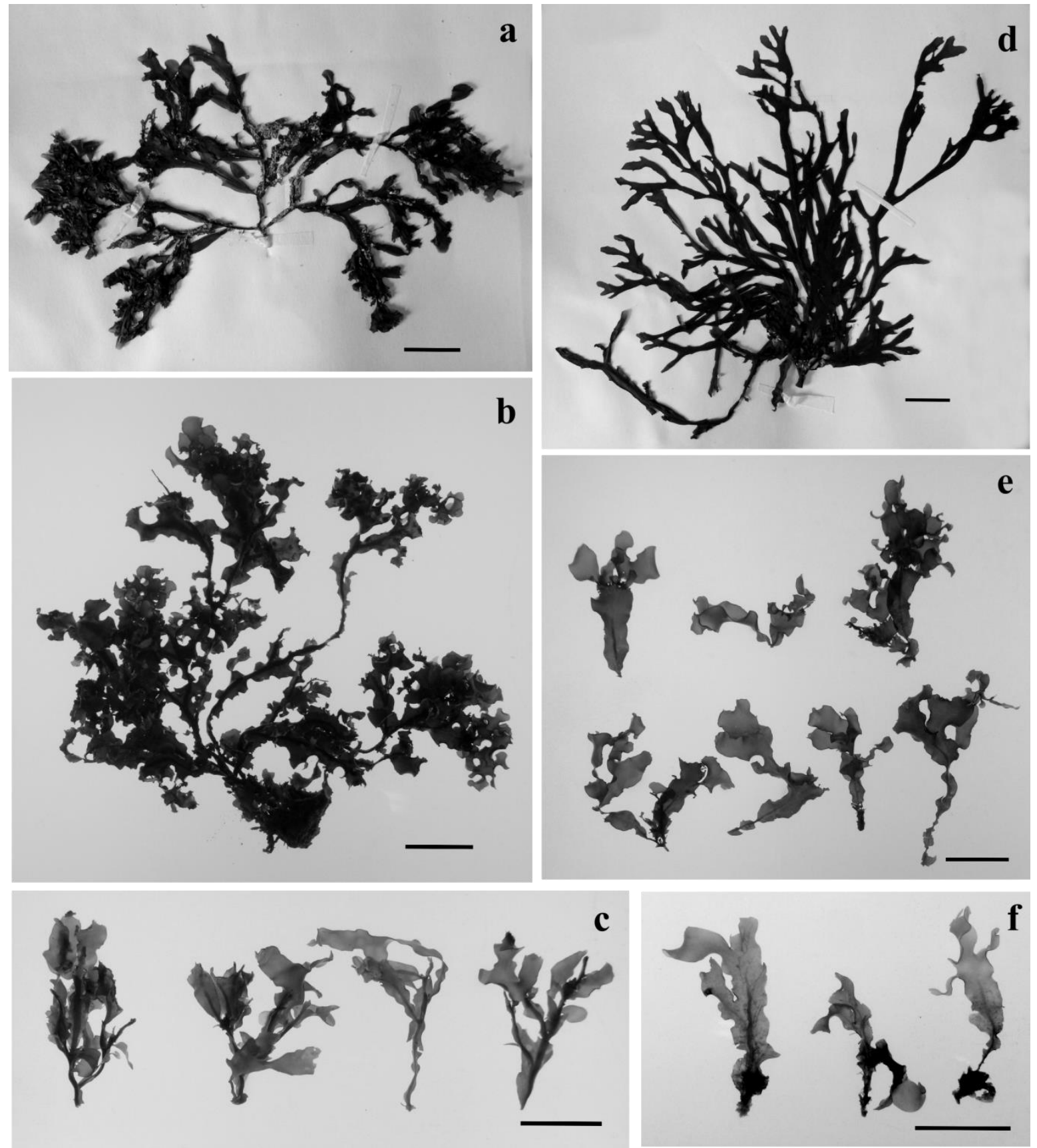

Figura 20. Cryptonemia seminervis 2 (a-c) e Cryptonemia seminervis 3 (d-f). Variação e convergência morfológica.
(a) Aspecto geral. Barra de escala: $2 \mathrm{~cm}$ (IBC 2194);
(b) Aspecto geral. Barra de escala: $2 \mathrm{~cm}$ (IBC 2222);
(c) Aspecto geral. Barra de escala: $2 \mathrm{~cm}$ (IBC 2225);
(d) Aspecto geral. Barra de escala: 2 cm (IBC 2195);
(e) Aspecto geral. Barra de escala: $2 \mathrm{~cm}$ (IBC 2221);
(f) Aspecto geral. Barra de escala: $2 \mathrm{~cm}$ (IBC 2216). 


\section{Halymenia C. Agardh}

\section{Do grego hals: o mar; hali: sal + humen: membrana. Espécie-tipo do gênero: Halymenia floresii (Clemente) C. Agardh}

O gênero Halymenia é caracterizado por apresentar talo cilíndrico ou achatado ou folioso, lanceolado a orbiculado, inteiro, fendido, bifurcado ou prolífero, distintamente estipitado. Consistência gelatinosa a firme. Região medular com poucos filamentos, predominantemente anticlinais. Filamentos estrelados de conteúdo normal entre região cortical e região medular. Filamentos refractivos formam células ganglionares de conteúdo refringente, imersos na região medular, orientados paralelamente à superfície do talo. Células corticais mais ou menos isodiamétricas, progressivamente menores em direção à cutícula. Espécies monoicas ou dioicas. Estruturas reprodutivas femininas em ampolas, com ramos de $3^{\mathrm{a}}$ e $4^{\mathrm{a}}$ ordem. Ramo carpogonial com duas células, intercalares em filamentos ampolares primários ou secundários. Filamentos conectivos partem diretamente do carpogônio fertilizado ou a partir de célula de fusão incluindo a célula hipógina, e conectam uma sucessão de células auxiliares em ampolas separadas. A inicial do gonimoblasto é direcionada à superfície do talo. Cistocarpo compacto, imerso e com muitos carposporângios pequenos. Pericarpo e ostíolo presentes. Espermatângios superficiais, cortados por paredes oblíquas, localizados em toda a fronde ou restritos às margens. Tetrasporófitos e gametófitos isomórficos. Tetrasporângios pequenos, cruciados, espalhados pelo córtex.

(Guiry \& Guiry 2016) 


\section{"Halymenia" elongata C. Agardh}

Figs 21 e 22

\section{Do latin elongata: longo, alongado.}

\section{Localidade-tipo: Espanha.}

Aspecto Geral: Talo de cor rosa, mucilaginoso e flácido. Frondes tubulares, cilíndrico-comprimidas, com até $14 \mathrm{~cm}$ de altura e até $1,3 \mathrm{~cm}$ de largura nas dicotomias. Ramificação dicotômica, até $7^{\mathrm{a}}$ ordem. Ápices afilados e bifurcados. Nervura ausente. Estipe cilíndrico, com $1 \mathrm{~cm}$ de comprimento e $3 \mathrm{~mm}$ de diâmetro. Apressório discoide, com 2 mm de diâmetro.

Região Apical: Região cortical com 1-

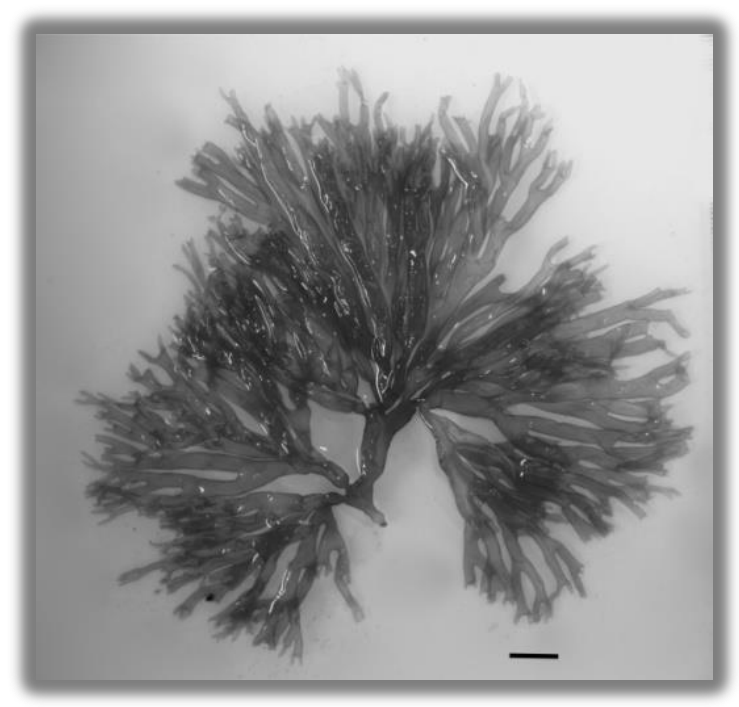

Figura 21. Aspecto geral. Barra de escala: $1 \mathrm{~cm}$ 2 camadas de células elipsoidais ou ovoides, de 3-5 $\mu \mathrm{m}$ de altura e 2-4 $\mu \mathrm{m}$ de largura. Região medular frouxa, com filamentos irregulares de 3-5 $\mu \mathrm{m}$ de diâmetro. Células ganglionares ausentes. Células estrelas com 17,5-27,5 $\mu \mathrm{m}$ de largura.

Região Mediana: Região cortical com 1-2 camadas de células elipsoidais ou ovoides, de 5-8 $\mu \mathrm{m}$ de altura e 3-4 $\mu \mathrm{m}$ de largura. Região subcortical com 1-2 camadas de células arredondadas, de 10-13 $\mu$ m de diâmetro. Região medular com filamentos irregulares de 3-5 $\mu \mathrm{m}$ de diâmetro. Células ganglionares ausentes. Células estreladas presentes, com 16-21 $\mu \mathrm{m}$ de largura.

Região Basal: Região cortical em vista superficial composto por células esféricas, elipsoidais ou ovoides, de 3-6 $\mu \mathrm{m}$ de diâmetro. Região medular com filamentos irregulares de 2-4 $\mu \mathrm{m}$ de diâmetro. Células ganglionares ausentes. Células estreladas com 37,5-55 $\mu \mathrm{m}$ de largura.

Estruturas Reprodutivas: Ampola da célula auxiliar ramificada irregularmente, composta por vários filamentos de células alongadas de aproximadamente $20 \mu \mathrm{m}$ de comprimento. Célula auxiliar ovoide, com 14-15 $\mu \mathrm{m}$ de altura e 11-12 $\mu \mathrm{m}$ de largura. 
Cistocarpos maduros visualizados nas regiões apical e mediana, com 112,5 $\mu \mathrm{m}$ de diâmetro. Gametófitos masculinos e tetrasporófitos não observados.

\section{Material examinado:}

Brasil, Ceará, Trairi, Praia de Guajiru, 25 de abril de 2013, C.A.A. Azevedo, T. Vieira-Pinto e B. Torrano-Silva. Rio Grande do Norte, Rio do Fogo, Praia de Rio do Fogo, 13 de janeiro de 2013, C.A.A. Azevedo e R.F. Menezes (SPF 57816/IBC 2095; SPF 57785/IBC 2094 - gametófito feminino). Espírito Santo, Anchieta, Iriri, $20 \mathrm{~m}$ de profundidade, 07 de abril de 2012, B. Torrano-Silva e C.E. Amâncio (IBC 2017).

\section{Comentários:}

Halymenia elongata foi diversas vezes citada para o litoral do Brasil, incluindo os estados do Ceará, Rio Grande do Norte, Paraíba, Pernambuco, Alagoas, Bahia, Espírito Santo, Rio de Janeiro, São Paulo e Santa Catarina (Oliveira Filho 1977). Muitas das citações são feitas sob o nome Halymenia agardhii De Toni, sendo Joly (1964) o primeiro autor a citar esse táxon para a costa brasileira. No entanto, atualmente $H$. agardhii é considerada sinônimo de Sebdenia flabellata (J.Agardh) P.G.Parkinson (Dawes \& Mathieson 2008).

O clado de "Halymenia" elongata está distantemente posicionado do clado que inclui a espécie-tipo do gênero, Halymenia floresii (Figuras 4 e 5). Além disso, esse táxon não apresenta relação próxima com nenhum outro gênero presente na análise filogenética, o que sugere que esses indivíduos representam um gênero distinto de Halymenia, possivelmente novo para a ciência. 

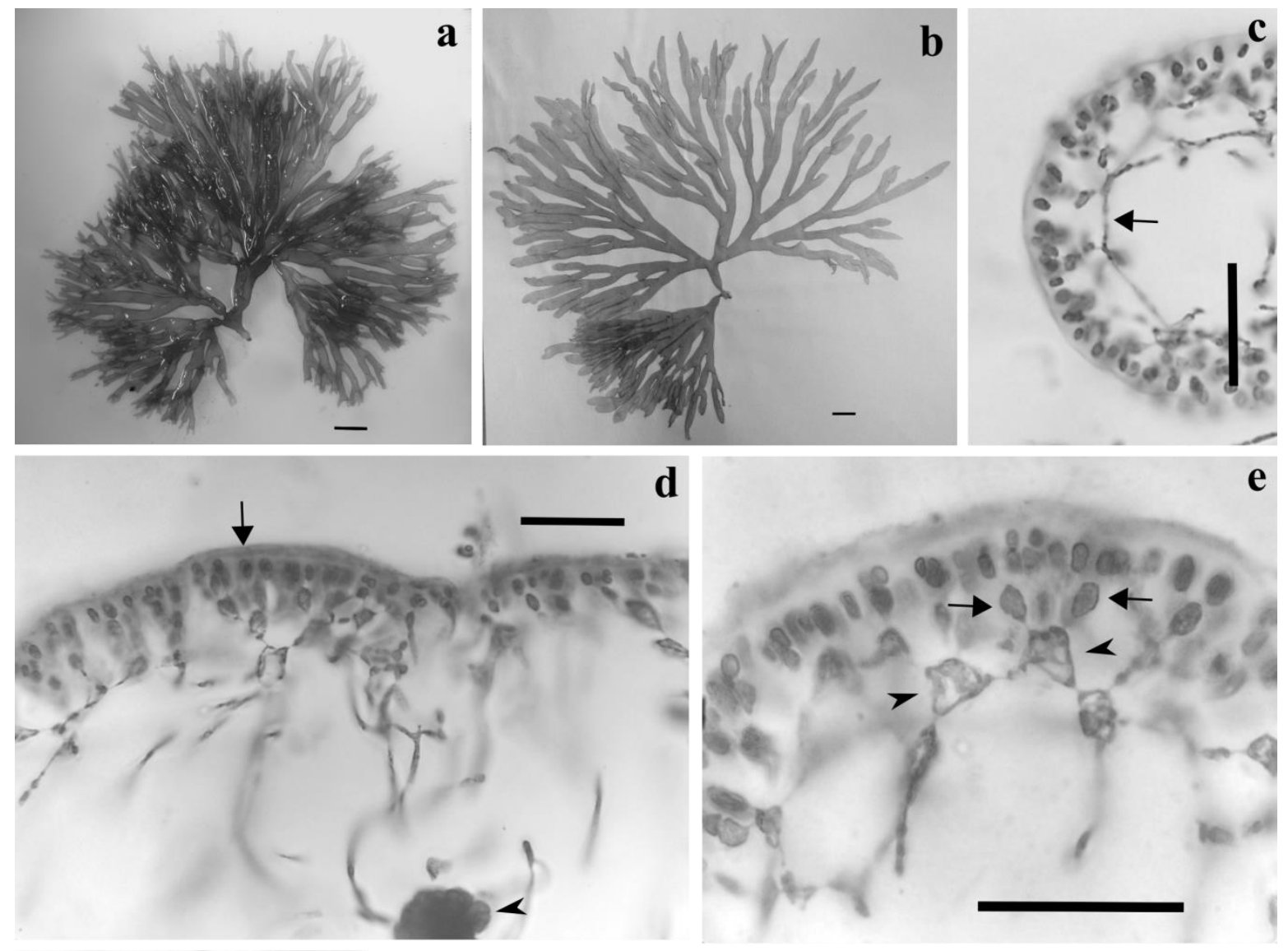

e
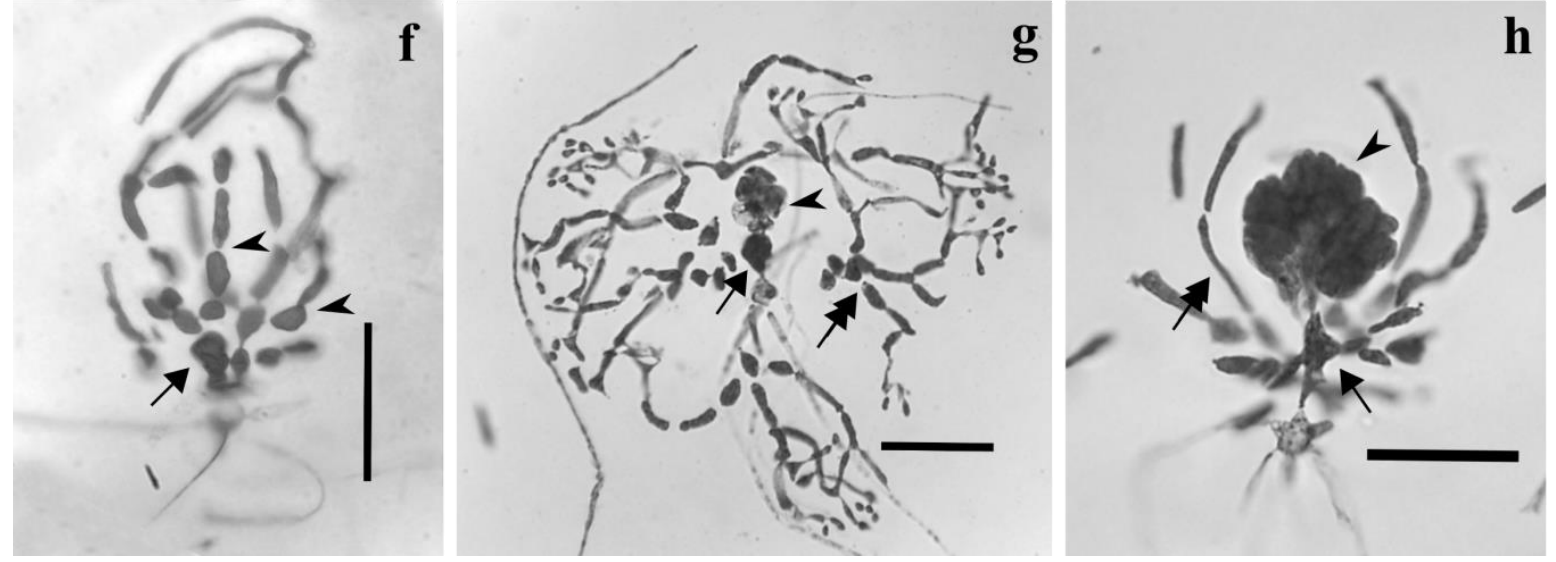

Figura 22. "Halymenia" elongata. Anatomia vegetativa e reprodutiva.

(a) Aspecto geral de "Halymenia" elongata. Barra de escala: $1 \mathrm{~cm}$ (IBC 2136);

(b) Aspecto geral de "Halymenia" elongata. Barra de escala: $1 \mathrm{~cm}$ (SPF 57785/IBC 2094);

(c) Corte transversal na região apical do talo. Seta indica filamento Região medularr. Barra de escala: $50 \mu \mathrm{m}$ (SPF 57785/IBC 2094);

(d) Corte transversal na região mediana do talo. Seta indica célula da região cortical, enquanto que ponta de seta indica parte do cistocarpo. Barra de escala: $50 \mu \mathrm{m}$ (SPF 57785/IBC 2094);

(e) Detalhe de corte transversal na região mediana mostrando células da região subcortical (setas) e células estreladas (pontas de seta). Barra de escala: 50 m (SPF 57785/IBC 2094); 
(f) Preparação de esmagamento na região apical mostrando ampola da célula auxiliar. Seta aponta célula auxiliar e pontas de seta indicam filamentos ampolares. Barra de escala: $50 \mu \mathrm{m}$ (SPF 57785/IBC 2094);

(g) Preparação de esmagamento na região apical mostrando cistocarpo em desenvolvimento. Seta, ponta de seta e seta dupla apontam, respectivamente, célula de fusão, gonimoblasto imaturo e filamentos do pericarpo. Barra de escala: $50 \mu \mathrm{m}$ (SPF 57785/IBC 2094);

(h) Preparação de esmagamento na região apical mostrando cistocarpo maduro. Seta, ponta de seta e seta dupla apontam, respectivamente, célula de fusão, gonimoblasto maduro e filamentos do pericarpo. Barra de escala: $50 \mu \mathrm{m}$ (SPF 57785/IBC 2094). 


\section{"Halymenia” floridana J.Agardh}

Figs 23 e 24

\section{Do latin floridana: da Flórida.}

\section{Localidade-tipo: Estados Unidos da América, Flórida.}

Aspecto Geral: Talo de cor rosa ou vermelha, flácido, pouco mucilaginoso, com até $6 \mathrm{~cm}$ de altura e $4 \mathrm{~cm}$ de largura. Frondes foliosas, de formato irregular, algumas lanceoladas, obovadas ou expandidas, irregularmente ramificadas. Margens inteiras e levemente onduladas e proliferações marginais presentes em alguns espécimes. Ápices arredondados. Poucas perforações em alguns espécimes. Nervura presente apenas na região basal. Estipe ramificado, cilíndrico, com 0,5 cm de comprimento e menos de $1 \mathrm{~mm}$ de diâmetro.

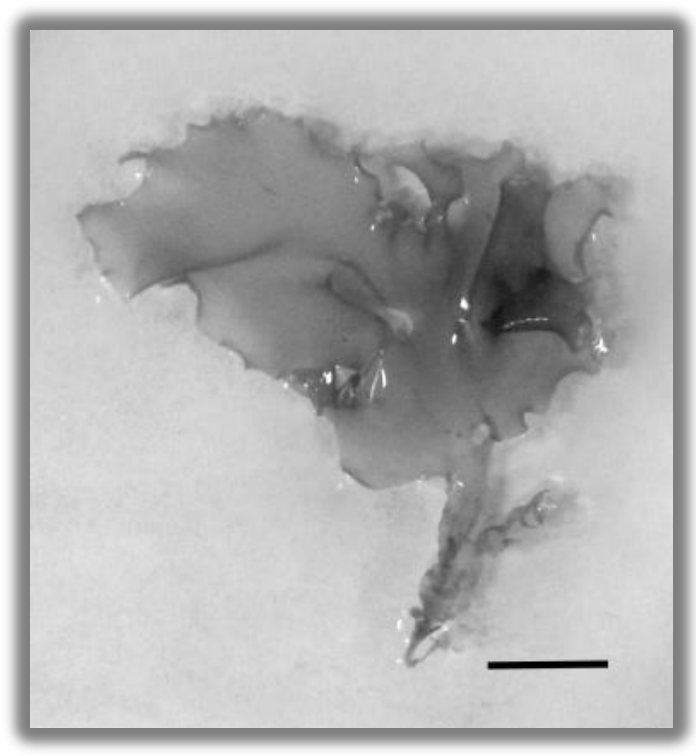

Figura 23. Aspecto geral. Barra de escala: 1 $\mathrm{cm}$. Apressório discoide, com $1 \mathrm{~mm}$ de diâmetro.

Região Apical: Talo com 97-127,5 $\mu \mathrm{m}$ de espessura. Região cortical com 1-2 camadas de células de formato irregular, algumas quadráticas, outras arredondadas ou ovoides, com 5-7 $\mu \mathrm{m}$ de altura e 3-4 $\mu \mathrm{m}$ de largura. Região subcortical com uma camada de células arredondadas alongadas periclinalmente, de 10-15 $\mu \mathrm{m}$ de diâmetro. Região medular frouxa, com poucos filamentos anticlinais e alguns periclinais, de 2-3 $\mu \mathrm{m}$ de diâmetro. Células ganglionares numerosas, grandes e conspícuas, imersas na região medular. Filamentos ganglionares de formato tubular e conteúdo refringente, muito visíveis. Células estreladas com 18-20 $\mu \mathrm{m}$ de diâmetro, conectando as células da região subcortical aos filamentos medulares.

Região Mediana: Talo com 70-140 $\mu \mathrm{m}$ de espessura. Região cortical com 1-2 camadas de células retangulares, mais largas que altas, de 3-5 $\mu \mathrm{m}$ de altura e 5-8 $\mu \mathrm{m}$ de largura. Região subcortical com 1-2 camadas de células arredondadas, alongadas 
periclinalmente, com 12-14 $\mu \mathrm{m}$ de diâmetro. Região medular frouxa, com filamentos anticlinais e periclinais de 2-4 $\mu \mathrm{m}$ de diâmetro. Células ganglionares numerosas e grandes. Filamentos ganglionares de formato tubular (aproximadamente $5 \mu \mathrm{m}$ de diâmetro) e conteúdo refringente, orientados periclinalmente e que se expandem formando as células ganglionares. Células estreladas com $10 \mu \mathrm{m}$ de diâmetro, conectando as células da região subcortical aos filamentos medulares.

Região Basal: Talo com 67,5-105 $\mu \mathrm{m}$ de espessura na lâmina e 237,5-390 $\mu \mathrm{m}$ na nervura. Região cortical composta por uma camada de células quadráticas ou retangulares, com 4-7 $\mu \mathrm{m}$ de altura e 4-5 $\mu \mathrm{m}$ de largura. Região subcortical com uma camada de células arredondadas ou periclinalmente alongadas, de 9-11 $\mu \mathrm{m}$ de diâmetro. Região medular muito densa, preenchida por células de lúmen grande de 12,5-16 $\mu \mathrm{m}$ de diâmetro e filamentos irregulares de 2-3 $\mu \mathrm{m}$ de diâmetro. Células ganglionares presentes. Células estreladas obscurecidas pelos densos filamentos.

Estruturas Reprodutivas: Tetrasporângios imaturos observados imersos no córtex da região apical, cortados apenas transversalmente, com 12,5-17,5 $\mu \mathrm{m}$ de altura e 7,5-10 $\mu \mathrm{m}$ de largura. Gametófitos femininos e masculinos não observados.

\section{Material Examinado:}

Brasil, Bahia, Camaçari, Praia de Guarajuba, 24 de maio de 2013, C.A.A. Azevedo, T. Vieira-Pinto, B. Torrano-Silva e M. Jamas (SPF 57812/IBC 2175 - tetrasporófito). Espírito Santo, Anchieta, Praia de Castelhanos, 09 de setembro de 2014, T. Vieira-Pinto (IBC 2210). Rio de Janeiro, Armação dos Búzios, Praia Rasa, 08 de março de 2015, C.A.A. Azevedo, V. Cassano e M. Mungioli (IBC 2218). São Paulo, Ubatuba, Praia Dura, 14 de outubro de 2008, E.C. Oliveira e M.C. Oliveira (SPF 57820/IBC 0054; IBC 0055). Ubatuba, Praia da Lagoinha, 23 de julho de 2009, E.C. Oliveira e F. Nauer (IBC 2161). Santa Catarina, Florianópolis, Praia de Ponta das Canas, 16 de junho de 2011, M.B. Batista (IBC 2205).

\section{Comentários:}


A espécie foi coletada nos estados da Bahia, Espírito Santo, Rio de Janeiro, São Paulo e Santa Catarina. De acordo com o nosso conhecimento, esta é a primeira citação de H. floridana para o estado de Santa Catarina.

Nossos dados moleculares indicam que esse táxon corresponde a um gênero distinto de Halymenia. Várias tentativas de amplificação da região COI-5P foram realizadas com amostras pertencentes a esse táxon, porém todas falharam. Consequentemente, apenas dados de UPA (Figura 2) e $r b c L$ (Figura 4) foram obtidos. Não foi possível comparar molecularmente a entidade brasileira com sequências de material da localidade-tipo devido à indisponibilidade das últimas. Para o marcador UPA, a divergência entre "Halymenia" floridana e outros integrandes de Cryptonemia, como Cryptonemia seminervis 2 e Cryptonemia seminervis 3, foi de apenas $0,8 \%$ e 1,1\%, respectivamente. Esse resultado indica que o táxon “H.” floridana é mais próximo de Cryptonemia do que de Halymenia.

Nas filogenias apresentadas neste estudo (Figuras 4 e 5), H. floridana aparece como grupo-irmão do clado que contém a espécie-tipo do gênero Cryptonemia. Na árvore de rbcL, o suporte de Bootstrap para esse clado é de $66 \%$, enquanto que na análise concatenada, o valor é de $93 \%$.

Morfologicamente, os indivíduos encontrados neste estudo concordam com a espécie identificada por Guimarães (1990) e Taylor (1960) como Halymenia bermudensis F.S. Collins \& M.A. Howe. Quando descrita, H. bermudensis foi diferenciada de $H$. floridana por apresentar coloração mais escura, talo mais lobado, textura mais firme, córtex mais espesso, abundância e anatomia das células ganglionares e pela aparente falta de reprodução sexual (Collins \& Howe 1916). No entanto, H. floridana, H. bermudensis e $H$. gelinaria F.S. Collins \& M.A. Howe foram sinonimizadas por Schneider \& Searles (1991), prevalecendo o nome mais antigo Halymenia floridana.

Guimarães (1990) cita que a ampola da célula auxiliar de Halymenia floridana (como H. bermudensis) difere do sistema de Chiang (1970) por apresentar formato mais cônico que o modelo de ampola do tipo Halymenia. Em relação ao número de filamentos ampolares, Guimarães (1990) também cita que encontrou tanto ampolas menos densas quanto mais densas. Essas ampolas cônicas e densas poderiam então se enquadrar na ampola do tipo Cryptonemia do sistema de Chiang. 
Em relação ao seu habitat, essa é a única espécie até então tratada como Halymenia citada para a costa brasileira que ocorre no mesolitoral. Todas as demais espécies de Halymenia ocorrem no infralitoral. Além disso, esta é a única espécie de Halymenia que foi coletada também em estações diferentes do verão. Joly (1964) descreve que $H$. floridana (como H. rosea) é encontrada em rochas do mesolitoral e é abundante durante os meses de inverno, e raríssima no verão. Essas características coincidem com as encontradas para espécies de Cryptonemia, as quais ocorrem no mesolitoral, em toda a extensão do litoral brasileiro e em todas as estações do ano. Segundo Guiry \& Irvine (1974), o espessamento na margem do talo é uma característica do gênero Cryptonemia. Guimarães (1990), ao analisar material até então identificado como Halymenia bermudensis, descreve esse espessamento. Esses elementos reforçam a transferência dessa entidade para o gênero Cryptonemia ou para um novo gênero.
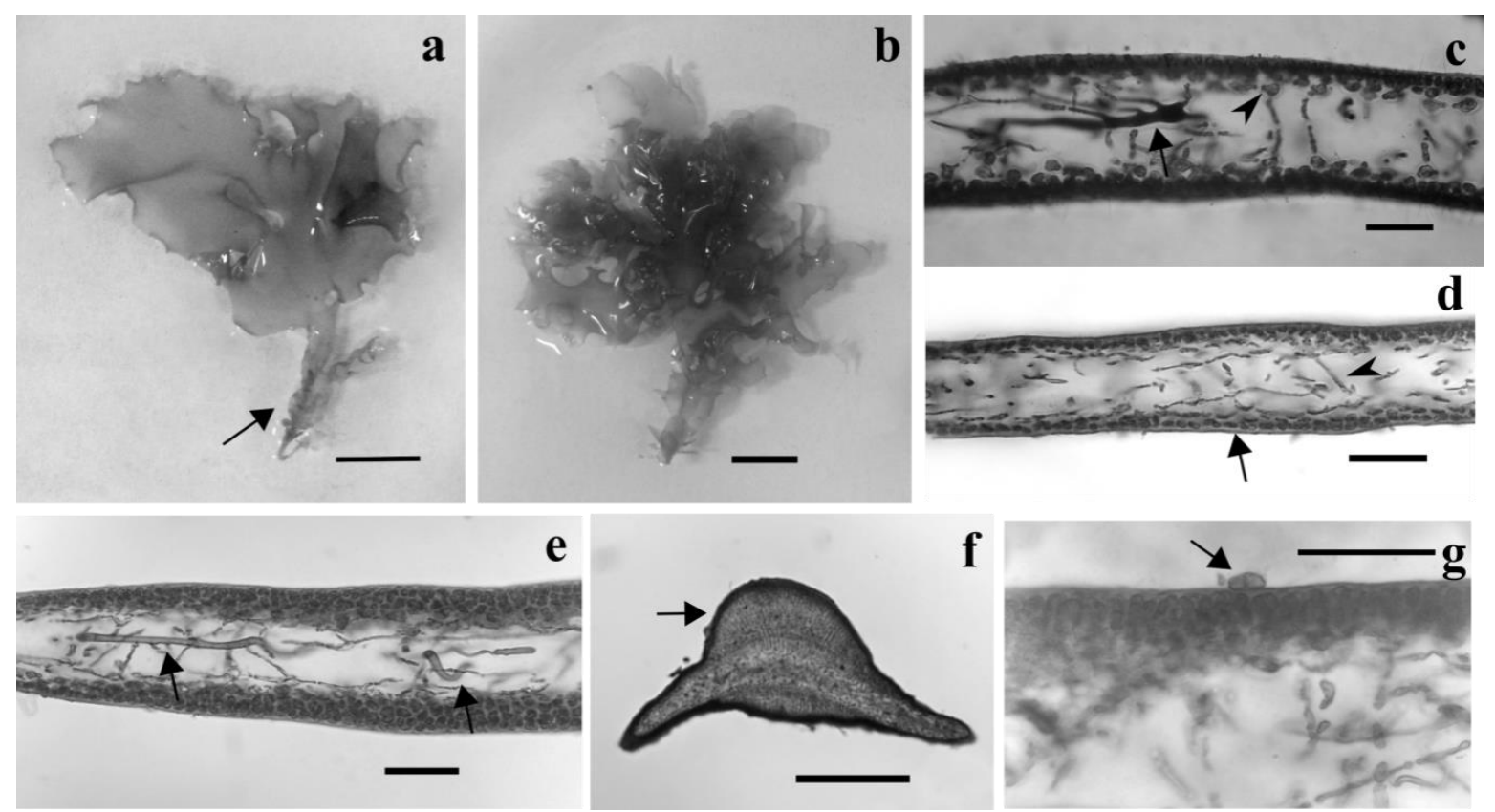

Figura 24. "Halymenia" floridana. Anatomia vegetativa e reprodutiva.

(a, b) Aspecto geral de "Halymenia" floridana. Seta indica a nervura restrita à base. Barras de escala: $1 \mathrm{~cm}$ (IBC 0055);

(c) Corte transversal na região apical do talo. Seta e ponta de seta indicam célula ganglionar e estrelada, respectivamente. Barra de escala: $50 \mu \mathrm{m}$ (IBC 0055);

(d) Corte transversal na região mediana do talo. Seta aponta célula da região cortical, enquanto que ponta de seta indica filamento medular. Barra de escala: $50 \mu \mathrm{m}$ (IBC 2175); 
(e) Corte transversal na região mediana do talo. Setas indicam filamentos ganglionares de aspecto tubular. Barra de escala: $50 \mu \mathrm{m}$ (IBC 2175);

(f) Corte transversal na região basal do talo. Seta aponta região da nervura. Barra de escala: $300 \mu \mathrm{m}$ (IBC 0054);

(g) Corte transversal na região apical do talo mostrando tetrasporângio imaturo (seta) dividido apenas transversalmente. Barra de escala: $50 \mu \mathrm{m}$ (IBC 2175). 


\section{Halymenia ignifera C.A.A. Azevedo, Cassano \& M.C. Oliveira Halymenia pinnatifida C.A.A. Azevedo, Cassano \& M.C. Oliveira}

\section{Halymenia silviae C.A.A. Azevedo, Cassano \& M.C. Oliveira}

Esses três táxons são apresentados no manuscrito intitulado "Diversity of Halymenia floresii (Halymeniales, Rhodophyta) complex on the Brazilian coast: molecular and morphological approaches reveal three new species", que corresponde ao Anexo III, submetido para o periódico Phycologia. 


\section{Halymenia sp. 1}

Figs 25 e 26

Aspecto geral: Talo mucilaginoso, de cor rosa, folioso e com lobos, com $9 \mathrm{~cm}$ de altura e até $4 \mathrm{~cm}$ de largura. Fronde apresenta perfurações e abundantes máculas superficiais uniformemente distribuídas em toda a superfície. Margens levemente onduladas. Apressório, estipe, nervura e proliferações superficiais ausentes na amostra.

Região apical: Talo com $87,5 \mu \mathrm{m}$ de espessura. Região cortical constituída por 1 camada de células alongadas, com 12-14 $\mu \mathrm{m}$ de altura e 1-2 $\mu \mathrm{m}$ de largura. Região subcortical composta por 1-2 camadas de células arredondadas, com 6-7 $\mu \mathrm{m}$ de diâmetro. Região medular frouxa, com filamentos periclinais. Células ganglionares

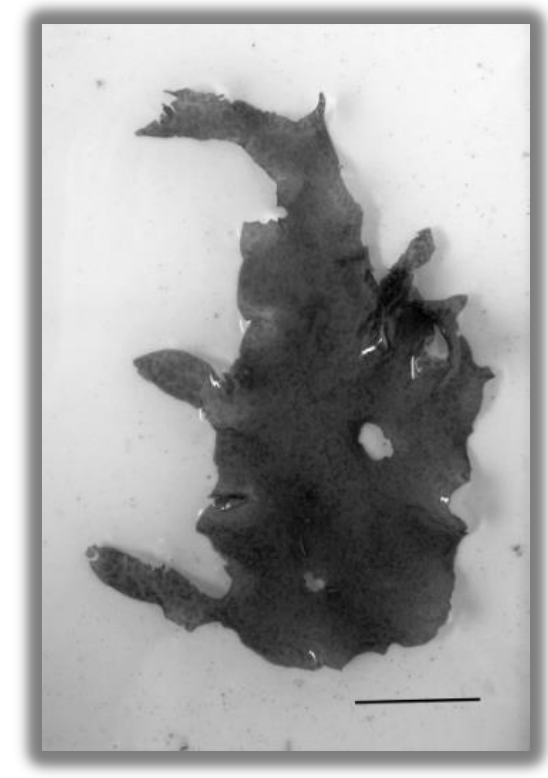

Figura 25. Aspecto geral. Barra de escala: $2 \mathrm{~cm}$.

raras, com conteúdo pouco refringente e discreto. Células estreladas alongadas, aparentemente conectadas apenas periclinalmente, com 10-14 $\mu \mathrm{m}$ de altura e $6 \mu \mathrm{m}$ de largura.

Região mediana: Talo com 110-117,5 $\mu \mathrm{m}$ de espessura. Região cortical composta por 1-2 camadas de células alongadas e estreitas, mais altas que largas, de 12-13 $\mu \mathrm{m}$ de altura e 2-3 $\mu \mathrm{m}$ de largura. Região subcortical constituída por 2-3 camadas de células arredondadas, de 6-9 $\mu \mathrm{m}$ de diâmetro. Região medular com filamentos periclinais, de 1-2 $\mu \mathrm{m}$ de diâmetro. Células ganglionares presentes, porém muito discretas. Células estreladas presentes, com 13-15 $\mu \mathrm{m}$ de altura e 8-10 $\mu \mathrm{m}$ de largura, conectadas apenas periclinalmente.

Região basal: Talo com 135-140 $\mu \mathrm{m}$ de espessura. Região cortical com 1-2 camadas de células alongadas e estreitas, de 13-15 $\mu \mathrm{m}$ de altura e 2-3 $\mu \mathrm{m}$ de largura. Região subcortical com 2-3 camadas de células arredondadas, de 7-11 $\mu \mathrm{m}$ de diâmetro. Região medular com filamentos periclinais de 1-2 $\mu \mathrm{m}$ de diâmetro. Células ganglionares 
presentes, pouco numerosas. Células estreladas alongadas, de 11-14 $\mu \mathrm{m}$ de altura e 5-6 $\mu \mathrm{m}$ de largura.

Estruturas Reprodutivas: Não observadas.

\section{Material examinado:}

Brasil, Ceará, Trairi, Praia de Guajirú, material arribado, infértil, 25 de abril de 2013, C.A.A. Azevedo, B. Torrano-Silva e T. Vieira-Pinto (SPF 57795/IBC 2138).

\section{Comentários:}

O táxon tratado aqui como Halymenia sp. 1 apresenta aspecto geral bem característico do gênero Halymenia, tais como talo folioso e mucilaginoso, além de numerosas manchas distribuídas uniformemente em toda a superfície do talo. No entanto, internamente, os filamentos medulares são periclinais, não coincidindo com os típicos filamentos anticlinais frequentemente observados em espécies de Halymenia. Apenas um indivíduo foi coletado, no estado do Ceará.

$\mathrm{Na}$ análise de agrupamento com dados de COI-5P (Figura 3), esse táxon aparece isolado, e tendo relação mais próxima com Halymenia ignifera. Os dados de $r b c \mathrm{~L}$ mostram que a linhagem mais próxima de Halymenia sp. 1 é Epiphloea bullosa (Harvey) De Toni (Figura 4).

O espécime concorda morfologicamente com Halymenia mirabilis D.L. Ballantine \& H. Ruiz, cuja localidade-tipo é Granada, Caribe (Ballantine \& Ruiz 2004). No entanto, não existem sequências disponíveis de $H$. mirabilis, e, ainda, foi encontrada apenas uma amostra que é um fragmento do talo. A correta identificação desse táxon requer a coleta de um maior número de indivíduos para a realização de mais observações morfológicas. 

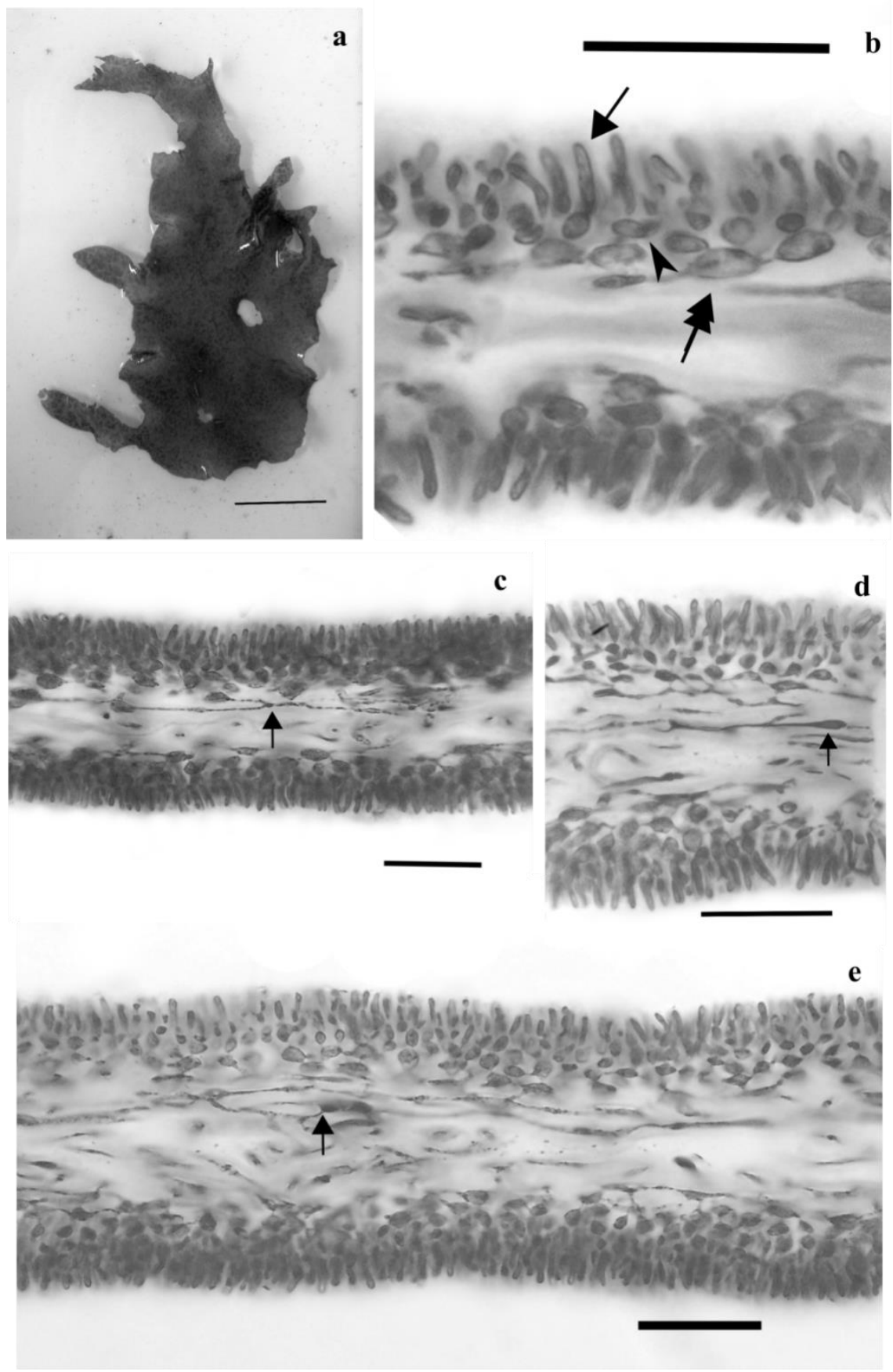

Figura 26. Halymenia sp. 1. Anatomia vegetativa. Todas as imagens são de IBC 2138.

(a) Aspecto geral mostrando manchas na superfície do talo. Barra de escala: $2 \mathrm{~cm}$;

(b) Corte transversal na região apical do talo. Seta, ponta de seta e seta dupla indicam célula da região cortical, célula da região subcortical e célula estrelada, respectivamente. Barra de escala: $50 \mu \mathrm{m}$;

(c) Corte transversal na região mediana do talo. Seta indica filamento refringente. Barra de escala: $50 \mu \mathrm{m}$;

(d) Corte transversal na região basal do talo. Seta indica filamento ganglionar. Barra de escala: $50 \mu \mathrm{m}$.

(e) Corte transversal na região basal do talo. Seta indica célula ganglionar. Barra de escala: $50 \mu \mathrm{m}$; 


\section{Halymenia sp. 2}

Figs 27-29

Aspecto Geral: Talo de cor rosa ou vermelha escura, folioso, mucilaginoso, porém firme. Frondes com lâminas fendidas, lobadas ou obovadas, de até 33 cm de altura e $23 \mathrm{~cm}$ de largura na região mediana. Talos de ramificação irregular ou não ramificados. Em alguns espécimes, várias lâminas podem se originar de um mesmo apressório. Talo com estruturas com aspecto de bolhas e rugosidades abundantes na região distal, e menos numerosas na região proximal em alguns espécimes. Em outros exemplares, bolhas, rugosidades e papilas espalhadas em toda a superfície do talo. Perforações superficiais raras, pequenas e distribuídas irregularmente. Ápices de formato irregular. Margens lisas na região distal e levemente denteadas na região basal. Em alguns

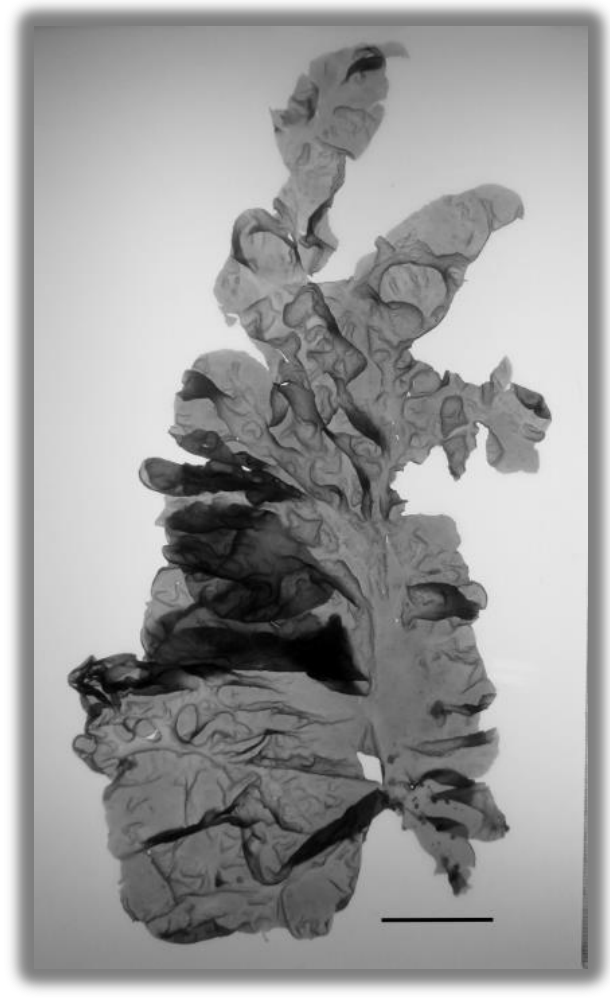

Figura 27. Aspecto geral. Barra de escala: $5 \mathrm{~cm}$.

exemplares, as margens são irregulares, com projeções denteadas pequenas e irregularmente distribuídas. Nervura ausente. Base não cuneada, alargada, com largura de 4 cm logo acima do estipe. Proliferações apicais e superficiais ausentes. Estipe achatado, pouco diferenciado, alcançando até $5 \mathrm{~mm}$ de comprimento e $3 \mathrm{~mm}$ de largura. Apressório discoide, com até $4 \mathrm{~mm}$ de diâmetro.

Região Apical: Talo com 62,5-320 $\mu \mathrm{m}$ de espessura. Região cortical composta por 1-2 camadas de células elipsoides ou ovoides, de 5-8 $\mu \mathrm{m}$ de altura e 2-5 $\mu \mathrm{m}$ de largura. Região subcortical constituída por 1-3 camada de células arredondadas ou periclinalmente alongadas, de 4-25 $\mu \mathrm{m}$ de diâmetro. Região medular frouxa, com filamentos anticlinais com pit-connections bastante evidentes e alguns periclinais, de 2-12,5 $\mu \mathrm{m}$ de diâmetro. Células ganglionares abundantes e muito conspícuas, de conteúdo refringente, imersas na 
região medular. Células estreladas de conteúdo normal, com 18-22 $\mu \mathrm{m}$ de largura, conectando as células da região subcortical aos filamentos medulares e periclinais.

Região Mediana: Talo com 75-500 $\mu \mathrm{m}$ de espessura. Região cortical com 1-2 camadas de células elipsoides ou ovoides, de 5-7,5 $\mu \mathrm{m}$ de altura e 4-5 $\mu \mathrm{m}$ de largura. Região subcortical constituída por 1-2 camadas de células arredondadas ou periclinalmente alongadas, de 4-15 $\mu \mathrm{m}$ de diâmetro. Região medular mais densa que na região apical, com filamentos predominantemente anticlinais, mas também com filamentos irregulares, de 3$15 \mu \mathrm{m}$ de diâmetro. Células ganglionares muito abundantes, de conteúdo refringente, imersas na região medular. Células estreladas de conteúdo normal, com 18-20 $\mu \mathrm{m}$ de diâmetro, conectando as células da região subcortical aos filamentos medulares e periclinais.

Região Basal: Talo com 520-740 $\mu \mathrm{m}$ de espessura. Região cortical composta por 13 camadas de células elipsoides ou ovoides, de 5-10 $\mu \mathrm{m}$ de altura e 2,5-5 $\mu \mathrm{m}$ de largura. Região subcortical constituída por 3-4 camadas de células arredondadas, de 8-15 $\mu \mathrm{m}$ de diâmetro. Região medular muito densa, com filamentos irregulares e entrelaçados de 2-17,5 $\mu \mathrm{m}$ de diâmetro. Poucas células ganglionares. Células estreladas com aproximadamente 17 $\mu \mathrm{m}$ de diâmetro.

Estruturas de Reprodução: Célula auxiliar alongada, com $24 \mu \mathrm{m}$ de altura e 12 $\mu \mathrm{m}$ de largura. Ampola não fertilizada com 75-87,5 $\mu \mathrm{m}$ e diâmetro, e com diâmetro de 100 $\mu \mathrm{m}$ após a fertilização. Cistocarpos imersos no talo nas regiões apical e mediana, com três gonimolobos e 62,5-90 $\mu \mathrm{m}$ de diâmetro. Gametófitos masculinos e tetrasporófitos não observados.

\section{Material Examinado:}

Brasil, estado do Ceará, Trairi, Praia de Guajiru, 25 de abril de 2013, C.A.A. Azevedo, T. Vieira-Pinto e B. Torrano-Silva (IBC 2129 - gametófito feminino; IBC 2132 gametófito feminino; IBC 2133 - infértil; IBC 2134 - infértil; IBC 2140 - gametófito feminino). Praia do Pacheco, infértil, 26 de abril de 2013, C.A.A. Azevedo, P.B. Carneiro, T. Vieira-Pinto, B. Torrano-Silva (SPF 57794/IBC 2143 - infértil; SPF 57793; IBC 2147 infértil). 


\section{Comentários:}

Os indivíduos de Halymenia sp. 2 foram coletados no estado do Ceará. A árvore de $r b c \mathrm{~L}$ mostra essa linhagem proximamente relacionada a Halymenia floresii e Halymenia pseudofloresii (Figura 4).

Este material apresenta papilas superficiais (Figura 28, c) que lembram as de $H$. duchassaingii, no entanto, essa entidade possui papilas muito mais escassas e menos conspícuas que o descrito na literatura para H. duchassaingii, (Joly et al. 1965b; Taylor 1960). Este material difere de $H$. brasiliana por apresentar numerosas e conspícuas células gangionares, em toda a extensão do talo.

$\mathrm{O}$ aspecto geral se assemelha muito a Halymenia sp. 4 descrita por Guimarães (1990) como material com superfície bastante rugosa. Essa espécie é objeto de um manuscrito em preparação.
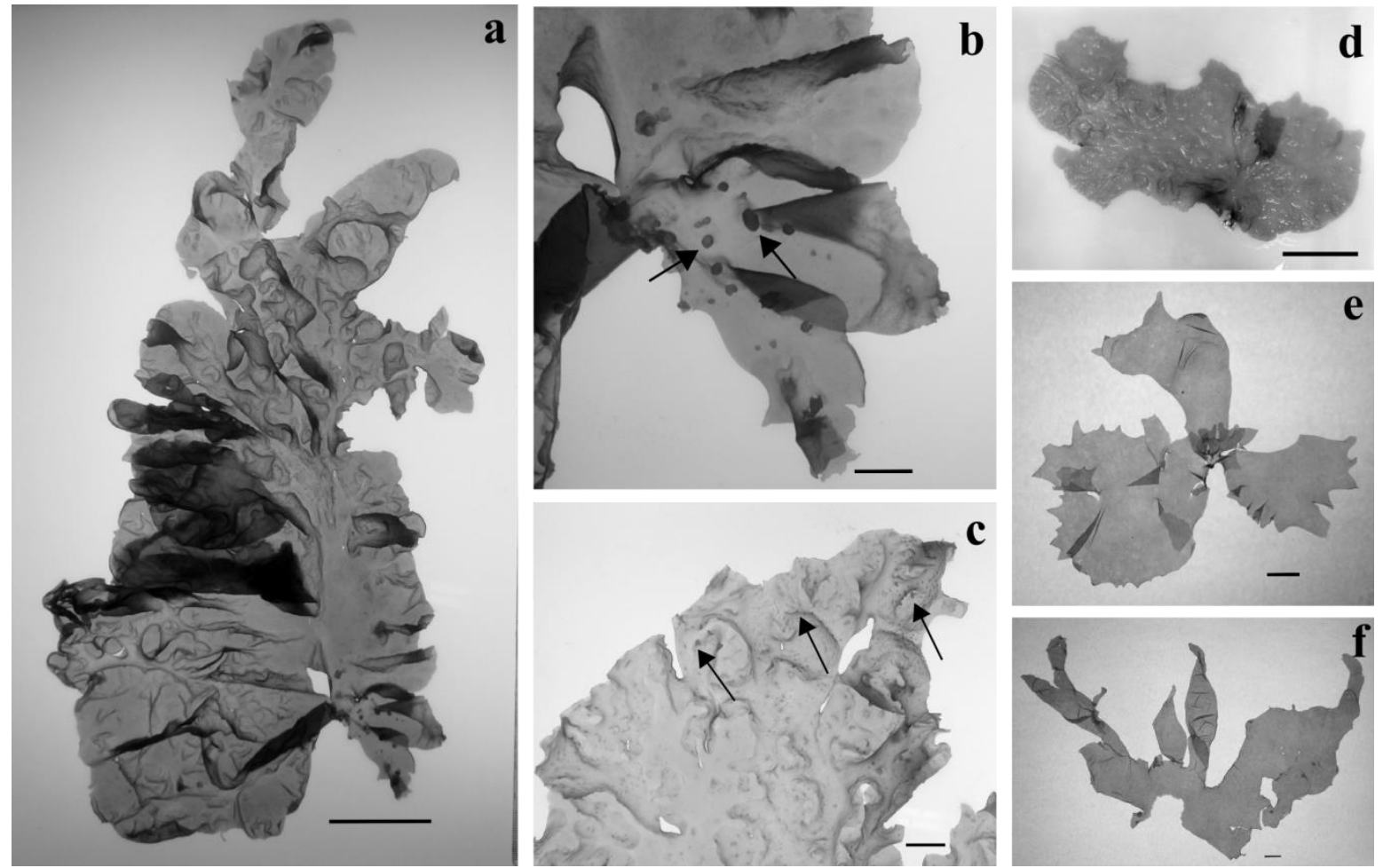

Figura 28. Halymenia sp. 2. Variação morfológica nos espécimes encontrados.

(a) Aspecto geral de espécime com rugosidades abundantes. Barra de escala: 5 cm (IBC 2129);

(b) Detalhe da região basal, mostrando papilas de formato globular (setas). Barra de escala: $1 \mathrm{~cm}$ (IBC 2129);

(c) Detalhe da região apical, mostrando papilas de formato espinescente (setas). Barra de escala: $1 \mathrm{~cm}$ (IBC 2134); 
(d) Aspecto geral de espécime com rugosidades e base larga. Barra de escala: $5 \mathrm{~cm}$ (IBC 2132);

(e) Aspecto geral de espécime com superfície lisa. Várias frondes partem de um mesmo apressório. Barra de escala: $1 \mathrm{~cm}$ (IBC 2143);

(f) Aspecto geral de espécime com poupas papilas e rugosidades. Barra de escala: $1 \mathrm{~cm}$ (IBC 2147).
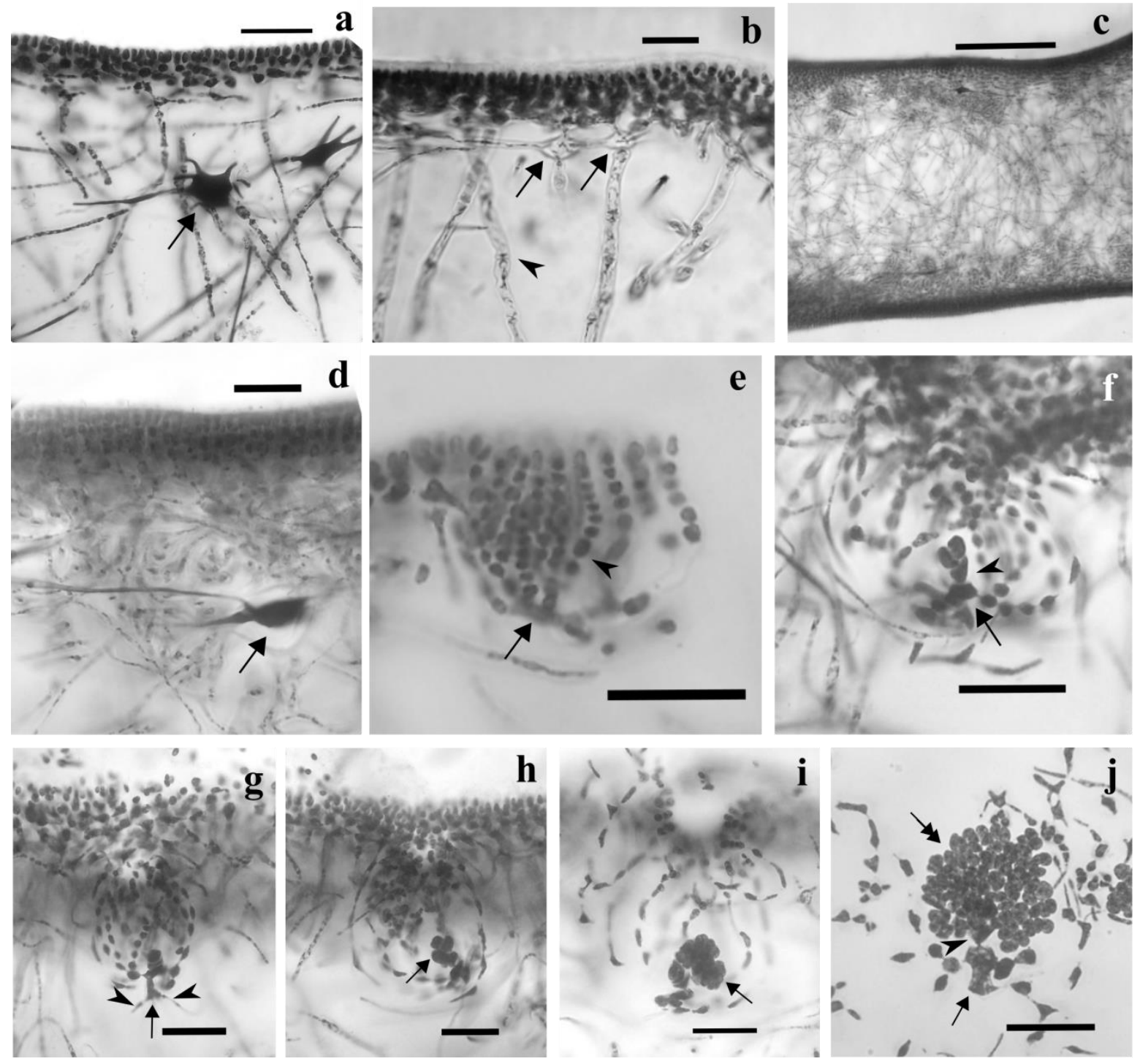

Figura 29. Halymenia sp. 2. Anatomia vegetativa e reprodutiva.

(a) Corte transversal na região apical do talo. Seta aponta célula ganglionar. Barra de escala: $50 \mu \mathrm{m}$ (IBC 2132);

(b) Corte transversal na região mediana do talo. Setas e ponta de seta indicam células estreladas e filamento medular anticlinal, respectivamente. Barra de escala: $50 \mu \mathrm{m}$ (IBC 2133);

(c) Corte transversal na região basal do talo. Barra de escala: $300 \mu \mathrm{m}$ (IBC 2132);

(d) Detalhe de corte transversal na região basal mostrando célula ganglionar (seta). Barra de escala: $50 \mu \mathrm{m}$ (IBC 2132); 
(e) Corte transversal na região mediana mostrando ampola da célula auxiliar. Seta indica célula auxiliar (fora de foco), enquanto que ponta de seta indica filamento ampolar. Barra de escala: $50 \mu \mathrm{m}$ (IBC 2132);

(f-j) Sequência de desenvolvimento do cistocarpo;

(f) Corte transversal na região apical mostrando início do desenvolvimento do carposporófito. Seta e ponta de seta indicam célula de fusão e inicial dos gonimoblastos, respectivamente. Barra de escala: $50 \mu \mathrm{m}$ (IBC 2129);

(g) Corte transversal na região apical mostrando célula de fusão (seta) e filamentos conectivos (pontas de seta). Barra de escala: $50 \mu \mathrm{m}$ (IBC 2129);

(h) Corte transversal na região apical mostrando gonimoblasto imaturo (seta). Barra de escala: $50 \mu \mathrm{m}$ (IBC 2129);

(i) Corte transversal na região apical mostrando gonimoblasto em desenvolvimento (seta). Barra de escala: 50 $\mu \mathrm{m}($ IBC 2129);

(j) Preparação de esmagamento na região apical mostrando cistocarpo maduro. Seta, ponta de seta e seta dupla indicam célula de fusão, inicial dos gonimoblastos e carposporângios, respectivamente. Barra de escala: $50 \mu \mathrm{m}($ IBC 2129). 


\section{Grateloupia C. Agardh}

\section{Grateloupia: em homenagem ao naturalista francês J. P. F. Grateloup. Espécie-tipo do gênero: Grateloupia filicina (J.V.Lamouroux) C.Agardh}

Talos mucilaginosos, achatados, foliosos, lineares ou lanceolados. Frondes inteiras, lobadas ou abundantemente ramificadas em uma a mais ordens, em um ou mais planos. Proliferações superficiais e marginais presentes em algumas espécies. Frondes com estipes cilíndricos ou achatados e apressórios discoides. Estrutura multiaxial. Região cortical com fileiras anticlinais de células mais ou menos isodiamétricas, progressivamente menores em direção à cutícula. Região subcortical com células arredondadas. Região medular esparsa, com filamentos irregulares predominantemente periclinais, algumas vezes com rizoides. Células estreladas presentes entre a região subcortical e a região medular externa. Gametófitos monoicos ou dioicos. Estruturas reprodutivas em ampolas, ramificadas geralmente apenas até segunda ordem. Ramos carpogoniais e células auxiliares em ampolas separadas. Filamentos ampolares ramificados de 1-2 ordens. Ampola da célula auxiliar consiste de um filamento primário e de 1-3 filamentos secundários não ramificados. Ramos carpogoniais com duas células. Após a fertilização, os filamentos conectivos se desenvolvem e podem se fundir com várias células auxiliares em ampolas separadas. Uma célula auxiliar de fusão pequena é formada. Uma única célula inicial dos gonimoblastos direcionada à superfície do talo produz um cistocarpo compacto e imerso com muitos carposporângios pequenos, envolto por um invólucro derivado dos filamentos ampolares e medulares. Cistocarpos geralmente de formato cônico e pequeno ostíolo geralmente presente. Espermatângios superficiais, espalhados pela superfície do talo e algumas vezes em soros nemateciais. Células-mãe de espermatâgios formadas a partir de células superficiais. Gametófitos e tetrasporófitos isomórficos. Tetrasporângios cruciados, fixos na base das células do córtex intermediário e espalhados pela superfície do talo.

(Guiry \& Guiry 2016) 


\section{Grateloupia cf. dichotoma J. Agardh}

Figs 30 e 31

\section{Do grego dichotomos: bifurcado ou igualmente dividido. Localidade-tipo: França, Mediterrâneo.}

Aspecto Geral: Talo vermelho-escuro ou marrom, firme, em forma de fita. Ramificação irregular ou não ramificado. Frondes com até $4 \mathrm{~cm}$ de altura e $3 \mathrm{~mm}$ de largura. Ápices bifurcados ou afilados, e alguns râmulos marginais na região distal. Proliferações superficiais ou marginais ausentes em alguns espécimes. Margens levemente denteadas. Nervura ausente e estipe não diferenciado. Apressório discoide, com 1-2 mm de diâmetro.

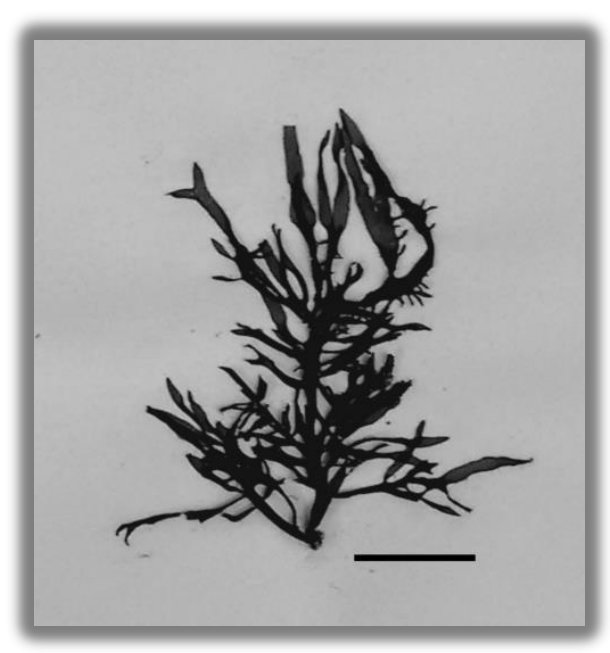

Figura 30. Aspecto geral. Barra de escala: $1 \mathrm{~cm}$.

Região Apical: Talo com espessura de 80-175 $\mu \mathrm{m}$. Região cortical composta por 1 camada de células retangulares ou quadráticas, de 5-6 $\mu \mathrm{m}$ de altura e 2-4 $\mu \mathrm{m}$ de largura. Região subcortical constituída por 1-2 camadas de células esféricas, de 3-8 $\mu$ m de diâmetro. Região medular frouxa, com filamentos irregulares de 2-4 $\mu \mathrm{m}$ de diâmetro. Células ganglionares não encontradas. Células estreladas presentes, expandidas, com 9-10 $\mu \mathrm{m}$ de diâmetro, conectando as células da região subcortical aos filamentos medulares.

Região Mediana: Talo com espessura de 260-340 $\mu \mathrm{m}$. Região cortical composta por 3-4 camadas de células quadráticas ou retangulares, com 4-6 $\mu \mathrm{m}$ de altura e 2-5 $\mu \mathrm{m}$ de largura. Região subcortical constituída por 2-3 camadas de células arredondadas, com 4-10 $\mu \mathrm{m}$ de diâmetro. Região medular densa, com abundantes filamentos irregulares e entrelaçados, com 3-4 $\mu \mathrm{m}$ de diâmetro. Células ganglionares não encontradas. Células estreladas poligonais, com 12,5-17,5 $\mu \mathrm{m}$ de diâmetro.

Região Basal: Talo com espessura de 250-350 $\mu \mathrm{m}$. Região cortical com 2-4 camadas de células quadráticas ou retangulares, com 3-5 $\mu \mathrm{m}$ de altura e 2-4 $\mu \mathrm{m}$ de largura. Região subcortical constituída por 2-3 camadas de células arredondadas, com 3-8 $\mu \mathrm{m}$ de 
diâmetro. Região medular bastante densa, com abundantes filamentos medulares e entrelaçados, alguns com aspecto de rizines, com 2-6 $\mu \mathrm{m}$ de diâmetro. Células ganglionares não encontradas. Células estreladas não visualizadas e provavelmente obscurecidas pelos filamentos densos.

Estruturas Reprodutivas: Tetrasporângios cruciados-decussados, imersos no Região cortical da região mediana, com 26-30 $\mu \mathrm{m}$ de altura e 10-14 $\mu \mathrm{m}$ de largura. Gametófitos femininos e masculinos não observados.

\section{Material Examinado:}

Brasil, Espírito Santo, Marataízes, Praia da Cruz, tetrasporófito, 07 de maio de 2012, B. Torrano-Silva, C. Iha, F. Nauer e M.C. Oliveira (SPF 57799/IBC 2038). Marataízes, Praia da Cruz, 10 de setembro de 2014, T. Vieira-Pinto (IBC 2211). São Paulo, São Vicente, Prainha da Ponte Pênsil, infértil, 21 de março de 2011, E.C. Oliveira (SPF 57821/IBC 2012). Itanhaém, Praia de Cibratel, 20 de julho de 2013, B. Torrano-Silva, B.

Vieira e W. Oliveira (IBC 2057). Peruíbe, Praia de Guaraú, 05 de maio de 2015, C.A.A. Azevedo e M. Mungioli (IBC 2235). Paraná, Ilha do Mel, 12 de julho de 2014, V. Cassano (IBC 2208).

\section{Comentários:}

A espécie Grateloupia dichotoma foi recentemente sinonimizada com Dermocorynus dichotomus (J.Agardh) Gargiulo, M.Morabito \& Manghisi (Gargiulo et al. 2013). G. dichotoma foi citada para o Brasil para os estados do Ceará, Espírito Santo, São Paulo e Santa Catarina (Guimarães 1990; Soares 2015). De acordo com nosso conhecimento, este estudo é a primeira citação do táxon para o litoral do Paraná.

Na árvore de $r b c \mathrm{~L}$, amostras de Grateloupia cf. dichotoma não se agrupam com a sequência de Dermocorynus dichotomus coletado na localidade-tipo (Figura 4). Além disso, as amostras aparecem inseridas no clado que contém Grateloupia filicina, a espécie-tipo do gênero Grateloupia (Figuras 4 e 5). Por essa razão, essa entidade é tratada como Grateloupa cf. dichotoma neste estudo. Os resultados obtidos aqui demonstram que os registros brasileiros de Grateloupia dichotoma não correspondem ao autêntico 
Dermocorynus dichotomus, nome atualmente válido, e sugerem ainda que essas algas constituem uma espécie do gênero Grateloupia, possivelmente nova para a ciência.

O material encontrado aqui difere de Grateloupia dichotoma identificada por Cordeiro-Marino (1978) para Santa Catarina por apresentar ramificação irregular, a qual é dicotômica no material catarinense. Além disso, Guimarães (1990) descreve margens lisas, enquanto que neste estudo foram encontradas margens levemente denteadas. Guimarães (1990) cita ainda duas camadas na região cortical na região mediana, enquanto que neste estudo foram observadas 3-4 camadas.
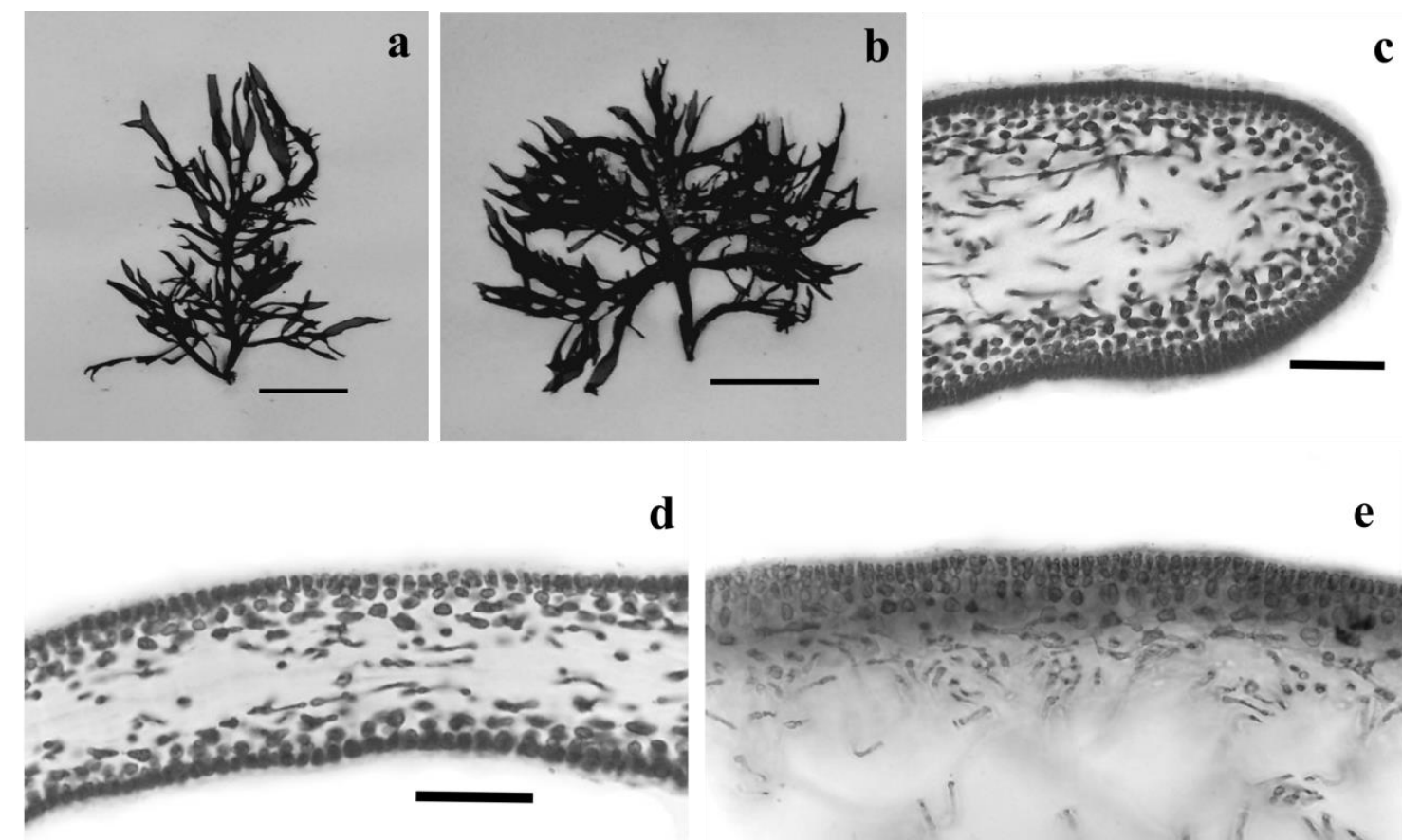

d

$\mathbf{e}$
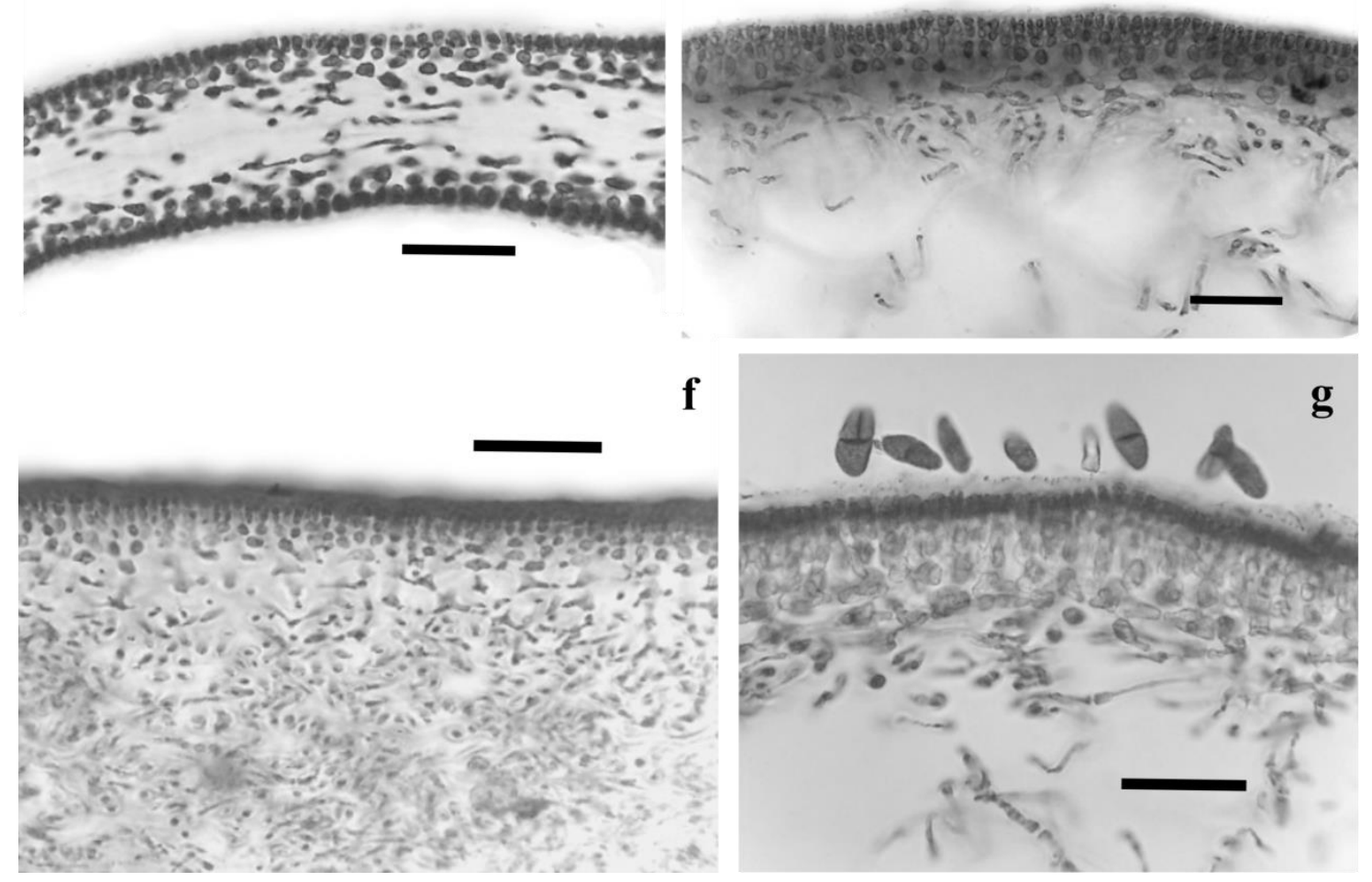

Figura 31. Grateloupia cf. dichotoma. Anatomia vegetativa e reprodutiva. 
(a, b) Aspecto geral. Barras de escala: $1 \mathrm{~cm}$ (SPF 57821/IBC 2012);

(c, d) Corte transversal na região apical do talo. Barras de escala: 50 ㅆ (SPF 57821/IBC 2012; IBC 2038);

(e) Corte transversal na região mediana do talo. Barra de escala: $50 \mu \mathrm{m}$ (IBC 2038);

(f) Corte transversal na região basal do talo. Barra de escala: $50 \mu \mathrm{m}$ (IBC 2038);

(g) Corte transversal na região mediana do talo mostrando tetrasporângios. Barra de escala: $50 \mu \mathrm{m}$ (IBC 2038). 


\title{
Complexo Grateloupia cf. filicina (J.V.Lamouroux) C.Agardh
}

\author{
Do Latim filix: filho. Provavelmente em referência à semelhança com plantas \\ vasculares da Classe Filicinae, tais como fetos e avencas. \\ Localidade-tipo: Trieste, Itália.
}

Neste estudo, considera-se como Grateloupia cf. filicina algas de eixos principais achatados, com ramos cilíndrico-comprimidos, conforme adotado por Guimarães (1990). Apesar de ser uma espécie amplamente citada para a costa brasileira, os dados moleculares mostram que nenhum dos espécimes coletados até o momento corresponde à autêntica Grateloupia filicina, cuja localidade-tipo é a Itália, e, ainda, sugerem que existem duas linhagens distintas com a mesma morfologia geral. Uma das linhagens está representada na filogenia inferida a partir do marcador $r b c \mathrm{~L}$ (Figura 4) pela sequência "IBC 2079 Grateloupia cf. filicina BA”, e apresenta maior afinidade com Grateloupia cf. dichotoma. A outra linhagem, por sua vez, inclui representantes coletados nos estados de São Paulo e Rio de Janeiro, e é próxima de Grateloupia filiformis e G. orientalis. A correta identificação desses dois táxons requer a realização de mais observações morfológicas. 


\section{Grateloupia cf. filicina 1}

Figs 32 e 33

Aspecto Geral: Talo mucilaginoso, porém firme. Frondes de até $13 \mathrm{~cm}$ de altura, cilíndricas na base e achatadas na região mediana, porção em que alcançam até $3 \mathrm{~mm}$ de largura. Ápices afilados. Talo abundantemente ramificado irregularmente, com várias ramificações pinadas e algumas alternadas. Ramos laterais constritos na base e de ápices afilados, também ramificados pinadamente. Foram observadas proliferações

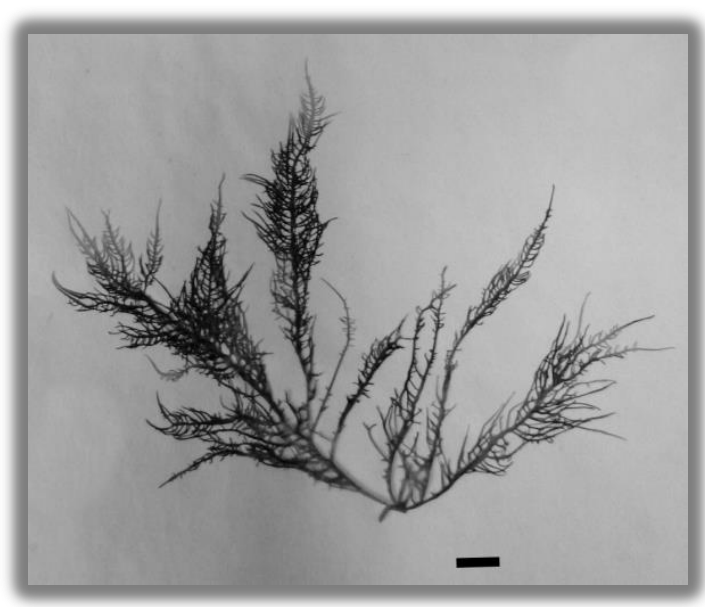

Figura 32. Aspecto geral. Barra de escala: 1 $\mathrm{cm}$.

marginais e superficiais, de aspecto dentado, visíveis apenas sob estereoscópio. Nervura ausente. Estipe não diferenciado. Apressório discóide, com $1 \mathrm{~mm}$ de diâmetro.

Região Apical: Talo com 110-125 $\mu \mathrm{m}$ de espessura. Região cortical composta por uma camada de células cujo formato não estava claro em corte transversal, porém, em visão superficial correspondem a células elipsoides, de 5-8 $\mu \mathrm{m}$ de altura e 3-4 $\mu \mathrm{m}$ de largura. Região subcortical constituída por 2-3 células arredondadas e levemente alongadas, com 6$9 \mu \mathrm{m}$ de diâmetro. Região medular frouxa, com aparência de vazia, com poucos filamentos irregulares de 2-4 $\mu \mathrm{m}$ de diâmetro. Células ganglionares e estreladas não foram observadas.

Região Mediana: Talo com 580-740 $\mu \mathrm{m}$ de espessura. Região cortical composta por 4-5 camadas de células elipsoides dispostas de forma moniliforme, de 5-12,5 $\mu \mathrm{m}$ de altura e 2,5-5 $\mu \mathrm{m}$ de largura. Região subcortical constituída por 2-3 camadas de células arredondadas, de 17,5-27,5 $\mu \mathrm{m}$ de diâmetro. Região medular preenchida por filamentos irregulares, de 2-4 $\mu \mathrm{m}$ de diâmetro. Filamentos densos com disposição longitudinal observados próximo à região subcortical. Células ganglionares não observadas. Células estreladas não encontradas, porém provavelmente obscurecidas pelos densos filamentos medulares.

Região Basal: Talo com 1020-1150 $\mu \mathrm{m}$ de espessura. Região cortical composta por 5-6 camadas de células elipsoides, de 5-10 $\mu \mathrm{m}$ de altura e 2,5-5 $\mu \mathrm{m}$ de largura. Região 
subcortical constituída por 2-3 camadas de células arredondadas, de 10-15 $\mu \mathrm{m}$ de diâmetro. Região medular bastante densa, preenchida por filamentos entrelaçados de 5-7,5 $\mu \mathrm{m}$ de diâmetro. Células ganglionares não observadas. Células estreladas não encontradas, porém, provavelmente obscurecidas pelos densos filamentos medulares.

Estruturas Reprodutivas: Não observadas.

\section{Material examinado:}

Brasil, Bahia, Lauro de Freitas, Praia de Vilas do Atlântico, infértil, 15 de outubro de 2012, V. Cassano (SPF 57786/IBC 2079). Rio de Janeiro, Armação dos Búzios, Praia Rasa, 17 de março de 2014, C.A.A. Azevedo, V. Cassano e M. Mungioli (IBC 2201). 

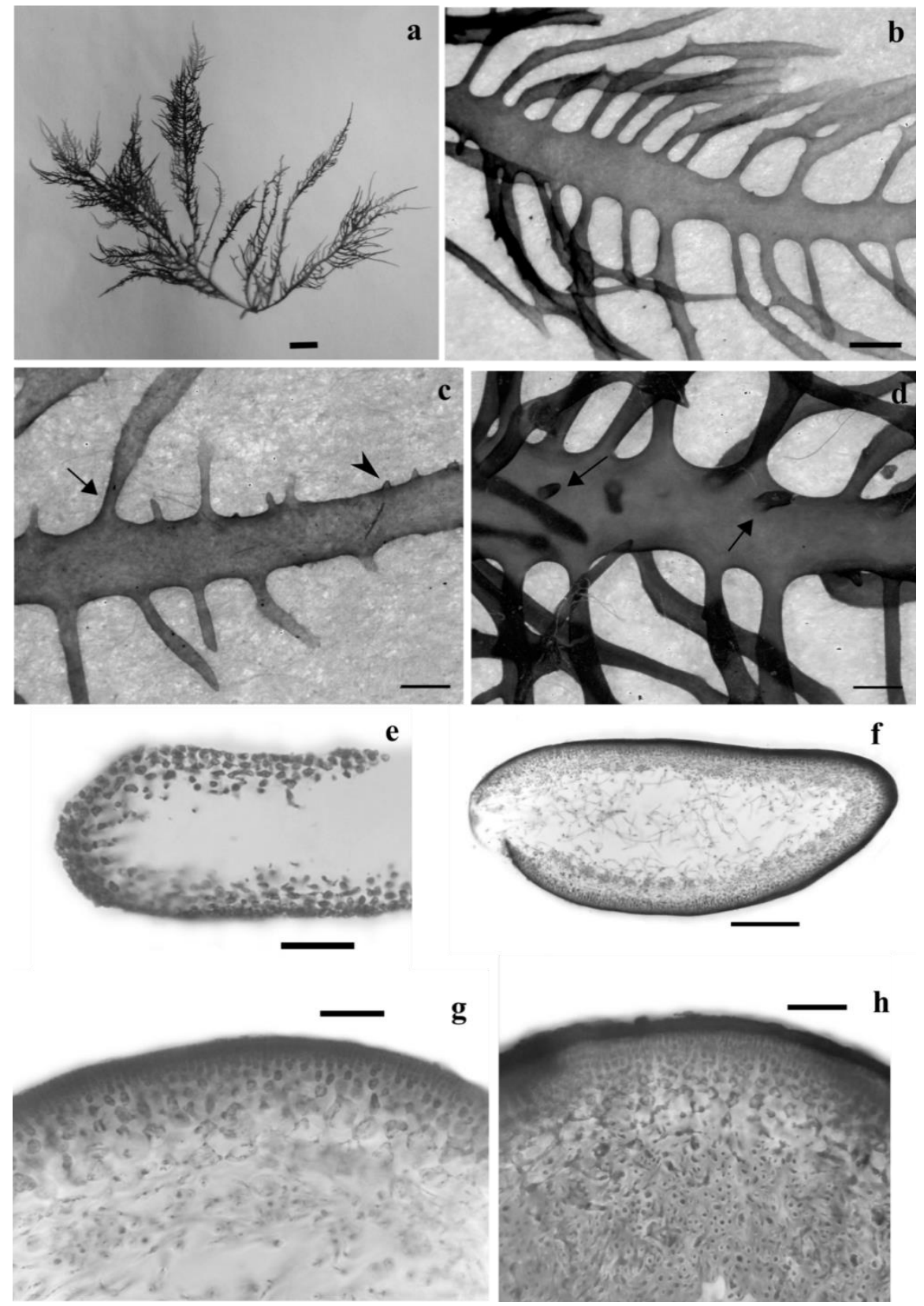

Figura 33. Grateloupia cf. filicina 1. Anatomia vegetativa. Todas as imagens são de SPF 57786/IBC 2079.

(a) Aspecto geral. Barra de escala: $1 \mathrm{~cm}$;

(b) Detalhe da região apical mostrando ramificação pinada. Barra de escala: $1 \mathrm{~mm}$;

(c) Detalhe da região apical mostrando constrição na base dos ramos (seta) e proliferações marginais denteadas (ponta de seta). Barra de escala: 0,5 mm;

(d) Detalhe da região distal mostrando proliferações superficiais (setas). Barra de escala: 0,5 mm;

(e) Corte transversal na região apical do talo. Barra de escala: $50 \mu \mathrm{m}$;

(f) Corte transversal na região mediana do talo. Barra de escala: $300 \mu \mathrm{m}$;

(g) Corte transversal na região mediana do talo. Barra de escala: $50 \mu \mathrm{m}$;

(h) Corte transversal na região basal do talo Barra de escala: $50 \mu \mathrm{m}$. 


\section{Grateloupia cf. filicina 2 (J.V.Lamouroux) C.Agardh}

Figs 34 e 35

Aspecto Geral: Talo mucilaginoso, porém firme, cilíndrico na base e achatado na região mediana, com ápices afilados. Planta com $2 \mathrm{~cm}$ de altura e $1 \mathrm{~mm}$ de largura na região mediana. Ramificação dicotômica na base e pinada na porção superior do talo. Ramos laterais com até $3 \mathrm{~mm}$ de comprimento, não constritos na base. Nervura ausente. Estipe não diferenciado. Apressório discoide com $0,5 \mathrm{~mm}$ de diâmetro.

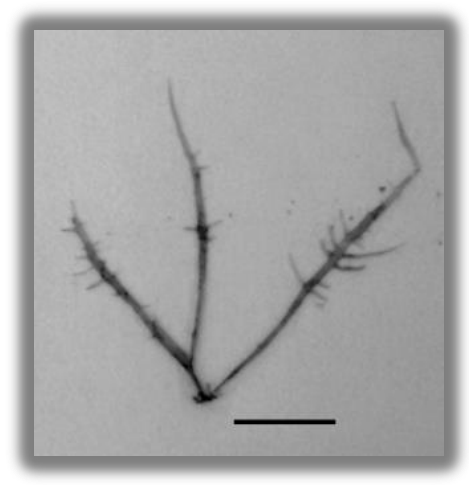

Figura 34. Aspecto geral. Barra de escala: $0,5 \mathrm{~mm}$.

Região Apical: Talo com 112,5 $\mu \mathrm{m}$ de espessura. Região cortical composta por uma camada de células retangulares, com 5-9 $\mu \mathrm{m}$ de altura e 3-4 $\mu \mathrm{m}$ de largura. Região subcortical com 3-4 camadas de células esféricas, de 4-8 $\mu \mathrm{m}$ de diâmetro. Região medular com aparência de vazia, de maneira que não foram visualizados os filamentos medulares. Células ganglionares e estreladas não observadas.

Região Mediana: Talo com espessura de 135-152,5 $\mu \mathrm{m}$. Região cortical composta por 2-3 camadas de células quadráticas, de 3-4 $\mu \mathrm{m}$ de altura e 2-3 $\mu \mathrm{m}$ de largura. Região subcortical constituída por 3-4 camadas de células esféricas ou alongadas, de 4-16 $\mu \mathrm{m}$ de diâmetro, que aumentam progressivamente de tamanho a partir da região cortical em direção à Rrgião medular. Região medular densa, completamente preenchida por filamentos entrelaçados de 3-4 $\mu \mathrm{m}$ de diâmetro. Células ganglionares e estreladas não observadas.

Região Basal: Talo com 260-290 $\mu$ m de espessura. Região cortical espessada, com aproximadamente 10 camadas de células retangulares ou quadráticas, com 3-4 $\mu \mathrm{m}$ de altura e 2-3 $\mu \mathrm{m}$ de largura. Região subcortical constituída por 2-3 camadas de células esféricas ou alongadas, de 6-8 $\mu \mathrm{m}$ de diâmetro. Região medular bastante densa, completamente preenchida por filamentos entrelaçados de 4-5 $\mu \mathrm{m}$ de diâmetro. Alguns filamentos são longitudinais. Células ganglionares e estreladas não observadas.

Estruturas Reprodutivas: Não observadas.

\section{Material examinado:}


Brasil, Rio de Janeiro, Armação dos Búzios, Praia da Ferradura, infértil, 25 de setembro de 2011, C. Iha, B. Torrano-Silva e F. Nauer (SPF 57781/IBC 0506). São Paulo, Ubatuba, Praia Domingas Dias, infértil, 04 de setembro de 2009, M. T. Fujii (IBT 0228).

\section{Comentários:}

Grateloupia cf. filicina 1 e Grateloupia cf. filicina 2 são muito semelhantes tanto em relação à morfologia externa, quanto à anatomia interna, sendo que na região mediana de Grateloupia cf. filicina 1 são observados filamentos densos de disposição longitudinal, localizados entre a região subcortical e a região medular. Esses filamentos não estão presentes em Grateloupia cf. filicina 2.
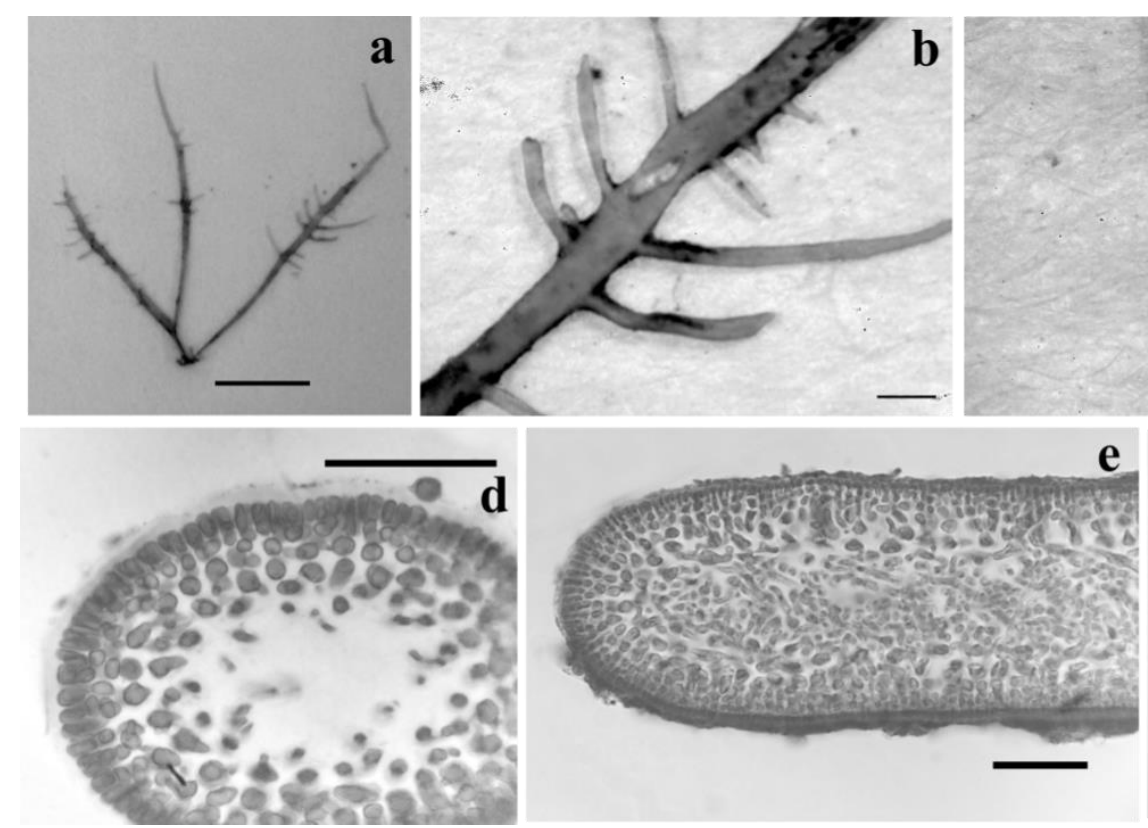

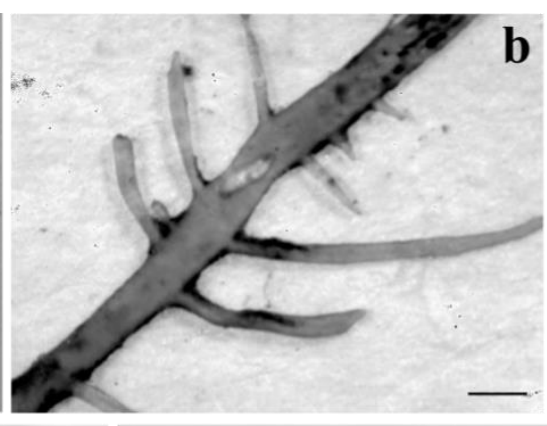

b

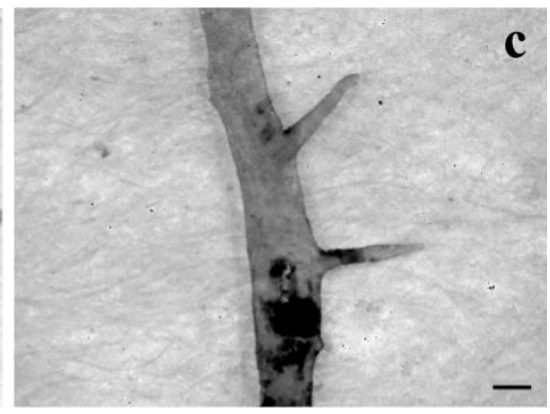

e

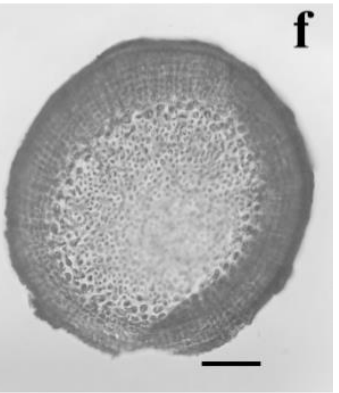

Figura 35. Grateloupia cf. filicina 2. Anatomia vegetativa. Todas as imagens são de SPF 57781/IBC 0506.

(a) Aspecto geral. Barra de escala: 0,5 cm;

(b) Detalhe da região mediana mostrando ramificação pinada. Barra de escala: 0,5 mm;

(c) Detalhe mostrando ramos laterais não constritos na base. Barra de escala: 0,2 mm;

(d) Corte transversal na região apical do talo. Barra de escala: $50 \mu \mathrm{m}$;

(e) Corte transversal na região mediana do talo. Barra de escala: $50 \mu \mathrm{m}$;

(f) Corte transversal na região basal do talo. Barra de escala: $50 \mu \mathrm{m}$. 


\section{Grateloupia filiformis Kützing}

Figs 36 e 37

\section{Do latim fili: fio + formus: forma.}

\section{Localidade-tipo: Peru.}

Aspecto Geral: Talo cilíndrico na base e na região mediana e achatado nos ápices, com até $10 \mathrm{~cm}$ de altura e $2 \mathrm{~mm}$ de largura. Ramificação irregular. Ápices afilados. Eixos com ramificação pinada ou unilateral. Râmulos laterais longos (com até 1,5 cm de comprimento), e de ápices afilados, sendo alguns levemente constritos na base e outros não. Proliferações superficiais presentes. Nervura ausente. Estipe indiferenciado. Apressório discoide, com 2 mm de diâmetro.

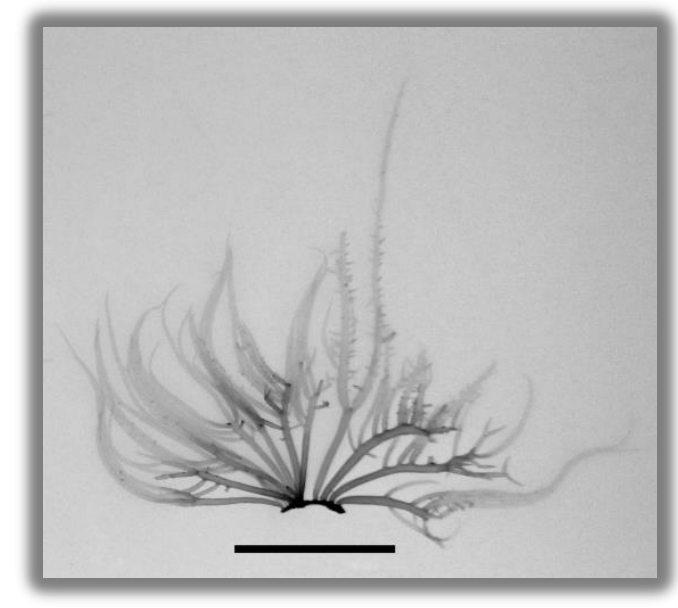

Figura 36. Aspecto geral. Barra de escala: 2 $\mathrm{cm}$.

Região Apical: Talo com 38-44 $\mu \mathrm{m}$ de espessura. Região cortical composta por uma camada de células retangulares de 6-9 $\mu \mathrm{m}$ de altura e 4-5 $\mu \mathrm{m}$ de largura. Região subcortical constituída por 1-2 camadas de células arredondadas de 5-7 $\mu \mathrm{m}$ de diâmetro. Região medular bastante frouxa, com filamentos irregulares de 2-4 $\mu \mathrm{m}$ de diâmetro. Células ganglionares ausentes. Células estreladas com $12 \mu \mathrm{m}$ de largura.

Região Mediana: Talo com $300 \mu \mathrm{m}$ de espessura. Região cortical constituída por uma camada de células quadráticas ou retangulares, de 6-8 $\mu \mathrm{m}$ de altura e 2-5 $\mu \mathrm{m}$ de largura. Região subcortical composta por 3-4 camadas de células arredondadas ou alongadas, de 3-10 $\mu \mathrm{m}$ de diâmetro. Região medular frouxa, com filamentos irregulares de 3-5 $\mu \mathrm{m}$ de diâmetro. Células ganglionares ausentes. Células estreladas com 10-17 $\mu \mathrm{m}$ de largura.

Região Basal: Talo com 370-690 $\mu$ m de espessura. Região cortical composta por 37 camadas de células quadráticas ou retangulares de 3-7,5 $\mu \mathrm{m}$ de altura e 2-6 $\mu \mathrm{m}$ de largura. Região subcortical constituída por três camadas de células arredondadas de 4-15 
$\mu \mathrm{m}$ de diâmetro. Região medular frouxa, com muitos filamentos irregulares de $2-4 \mu \mathrm{m}$ de diâmetro. Células ganglionares ausentes. Células estreladas com 11-13 $\mu \mathrm{m}$ de largura.

Estruturas Reprodutivas: Tetrasporângios imersos na região cortical de ramos laterais, cruciado-decussados, com 25-27,5 $\mu \mathrm{m}$ de altura e 12,5-17,5 $\mu \mathrm{m}$ de diâmetro.Tetrasporócitos observados. Gametófitos femininos e masculinos não observados.

\section{Material Examinado:}

Brasil, Alagoas, Jarapatinga, Praia de Jarapatinga, 22 de novembro de 2014, V. Cassano (IBC 2213). Bahia, Itacaré, Praia do Pedrão, infértil, 02 de agosto de 2012, V. Cassano (SPF 57798/IBC 2060). Ilhéus, Praia do Morro de Pernambuco, 13 de maio de 2014, J. Pires, A.S. Santos e B. Torrano-Silva (IBC 2616). Espírito Santo, Aracruz, Praia dos Padres, infértil, 14 de novembro de 2012, M.T. Fujii (SPF 57789/IBC 2080). São

Paulo, Ubatuba, Praia Vermelha, tetrasporófito, 17 de outubro de 2013, M.C. Oliveira e E.C. Oliveira (IBC 2193).

\section{Comentários:}

Na filogenia inferida a partir do gene $r b c \mathrm{~L}$ (Figura 4), espécimes de G. filiformis aparecem como uma linhagem-irmã de Grateloupia orientalis. Não foi possível comparar com sequências de G. filiformis da localidade-tipo, devido à inexistência das últimas.

O aspecto morfológico geral (Figura 37, a) está de acordo com o descrito para o táxon tratado por Guimarães (1990) como Grateloupia sp. e posteriormente reconhecido como G. filiformis por Yokoya et al. (1993). A espécie já foi previamente citada para os estados do Maranhão, Ceará, Espírito Santo, São Paulo e Santa Catarina (Guimarães 1990; Soares 2015). Neste estudo, a espécie foi encontrada nos estados de Alagoas, Bahia, Espírito Santo e São Paulo. De acordo com nosso conhecimento, este estudo constitui a primeira citação da espécie para o estado da Bahia.

Diversos autores trataram exemplares de eixos achatados e cilíndricos como variações morfológicas de Grateloupia filicina (Joly 1957; Joly 1964; Cordeiro-Marino 1978; Ferreira-Correia 1983; Nunes 2005). No entanto, suspeita-se que as plantas de talo cilíndrico correspondam a G. filiformis. É necessária uma extensa revisão do material depositado nos herbários para correção de possíveis identificações equivocadas. 
Em relação à anatomia interna, a região mediana de G. filiformis apresenta região cortical com uma camada de células retangulares ou quadráticas e região subcortical com 34 camadas de células arredondadas, enquanto que em Grateloupia cf. filicina 1, a região cortical é composta por 4-5 camadas de células elipsoides, e a subcortical por 2-3 camadas de células arredondadas. Além disso, a região medular de G. filiformis na região mediana é frouxa e apresenta poucos filamentos irregulares, enquanto que em Grateloupia cf. filicina 2, a região medular é bastante densa e completamente preenchida por filamentos entrelaçados.

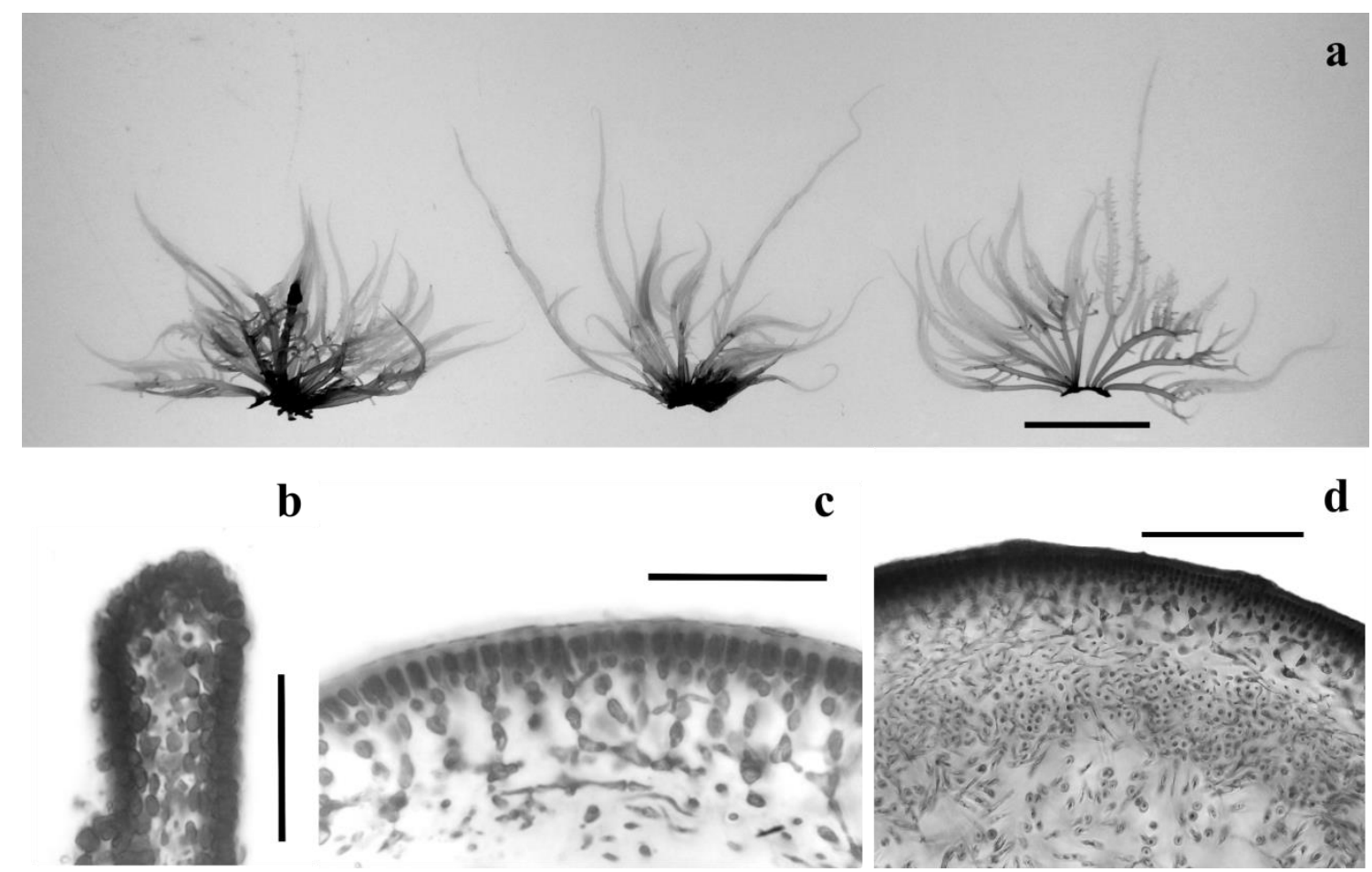

Figura 37. Grateloupia filiformis. Anatomia vegetativa.

(a) Aspecto geral. Barra de escala: 2 cm (IBC 2193);

(b) Corte transversal na região apical do talo. Barra de escala: $50 \mu \mathrm{m}$ (SPF 57789; IBC 2080);

(c) Corte transversal na região mediana do talo. Barra de escala: $50 \mu \mathrm{m}$ (SPF 57789; IBC 2080);

(d) Corte transversal na região basal do talo. Barra de escala: $50 \mu \mathrm{m}$ (SPF 57798; IBC 2060). 


\title{
“Grateloupia” gibbesii Harvey
}

Figs 38 e 39

\begin{abstract}
gibbesii: em homenagem ao coletor americano Lewis R. Gibbes.
Localidade-tipo: Estados Unidos da América, Carolina do Sul.
\end{abstract}

Aspecto Geral: Talo de cor verde escura, mucilaginoso, consistência firme e em forma de fitas lanceoladas, com até 8 cm de altura. Ramificação irregular e abundante. Base cuneada, com fitas mais largas até a região mediana, na qual atingem $0,8 \mathrm{~cm}$ de largura, e mais estreitas em direção ao ápice, com ápice afilado. Frondes levemente retorcidas. Numerosas proliferações superficiais, marginais e apicais.

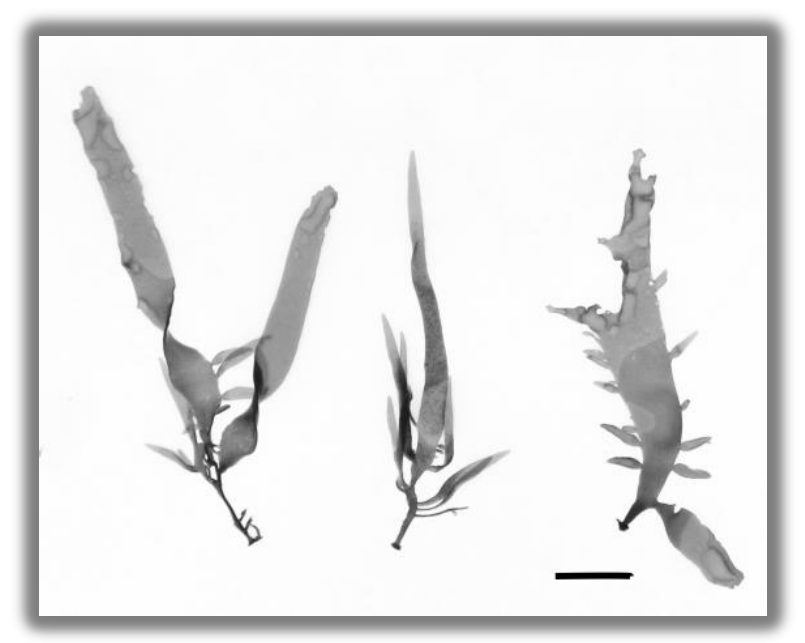

Figura 38. Aspecto geral. Barra de escala: $1 \mathrm{~cm}$. Nervura ausente. Em alguns espécimes, a região proximal é mais escura e mais rígida que o restante do talo. Estipe comprimido, com 1-4 mm de comprimento e $1 \mathrm{~mm}$ de largura. Apressório discoide, com 1-2 mm de diâmetro.

Região Apical: Talo com espessura de 80-157,5 $\mu \mathrm{m}$. Região cortical composta por 1-2 camadas de células retangulares, elipsoides ou ovoides, com 5-10 $\mu \mathrm{m}$ de altura e 3-5 $\mu \mathrm{m}$ de largura. Região subcortical constituída por 2-4 camadas de células arredondadas, com 4-12 m de diâmetro. Região medular frouxa, preenchida por filamentos irregulares, com 1-3 $\mu \mathrm{m}$ de diâmetro. Células ganglionares não foram observadas. Células estreladas expandidas, poligonais, conectando células da região subcortical e filamentos medulares e também entre filamentos medulares, com 10-19 $\mu \mathrm{m}$ de largura.

Região Mediana: Talo com espessura de 175-237,5 $\mu \mathrm{m}$. Região cortical composta por 2-4 camadas moniliformes de células elipsoides ou ovoides, com 4-8 $\mu \mathrm{m}$ de altura e 3-4 $\mu \mathrm{m}$ de largura. Região subcortical constituída por 3-4 camadas de células arredondadas, poligonais ou expandidas, com 3-10 $\mu \mathrm{m}$ de diâmetro. Região medular mais densa que na 
região apical, composta por numerosos filamentos irregulares e entrelaçados, de 2-3 $\mu \mathrm{m}$ de diâmetro. Células ganglionares não observadas. Células estreladas com 9-18 $\mu \mathrm{m}$ de diâmetro, conectando células da região subcortical e fillamentos medulares.

Região Basal: Talo com 270-340 $\mu \mathrm{m}$ de espessura. Corticação secundária presente em alguns espécimes. Região cortical com aproximadamente 20 camadas de células quadráticas, com 3-5 $\mu \mathrm{m}$ de altura e 2-4 $\mu \mathrm{m}$ de largura. Região subcortical constituída por 2-4 camadas de células arredondadas, 5-9 $\mu \mathrm{m}$ de diâmetro. Região medular muito densa, completamente preenchida com numerosos filamentos irregulares, entrelaçados e semelhantes a rizines, de 2-5 $\mu \mathrm{m}$ de diâmetro. Células ganglionares não observadas. Células estreladas presentes, com 10-13 $\mu \mathrm{m}$ de diâmetro.

Estruturas Reprodutivas: Cistocarpos abundantes na região mediana, imersos na região medular, mas que causam uma leve protuberância no talo em virtude de seu grande tamanho. Cistocarpos maduros com 67,5-197,5 $\mu \mathrm{m}$ de diâmetro, constituídos por 1 ou 2 gonimolobos. Pericarpo com $210 \mu \mathrm{m}$ de diâmetro. Carposporângios arredondados ou de formato poligonal, com 4-11 $\mu \mathrm{m}$ de diâmetro. Célula de fusão com 11-22,5 $\mu \mathrm{m}$ de diâmetro. Ampolas da célula auxiliar abundantes na região mediana, constituídas por célula auxiliar intercalar (9-15 $\mu \mathrm{m}$ de altura e 5-9 $\mu \mathrm{m}$ de largura) e 2-3 filamentos ampolares com aproximadamente 8 células. O filamento primário é ramificado apenas uma vez. Espermatângios visualizados na região mediana do talo, de formato elipsoide ou ovoide, com 2-3 $\mu \mathrm{m}$ de diâmetro. Células-mães de espermatângios divididas obliquamente ou transversalmente. Tetrasporófitos não observados.

\section{Material examinado:}

Brasil, Espírito Santo, Itapemirim, Praia de Itaoca, gametófito feminino, 06 de maio de 2012, B. Torrano-Silva, C. Iha e F. Nauer (IBC 2032). Guarapari, Praia dos Namorados, gametófito feminino, 08 de maio de 2012, B. Torrano-Silva, C. Iha, F. Nauer, M.C. Oliveira (SPF 57803/IBC 2040). Marataízes, Praia da Cruz, 10 de setembro de 2014, T. Vieira-Pinto (IBC 2212). Guarapari, Praia de Areia Preta, 05 de abril de 2012, B. Torrano-Silva e C.E. Amâncio (IBC 2014). Rio de Janeiro, Armação dos Búzios, Praia Rasa, gametófito feminino, 17 de março de 2014, C.A.A. Azevedo, V. Cassano, M. Mungioli, J.C. De Paula, E. Lopes Filho (IBC 2202). Armação dos Búzios, Praia da Foca, 
09 de março de 2015, C.A.A. Azevedo, V. Cassano e M. Mungioli (IBC 2223). Armação dos Búzios, Ponta da Lagoinha, 05 de maio de 2012, V. Cassano (IBC 2029; IBC 2030). São Paulo, São Vicente, Prainha da Ponte Pênsil, 21 de março de 2011, E.C. Oliveira (IBC 2011). Santa Catarina, Florianópolis, Prainha, 17 de outubro de 2011, E.C. Oliveira e M.C. Oliveira (IBC 2000; IBC 2001).

\section{Comentários:}

Diversos indivíduos tratados aqui como Grateloupia gibbesii foram coletados no litoral do Brasil, nos estados do Espírito Santo, Rio de Janeiro, São Paulo e Santa Catarina. $\mathrm{Na}$ árvore de $r b c \mathrm{~L}$ (Figura 4), essas amostras agruparam com a sequência de Grateloupia gibbesii coletada na localidade-tipo da espécie (Carolina do Sul, Estados Unidos), e formaram um clado com 98\% de suporte. As amostras IBC 2030, IBC 2223, IBC 2226 e IBC 2228 divergiram apenas 0,2-0,4\% em relação à sequência de G. gibbesii proveniente da Carolina do Sul (Tabela 10). No entanto, IBC 2001 divergiu 1,7-1,9\% do grupo formado por IBC 2030, IBC 2223, IBC 2226 e IBC 2228. IBC 2014, por sua vez, divergiu em 2,8\% em relação a IBC 2001, e em 1,4-1,6\% em relação às demais amostras. Em relação ao marcador UPA, apenas a amostra IBC 2014 divergiu das demais, em 0,3\%, isto é, apenas os marcadores plastidiais indicaram uma divergência entre essa amostra e as demais. Todas as sequências de COI-5P desses indivíduos pertenceram a um único clado.

Tabela 10. Valores de divergência (\%) de $r b c \mathrm{~L}$ para amostras de Grateloupia gibbesii.

\begin{tabular}{cccccccc}
\hline & G. & IBC & IBC & IBC & IBC & IBC & IBC \\
& gibbesii* & 2001 & 2014 & 2030 & 2223 & 2226 & 2228 \\
\hline G. gibbesii * & & & & & & & \\
IBC 2001 & 1,9 & & & & & & \\
IBC 2014 & 1,5 & 2,8 & & & & & \\
IBC 2030 & 0,2 & 1,7 & 1,4 & & & & \\
IBC 2223 & 0,2 & 1,7 & 1,4 & 0 & & & \\
IBC 2226 & 0,2 & 1,7 & 1,5 & 0,1 & 0,1 & & \\
IBC 2228 & 0,4 & 1,9 & 1,6 & 0,2 & 0,2 & 0,2 \\
*Corresponde à sequência "Grateloupia gibbesii JX645160 EUA-Carolina do Sul".
\end{tabular}

Esse táxon foi registrado diversas vezes no Brasil sob os nomes de Grateloupia doryphra (Montagne) M.A.Howe (Guimarães, 1990) e Grateloupia cuneifolia J.Agardh ex 
Kützing (Cordeiro-Marino, 1978). O material analisado aqui concorda com G. doryphora de Guimarães (1990). Os espécimes do estado de Santa Catarina identificado por CordeiroMarino (1978) como Grateloupia cuneifolia diferem do material encontrado neste estudo apenas por apresentar estipe cilíndrico e ramificação ausente. Os demais aspectos estão de acordo.

Alguns autores sugeriram que as espécies Grateloupia cuneifolia, Grateloupia gibbesii, G. schizophylla Kützing, G. californica Kylin, G. lanceola (J.Agardh) J.Agardh e G. doryphora correspondem a um mesmo táxon, sendo G. cuneifolia o nome prioritário (Howe 1914; Ardré \& Gayral 1961; Dawson et al. 1964; De Masi \& Gargiulo 1982). As localidades-tipo dessas espécies são, respectivamente, Venezuela, EUA-Carolina do Sul, Chile, EUA-California, Espanha e Peru. Entre essas, não existem sequências de COI-5P ou $r b c \mathrm{~L}$ disponíveis de $G$. cuneifolia e G. lanceola. Em relação às demais, o material aqui encontrado coincide molecularmente com Grateloupia gibbesii, mas é distinto de $G$. schizophylla, G. californica e G. doryphora.

Sendo assim, opta-se por comparar o material brasileiro apenas com G. cuneifolia e G. gibbesii, que são espécies cuja localidade-tipo é o Atlântico Ocidental. A descrição original de G. cuneifolia diz que a espécie possui estipe comprimido-cuneado, ramificação palmada abundante, frondes alongadas fendidas com base geralmente constrita, margens adultas com proliferações diminutas semelhantes a cílios e ápices lobados (Kützing 1849). A partir da descrição original de G. gibbesii, não é possível apontar nenhuma característica sólida que a separe de G. cuneifolia (Harvey 1853). Harvey (1853) incluiu as duas entidades em sua obra como táxons distintos, mas não fez uma comparação entre elas, e, ainda, ressaltou que a G. gibbesii exibe frondes de morfologia muito variada. Taylor (1960) mencionou que G. gibbesii poderia ser uma variante morfológica de G. cuneifolia. Pela morfologia externa, os indivíduos coletados no Brasil poderiam corresponder tanto a $G$. cuneifolia quanto a G. gibbesii.

Considerando que a sequência da entidade brasileira agrupa com Grateloupia gibbesii da Carolina do Sul, é bastante provável que G. cuneifolia da Venezuela seja a mesma espécie. No entanto, devido à ausência de sequências de G. cuneifolia coletada na localidade-tipo, não é possível inferir coespecificidade entre essas três entidades. Opta-se, portanto, por tratar o táxon brasileiro como Grateloupia gibbesii até que sequências de $G$. 
cuneifolia estejam disponíveis. Caso G. gibbesii seja de fato uma variante morfológica de $G$. cuneifolia, as duas deverão ser sinonimizadas, prevalecendo o nome mais antigo $G$. cuneifolia. 

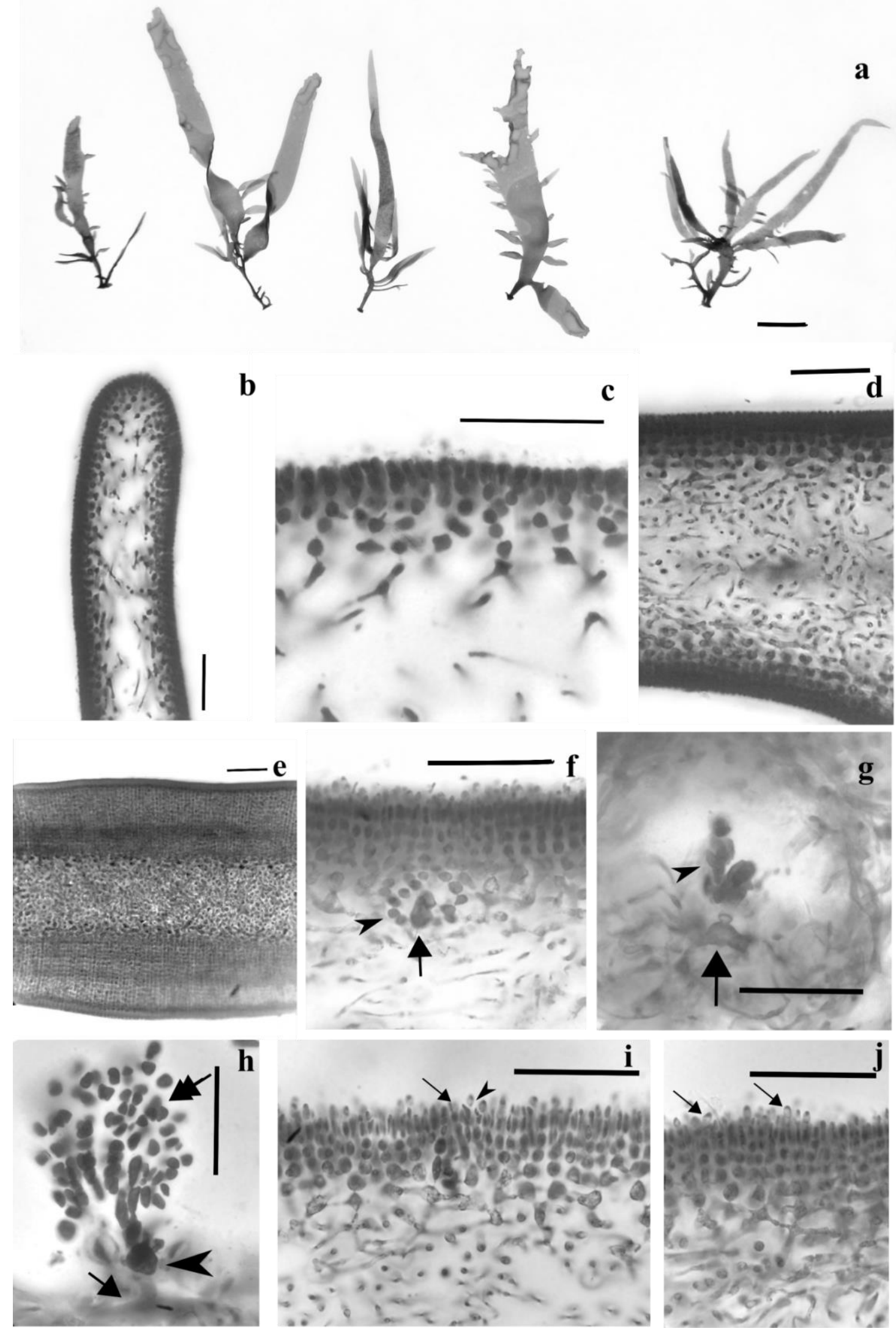

Figura 39. "Grateloupia" gibbesii. Anatomia vegetativa e reprodutiva. 
(a) Aspecto geral. Barra de escala: $1 \mathrm{~cm}$ (IBC 2032);

(b) Corte transversal na região apical do talo. Barra de escala: $50 \mu \mathrm{m}$ (IBC 2032);

(c) Detalhe do corte transversal na região apical do talo. Barra de escala: $50 \mu \mathrm{m}$ (IBC 2202);

(d) Corte transversal na região mediana do talo. Barra de escala: $50 \mu \mathrm{m}$ (IBC 2040);

(e) Corte transversal na região basal do talo. Barra de escala: $50 \mu \mathrm{m}$ (IBC 2040);

(f) Corte transversal na região mediana do talo mostrando ampola da célula auxiliar em visão longitudinal. Seta e ponta de seta indicam, respectivamente, célula auxiliar e filamento ampolar. Barra de escala: $50 \mu \mathrm{m}$ (IBC 2202);

(g) Corte transversal na região mediana do talo mostrando carposporófito em desenvolvimento, em visão longitudinal. Seta indica célula auxiliar após a fusão com o núcleo diploide e ponta de seta indica gonimoblastos. Barra de escala: $50 \mu \mathrm{m}$ (IBC 2032);

(h) Corte transversal na região mediana do talo mostrando carposporófito em desenvolvimento. Seta indica célula auxiliar após fusão com o núcleo diploide, ponta de seta aponta para a inicial dos gonimoblastos e seta dupla indica carposporângios. Barra de escala: 50 m (IBC 2040);

(i) Corte transversal na região mediana do talo mostrando células-mãe de espermatângios cortadas obliquamente (seta) e espermatângios (ponta de seta). Barra de escala: 50 m (IBC 2202);

(j) Corte transversal na região mediana do talo mostrando espermatângios (setas). Barra de escala: $50 \mu \mathrm{m}$ (IBC 2202). 


\section{Grateloupia orientalis S.M.Lin \& H.Y.Liang}

Figs 40 e 41

orientalis: indica a localidade geográfica onde a espécie foi encontrada, na Ásia oriental.

Localidade-tipo: Taiwan.

Aspecto Geral: Talo de cor vermelha escura ou marrom, mucilagioso e delicado. Talo comprimido, de ápices afilados. Alguns exemplares apresentam ramificação pinada, outros, ramificação escassa e irregular. Râmulos laterais abundantes em alguns espécimes ou ausentes em outros. Frondes de até $9 \mathrm{~cm}$ de altura e $1 \mathrm{~mm}$ de largura. Nervura ausente. Estipe cilíndrico, de $1 \mathrm{~mm}$ de comprimento e $0,5 \mathrm{~mm}$ de diâmetro. Apressório discoide, de $1 \mathrm{~mm}$ de diâmetro.

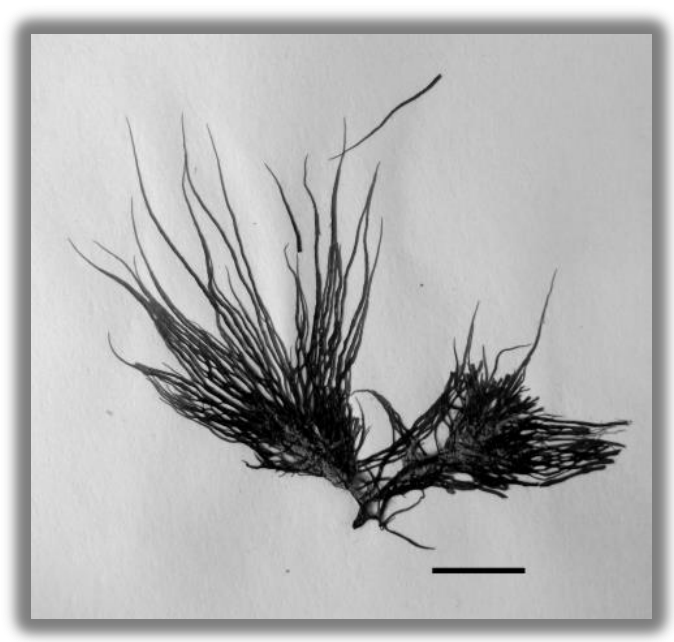

Figura 40. Aspecto geral. Barra de escala: 1 $\mathrm{cm}$.

Região Apical: Talo com 150-160 $\mu \mathrm{m}$ de espessura. Região cortical composta por 3 camadas de células quadráticas moniliformes, de 4-5 $\mu \mathrm{m}$ de altura e 3-4 $\mu \mathrm{m}$ de largura. Região subcortical constituída por 1-2 camadas de células arredondadas ou poligonais, de 5-7 $\mu \mathrm{m}$ de diâmetro. Região medular com filamentos irregulares de 1-2 $\mu \mathrm{m}$ de diâmetro. Células ganglionares e estreladas não observadas.

Região Mediana: Talo com 300-320 $\mu \mathrm{m}$ de espessura. Região cortical composta por 4-5 camadas de células quadráticas moniliformes, de 4-5 $\mu \mathrm{m}$ de altura e 3-4 $\mu \mathrm{m}$ de largura. Região subcortical constituída por 2-3 camadas de células arredondadas ou poligonais, de 5-7 $\mu \mathrm{m}$ de diâmetro. Região medular preenchida por filamentos irregulares de 1-2 $\mu \mathrm{m}$ de diâmetro. Células ganglionares não encontradas. Células estreladas presentes.

Região Basal: Talo com 235-270 $\mu \mathrm{m}$ de espessura. Região cortical bastante espessa, com aproximadamente 8 camadas de células quadráticas, de 5-6 $\mu \mathrm{m}$ de altura e 4-5 $\mu \mathrm{m}$ de largura. Região subcortical com 2-3 camadas de células poligonais, de 5-6 $\mu \mathrm{m}$ de 
diâmetro. Região medular bastante densa, com abundantes filamentos longitudinais com aspecto de rizines, de 1-2 $\mu \mathrm{m}$ de diâmetro. Células ganglionares não observadas. Células estreladas presentes, mas obscurecidas pelos densos filamentos.

Estruturas Reprodutivas: Ampola da célula auxiliar composta por três filamentos não ramificados, com aproximadamente 7-9 células. Cistocarpo completamente imerso no talo, com 1-2 gonimolobos. Gonimoblasto com 87,5-112,5 $\mu \mathrm{m}$ de diâmetro. Cistocarpos com 102,5-142,5 $\mu \mathrm{m}$ de diâmetro. Gametófitos masculinos e tetrasporófitos não observados.

\section{Material examinado:}

Brasil, São Paulo, São Vicente, Prainha da Ponte Pênsil, gametófito feminino, 21 de março de 2011, E.C. Oliveira (SPF 57822; IBC 2009). São Paulo, São Vicente, Prainha da Ponte Pênsil, infértil, 21 de março de 2011, E.C. Oliveira (SPF 57807; IBC 2010). São Vicente, Ilha Porchat, gametófito feminino, 21 de março de 2011, E.C. Oliveira (SPF 57806; IBC 2013). Ubatuba, Praia do Lázaro, 17 de maio de 2015, C.A.A. Azevedo (IBC 2248).

\section{Comentários:}

Indivíduos de G. orientalis formam um agrupamento de elevado suporte (100) na árvore gerada com dados de COI-5P (Figura 3). A sequência de $r b c \mathrm{~L}$ representante desse grupo tem 99,9\% de identidade em relação à sequência de material da localidade-tipo de $G$. orientalis. Morfologicamente, tanto as características vegetativas quanto as reprodutivas estão de acordo com a descrição original da espécie (Lin et al. 2008).

Neste estudo, esse táxon foi encontrado no ano de 2011 em duas praias no município de São Vicente, e em 2015, em uma praia de Ubatuba, no litoral de São Paulo. De acordo com o nosso conhecimento, esta é a primeira vez que G. orientalis é registrada fora de sua localidade-tipo. Não se sabe se a espécie é uma potencial invasora, uma vez que não foram encontrados tais registros na literatura. 

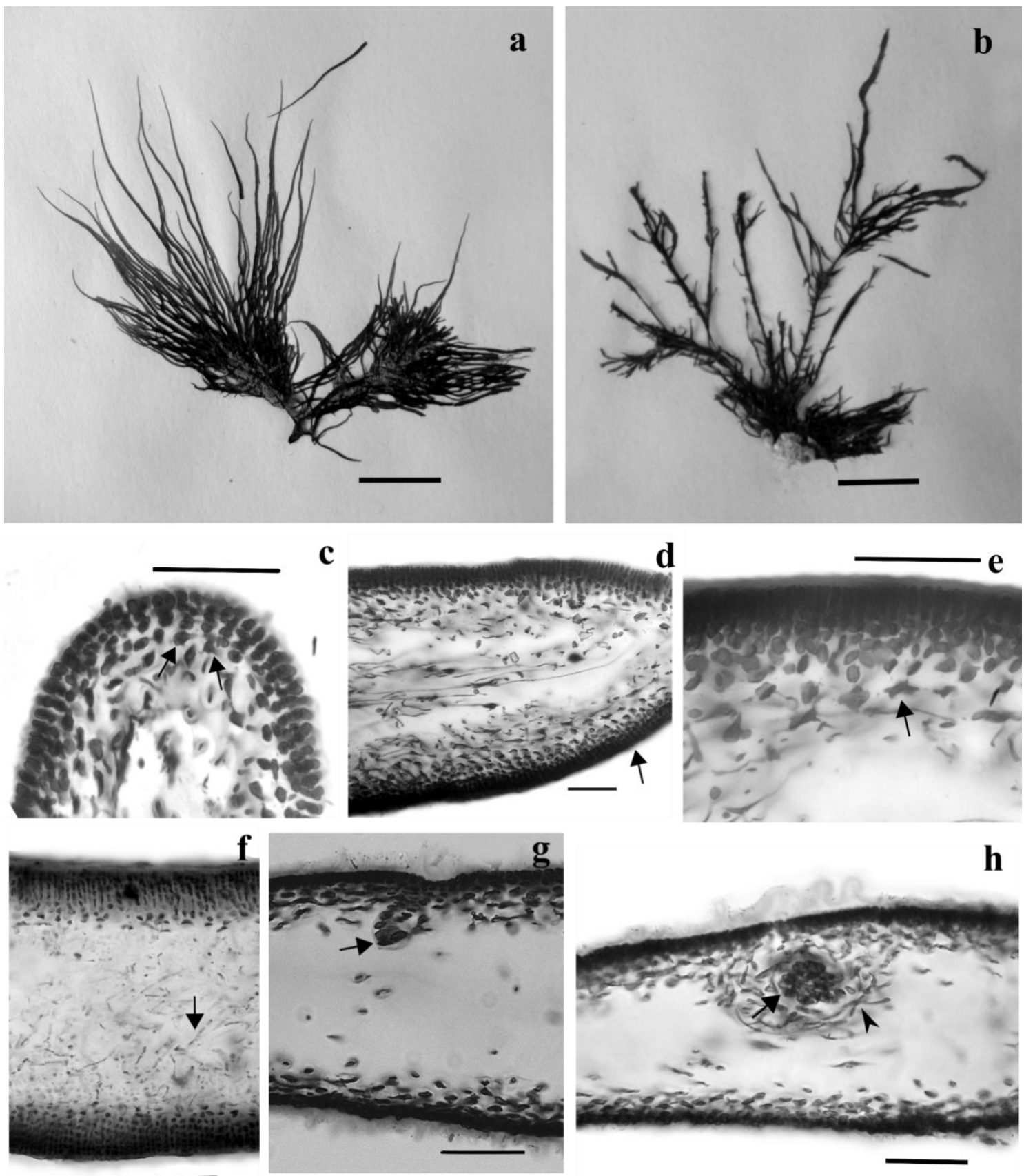

Figura 41. Grateloupia orientalis. Anatomia vegetativa e reprodutiva.

(a) Aspecto geral mostrando talo com ramificação escassa. Barra de escala: 1 cm (SPF 57822/IBC 2009);

(b) Aspecto geral mostrando talo com ramificação pinada. Barra de escala: 1 cm (SPF 57806/IBC 2013);

(c) Corte transversal na região apical do talo. Setas indicam células da região subcortical. Barra de escala: 50 $\mu \mathrm{m}(\mathrm{SPF} 57806 / \mathrm{IBC} 2013)$;

(d) Corte transversal na região mediana do talo. Seta indica a região cortical. Barra de escala: $50 \mu \mathrm{m}$ (SPF 57806/IBC 2013);

(e) Detalhe do corte transversal na região mediana do talo. Seta indica célula estrelada. Barra de escala: 50 $\mu \mathrm{m}(\mathrm{SPF} 57806 / \mathrm{IBC} 2013)$; 
(f) Corte transversal na região basal do talo. Seta indica filamento medular. Barra de escala: $50 \mu \mathrm{m}$ (SPF 57822/IBC 2009);

(g) Corte transversal na região mediana do talo mostrando ampola da célula auxiliar composta por 2-3 filamentos ampolares não ramificados (seta). Barra de escala: 50 m (SPF 57822/IBC 2009);

(h) Corte transversal na região mediana do talo mostrando cistocarpo em desenvolvimento. A seta indica o gonimoblasto e a ponta de seta indica os filamentos do pericarpo. Barra de escala: $50 \mu \mathrm{m}$ (SPF 57822/IBC 2009). 


\section{Grateloupia turuturu}

Esse táxon é tratado no anexo IV, que corresponde ao artigo intitulado "Detecting the nonnative Grateloupia turuturu (Halymeniales, Rhodophyta) in southern Brazil", submetido ao periódico Phycologia. 


\section{Grateloupia yangjiangensis W.-X. Li \& Z.-F. Ding}

Figs 42 e 43

\section{Em referência à localidade-tipo Yangjiang, China. \\ Localidade-tipo: Zhapo, Yangjiang, Guangdong, China.}

\section{Aspecto Geral: Talo firme,} cartilaginoso, cilíndrico nas regiões basal e apical e achatado na região mediana, com até $2 \mathrm{~cm}$ de altura e $2 \mathrm{~mm}$ de largura. Ramificação predominantemente pinada, mas com algumas ramificações unilaterais e alternadas. Ápices em sua maioria afilados, e alguns bifurcados. Râmulos laterais não constritos na base, ou com raras constrições discretas. Proliferações superficiais de aspecto espinescente.

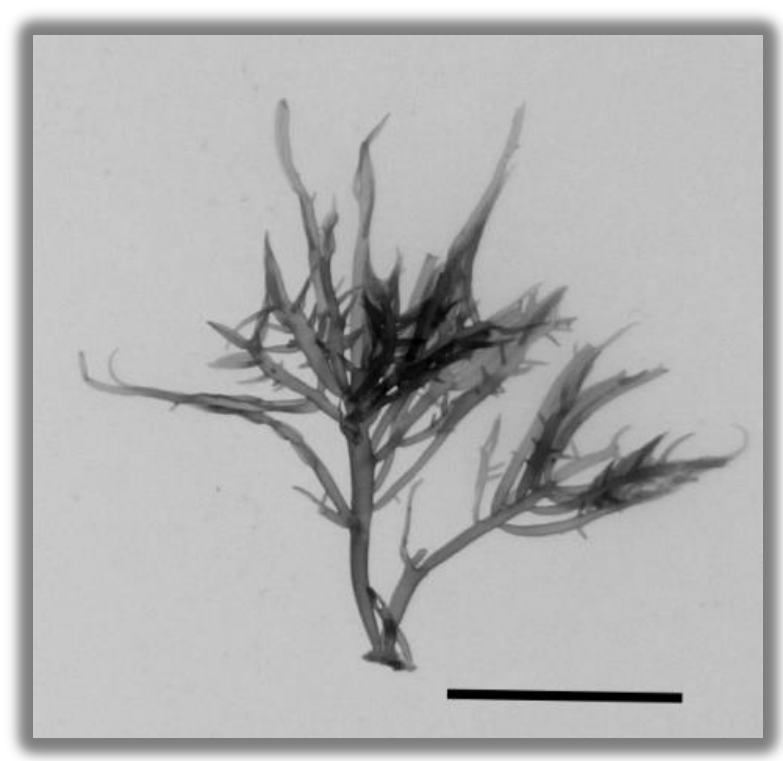

Figura 42. Aspecto geral. Barra de escala: $1 \mathrm{~cm}$. Nervura ausente. Estipe indiferenciado. Apressório discoide, com aproximadamente 0,5 mm de diâmetro.

Região Apical: Talo com 150-205 $\mu \mathrm{m}$ de espessura. Região cortical composta por uma cada de células retangulares ou quadráticas, de 2,5-7,5 $\mu \mathrm{m}$ de altura e 2,5-7,5 $\mu \mathrm{m}$ de largura. Região subcortical constituída por 1-2 camadas de células esféricas e periclinalmente alongadas, de 2,5-5 $\mu$ m de diâmetro. Região medular com aparência de vazia, com poucos filamentos dispostos irregularmente, de 2,5 $\mu \mathrm{m}$ de diâmetro. Células ganglionares ausentes. Células estreladas de formato poligonal, com 10-12,5 $\mu \mathrm{m}$ de largura.

Região Mediana: Talo com espessura de 420-550 $\mu \mathrm{m}$. Região cortical com 3-4 camadas moniliformes de células elipsoides, de 5-7,5 $\mu \mathrm{m}$ de altura e 2,5 $\mu \mathrm{m}$ de largura. Região subcortical composta por 2-3 camadas de células esféricas de 5-7,5 $\mu \mathrm{m}$ de diâmetro. Região medular densa, com filamentos entrelaçados de 2,5-5 $\mu \mathrm{m}$ de diâmetro. Células ganglionares ausentes. Células estreladas de formato poligonal, com 12,5-15 $\mu \mathrm{m}$ de largura. 
Região Basal: Talo com 540-560 $\mu \mathrm{m}$ de espessura. Região cortical com 6-7 camadas moniliformes de células elipsoides, de 5-7,5 $\mu \mathrm{m}$ de altura e 2,5-5 $\mu \mathrm{m}$ de largura. Região subcortical com 3-4 camadas de células esféricas de 5-7,5 $\mu \mathrm{m}$ de diâmetro. Região medular mais densa que na região mediana, com filamentos entrelaçados de 5-7,5 $\mu \mathrm{m}$ de diâmetro. Células ganglionares ausentes. Células estreladas de formato poligonal, com 2022,5 $\mu \mathrm{m}$ de largura.

Estruturas Reprodutivas: Não observadas.

\section{Material Examinado:}

Brasil, São Paulo, Ubatuba, Praia do Lázaro, 17 de maio de 2015, C.A.A. Azevedo (IBC 2246; IBC 2247 e IBC 2249).

\section{Comentários:}

Segundo Wang et al. (2014), G. yangjiangensis possui região cortical composta por 5-8 camadas de células e região subcortical com 2-3 camadas células. No entanto, os autores não mencionam em que região do talo as medições foram feitas. Essa espécie se assemelha muito, no aspecto geral, a Grateloupia filiformis que ocorre no Brasil. Em relação à anatomia interna, as duas espécies diferem apenas na estrutura da região mediana do talo, a qual é densa em G. yangjiangensis e frouxa em G. filiformis. Além disso, em G. filiformis, a região cortical possui uma camada de células e o interno apresenta 3-4 camadas, enquanto que em G. yangjiangensis, a região cortical é composta por 3-4 e o interno por 1-2 camadas de células.

Foi observada uma grande semelhança na morfologia externa de G. yangjiangensis, G. filiformis, G. orientalis, Grateloupia cf. filicina 1 e Grateloupia cf. filicina 2, as quais compreendem indivíduos de talo cilíndrico ou levemente achatado, com ramificação pinada ou alternada e ápices afilados, de maneira que não é possível distinguir essas espécies observando apenas o aspecto geral. Algumas diferenças na anatomia interna foram observadas e discutidas nas seções anteriores.

De acordo com nosso conhecimento, essa é a primeira vez que G. yangjiangensis é registrada fora de sua localidade-tipo (China). Não se sabe se a espécie é uma potencial invasora, uma vez que não foram encontrados tais registros na literatura. 


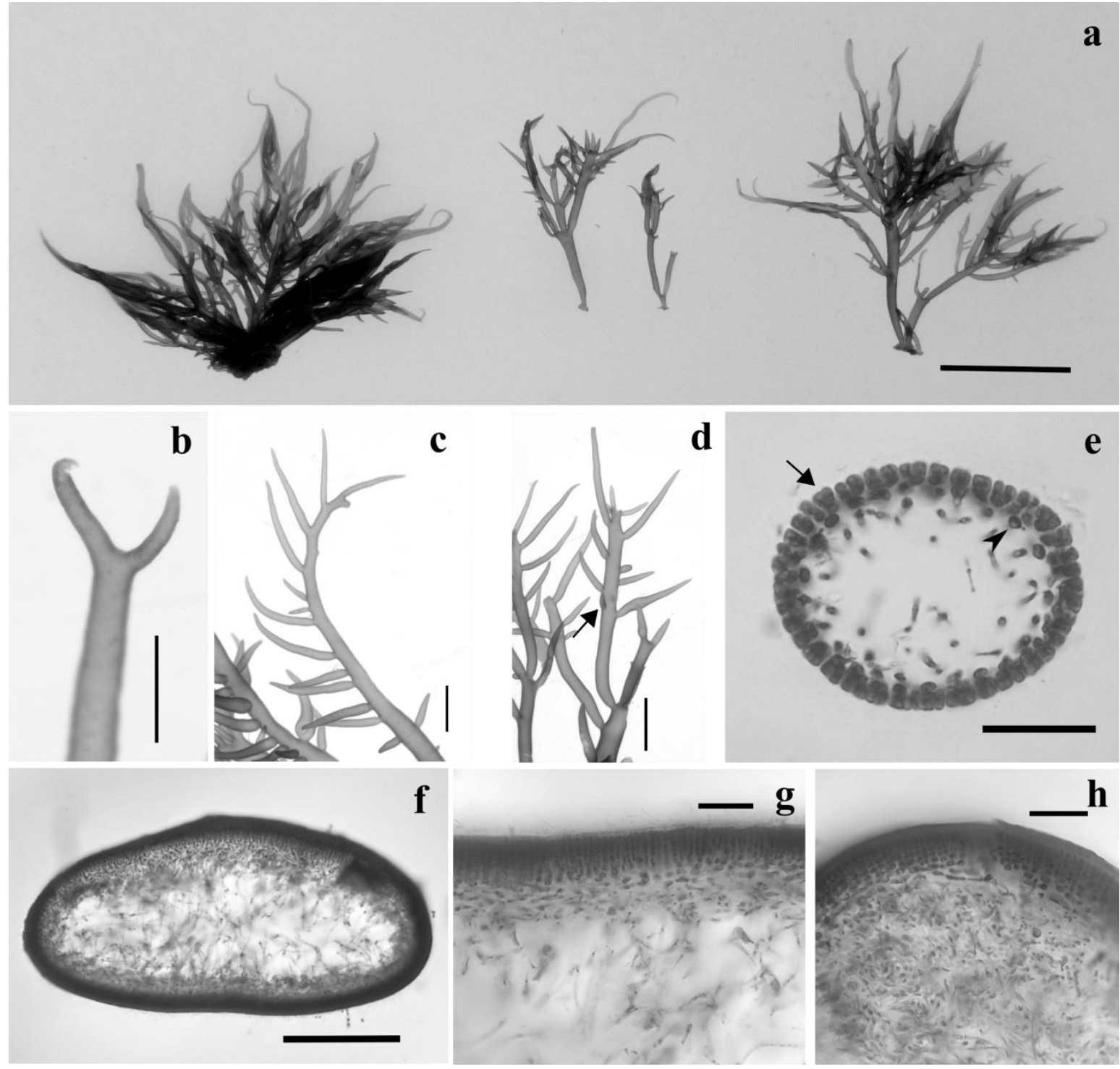

Figura 43. Grateloupia yangjiangensis. Anatomia vegetativa. Todas as imagens são de IBC 2247.

(a) Aspecto geral. Barra de escala: $1 \mathrm{~cm}$;

(b) Detalhe de ápice bifurcado. Barra de escala: 0,5 mm;

(c) Detalhe mostrando ramificação unilateral. Barra de escala: $1 \mathrm{~mm}$;

(d) Detalhe mostrando proliferação superficial (seta). Barra de escala: 0,5 mm;

(e) Corte transversal na região apical do talo. Seta e ponta de seta indicam célula da região cortical e subcortical, respectivamente. Barra de escala: $50 \mu \mathrm{m}$;

(f) Corte transversal na região mediana do talo. Barra de escala: $300 \mu \mathrm{m}$;

(g) Detalhe do corte transversal na região mediana. Barra de escala: $50 \mu \mathrm{m}$;

(h) Corte transversal na região basal do talo. Barra de escala: $50 \mu \mathrm{m}$. 
TÁXONS INDEFINIDOS 


\section{Halymeniales sp. 1}

Figs 44 e 45

Aspecto Geral: Talo de cor rosa, mucilaginoso, muito flácido e delicado, de $6 \mathrm{~cm}$ de altura e largura de até $1,7 \mathrm{~cm}$. Lâmina única, fendida. Margens lisas. Nervura ausente. Estipe cilíndrico, de $3 \mathrm{~mm}$ de comprimento e $1 \mathrm{~mm}$ de diâmetro. Apressório discoide, de $1 \mathrm{~mm}$ de diâmetro.

Região Apical: Região medular bem frouxa, com filamentos anticlinais.

Região Mediana: Talo com 75-87,5 $\mu \mathrm{m}$ de espessura. Região cortical com 1-2 camadas de células de formato irregular, incluindo retangulares, quadráticas e elipsoides, de

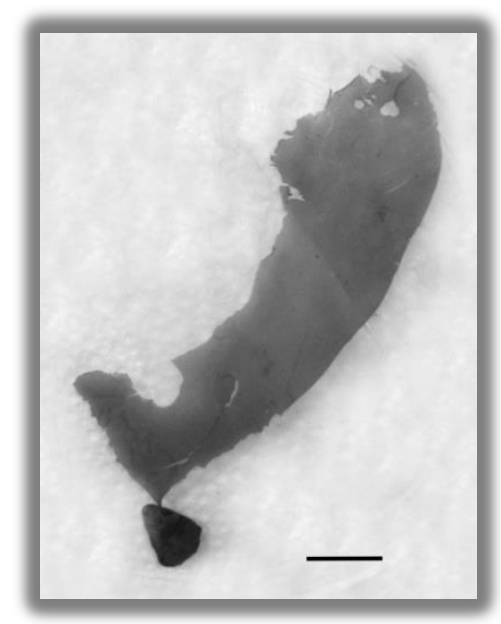

Figura 44. Aspecto geral. Barra de escala: $1 \mathrm{~cm}$. 7,5-10 $\mu \mathrm{m}$ de altura e 12,5-15 $\mu \mathrm{m}$ de largura. Região medular frouxa, com filamentos de 5 $\mu \mathrm{m}$ de diâmetro.

Região Basal: Talo com 117,5-160 $\mu \mathrm{m}$ de espessura. Região cortical com 1-2 camadas de células de formato irregular, incluindo retangulares, quadráticas e elipsoides, de 7,5-10 $\mu \mathrm{m}$ de altura e 12,5-15 $\mu \mathrm{m}$ de largura.

Estruturas Reprodutivas: Tetrasporângios cruciado-decussados, com 17,5 $\mu \mathrm{m}$ de altura e 10-12,5 um de largura, imersos no Região cortical da região mediana. Gametófitos femininos e masculinos não observados.

\section{Material Examinado:}

Brasil, Bahia, Salvador, Banco da Panela, infralitoral, tetrasporófito, 22 de maio de 2013, B. Torrano-Silva e M. Jamas (SPF 57811/IBC 2161).

\section{Comentários:}

As reconstruções filogenéticas mostram Halymeniales sp. 1 isolada e fora do clado que contém espécie-tipo do gênero Halymenia, o que é um indicativo de que essa entidade corresponde a outro gênero (Figuras 4 e 5). 
Morfologicamente, o táxon Halymeniales sp. 1 se aproxima muito da descrição original de Halymenia integra M.A. Howe \& W.R. Taylor, no entanto, difere do materialtipo de $H$. integra analisado por não apresentar as grandes células esféricas na região subcortical.
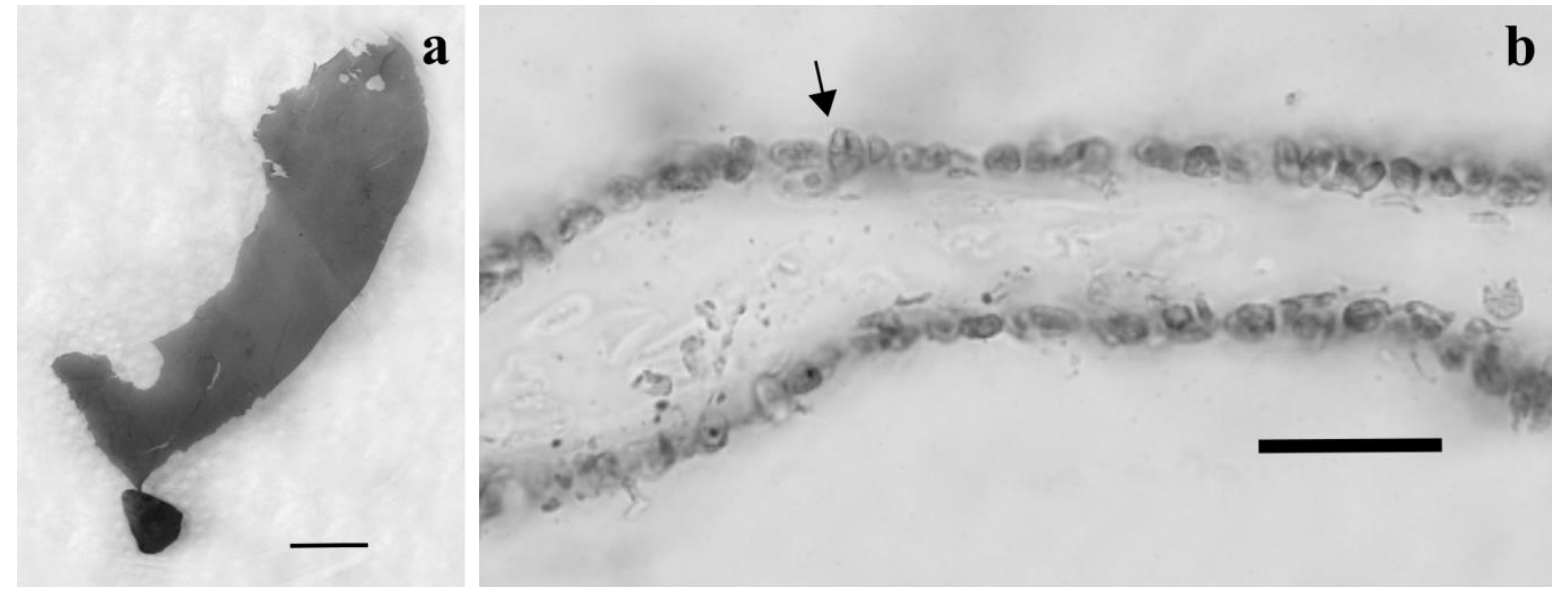

Figura 45. Halymeniales sp. 1. Anatomia vegetativa e reprodutiva. Imagens de SPF 57811/IBC 2164.

(a) Aspecto geral. Barra de escala: $1 \mathrm{~cm}$;

(b) Corte transversal na região mediana do talo. Seta indica tetrasporângio cruciado. Barra de escala: $50 \mu \mathrm{m}$. 


\section{Halymeniales sp. 2}

Figs 46 e 47

Aspecto Geral: Talo de cor rosa, mucilaginoso, membranoso, muito delicado, que se rasga facilmente. Lâmina fragmentada, de maneira que não é possível saber qual a altura do talo. $\mathrm{O}$ fragmento possui $3,5 \mathrm{~cm}$ de comprimento e 1,2 de largura. Ápice arredondado e margens levemente onduladas. Proliferações superficiais e marginais ausentes. Região basal, estipe e apressório ausentes na amostra. Apenas um corte foi realizado no que

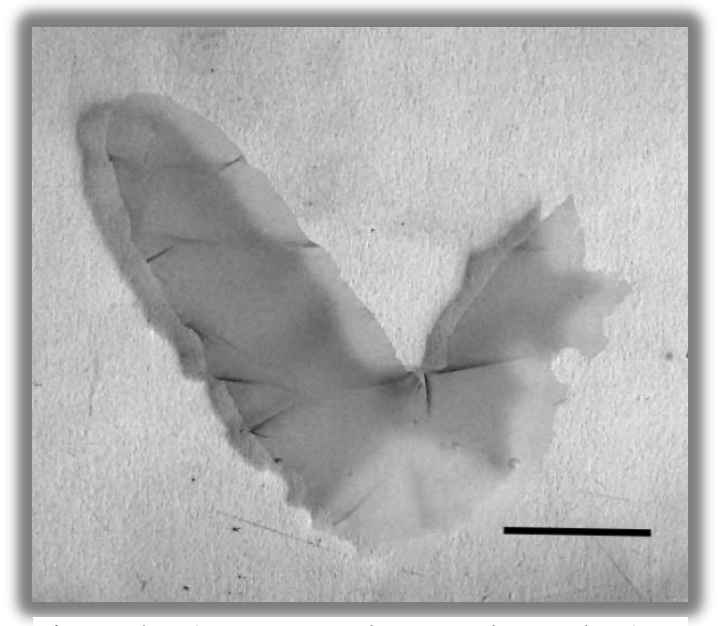
Figura 46. Aspecto geral. Barra de escala: 1 $\mathrm{cm}$.

supostamente corresponde à região mediana. Talo com 35-37,5 $\mu \mathrm{m}$ de espessura. Região cortical composta por uma camada de células retangulares ou de formato irregular, mais largas que altas, com 4-5 $\mu \mathrm{m}$ de altura e 8-9 $\mu \mathrm{m}$ de largura. Região subcortical ausente. Região medular muito frouxa, apenas com poucos filamentos periclinais de 3-4 $\mu \mathrm{m}$ de diâmetro. Células ganglionares e estreladas não encontradas. Tetrasporângios abundantes, imersos na região cortical, cruciados-decussados, com 15-17,5 $\mu \mathrm{m}$ de altura e 12-12,5 $\mu \mathrm{m}$ de largura. Gametófitos femininos e masculinos não observados.

\section{Material Examinado:}

Brasil, Bahia, Salvador, Banco da Panela, tetrasporófito, 22 de maio de 2013, B. Torrano-Silva e M. Jamas (IBC 2165).

\section{Comentários:}

A morfologia externa desse indivíduo se assemelha a Halymeia vinacea e Halymenia integra, porém difere de $H$. vinacea em virtude das margens onduladas e da ausência de células ganglionares. Também não poderia ser $H$. integra, pois não apresenta as grandes células arredondadas na região subcortical. 

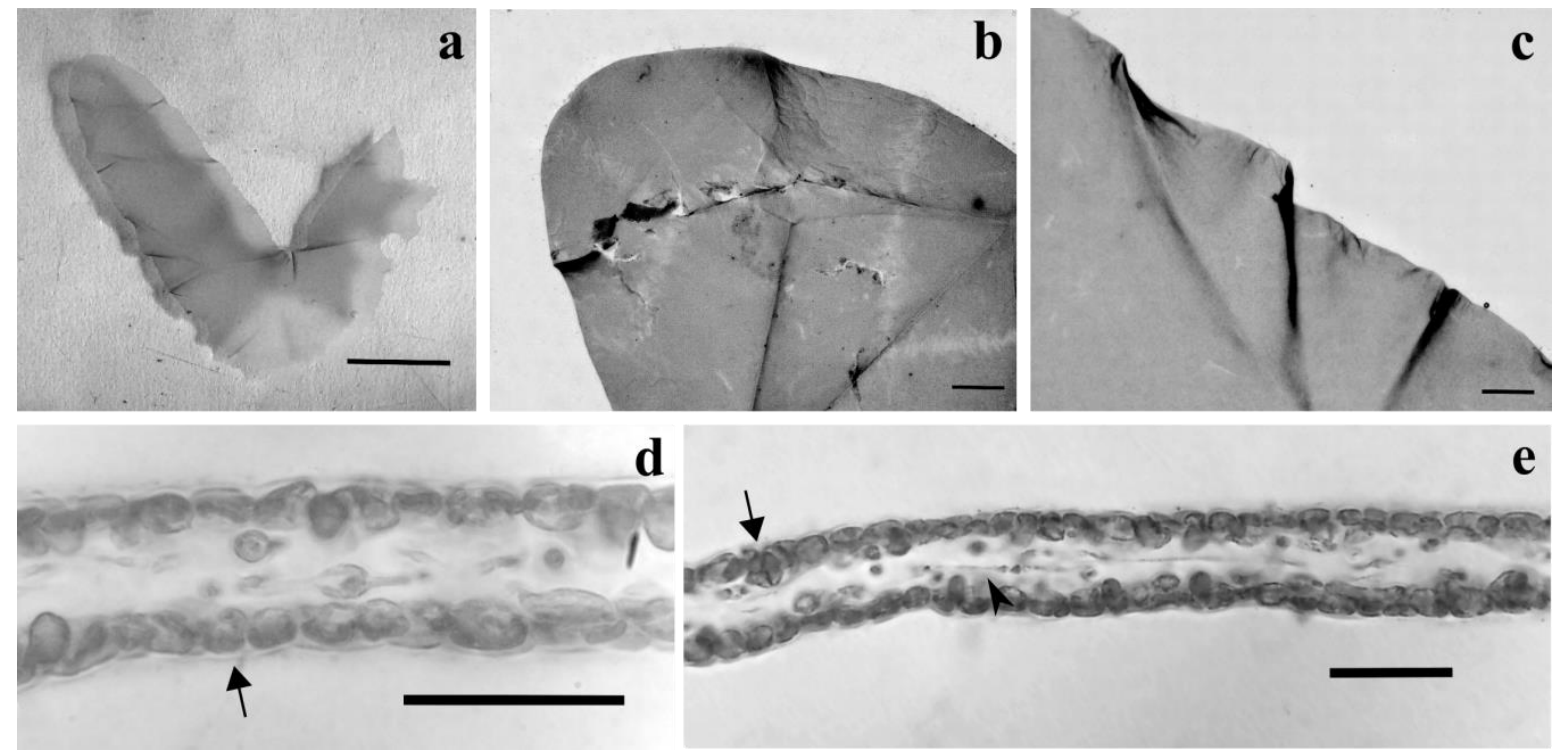

Figura 47. Halymeniales sp. 2. Anatomia vegetativa e reprodutiva. Todas as imagens são de IBC 2165.

(a) Aspecto geral. Barra de escala: $1 \mathrm{~cm}$;

(b) Detalhe mostrando ápice obtuso. Barra de escala: $1 \mathrm{~mm}$;

(c) Detalhe mostrando margem levemente ondulada. Barra de escala: $1 \mathrm{~mm}$;

(d) Corte transversal mostrando região cortical e medular com aparência de vazia. Seta indica célula da região cortical. Barra de escala: $50 \mu \mathrm{m}$;

(e) Corte transversal mostrando tetrasporângio cruciado (seta) e filamentos medulares periclinais (ponta de seta). Barra de escala: $50 \mu \mathrm{m}$. 


\section{MATERIAIS-TIPO OU PROVENIENTES DE LOCALIDADES-TIPO (OU DE LOCAIS PRÓXIMOS À LOCALIDADE-TIPO) ANALISADOS}

A seção a seguir corresponde à análise morfológica de materiais de algumas espécies citadas para a costa brasileira e não encontradas neste estudo, para as quais não foram obtidos dados moleculares. 


\section{Halymenia clathrata E.C. Oliveira, F. Pinheiro-Vieira \& R.E. Norris}

Fig. 48

\section{Do latin clathratus: gradeado, entrançado.} Localidade-tipo: Brasil, estado do Espírito Santo, Piúma, Praia de Piabanha.

Aspecto Geral: Talo de cor rosa, mucilaginoso e bastante delicado, com $30 \mathrm{~cm}$ de altura e $16 \mathrm{~cm}$ de largura. Frondes foliosas, com lobos. Ramificação irregular. Talo apresenta perfurações redondas ou elípticas, de tamanhos variados, em toda a extensão do talo, e com menor diâmetro próximo às margens. Margens lisas. Base cuneada. Nervura ausente. Estipe e apressório ausentes na amostra.

Região Apical: Talo com espessura de 130-160 $\mu \mathrm{m}$. Região cortical composta por uma camada de células ovoides e alongadas, mais altas que largas, de 13-15 $\mu \mathrm{m}$ de altura e 3-4 $\mu \mathrm{m}$ de largura. Região subcortical com 1-2 camadas de células arredondadas ou alongadas periclinalmente, de 12-22 $\mu \mathrm{m}$ de diâmetro. Região medular com filamentos anticlinais de 4-10 $\mu \mathrm{m}$ de diâmetro. Células ganglionares abundantes, longas e largas. Células estreladas presentes, de 22,5 $\mu \mathrm{m}$ de diâmetro.

Região Mediana: Talo com 290-350 $\mu \mathrm{m}$ de espessura. Região cortical com uma camada de células ovoides ou alongadas, de 11-16 $\mu \mathrm{m}$ de altura e 2-3 $\mu \mathrm{m}$ de largura. Região subcortical com 2-3 camadas de células arredondadas de 14-20 $\mu \mathrm{m}$ de diâmetro. Região medular com filamentos anticlinais de 4-7 $\mu \mathrm{m}$ de diâmetro. Células ganglionares abundantes, longas e largas. Células estreladas com 22,5-35 $\mu \mathrm{m}$ de diâmetro.

Região Basal: Talo com 580-690 $\mu \mathrm{m}$ de espessura. Região cortical com 1-2 camadas de células ovoides e alongadas, de 15-17 $\mu \mathrm{m}$ de altura e 2-3 $\mu \mathrm{m}$ de largura. Região subcortical com duas camadas de células arredondadas, de 20-22,5 $\mu \mathrm{m}$ de diâmetro. Região medular mais densa que na região mediana, com filamentos entrelaçados de 2-4 $\mu \mathrm{m}$ de diâmetro. Células ganglionares grandes, porém menos abundantes que na região mediana. Células estreladas presentes, porém obscurecidas pelos densos filamentos. 
Material Examinado: Holótipo (SPF 2864), Brasil, Espírito Santo, Piúma, Praia de Piabanha, arribada, 29 de julho de 1965, E. C. Oliveira. $30 \mathrm{~km}$ da costa de Itaipava, a deriva em 15 m de profundidade, fevereiro de 1987, F. Berchez (SPF 51665).

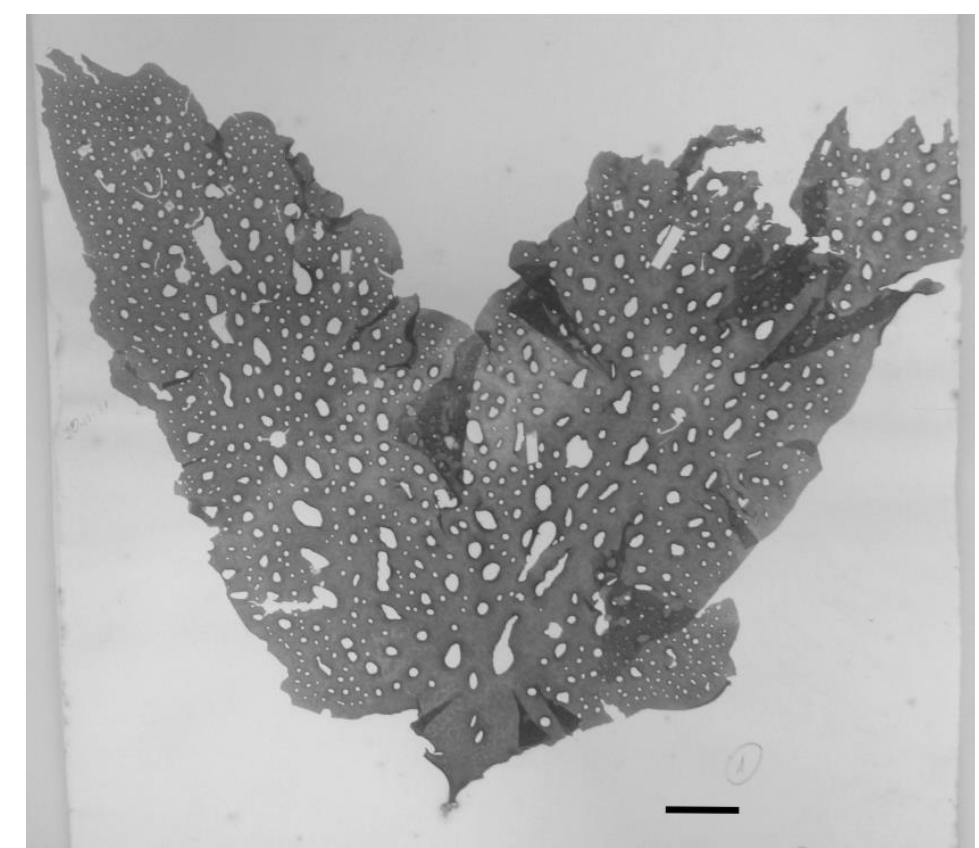

Figura 48. Halymenia clathrata. Aspecto geral (Holótipo - SPF 2864). Barra de escala: $2 \mathrm{~cm}$. 


\section{Halymenia duchassaingii (J.Agardh) Kylin}

Fig. 49

\section{duchassaingii: em homenagem ao coletor Édmond Placide Duchassaingii de Fontbressin, de origem francesa porém nascido em Guadalupe. Localidade-tipo: Guadalupe.}

\section{Material do Caribe Panamenho:}

Aspecto Geral: Talo firme, folioso, de $18 \mathrm{~cm}$ de altura e $5 \mathrm{~cm}$ de largura. Frondes falcadas, estreitas na base e mais alargadas na região mediana. Ápices de formato irregular, alguns arredondados, outros afilados. Ramificação irregular. Margens denteadas em toda a extensão do talo. Abundantes papilas distribuídas em toda a superfície do talo, principalmente na região distal. Algumas células da região subcortical apresentam discreto conteúdo granular. Aparentamente, sem proliferações superciais. Nervura ausente. Estipe achatado, com $0,5 \mathrm{~cm}$ de altura e $2 \mathrm{~mm}$ de largura. Não foi possível observar o apressório desta amostra.

Região Apical: Região medular com filamentos anticlinais de 8-12,5 $\mu \mathrm{m}$ de diâmetro. Células ganglionares presentes.

Região Mediana: Talo com 250-270 $\mu \mathrm{m}$ de espessura. Região cortical com 3-4 camadas de células quadráticas ou ovoides, de 5-6 $\mu \mathrm{m}$ de altura e 3-4 $\mu \mathrm{m}$ de largura. Região subcortical com 2-3 camadas de células arredondadas ou periclinalmente alongadas, de 9-14 $\mu \mathrm{m}$ de diâmetro. Região medular com filamentos anticlinais e periclinais de 10-15 $\mu \mathrm{m}$ de diâmetro. Filamentos ganglionares presentes. Células estreladas com 27,5-35 $\mu \mathrm{m}$ de largura.

Região Basal: Talo com 470-550 $\mu \mathrm{m}$ de espessura. Região cortical com 3-4 camadas de células quadráticas ou retangulares, de 5-6 $\mu \mathrm{m}$ de altura e 5-6 $\mu \mathrm{m}$ de largura. Região subcortical com 5-6 camadas de células esféricas ou periclinalmente alongadas, de 15-62,5 ㅆm de diâmetro, que aumentam de tamanho em direção à região medular. Região medular densa, preenchida por filamentos longitudinais de 10-12,5 $\mu \mathrm{m}$ de diâmetro. Células ganglionares não encontradas. Células estreladas obscurecidas pelos densos filamentos medulares. 
Estruturas Reprodutivas: Tetrasporângios cruciado-decussados muito abundantes nas regiões apical e mediana, medindo 18-20 $\mu \mathrm{m}$ de altura e 11-14 $\mu \mathrm{m}$ de largura.

\section{Material Examinado:}

Panamá, Bocas del Toro, Isla Colón, Sandfly Bay, tetrasporófito, 08 de maio de 2012, C.A.A. Azevedo (IBC 2063).

\section{Comentários:}

Halymenia duchassaingii foi descrita por Agardh (1872), sob o basiônimo Meristotheca duchassaingii. Foi citada para a costa brasileira pela primeira vez por Joly et al. (1965b), quando coletada no estado da Bahia. Posteriormente, a espécie foi também registrada no Ceará e na Paraíba (Nunes 2005).

H. duchassaingii é caracterizada por apresentar numerosas papilas de aspecto espinescente em toda a superfície do talo, em ambas as faces.

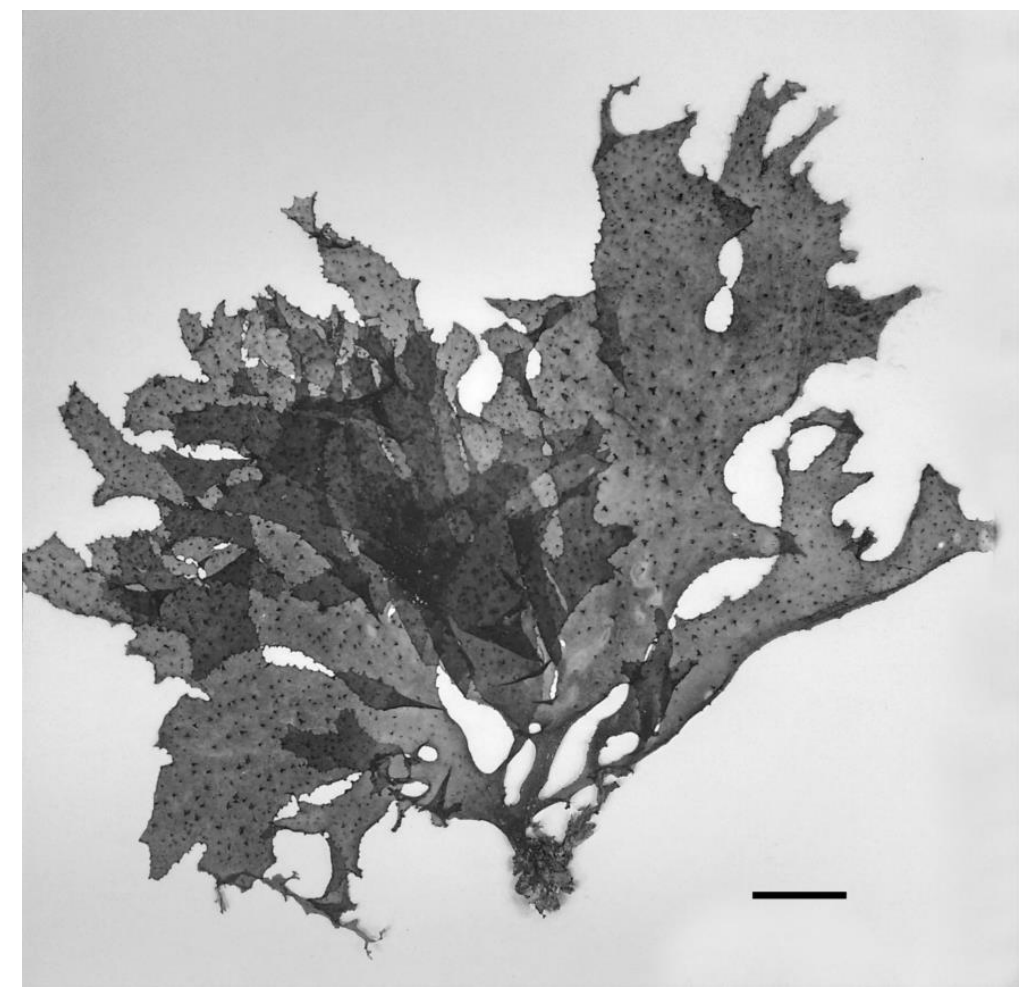

Figura 49. Halymenia duchassaingii. Aspecto geral. Barra de escala: $2 \mathrm{~cm}$ (IBC 2063). 


\section{Halymenia vinacea M. Howe \& W.R. Taylor}

Fig. 50

\section{Localidade-tipo: Brasil, Cabo Frio.}

Talo de cor vermelha, folioso, não ramificado, com até $18,5 \mathrm{~cm}$ de altura e $8,1 \mathrm{~cm}$ de largura. Base cuneada. A fronde se expande a partir da base até a região mediana, e então se torna levemente mais estreita até o ápice. Ápice arredondado, obtuso. Margens inteiras. Proliferações superficiais, marginais ou apicais ausentes. Nervura tênue na região basal, que alcança aproximadamente $0,5 \mathrm{~cm}$ acima do estipe. Não é possível distinguir a forma do estipe, o qual tem $4 \mathrm{~mm}$ de comprimento e $1 \mathrm{~mm}$ de largura. Apressório discoide, com $1 \mathrm{~mm}$ de diâmetro.

$\mathrm{Na}$ região mediana, talo com 55-70 $\mu \mathrm{m}$ de espessura. Região cortical com uma camada de células de formatos variados, algumas mais largas que altas, com 3-7 $\mu \mathrm{m}$ de altura e 4-7 $\mu \mathrm{m}$ de largura. Região medular com filamentos periclinais de 1-2 $\mu \mathrm{m}$ de diâmetro. Células ganglionares grandes, com longos braços. Células estreladas não encontradas.

O material-tipo foi examinado. A descrição original de Howe \& Taylor (1931) não comenta a pequena e discreta nervura que há na base do material-tipo, e também não é possível visualizá-la na imagem que há na obra, de maneira que é difícil distinguir $H$. vinacea de $H$. integra, também descrita pelos mesmos autores baseado-se apenas na descrição feita pelos autores. Essa nervura é citada por Guimarães \& Fujii (1998). As células ganglionares citadas aqui são tratadas na descrição original como "gânglios estrelados".

Material examinado: Holótipo (FH s/n), Brasil, Rio de Janeiro, Cabo Frio, dragagem, Hassler Expedition 1043-a, janeiro de 1872. 


\section{Halymenia integra M. Howe \& W.R. Taylor}

Fig. 50

\section{Localidade-tipo: Brasil, Cabo Frio.}

Talo de cor vermelha, folioso, não ramificado, com até $18,5 \mathrm{~cm}$ de altura e $6 \mathrm{~cm}$ de largura. Base cuneada. A fronde se expande a partir da base até a região mediana, e então se torna levemente mais estreita até o ápice. Ápice arredondado, obtuso em alguns espécimes e agudo em outros. Margens inteiras. Proliferações superficiais, marginais ou apicais ausentes. Nervura ausente. Estipe cilíndrico, com até $7 \mathrm{~mm}$ de comprimento e $1 \mathrm{~mm}$ de diâmetro. Apressório discoide, com $1 \mathrm{~mm}$ de diâmetro.

Não foi possível obter boas preparações de seções transversais, uma vez que o material está desidratado há 143 anos. Portanto, as observações de anatomia interna foram feitas a partir de vista superficial.

Em vista superficial, Região cortical composta por células de formatos variados, com 11-19 $\mu \mathrm{m}$ em sua maior medida. As células superficiais estão dispostas em agrupamentos de 2-4 células. Sob o córtex há células esféricas e elipsoides grandes, com 157,5-165 $\mu \mathrm{m}$ de diâmetro, que correspondem às células da região subcortical descritas por Howe \& Taylor (1931). Guimarães \& Fujii (1998) sugerem que essa espécie provavelmente não pertence ao gênero Halymenia.

Material examinado: Holótipo (FH s/n), Brasil, Rio de Janeiro, Cabo Frio, dragagem, Hassler Expedition 1042, janeiro de 1872. 


\section{Halymenia rosea M. Howe \& W.R. Taylor}

Fig. 50

\section{Localidade-tipo: Brasil, Cabo Frio.}

Talo de cor rosa, folioso, suborbicular, não ramificado, com $6 \mathrm{~cm}$ de altura e $4 \mathrm{~cm}$ de largura. Base cuneada. Ápice arredondado. Margens inteiras. Proliferações superficiais, marginais ou apicais ausentes. Nervura ausente. Não é possível distinguir a forma do estipe, o qual tem $3 \mathrm{~mm}$ de comprimento e menos de $1 \mathrm{~mm}$ de largura. Apressório discoide, com menos de $1 \mathrm{~mm}$ de diâmetro.

Não foi possível obter cortes transversais visíveis. Em vista superficial, córtex com células de formatos variados, com 4-9 $\mu \mathrm{m}$ em sua maior medida. Além das células da região cortical, há grandes células de formato estrelado com 50-57,5 $\mu \mathrm{m}$ de diâmetro e longos e numerosos (5-8) braços, alguns septados. Essas células foram chamadas de "gânglios estrelados" por Howe \& Taylor (1931) e, segundo os autores, estão presentes na região subcortical e na região medular de $H$. rosea. No entanto, essas células não coram da mesma maneira intensa e refringente típica de células ganglionares, e também não estão restritas à região subcortical, como é comum às células estreladas de Halymenia . Considerando que existe uma distinção entre células ganglionares e estreladas adotada neste estudo, as células de formato estrelado de $H$. rosea podem não corresponder a nenhuma dessas duas estruturas.

Material examinado: Holótipo (FH s/n), Brasil, Rio de Janeiro, Cabo Frio, dragagem, Hassler Expedition 1043, janeiro de 1872. 

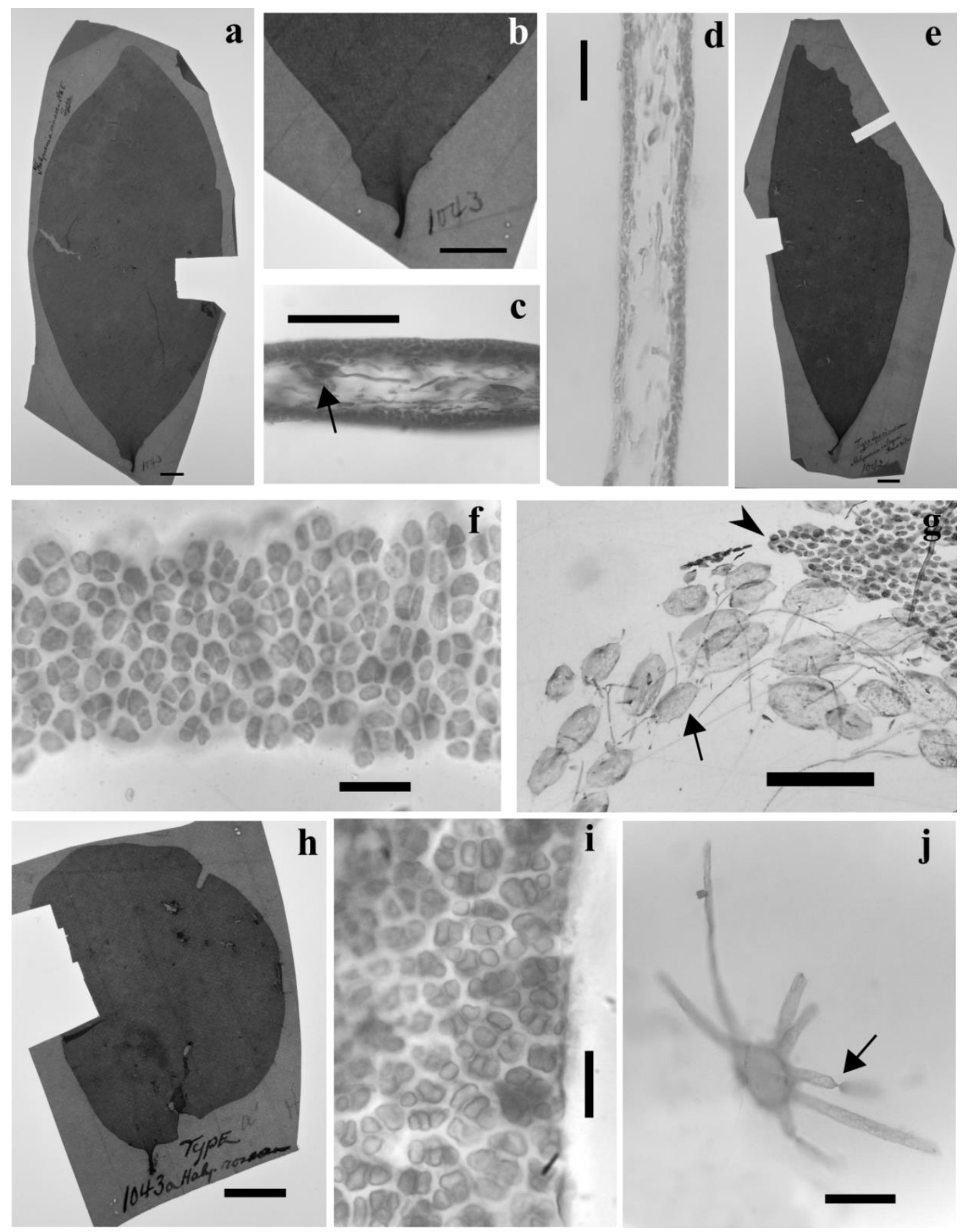

Figura 50. Materiais-tipo de $H$. vinacea, $H$. integra e $H$. rosea.

(a-d) H. vinacea;

(a) Aspecto geral do holótipo. Barra de escala: 1 cm (FH, Hassler Expedition 1043-a);

(b) Detalhe da região basal de $H$. vinacea mostrando a nervura. Barra de escala: $1 \mathrm{~cm}$ (FH, Hassler Expedition 1043-a);

(c) Corte transversal na região mediana do talo. Seta indica célula ganglionar. Barra de escala: $50 \mu \mathrm{m}(\mathrm{FH}$, Hassler Expedition 1043-a); 
(d) Corte transversal na região mediana do talo. Barra de escala: $50 \mu \mathrm{m}$ (FH, Hassler Expedition 1043-a); (e-g) H. integra;

(e) Aspecto geral do holótipo. Barra de escala: 1 cm (FH, Hassler Expedition 1042);

(f) Visão superficial da região cortical. Barra de escala: $50 \mu \mathrm{m}$ (FH, Hassler Expedition 1042);

(g) Preparação de esmagamento mostrando células da região cortical (ponta de seta) e região subcortical (seta). Barra de escala: $50 \mu \mathrm{m}$ (FH, Hassler Expedition 1042);

(h-j) H. rosea;

(h) Aspecto geral do holótipo. Barra de escala: $1 \mathrm{~cm}$ (FH, Hassler Expedition 1043);

(i) Visão superficial da região cortical. Barra de escala: $50 \mu \mathrm{m}$ (FH, Hassler Expedition 1043);

(j) Célula de formato estrelado com braços septados (seta). Barra de escala: $50 \mu \mathrm{m}$ (FH, Hassler Expedition 1043). 


\section{Considerações Finais}

Neste estudo, foi possível constatar elevada incidência de diversidade críptica ou pseudo-críptica entre as algas da ordem Halymeniales que ocorrem na costa brasileira. Isso demonstra que a diversidade dessas algas está subestimada na costa do Brasil, o que corrobora a hipótese levantada neste estudo. Foram encontradas pelo menos 26 táxons da ordem ocorrendo no litoral brasileiro (Tabela 11). Antes da realização deste estudo, havia registro de 24 espécies, das quais nove não foram obtidas. Se todas essas nove espécies constituírem entidades válidas, o número de táxons da ordem no Brasil seria de 35 espécies. Os resultados moleculares e morfológicos indicam que diversas citações de táxons correspondem a complexos de espécies ("Cryptonemia" crenulata, Cryptonemia seminervis, Halymenia floresii e Grateloupia cf. filicina), e que há espécies e gêneros provavelmente novos para a ciência e cujas descrições e publicações requerem a realização de mais estudos morfológicos e moleculares, que incluam a observação de material ficológico depositado em diversos herbários e coleta e sequenciamento nas localidades-tipo (Tabelas 11 e 12).

Em relação aos marcadores moleculares, foi avaliada a viabilidade de aplicação do UPA e COI-5P no estudo da diversidade da ordem. Os dois marcadores apresentaram valores comparáveis de divergências intraespecfícia $(0,0-1,1 \%$ para o UPA e 0,0-1,2\% para o COI-5P), sendo que em ambos os casos, muitos agrupamentos não exibem divergência intraespecífica. Porém, os dois marcadores diferem em relação aos valores de diversidade interespecífica, que foram superiores no COI-5P (6,6-11,9\%), em comparação com o UPA (0,5-3,2\%). A sobreposição entre divergência intra e interespecífica observada no marcador UPA é considerada uma limitação à sua aplicação como DNA barcode (Yang \& Kim 2014b), porém, é importante ressaltar que neste estudo esse marcador resultou nos mesmos agrupamentos genéticos obtidos com o COI-5P. O marcador UPA é uma região de fácil amplificação e sequenciamento, enquanto que o COI-5P, por sua vez, é uma região muito útil para diferenciação de espécies, porém, em virtude das grandes dificuldades 
previamente relatadas neste estudo para o COI-5P, foi necessário investir grande quantidade de tempo até a obtenção desses dados.

Em relação ao $r b c \mathrm{~L}$, observou-se facilidade em sua amplificação e grande adequabilidade para inferências filogenéticas. As análises filogenéticas realizadas apenas com $r b c \mathrm{~L}$ e com $r b c \mathrm{~L}$ combinado com COI-5P (análise concatenada) demonstraram que os gêneros Cryptonemia e Halymenia são polifiléticos, enquanto que Grateloupia é parafilético. No entanto, os valores de suporte nos ramos mais profundos das árvores são, na maioria dos casos, inferiores a 50, isto é, insuficientes para proposição dos novos gêneros. Para tanto, é necessário obter árvores mais robustas, que incluam um maior número de marcadores moleculares.

Além disso, foi detectada no litoral do Brasil a presença de três táxons, cuja localidade-tipo é a Ásia: “Grateloupia” turuturu, Grateloupia orientalis e Grateloupia yangjiangensis. Os dois primeiros táxons foram encontrados nos municípios de Florianópolis e São Vicente, respectivamente, isto é, em locais próximos aos dois maiores portos de navegação do Brasil, que são os portos de Itajaí (SC) e de Santos (SP). G. yangjiangensis, por sua vez, foi coletada em uma praia em Ubatuba. G. turuturu é uma espécie invasora bastante documentada na literatura (Anexo IV), enquanto que G. orientalis e G. yangjiangensis nunca haviam sido detectadas fora de suas localidades-tipo, segundo o nosso conhecimento. G. orientalis e G. yangjiangensis podem ser facilmente confundidas com outros táxons que ocorrem na costa brasileira: G. filiformis, G. cf. filicina 1 e $G$. cf. filicina 2. Dessa forma, não é possível saber se as espécies são realmente exóticas, e, consequentemente, é mais prudente considerá-las espécies criptogênicas. É importante também ressaltar que foram observados indivíduos férteis desses táxons. Esses resultados reforçam a necessidade de monitoramento da ocorrência dessas espécies.

A distribuição geográfica dos táxons encontrados está de acordo com as Zonas de Diversidade de Algas propostas por Horta et al. (2001). Alguns táxons foram exclusivos da Zona Tropical, enquanto que outros ocorreram apenas na Zona Temperada Quente. Na Zona de Transição, por sua vez, foram observadas espécies comuns tanto à Zona Tropical, quanto à Zona Temperada Quente. Apenas “Halymenia” floridana e Grateloupia filiformis foram encontradas nas três zonas. Esse padrão foi também parcialmente observado para a distribuição dos gêneros, sendo que Corynomorpha foi registrada apenas na Zona Tropical, 
Halymenia ocorreu predominantemente na Zona Tropical, Grateloupia foi encontrada principalmente na Zona Temperada Quente e Cryptonemia foi observada nas três zonas.

A utilização da ferramenta molecular foi extremamente útil na delimitação de espécies de Halymeniales e essencial na descoberta de ampla diversidade críptica em grupos morfologicamente muito semelhantes. Os dados aqui apresentados fornecem importantes informações sobre as relações filogenéticas da ordem e ressaltam a necessidade de realização de mais investigações para a resolução dos problemas sistemáticos do grupo. De maneira geral, este estudo contribui significativamente para o conhecimento da flora marinha brasileira e é fundamental para viabilizar a utilização racional desses recursos naturais do país.

Tabela 11. Cenário atual do conhecimento da diversidade de Halymeniales no litoral do Brasil, proposto neste estudo.

\begin{tabular}{|c|c|c|}
\hline Espécie & Distribuição atual & Status proposto \\
\hline Corynomorpha cf. clavata & $\mathrm{BA}, \mathrm{CE}, \mathrm{ES}, \mathrm{PE}, \mathrm{RN}$ & Espécie nova \\
\hline "Cryptonemia" bengryi & $\mathrm{AL}, \mathrm{BA}, \mathrm{CE}, \mathrm{ES}, \mathrm{PB}, \mathrm{PE}, \mathrm{RN}$ & Gênero novo \\
\hline "Cryptonemia" crenulata & $\begin{array}{l}\text { Arq. F. N., AL, BA, CE, ES, } \\
\text { MA, PB, PE, RJ, RN, SP }\end{array}$ & $\begin{array}{l}\text { Gênero novo/Complexo de } \\
\text { pelo menos três espécies, sendo } \\
\text { duas espécies novas }\end{array}$ \\
\hline "Cryptonemia" delicatula & $\begin{array}{l}\text { BA, CE, ES, RJ, RN, RS, } \\
\text { SC, SP }\end{array}$ & Gênero novo \\
\hline Cryptonemia flabelifolia & $\mathrm{CE}, \mathrm{ES}, \mathrm{RJ}$ & Não encontrada neste estudo \\
\hline Cryptonemia limensis & CE, ES, RJ, SP & $\begin{array}{l}\text { Pertence ao Complexo } \\
\text { Cryptonemia seminervis }\end{array}$ \\
\hline Cryptonemia seminervis & $\begin{array}{l}\mathrm{AL}, \mathrm{BA}, \mathrm{CE}, \mathrm{ES}, \mathrm{MA}, \mathrm{PB}, \\
\mathrm{PE}, \mathrm{RJ}, \mathrm{RN}\end{array}$ & $\begin{array}{l}\text { Complexo de pelo menos } \\
\text { três espécies, sendo duas } \\
\text { espécies novas }\end{array}$ \\
\hline Dermocorynus dichotomus & CE, ES, PR, RJ, SC, SP & $\begin{array}{l}\text { Espécie nova pertencente ao } \\
\text { gênero Grateloupia }\end{array}$ \\
\hline
\end{tabular}


Tabela 11. Continuação.

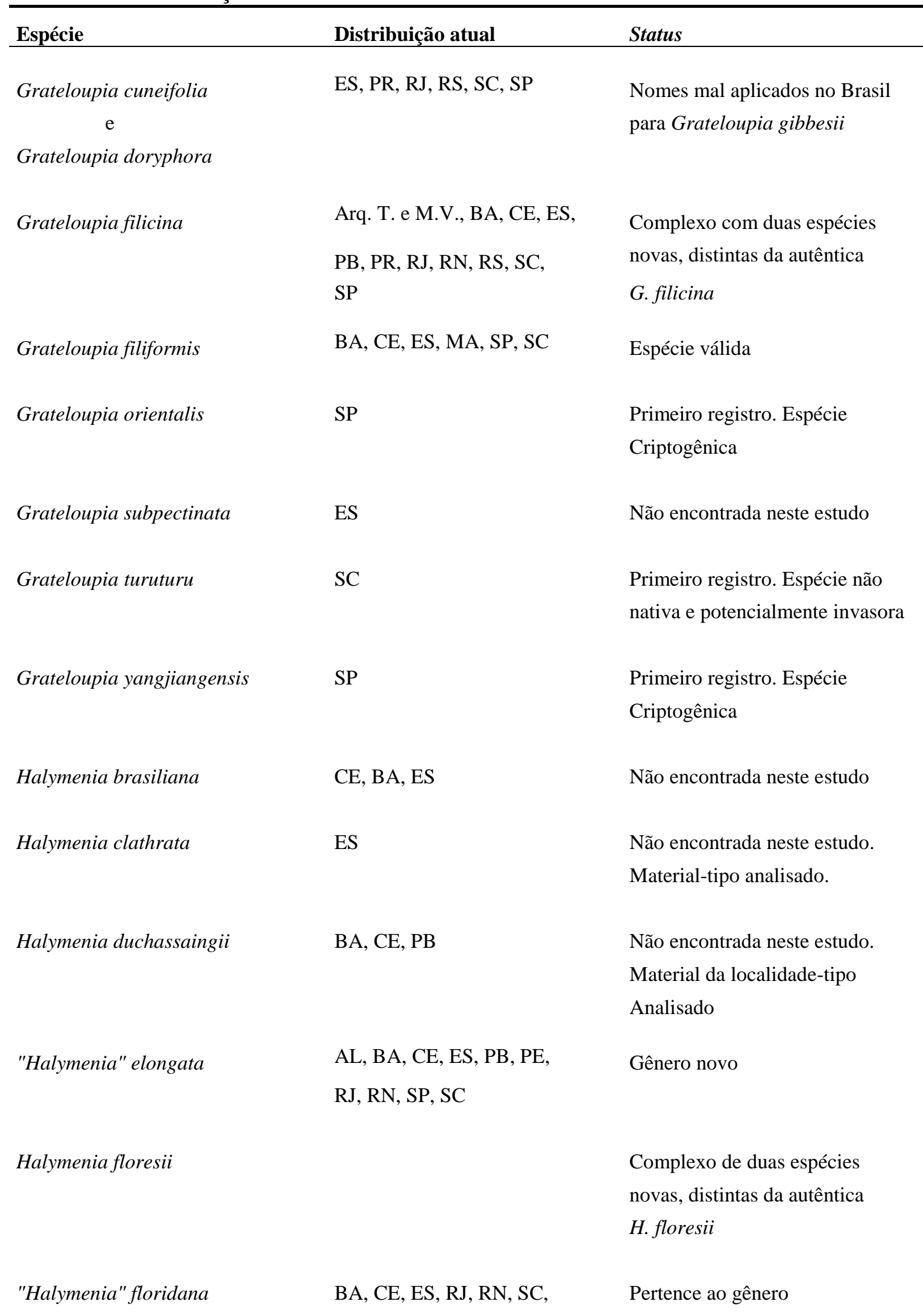


Tabela 11. Continuação.

\begin{tabular}{|c|c|c|}
\hline Espécie & Distribuição atual & Status \\
\hline & SP & Cryptonemia ou gênero novo \\
\hline Halymenia ignifera & CE, RN, ES & $\begin{array}{l}\text { Espécie nova, previamente } \\
\text { tratada como } H \text {. floresii }\end{array}$ \\
\hline Halymenia integra & $\mathrm{CE}, \mathrm{RJ}$ & $\begin{array}{l}\text { Não encontrada neste estudo. } \\
\text { Material-tipo analisado. }\end{array}$ \\
\hline Halymenia pinnatifida & $\mathrm{RN}$ & $\begin{array}{l}\text { Espécie nova, previamente } \\
\text { tratada como } H \text {. floresii }\end{array}$ \\
\hline Halymenia pseudofloresii & & Corresponde a $H$. silviae \\
\hline Halymenia rosea & CE, ES, RJ, SP & $\begin{array}{l}\text { Não encontrada neste estudo. } \\
\text { Material-tipo analisado. }\end{array}$ \\
\hline Halymenia silviae & $\mathrm{AL}, \mathrm{BA}, \mathrm{CE}, \mathrm{RN}$ & $\begin{array}{l}\text { Espécie nova, previamente } \\
\text { tratada como } H \text {. pseudofloresii }\end{array}$ \\
\hline Halymenia vinacea & ES, RJ & $\begin{array}{l}\text { Não encontrada neste estudo. } \\
\text { Material-tipo analisado. }\end{array}$ \\
\hline Halymenia sp. 1 & $\mathrm{CE}$ & $\begin{array}{l}\text { Táxon indefinido. Provavelmente } \\
\text { H. mirabilis }\end{array}$ \\
\hline Halymenia sp. 2 & $\mathrm{CE}$ & Espécie nova \\
\hline Halymeniales sp. 1 & BA & Gênero novo \\
\hline Halymeniales sp. 2 & BA & Gênero novo \\
\hline Tsengia sp. & ES & Não encontrada neste estudo. \\
\hline
\end{tabular}

${ }^{*}$ Estados da Federação Brasileira. AL: Alagoas, BA: Bahia, CE: Ceará, ES: Espírito Santo, MA: Maranhão, PB: Paraíba, PE: Pernambuco, PR: Paraná, RJ: Rio de Janeiro, RN: Rio Grande do Norte, RS: Rio Grande do Sul, SC: Santa Catarina, SP: São Paulo. Arquipélagos. Arq. F.N.: Arquipélago de Fernando de Noronha, Arq. T. e M.V.: Arquipélago de Trindade e Martim Vaz. 
Tabela 12. Comparação das características vegetativas dos principais gêneros encontrados neste estudo.

\begin{tabular}{|c|c|c|c|c|c|c|c|c|c|}
\hline Características & Corynomorpha & Cryptonemia & $\begin{array}{l}\text { Gênero novo } \\
\text { "Cryptonemia" } \\
\text { bengryi }\end{array}$ & $\begin{array}{l}\text { Gênero novo } \\
\text { "Cryptonemia" } \\
\text { delicatula }\end{array}$ & $\begin{array}{l}\text { Gênero novo } \\
\text { "Cryptonemia" } \\
\text { crenulata }\end{array}$ & Halymenia & $\begin{array}{l}\text { Gênero novo } \\
\text { "Halymenia" } \\
\text { elongata }\end{array}$ & $\begin{array}{l}\text { Gênero novo } \\
\text { "Halymenia" } \\
\text { floridana }\end{array}$ & Grateloupia \\
\hline Hábito & $\begin{array}{l}\text { Talo cilíndrico, } \\
\text { Claviforme }\end{array}$ & $\begin{array}{l}\text { Talo em forma } \\
\text { de fitas }\end{array}$ & $\begin{array}{l}\text { Talo em forma } \\
\text { de fitas }\end{array}$ & $\begin{array}{l}\text { Talo em forma } \\
\text { de fitas }\end{array}$ & $\begin{array}{l}\text { Talo em forma } \\
\text { de fitas }\end{array}$ & $\begin{array}{l}\text { Talo folioso, } \\
\text { lanceolado, } \\
\text { obovado, } \\
\text { fendido } \\
\text { ou expandido }\end{array}$ & $\begin{array}{l}\text { Talo tubular, } \\
\text { cilíndrico- } \\
\text { comprimido }\end{array}$ & $\begin{array}{l}\text { Talo folioso, } \\
\text { lanceolado, } \\
\text { obovado, } \\
\text { fendido } \\
\text { ou expandido }\end{array}$ & $\begin{array}{l}\text { Talo folioso, } \\
\text { com } \\
\text { frondes lineares, } \\
\text { lanceoladas ou } \\
\text { expandidas, ou } \\
\text { frondes } \\
\text { cilíndrico- } \\
\text { comprimidas }\end{array}$ \\
\hline Consistência & Firme & Firme & Firme & Flácida & Firme & Flácida & Flácida & Flácida & Flácida ou firme \\
\hline Textura & Mucilaginosa & $\begin{array}{l}\text { Não- } \\
\text { mucilaginosa }\end{array}$ & $\begin{array}{l}\text { Não- } \\
\text { mucilaginosa }\end{array}$ & Mucilaginosa & $\begin{array}{l}\text { Não- } \\
\text { mucilaginosa }\end{array}$ & Mucilaginosa & Mucilaginosa & Mucilaginosa & Mucilaginosa \\
\hline Nervura & Ausente & $\begin{array}{l}\text { Presente, } \\
\text { alcança } \\
\text { até } 1 \mathrm{~cm} \text { do } \\
\text { ápice }\end{array}$ & Ausente & $\begin{array}{l}\text { Presente, } \\
\text { tênue e restrita à } \\
\text { base }\end{array}$ & Ausente & Ausente & Ausente & $\begin{array}{l}\text { Presente apenas } \\
\text { na região basal }\end{array}$ & Ausente \\
\hline $\begin{array}{l}\text { Região } \\
\text { medular }\end{array}$ & $\begin{array}{l}\text { Filamentos } \\
\text { Irregulares }\end{array}$ & $\begin{array}{l}\text { Filamentos } \\
\text { longitudinais e } \\
\text { periclinais }\end{array}$ & $\begin{array}{l}\text { Filamentos } \\
\text { irregulares }\end{array}$ & $\begin{array}{l}\text { Células esféricas } \\
\text { irregularmente } \\
\text { distribuídas e } \\
\text { alguns } \\
\text { filamentos } \\
\text { periclinais }\end{array}$ & $\begin{array}{l}\text { Filamentos } \\
\text { longitudinais e } \\
\text { periclinais }\end{array}$ & $\begin{array}{l}\text { Filamentos } \\
\text { anticlinais e } \\
\text { alguns } \\
\text { periclinais }\end{array}$ & $\begin{array}{l}\text { Filamentos } \\
\text { irregulares }\end{array}$ & $\begin{array}{l}\text { Filamentos } \\
\text { anticlinais e } \\
\text { alguns } \\
\text { periclinais }\end{array}$ & $\begin{array}{l}\text { Filamentos } \\
\text { irregulares e } \\
\text { entrelaçados }\end{array}$ \\
\hline $\begin{array}{l}\text { Células ou } \\
\text { filamentos } \\
\text { ganglionares }\end{array}$ & Ausentes & Presentes & Presentes & Presentes & Presentes & Presentes & Ausentes & Presentes & Ausentes \\
\hline $\begin{array}{l}\text { Células } \\
\text { estreladas }\end{array}$ & Presentes & Presentes & Presentes & Ausentes & Presentes & Presentes & Presentes & Presentes & Presentes \\
\hline $\begin{array}{l}\text { Conteúdo } \\
\text { granular }\end{array}$ & Ausente & Ausente & $\begin{array}{l}\text { Presente, } \\
\text { abundante }\end{array}$ & Presente, raro & $\begin{array}{l}\text { Presente, } \\
\text { abundante }\end{array}$ & Ausente & Ausente & Ausente & Ausente \\
\hline
\end{tabular}


6. Referências Bibliográficas

AgARDH J.G. 1842. Algae maris Mediterranei et Adriatici, observationes in diagnosin specierum et dispositionem generum. Apud Fortin, Masson et Cie, Parisiis [Paris]. pp.

AgARDH J.G. 1872. Bidrag till Florideernes systematik. Lunds Universitets Års-Skrift, Afdelningen for Mathematik och Naturvetenskap 8: 1-60.

Amado-Filho G., Maneveldt G., Pereira-Filho G., Manso R., Bahia R., BarrosBARRETO M. \& GuimARÃES S. 2010. Seaweed diversity associated with a Brazilian tropical rhodolith bed. Ciencias Marinas 36: 371-391.

Amado Filho G.M., Barreto M.B.B., Marins B.V., Felix C. \& Reis R.P. 2003. Estrutura das comunidades fitobentônicas do infralitoral da Baía de Sepetiba, RJ, Brasil. Revista Brasileira de Botânica 26: 329 - 342.

AmAdo FilHo G.M. \& BAHIA R.G. 2007. Algas marinhas bentônicas do estado do Rio de Janeiro. http://www.jbrj.gov.br/jabot/mapa/algasrj.php, July, 2nd 2011.

ARdre F. \& GAYRAL P. 1961. Quelques Grateloupia de l'Atlantique et du Pacifique. Revue algol 6: 38-48.

Athukorala Y., Lee K.W., Song C., Ahn C.B., Shin T.S., Cha Y.J., Shahidi F. \& JEON Y.J. 2003. Potential antioxidant activity of marine red alga Grateloupia filicina extracts. Journal of Food Lipids 10: 251 - 265.

Azevedo C.A.A., Cassano V., Horta Júnior P.A., Batista M.B. \& Oliveira M.C. 2015. Detecting the non-native Grateloupia turuturu (Halymeniales, Rhodophyta) in southern Brazil. Phycologia 54: 451-454.

BALAKRISHNAN M.S. 1962. Studies on Indian Cryptonemiales II. Corynomorpha J. Ag. Phytomorphology 12: 77-86.

Ballantine D.L. \& RuIZ H. 2004. Halymenia mirabilis sp. nov. (Cryptonemiales, Rhodophyta), a spectacular alga from Grenada, Caribbean Sea. Phycologia 43: 75-78.

BenNETT B.C. \& BALICK M.J. 2014. Does the name really matter? The importance of botanical nomenclature and plant taxonomy in biomedical research. Journal of Ethnopharmacology 152: 387-392.

Boo G.H., PARK J.K., Gerung G.S. \& Boo S.M. 2013. Transfer of the red alga Gelidium zollingeri Sonder (Gelidiales) to Yonagunia (Halymeniales) based on morphological and molecular evidence. . Phycologia 52279 - 287.

CAlderon M.S., Boo G.W. \& Boo S.M. 2014a. Morphology and phylogeny of Ramirezia osornoensis gen. \& sp. nov. and Phyllymenia acletoi sp. nov. (Halymeniales, Rhodophyta) from South America. Phycologia 53: 23-36.

CAlderon M.S., Boo G.H. \& Boo S.M. 2014b. Neorubra decipiens gen. \& comb. nov. and Phyllymenia lancifolia comb. nov. (Halymeniales, Rhodophyta) from South America. Phycologia 53: 409-422.

CALISHER C.H. 2007. Taxonomy: what's in a name? Doesn't a rose by any other name smell as sweet? Croatian Medical Journal 48: 268-70.

CÂMARA-Neto C. 1971. Primeira contribuição ao inventário das algas marinhas bentônicas do litoral do Rio Grande do Norte. Boletim do Departamento de 
Oceanografia e Limnologia. Universidade Federal do Rio Grande do Norte 5: 137-154.

CHIANG Y.M. 1970. Morphological studies of red algae of the family Cryptonemiaceae. University of California Publications in Botany 58: vi +95.

CHOPIN T., KERIN B.F. \& MAZEROLle R. 1999. Phycocolloid chemistry as a taxonomic indicator of phylogeny in the Gigartinales, Rhodophyceae: A review and current developments using Fourier transform infrared diffuse reflectance spectroscopy. Phycological Research 47: 167-188.

Cianciola E.N., Popolizio T.R., Schneider C.W. \& Lane C.E. 2010. Using molecular-assisted alpha taxonomy to better understand red algal biodiversity in Bermuda. Diversity 2: 946 - 958.

Clarkston B.E. \& SAunders G.W. 2010. A comparison of two DNA barcode markers for species discrimination in the red algal family Kallymeniaceae (Gigartinales, Florideophyceae), with a description of Euthora timburtonii sp. nov. Botany 88: $119-131$.

Clarkston B.E. \& SAunders G.W. 2013. Resolving species diversity in the red algal genus Callophyllis (Kallymeniaceae, Gigartinales) in Canada using molecular assisted alpha taxonomy. European Journal of Phycology 48: 27 - 46.

COLlins F.S. \& HowE M.A. 1916. Notes on species of Halymenia. Bulletin of the Torrey Botanical Club 43: 169-182.

CORDEIRO-MARINO M. 1978. Rodofíceas bentônicas marinhas do Estado de Santa Catarina. Rickia 7: 1-243.

Costa E.S., Plastino E.M., Petti R., Oliveira E.C. \& Oliveira M.C. 2012. The Gracilariaceae Germplasm Bank of the University of São Paulo, Brazil-a DNA barcoding approach. Journal of Applied Phycology 24: 1643 - 1653.

Creed M., FujiI M.T., Barros-Barreto M.B.D., Guimarães S.M.P.B., Cassano V., Pereira S.M.B., OliveIRA-CARVAlHo M.F. \& Khader S. 2015. Rhodophyceae in Lista de Espécies da Flora do Brasil. (http://floradobrasil.jbrj.gov.br/2010/FB100056). Jardim Botânico do Rio de Janeiro.

D'Archino R., Nelson W.A. \& Zuccarello G.C. 2014. Amalthea and Galene, two new genera of Halymeniaceae (Rhodophyta) from New Zealand. Botanica Marina 57: 185-201.

DAwES C.J. \& MATHIESON A.C. 2008. The seaweeds of Florida. University Press of Florida, Gainesville, Florida. 592 pp.

DAwson E.Y. 1954. Marine red algae of Pacific Mexico Part 2. Cryptonemiales (contd.). Allan Hancock Pacific Expeditions 17: 241-398.

Dawson E.Y., ACleto C. \& FoldVIK N. 1964. The seaweeds of Peru. Nova Hedwigia 13: $1-111$.

De Clerck O., Gavio B., Fredericq S., Cocquyt E. \& Coppejans E. 2005a. Systematic reassessment of the red algal genus Phyllymenia (Halymeniaceae, Rhodophyta). European Journal of Phycology 40: 169 - 178.

De Clerck O., Gavio B. \& FredericQ S. 2005b. Systematics of Grateloupia filicina (Halymeniaceae, Rhodophyta), based on $r b c \mathrm{~L}$ sequence analyses and morphological evidence, including the reinstatement of Grateloupia minima and the description of Grateloupia capensis sp. nov. Journal of Phycology 41.

De Clerck O., Guiry M.D., Leliaert F., Samyn Y. \& Verbruggen H. 2013. Algal taxonomy: a road to nowhere? . Journal of Phycology 49: 215 - 225.

De Masi F. \& GARGiUlo G.M. 1982. Grateloupia doryphora (Mont.) Howe (Rhodophyta, Cryptonemiales) em Méditerranée. Allionia 25: 105-108. 
De Smedt G., De Clerck O., Leliaert F., Coppejans E. \& Liao L.M. 2001. Morphology and systematics of the genus Halymenia C. Agardh (Halymeniales, Rhodophyta) in the Philippines. Nova Hedwigia 73: 293-322.

Faugeron S., Valero M., Destombe C., Martinez E.A. \& Correa J.A. 2001. Hierarquical spatial structure and discriminant analyses of genetic diversity in the red alga Mazzaella laminarioides (Gigartinales, Rhodophyta). Journal of Phycology 37: 705-717.

FERREIRA-CORREIA M.M. 1983. Rodofíceas marinhas bentônicas do litoral oriental do estado do Maranhão. Universidade Estadual Paulista "Júlio de Mesquita Filho", Rio Claro. 266 pp.

FERREIRA-CORREIA M.M. 1987. Rodofíceas marinhas bentônicas do litoral oriental do estado do Maranhão. Coleção Ciências Biológicas, Série Botânica 01: 1 - 256.

Figueroa F.L., Korbee N., De Clerck O., BÁRbara I. \& Gall E.A.R. 2007. Characterization of Grateloupia lanceola (Halymeniales, Rhodophyta), an obscure foliose Grateloupia from the Iberian Peninsula, based on morphology, comparative sequence analysis and mycosporine-like amino acid composition. European Journal of Phycology 42: 231-242.

FRESHWATER D.W. \& RUENESS J. 1994. Phylogenetic relationships of some European Gelidium (Gelidiales, Rhodophyta) species, based on $r b c \mathrm{~L}$ nucleotide sequence analysis. Phycologia 33: 187-194.

Freshwater D.W., FredericQ S., Butler B.S., Hommersand M.H. \& Chase M.W. 1994. A gene phylogeny of the red algae (Rhodophyta) based on plastid $r b c \mathrm{~L}$. Proceedings of the National Academy of Sciences of the United States of America 91: 7281-7285.

GARCÍA-JimÉnez P., GERALDino P., Boo S. \& RoBAinA R. 2008. Red alga Grateloupia imbricata (Halymeniaceae), a species introduced into the Canary Islands. Phycological Research 56: 166-171.

Gargiulo G.M., Morabito M. \& Manghisi A. 2013. A Re-Assessment of Reproductive Anatomy and Postfertilization Development in the Systematics of Grateloupia (Halymeniales, Rhodophyta). Cryptogamie, Algologie 34: 13-35.

GAVIO B. \& FREDERICQ S. 2002. Grateloupia turuturu (Halymeniaceae, Rhodophyta) is the correct name of the non-native species in the Atlantic known as Grateloupia doryphora. European Journal of Phycology 37: 349-359.

GofF L.J. \& MOON D.A. 1993. PCR amplification of nuclear and plastid genes from algal herbarium specimens and algal spores. Journal of Phycology 29: 381-384.

GUIMARÃES S.M.P.B. 1990. Rodofíceas marinhas bentônicas do Estado do Espírito Santo: ordem Cryptonemiales. Universidade de São Paulo. São Paulo. 275 pp.

Guimarães S.M.P.B. \& FuJII M.T. 1998. Two species of foliose Halymenia (Halymeniaceae, Rhodophyta) from Brazil. Botanica Marina 41: 495-504.

GUIMARÃES S.M.P.B. 2006. A revised checklist of benthic marine Rhodophyta from the State of Espírito Santo, Brazil. Boletim do Instituto de Botânica 17: 143-194.

GUIRY M.D. \& IRVINE L.M. 1974. A species of Cryptonemia new to Europe. British Phycological Journal 9: 225-237.

GUIRY M.D. \& GUIRY G.M. 2016. AlgaeBase. World-wide electronic publication, National University of Ireland, Galway. http://www.algaebase.org, 12 February 2016.

HALL T.A. 1999. BioEdit: a user-friendly biological sequence alignment editor and analysis program for Windows 95/98/NT. Nucleic Acids Symposium Series 41: 95-98. 
HARVEY W.H. 1853. Nereis boreali-americana; or, contributions towards a history of the marine algae of the atlantic and pacific coasts of North America. Part II. Rhodospermeae. Smithsonian Contributions to Knowledge. 258 pp.

HERnÁNDEZ-KANTUN J.J., RIOSMENA-RodRIGUEZ R. \& LEÓN-CiSNEROS K. 2009. Morphology and anatomy of Halymenia actinophysa (Halymeniales, Rhodophyta) from the southwestern Gulf of California, Mexico. Botanica Marina 52: 248-255.

Hernández-Kantún J.J., SHerwood A.R., Riosmena-Rodríguez R., Huisman J.M. \& DE CLERCK O. 2012. Branched Halymenia species (Halymeniaceae, Rhodophyta) in the Indo-Pacific region, including descriptions of Halymenia hawaiiana sp. nov. and H. tondoana sp. nov. European Journal of Phycology 47: 421-432.

Hommersand M.H., Leister G.L., RAmíREZ M.E., GABRIElson P.W. \& NELSON W.A. 2010. A morphological and phylogenetic study of Glaphyrosiphon gen. nov. (Halymeniaceae, Rhodophyta) based on Grateloupia intestinalis with descriptions of two new species: Glaphyrosiphon lindaueri from New Zealand and Glaphyrosiphon chilensis from Chile. Phycologia 49: 554-573.

HoRTA P.A. 2000. Macroalgas do infralitoral do sul e sudeste brasileiro. Universidade de São Paulo, São Paulo. 301 pp.

Horta P.A., Amancio C.E., Coimbra C. \& Oliveira E.C. 2001. Considerações sobre a distribuição e origem da flora de macroalgas marinhas brasileiras. Hoehnea 28: 243-265.

Howe M.A. 1914. The marine algae of Peru. Memoirs of the Torrey Botanical Club 15: $1-185$.

HOWE M.A. \& TAYLOR W.R. 1931. Notes on new or little-known marine algae from Brazil. Brittonia 1: 7-33.

Iha C., Milstein D., Guimarães S.M.P.B., Freshwater D.W. \& Oliveira M.C. 2015. DNA barcoding reveals high diversity in the Gelidiales of the Brazilian southeast coast. Botanica Marina 58: 295-305.

JoHN D.M. \& MAGGS C.A. 1997. Species problems in eukaryotic algae: a modern perspective. In Species: The Units of Biodiversity. (ed. by M.F. Claridge, H.A. Dawah \& M.R. Wilson), pp. 83-107. Chapman \& Hall, London.

JOLY A.B. 1957. Contribuição ao conhecimento da flora ficológica marinha da baía de Santos e arredores. Boletim da Faculdade de Filosofia, Ciências e Letras,Universidade de São Paulo, série Botânica 14: 1 - 196.

JOLY A.B. 1964. Flora marinha do litoral norte do estado de São Paulo e regiões circunvizinhas. Boletim da Faculdade de Filosofia, Ciências e Letras da Universidade de São Paulo, série Botânica 21: 1 - 393.

Joly A.B., Cordeiro M., YAmaguishi N. \& UGAdiM Y. 1965a. New marine algae from Southern Brazil. Rickia 2.

Joly A.B., Cordeiro-Marino M., Yamaguishi-Tomita N., Ugadim Y., OliveiraFilHo E.C. \& FERREIRA M.M. 1965b. Additions to the marine flora of Brazil V. Arquivos da Estação de Biologia Marinha da Universidade Federal do Ceará 5: 65-78.

Joly A.B., Ugadim Y., Oliveira Filho E.C. \& Cordeiro Marino M. 1967. Additions to the marine flora of Brazil VI. Boletim da Faculdade de Filosofia, Ciências e Letras da Universidade de São Paulo, Série Botânica 22: 171-194.

KAWAGUCHI S. 1997. Taxonomic notes on the Halymeniaceae (Gigartinales, Rhodophyta) from Japan. III. Synonymization of Pachymeniopsis Yamada in Kawabata with Grateloupia C. Agardh. Phycological research 45: 9-21. 
KIM S.Y., SeO T.H., PARK J.K., Boo G.H., KIM K.M. \& Boo S.M. 2012. Cryptonemia rotunda (Halymeniales) and Schizymenia apoda (Nemastomatales), two new records of red algae from Korea. Algae 27: 1-8.

KIM S.Y., HAN E.G., KIM M.S., PARK J.K. \& Boo S.M. 2013. Grateloupia jejuensis (Halymeniales, Rhodophyta): a new species previously confused with G. elata and G. cornea in Korea. Algae 28: 233-240.

KRAFT L.G. \& SAUNDERS G.W. 2013. Systematic investigation of the red algal order Halymeniales (Florideophyceae, Rhodophyta) in Australia. Phycologia 52: 56.

KÜTZING F.T. 1849. Species algarum. F.A. Brockhaus, Lipsiae [Leipzig]. pp. [i]-vi, [1]$922 \mathrm{pp}$.

KYLIN H. 1932. Die Florideenordung Gigartinales. Acta Universitatis Lundensis 28: 188.

KYLIN H. 1956. Die Gattungen der Rhodophyceen. C.W.K. Gleerups, Lund. pp.

Leliaert F., Verbruggen H., VANORMELINGen P., STEen F., LóPEZ-BAUtista J.M., ZuCCAREllo G.C. \& DE CleRCK O. 2014. DNA-based species delimitation in algae. European Journal of Phycology 49: 179-196.

LEWIS J.A. 1990. Cryptonemia limensis (Kützing) Lewis, comb. nov. (Halymeniaceae, Rhodophyta) from Peru. Taxon 39: 98-104.

LiN S.M., LiANG H.Y. \& HOMMERSAND M.H. 2008. Two types of auxiliary cell ampullae in Grateloupia (Halymeniaceae, Rhodophyta), including $G$. taiwanensis sp. nov. and G. orientalis sp. nov. from Taiwan based on $r b c \mathrm{~L}$ gene sequence analysis and cystocarp development. Journal of Phycology 44: 196214.

LIN S.M. \& LiANG H.Y. 2011. Grateloupia huangiae (Halymeniaceae, Rhodophyta), a new species from Taiwan previously confused with Polyopes lancifolius, with emphasis on the development of the auxiliary-cell ampullae. Phycologia 50: 232 $-240$.

Lucena L.A.F., Kanagawa A.I., Martins G.J.M., Targino C.H., Miranda G.E.C. \& HoRTA P.A. 2007. Levantamento da flora do infralitoral do município de Pitimbú, litoral sul do estado da Paraíba, Brasil. Revista Brasileira de Biociências 5: 585 - 587.

LyRa G.M., SANTOS A.C.C. \& NunES J.M.C. 2007. Rodofíceas bentônicas das praias da Concha e Engenhoca, município de Itacaré - Bahia, Brasil. Acta Botanica Malacitana 32: 234 - 240.

Machín-Sánchez M., Le Gall E., Neto A.I., Rousseau F., Cassano V., Sentíes A., FuJII M.T., DÍAZ-LARREA J., VAN REINE W.F.P., BONILlo C. \& GIL-RODRÍGUEZ M.C. 2014. A combined barcode and morphological approach to the systematics and biogeography of Laurencia pyramidalis and Laurenciella marilzae (Rhodophyta). European Journal of Phycology 49: 115-127.

Maggs C.A., Verbruggen H. \& De ClercK O. 2007. Molecular systematics of red algae: building future structures on firm foundations. In: Brodie, J \& Lewis, J.M. (eds.) Unravelling the algae: the past, present, and future of algal systematics. The Systematics Association Special Volume Series 75: 103 - 121.

Manghisi A., Le Gall L., Ribera M.A., Bonillo C., Gargiulo G.M. \& Morabito M. 2014. The Mediterranean Endemic New genus Felicinia (Halymeniales, Rhodophyta) Recognized by a Morphological and Phylogenetic Integrative Approach. Cryptogamie, Algologie 35: 221-243.

MAYDEN R.L. 1997. A hierarchy of species concepts: the denouement in the saga of the species problem. In Species: The Units of Biodiversity. (ed. by M.F. Claridge, H.A. Dawah \& M.R. Wilson), pp. 381-424. Chapman and Hall, London. 
MaYR E. \& ASHLOCK P.D. 1991. Principles of Systematic Zoology. McGraw-Hill, New York, NY. pp.

Mendes G.S., Duarte M.R., Colodi F.G., Noseda M.D., Ferreira L.G., Berté S.D., Cavalcanti J.F., Santos N. \& Romanos M.T.V. 2014. Structure and antimetapneumovirus activity of sulfated galactans from the red seaweed Crytonemia seminervis. Carbohydrate Polymers 101: 313 - 323.

MilsteIN D. \& SAUNDERS G.W. 2012. DNA barcoding of Canadian Ahnfeltiales (Rhodophyta) reveals a new species - Ahnfeltia borealis sp. nov. Phycologia 51: $247-259$.

Milstein D., Medeiros A.S., Oliveira E.C. \& Ollveira M.C. 2012. Will a DNA barcoding approach be useful to identify Porphyra species (Bangiales, Rhodophyta)? Journal of Applied Phycology 24: 837-845.

Mineur F., De Clerck O., Le RouX A., Maggs C.A. \& Verlaque M. 2010. Polyopes lancifolius (Halymeniales, Rhodophyta), a new component of the Japanese marine flora introduced to Europe. Phycologia 49: 86-96.

Nauer F., Guimarães N.R., Cassano V., Yokoya N.S. \& Oliveira M.C. 2014. Hypnea species (Gigartinales, Rhodophyta) from the southeastern coast of Brazil based on molecular studies complemented with morphological analyses, including descriptions of Hypnea edeniana sp. nov. and $H$. flava sp. nov. European Journal of Phycology 49: 550-575.

NeI M. \& KuMAR S. 2000. Molecular Evolution and Phylogenetics. Oxford University Press, New York. 333 pp.

NuNES J.M.C. 1998. Catálogo de algas marinhas bentônicas do estado da Bahia, Brasil. Acta Botanica Malacitana 23: 5 - 21.

NUNES J.M.C. 2005. Rodofíceas marinhas bentônicas do estado da Bahia. Universidade de São Paulo, São Paulo. 410 pp.

OlIVEIRA FILHO E.C. 1977. Algas marinhas bentônicas do Brasil. Instituto de Biociências. Universidade de São Paulo, São Paulo. 406 pp.

PACHECO M.R. 2011. Macroalgas marinhas associadas a bancos de rodolitos do infralitoral do Espírito Santo, Brasil. Universidade de São Paulo. São Paulo. 371 pp.

Payo D.A., Leliaert F., Verbruggen H., D'hondt S., Calumpong H.P. \& De CLERCK O. 2013. Extensive cryptic species diversity and fine-scale endemism in the marine red alga Portieria in the Philippines. Proceedings of the Royal Society B 280: 1-8.

PEČNIKAR Z.F. \& BUZAN E.V. 2014. 20 years since the introduction of DNA barcoding: from theory to application. Journal of Applied Genetics 55: 43-52.

Pedrini A.G., De-Paula J.C. \& Barreto M.B.B. 1998. Algas bentônicas da Lagoa de Itaipu, Niterói, RJ, Brasil: composição taxonômica e variação espaço-temporal. In IV Simpósio Latinoamericano de Ficologia. pp. 379 - 387. Sociedade Ficológica da América Latina e Caribe, São Paulo.

Pereira S.M.B., Oliveira-Filho E.C., Araújo M.S., Paes e Mello L.B., Carvalho F. \& CÂmara Neto C. 1981. Prospecção dos bancos de algas marinhas do estado do Rio Grande do Norte, 2a parte - profundidade 10 - 45m. Série, Brasil. SUDENE 9: 27 - 81.

Pereira S.M.B., Carvalho M.F.O., Angeiras J.A., Pedrosa M.E.B., Oliveira N.M.B., Torres J., Gestinari L.M.S., Concentino A.M., SANTOS M.D., NASCIMENTO P.R.F. \& CAVALCANTI D.R. 2002. Algas marinhas bentônicas do estado de Pernambuco. In Diagnóstico da biodiversidade de Pernambuco. 
Secretaria de Ciência, Tecnologia e Meio Ambiente. (ed. by M. Tabarelli \& J.M.C. Silva), pp. 97 - 124. Editora Massangana, Recife.

PEREIRA S.M.B., Ribeiro F.A. \& BANDEIRA-PEDrosA M.E. 2007. Algas pluricelulares do infralitoral da praia de Gaibú (Pernambuco - Brasil). Revista Brasileira de Biociências 5: 951 - 953.

PinheIRO-Joventino F. 1977. Morfologia, taxonomia e distribuição de Cryptonemia J. Agardh, no Brasil (Rhodophyta, Cryptonemiaceae). Arquivos Ciências do Mar 17: $1-19$.

Pinheiro-Joventino F. \& Oliveira-Filho E.C. 1977. A new species of Cryptonemia from Brazil. Arquivos de Ciências do Mar 17: 49 - 51.

Pinheiro-Joventino F., DANTAS N.P. \& MARASChin C.D.H. 1998. Distribuição de algas marinhas no litoral de Fortaleza, Ceará, Brasil. Arquivos Ciências do Mar 31: 29 - 40.

PricE J.H., JoHN D.M. \& LAwSON G.W. 1986. Seaweeds of the western coast of tropical Africa and adjacent islands: a critical assessment. IV. Rhodophyta (Florideae). 1. Genera A-F. Bulletin of the British Museum (Natural History) Botany 15: 1-122.

PuESCHEL C.M. \& COLE K.M. 1982. Rhodophycean pit plugs: an ultrastructural survey with taxonomic implications. American Journal of Botany 69: 703-720.

Radulovici A.E., Archambault P. \& Dufresne F. 2010. DNA Barcodes for marine biodiversity: moving fast forward? Diversity 2: 450 - 472.

Ratnasingham S. \& Hebert P.D.N. 2007. BOLD: The Barcode of Life Data System (www.barcodinglife.org). Molecular Ecology Notes 7: 355-364.

Robba L., Russell S.J., BARKer G.L. \& Brodie J. 2006. Assessing the use of the mitochondrial cox1 marker for use in DNA barcoding of red algae (Rhodophyta). American Journal of Botany 93: 1101 - 1108.

SAUNDERS G.W. \& KRAFT G.T. 1996. Small-subunit rRNA gene sequences from representatives of selected families of the Gigartinales and Rhodymeniales (Rhodophyta). 2. Recognition of the Halymeniales ord.nov. Canadian Journal of Botany 74: 694 - 707.

SAunders G.W. \& KrafT G.T. 2002. Two new Australian species of Predaea (Nemastomataceae, Rhodophyta) with taxonomic recommendations for an emended Nemastomatales and expanded Halymeniales. Journal of Phycology 38: $1245-1260$.

SAUNDERS G.W. \& HOMMERSAND M.H. 2004. Assessing red algal supraordinal diversity and taxonomy in the context of contemporary systematic data. American Journal of Botany 91: 1494-1507.

SAUNDERS G.W. 2005. Applying DNA barcoding to red macroalgae: a preliminary appraisal holds promise for future applications. Philosophical Transactions of the Royal Society B 360: 1879-1888.

SAUNDERS G.W. 2008. A DNA barcode examination of the red algal family Dumontiaceae in Canadian waters reveals substantial cryptic species diversity. 1. The foliose Dilsea-Neodilsea complex and Weeksia. Botany 86: 773-789.

SAUNDERS G.W. \& MCDEVIT D.C. 2012. Methods for DNA barcoding photosynthetic protists emphasizing the macroalgae and diatoms. Methods in Molecular Biology 858: 207 -222.

SAUNDERS G.W. \& MOORE T.E. 2013. Refinements for the amplification and sequencing of red algal DNA barcode and RedToL phylogenetic markers: a summary of current primers, profiles and strategies. Algae 28: 31-43. 
SAUNDERS G.W. \& MiLLAR K.R. 2014. A DNA barcode survey of the red algal genus Mazzaella in British Columbia reveals overlooked diversity and new distributional records: descriptions of $M$. dewreedei sp. nov. and M. macrocarpa sp. nov. Botany 92: 223-231.

SchMitz F. 1883. Untersuchungen über die Befruchtung der Florideen. Sber Akad Wiss 215-258.

SCHMitz F. 1889. Systematische Übersicht der bisher bekannten Gattungen der Florideen. Flora oder Allgemeine botanische Zeitung 72: 435-456.

SCHMITZ F. 1892. [6. Klasse Rhodophyceae]. 2. Unterklasse Floridea. In Syllabus der Vorlesungen über specielle und medicinisch-pharmaceutische Botanik. Eine Uebersicht über das gesammte Pflanzensystem mit Berücksichtigung der Medicinal- und Nutzpflanzen. (ed. by A.E. Grosse Ausgabe. (Engler), pp. 16-23. Borntraeger, Berlin.

SCHMitZ F. \& HAUPTFLEISCH P. 1897. Rhodophyceae. In Die naturlichen Pplanzenfamilien. (ed. by A. Engler \& K. Prantl), pp. 298-544. Verlag von Wilhelm Engelmann, Leipzig.

SCHNEIDER C.W. \& SEARLES R.B. 1991. Seaweeds of the southeastern United States. Cape Hatteras to Cape Canaveral. Duke University Press, Durham \& London. $563 \mathrm{pp}$.

SChNEIDER C.W., LANE C.E. \& SAUNDERS G.W. 2010. Notes on the marine algae of the Bermudas. 11. More additions to the benthic flora and a phylogenetic assessment of Halymenia pseudofloresii (Halymeniales, Rhodophyta) from its type locality. Phycologia 49: 154-168.

SCHNEIDER C.W., SAUnders G.W. \& LANE C.E. 2014. The monospecific genua Meredithia (Kallymeniaceae, Gigartinales) is species rich and geographically widespread with species from temperate Atlantic, Pacific and Indian Oceans. Journal of Phycology 50: 167-186.

Sen S., A.K., Das A.K., Banerji N., Siddhanta A.K., Mody K.H., Ramavat B.K., Chauhan V.D., Vedasiromoni J.R. \& Ganguly D.K. 1994. A new sulfated polysaccharide with potent anti-coagulant activity from the red seaweed Grateloupia indica. International Journal of Biological Macromolecules 16: 279 $-280$.

Sherwood A.R. \& Presting G.G. 2007. Universal primers amplify a 23 S rDNA plastid marker in eukaryotic algae and cyanobacteria. Journal of Phycology 43: 605-608.

Silva I.B. 2006. Diversidade de macroalgas marinhas bentônicas dos recifes de Maracajaú, Área de Preservação Ambiental dos Recifes de Corais, Rio Grande do Norte, Brasil. Universidade Federal do Rio Grande do Norte, Rio Grande do Norte, Natal. 58 pp.

Silva I.B. 2010. Algas marinhas bentônicas dos recifes e ambientes adjacentes de Maracajaú, APA dos Recifes de Corais, RN, Brasil. Instituto de Botânica da Secretaria de Estado do Meio Ambiente, São Paulo. 377 pp.

SOARES L.P. 2015. Diversidade das rodofíceas marinhas bentônicas do estado do Ceará, Brasil, baseada em evidências morfológicas e moleculares. Instituto de Botânica da Secretaria do Meio Ambiente. São Paulo. 339 pp.

Stamatakis A., Hoover P. \& Rougemont J. 2008. A Rapid Bootstrap Algorithm for the RAxML Web-Servers. Systematic Biology 75: 758-771.

Stoeckle M. 2003. Taxonomy, DNA and the bar code of life. BioScience 53: 796 797. 
SzÉCHY M.T.M. \& NASSAR C.A.G. 2005. Flora ficológica bentônica da Baía da Ribeira, sul do estado do Rio de Janeiro: avaliação após duas décadas de operação da Central Nuclear Almirante Álvaro Alberto. In Reunião Brasileira de Ficologia 10, Formação de ficólogos: um compromisso com a sustentabilidade dos recursos aquáticos. (ed. by O.S.B.d. Ficologia), pp. 361 - 372. Museu Nacional, Rio de Janeiro.

Talarico L.B., ZibetTi R.G.M., Faria P.C.S., Scolaro L.A., Duarte M.E.R., NosedA M.D., Pujol C.A. \& DAmonTE E.B. 2004. Anti-herpes simplex virus activity of sulfated galactans from the red seaweeds Gymnogongrus griffithsiae and Cryptonemia crenulata. International Journal of Biological Macromolecules 34: 63 - 71.

Talarico L.B., Duarte M.E., Zibetti R.G., Noseda M.D. \& Damonte E.B. 2007. An algal-derived DL-galactan hybrid is an efficient preventing agent for in vitro dengue virus infection. Planta medica 73: 1464 - 1468.

Tamura K., Stecher G., Peterson D., Filipski A. \& Kumar S. 2013. MEGA6: Molecular Evolutionary Genetics Analysis version 6.0. Molecular Biology and Evolution 30: 2725-2729.

TAn P.L., Lim P.E., Phang S.M., Draisma S.G.A. \& LiaO L.M. 2015. Foliose Halymenia species (Halymeniaceae, Rhodophyta) from Southeast Asia, including a new species, Halymenia malaysiana sp. nov. Botanica Marina 58: 203-217.

TAOUIL A. \& Yoneshigue-VAlentin Y. 2002. Alterações na composição florística das algas da Praia de Boa Viagem (Niterói, RJ). Revista Brasileira de Botânica 25: $405-412$.

TAYLOR W.R. 1960. Marine algae of the eastern tropical and subtropical coasts of the Americas. The University of Michigan Press, Ann Arbor. 870 pp.

Verbruggen H., Maggs C.A., Saunders G.W., Le Gall L., Yoon H.S. \& De CleRCK O. 2010. Data mining approach identifies research priorities and data requirements of resolving the red algal tree of life. BMC Evolutionary Biology: $10-16$.

Verlaque M., Brannock P.M., Komatsu T., Villalard-Bohnsack M. \& Marston M. 2005. The genus Grateloupia C. Agardh (Halymeniaceae, Rhodophyta) in the Thau Lagoon (France, Mediterranean): a case study of marine plurispecific introductions. Phycologia 44: 477 - 496.

Wang H., GuO S., Zhang X., ZhaO D., Zhang W. \& LuAN R. 2014. Re-identifying Grateloupia yangjiangensis (Rhodophyta, Halymeniaceae) based on morphological observations, life history and $\mathrm{rbcL}$ sequence analyses. Acta Oceanologica Sinica 33: 77-84.

Wang H.W., Kawaguchi S., Horiguch T. \& Masuda M. 2001. A morphological and molecular assessment of the genus Prionitis J. Agardh (Halymeniaceae, Rhodophyta). Phycological Research 49: 251-261.

WILKES R.J., MCIVOR L.M. \& GUIRY M.D. 2005. Using $r b c$ L sequence data to reassess the taxonomic position of some Grateloupia and Dermocorynus species (Halymeniaceae, Rhodophyta) from the north-eastern Atlantic. European Journal of Phycology 40: 53-60.

Williams S. \& SMITH J. 2007. A Global Review of the Distribution, Taxonomy, and Impacts of Introduced Seaweeds. The Annual Review of Ecology, Evolution, and Systematics 38: 327-359.

Withall R.D. \& SAUnders G.W. 2006. Combining small and large subunit ribosomal DNA genes to resolve relationships among orders of the Rhodymeniophycidae 
(Rhodophyta): recognition of the Acrosymphytales ord. nov. and Sebdeniales ord. nov. European Journal of Phycology 41: 379-394.

Wolf M.A., SFriso A. \& MORO I. 2014. Thermal pollution and settlement of new tropical alien species: The case of Grateloupia yinggehaiensis (Rhodophyta) in the Venice Lagoon. Estuarine, Coastal and Shelf Science 147: 11-16.

YANG M.M. \& KIM M.S. 2014a. Cryptonemia asiatica sp. nov. (Halymeniaceae, Rhodophyta), a new marine macroalgal species from Korea and Japan. Journal of Ecology and Environment 37: 387-393.

YANG M.Y., HAN E.G. \& KIM M.S. 2013. Molecular identification of Grateloupia elliptica and $G$. lanceolata (Rhodophyta) inferred from plastid $r b c \mathrm{~L}$ and mitochondrial COI genes sequence data. Genes \& Genomics 35: 239-246.

YANG M.Y. \& KIM M.S. 2014b. Taxonomy of Grateloupia (Halymeniales, Rhodophyta) by DNA barcode marker analysis and a description of Pachymeniopsis volvita sp. nov. Journal of Applied Phycology 27: 1373-1384.

YokoYa N.S., GuIMARAES S.M.P.B. \& HANDRO W. 1993. Development of callus-like structures and plant regeneration in thallus segments of Grateloupia filiformis Kützing (Rhodophyta). Hydrobiologia 260/261: 407-413.

Yoneshigue-Valentin Y., Fernandes D.R.P., Pereira C.B. \& Ribeiro S.M. 2005. Macroalgas da plataforma continental da Ilha da Trindade e do Arquipélago de Martin Vaz (ES - Brasil). In Reunião Brasileira de Ficologia 10, 2004. Formação de ficólogos: um compromisso com a sustentabilidade dos recursos aquáticos. (ed. by S.B.d. Ficologia), pp. 361 - 372. Museu Nacional do Rio de Janeiro, Salvador.

Yoneshigue-Valentin Y., Loivos A.M., Silva R.C.C. \& Fernandes D.R.P. 2008. Contribuição ao conhecimento e preservação das algas multicelulares bentônicas do Costão dos Cavaleiros - Macaé, estado do Rio de Janeiro. Iheringia 63: 129 134.

YONESHIGUE Y. 1985. Taxonomie et ecologie des algues marines dans la region de Cabo Frio, Rio de Janeiro, Bresil. L'Universite D'Aix-Marseille II, Luminy. 466 pp.

ZEMKE-White W.L. \& OHNO M. 1999. World seaweed utilization: an end-of-century summary. Journal of Applied Phycology 11: 369 - 376.

ZiBETTI R.G.M. 2005. Determinação da estrutura química de polissacarídeos isolados de algas pertencentes à ordem Halymeniales (Rhodophyta). Universidade Federal do Paraná, Paraná, Curitiba. 118 pp. 
ANEXOS 


\section{ANEXO I \\ PROTOCOLO DE ESTUDO MORFOLÓGICO \\ Caracteres Vegetativos}

$\mathrm{N}^{\circ}$ de Campo

Cor:

Estádio:

Altura:

Estipe:

Região

Apical

Região

Mediana

Região da

Base
Forma

Comprimento

Diâmetro

Espessura

Espessura na nervura

Região subcortical

Região cortical

Região medular

Células ganglionares

Espessura

Espessura na nervura

Região subcortical

Região cortical

Região medular

Células ganglionares

Espessura

Espessura na nervura

Região subcortical

Região cortical

Região medular

Células ganglionares
Identificação

preliminar

Textura/

aspecto

Largura das

frondes

Nervura

Apressório

Medidas

de células

Medidas

de células

Medidas

de células

Células estreladas

Identificação

definitiva

Ramificação

Largura

Diâmetro

Altura

Largura

Diâmetro

Altura

Largura

Diâmetro

Medidas

Altura

Largura

Diâmetro

de células

Medidas

Altura

Largura

Diâmetro

de células

Medidas

Altura

de células

Células estreladas

Medidas

Altura

Largura

Diâmetro

de células

Medidas

Altura

Largura

Diâmetro

de células

Medidas

Altura

Largura

Diâmetro

Células estreladas 


\section{ANEXO II \\ PROTOCOLO DE ESTUDO MORFOLÓGICO \\ Caracteres Reprodutivos}

$\mathbf{N}^{0}$ de Campo

Cor:

Estádio:

Altura:

Espermatângios

Ampola da

célula auxiliar

Ampola do

Ramo

carpogonial

Cistocarpos

Tetrasporângios

Desenvolvimento

Localização

Desenvolvimento

Ramificação

Desenvolvimento

Ramificação

Desenvolvimento

Localização

Pericarpo
Identificação

preliminar

Textura/

aspecto

Largura das

frondes

\section{Observações}

Identificação

Definitive

Ramificação

Diâmetro

Diâmetro

Gonimolobos

Altura

Diâmetro 


\section{ANEXO III}

Manuscrito submetido ao periódico Phycologia. 
Diversity of branched Halymenia (Halymeniales, Rhodophyta) species on the Brazilian coast: molecular and morphological analyses reveal three new species

\author{
Carolina Angélica AraúJo de AZevedo ${ }^{1 *}$, Valéria Cassano and Mariana \\ CABRAL OLIVEIRA
}

Laboratório de Algas Marinhas Édson José de Paula, Departamento de Botânica, Instituto de Biociências, Universidade de São Paulo, R. do Matão 277, 05508-090 São Paulo, SP, Brazil

Running title: Branched Halymenia species

* Corresponding author (caaazevedo@ hotmail.com) 
ABSTRACT: The diversity of branched Halymenia species in Brazil was assessed by molecular analyses and morphological examination to clarify the status of taxa previously identified as Halymenia floresii and H. pseudofloresii. Molecular tools included sequencing the COI-5P molecular marker for DNA barcoding and $r b c \mathrm{~L}$ for phylogenetic inferences. Both molecular and morphological results demonstrated that Brazilian specimens previously attributed to $H$. floresii and $H$. pseudofloresii do not correspond to these species but constitute three distinct lineages that we propose as the new species, Halymenia ignifera sp. nov., Halymenia pinnatifida sp. nov., and Halymenia silviae sp. nov. We propose that $H$. floresii and $H$. pseudofloresii be removed from the Brazilian marine flora. We highlight that without the use of molecular tools, the morphological divergences observed in Brazilian specimens could be misinterpreted as morphological plasticity and lead to incorrect species determinations. KEY WoRDS: Brazilian coast, COI-5P, DNA barcoding, Halymenia, morphology, $r b c$ L.

\section{INTRODUCTION}

Halymenia C.Agardh (Halymeniaceae, Rhodophyta) currently includes 76 accepted taxa (Guiry \& Guiry 2016), inhabiting warm to temperate marine waters worldwide, but most species are tropical (Gargiulo et al. 1986; Abbott 1999; De Smedt et al. 2001; Lewmanomont \& Kawaguchi 2002; Hernández-Kantún et al. 2012). The generitype, Halymenia floresii (Clemente) C.Agardh, was originally described as Fucus floresius by Clemente (1807) for specimens from Cádiz Bay, Spain. The epithet honored D. Francisco Flores, and, as noted by Schneider (2003), the orthography should be floresii. Later, Agardh (1817) described the new genus Halymenia and included Fucus floresii as one of its members, as Halymenia 'floresia'. Since then, the name Halymenia 
floresia has been vastly applied in the literature to refer to Halymenia floresii (Taylor 1960; Dawes 1974; Oliveira Filho 1977; Gargiulo et al. 1986; Kawaguchi 2004).

Halymenia floresii has previously been considered a species with a wide geographic distribution in tropical waters, being recorded from Europe, several islands in the Atlantic, North America, Central America, Caribbean Islands, South America, Africa, Indian Ocean Islands, Asia, Australia, New Zealand and islands in the Pacific (Guiry \& Guiry 2016). Halymenia pseudofloresii Collins \& M.Howe (1916) was described for specimens from Bermuda that differed from $H$. floresii in being a deeper red colour, having a firmer consistency, a verruculose surface in older fronds, and a broader base. Its currently reported geographic distribution includes islands in the Atlantic and in the Caribbean, Western Atlantic, South America and Southeast Asia (Guiry \& Guiry 2016). However, other studies have indicated that the distribution ranges of these entities can be much more restricted than previously thought because many records constitute misidentifications (Abbott 1999; De Smedt et al. 2001; Schneider et al. 2010; Hernández-Kantún et al. 2012).

After a morphological examination of Halymenia specimens from the southwestern Pacific, Abbott (1999) noted that specimens identified as Halymenia floresii lacked the anticlinal medullary filaments typical of the lectotype, and therefore, corresponded more closely to the morphologically similar Halymenia durvillei Bory. De Smedt et al. (2001) examined specimens from the Indo-Pacific attributed to H. floresii and, like Abbott (1999), did not observe features characteristic of the species, such as the absence of surface proliferations, a thin cortex, regular pinnate branching and 3-4 cortical cells layers. Therefore, they also suggested that the Indo-Pacific entity corresponded to H. durvillei. 
Schneider et al. (2010) used molecular methods to demonstrate that records of Halymenia floresii in the Bermudian flora actually corresponded to morphological variants of Halymenia pseudofloresii. Hernández-Kantún et al. (2012), based on morphological and molecular assessments, removed Halymenia floresii from the IndoPacific flora. In addition, those authors demonstrated that Halymenia floresii subsp. harveyana (J.Agardh) Womersley \& Lewis (type locality: Australia) did not join with $H$. floresii in molecular analyses and warranted recognition at the species level, for which they resurrected the name Halymenia harveyana J.Agardh.

These results raise the question of uncertainty of Brazilian records of Halymenia species. The first records of Halymenia floresii and $H$. pseudofloresii for Brazilian tropical waters date back to 1875 (Dickie 1875) and 1967 (Joly et al. 1967), respectively. Present records show these entities overlapping along northeastern and southeastern waters of Brazilian coasts, ranging from Ceará State to Rio de Janeiro State.

In this study we assessed Brazilian taxa referred to Halymenia floresii and Halymenia pseudofloresii through molecular and morphological analyses. Based on our results, we propose three new species: Halymenia ignifera sp. nov., $H$. pinnatifida sp. nov., and $H$. silviae sp. nov. to accommodate the taxa previously referred to as $H$. floresii and H. pseudofloresii from Brazil.

\section{MATERIALS AND METHODS}

This study included a total of 18 specimens collected along the Brazilian coast from 2012 to 2014 (Table S1). For each sample, a small piece of tissue was dehydrated in silica gel for molecular analyses, while the remaining material was preserved in $4 \%$ formalin/seawater or pressed as herbarium vouchers for morphological studies. 
DNA extraction protocols followed Goff \& Moon (1993) and Saunders \& McDevit (2012). PCR protocol for the COI-5P followed Saunders \& Moore (2013), with application of M13LF3-M13Rx or M13LF3-M13Ri primer pairs. $r b c \mathrm{~L}$ molecular marker was amplified according to Freshwater et al. (1994) and Saunders \& Moore (2013). Sequencing reactions were carried out by McGill University and Génome Québec Innovation Centre (Montréal, Canada) or followed Milstein et al. (2012).

Bi-directional reads were used to generate consensus sequences using Sequencher 5.0 (Gene Codes Corporation, Ann Arbor, MI) or BioEdit 7.0.9.0 (Hall 1999). COI-5P multiple sequence alignments were constituted by 23 sequences, 611 bp in length. A search carried out at MEGA 5 software (Tamura et al. 2011) under the Bayesian Information Criterion (BIC) indicated the Tamura 3-parameter method $(\mathrm{T} 92+\mathrm{G}, \mathrm{G}=0,10)$ as the best nucleotide substitution model for the dataset. Neighborjoining was conducted in MEGA 5 software in order to assign specimens to genetic species groups. Node supports were estimated after 1000 bootstrap replicates.

For each genetic group obtained with the Neighbor-joining method, $r b c \mathrm{~L}$ data were generated as outlined above in order to investigate phylogenetic relationships. The $r b c \mathrm{~L}$ alignment included a total of 42 sequences of $1259 \mathrm{bp}$ length. We attempted to include representatives of all genera of Halymeniaceae according to the availability of $r b c \mathrm{~L}$ sequences in BOLD and Genbank, and, whenever possible, sequences from generitype species collected at type localities. "Tsengia lanceolata AY294386 South Africa-Western Cape" was used as the outgroup. This alignment was submitted to Maximum Likelihood at the web-served RaxML Blackbox (Stamatakis et al. 2008), under the model GTR $+\mathrm{G}+\mathrm{I}$ (by default). The $r b c \mathrm{~L}$ alignment was partitioned by codon position (3 partitions). Bayesian Inference (BI) was used for phylogenetic analyses, performed with MrBayes v.3.0 beta 4 (Huelsenbeck \& Ronquist 2001). Modeltest 
version 3.06 (Posada \& Crandall 1998) was used to select the most appropriate model of sequence evolution for BI analysis under the Akaike Information Criterion (AIC). The model selected was the general-time-reversible model of nucleotide substitution with invariant sites and gamma distributed rates for the variable sites $(\mathrm{GTR}+\mathrm{I}+\mathrm{G})$. For BI two runs with four MCMC chains were carried out with 4 million generations and sampling every 1000 generations. The first 50,000 generations were discarded in both runs as burn-in to build the consensus tree. For both markers, pairwise distances were obtained at MEGA 5 software, considering all three codon positions, with 1,000 bootstrap replicates and removal of ambiguous positions for each sequence pair. For morphological examination, samples were sectioned by hand and stained with $1 \%$ aniline blue acidified with diluted $1 \% \mathrm{HCl}$. Squash preparations were made after immersion in diluted $1 \% \mathrm{HCl}$ for 3-5 min. All measurements made with the optical microscope are given as length $\mathrm{x}$ width. Macroscopic images were taken with a Panasonic Lumix DMC-TS20 (Kadoma, Japan), while microscopic ones were captured with a Leica DFC 420 mounted on a Leica DM 4000B microscope (Leica Microsystems, Wetzlar, Germany). In order to differentiate between ganglionic and stellate cells, we followed the definition adopted by Guimarães \& Fujii (1998), which states that ganglionic cells consist of interconnected filaments with refractive contents, parallel to the thallus surface, while stellate cells display normal contents and are derived from the stretching of cells as the tissue matures. Vouchers were deposited in SPF (Herbarium of the University of São Paulo). Herbarium abbreviations follow the online Index Herbariorum (Thiers continuously updated).

\section{RESULTS}


The COI-5P Neighbor joining analysis (Fig. 1) indicated that specimens collected from the Brazilian coast belonged to three different genetic species groups. All three clades were resolved with moderate to high Bootstrap node support. None of the Brazilian samples matched authentic H. floresii or H. pseudofloresii, or any other species represented in molecular libraries. COI-5P intraspecific divergence ranged from 0.0$0.5 \%, 0.2 \%$ and $0.0-0.3 \%$ among representatives of $H$. ignifera, $H$. pinnatifida and $H$. silviae, respectively. Interspecific divergences values are shown in Table 1.

The phylogeny inferred from our $r b c \mathrm{~L}$ analysis indicated that the Brazilian Halymenia lineages treated in this study resolved in the clade including the generitype H. floresii, indicating that they indeed corresponded to the genus Halymenia (Fig. 2). Divergences among lineages from Brazil and generitype sequences are shown in Table 1. Our $r b c \mathrm{~L}$ phylogeny recovered the same pattern suggested by the COI-5P distance analysis, in which Halymenia species collected in Brazil and previously attributed to $H$. floresii and $H$. pseudofloresii actually corresponded to three molecularly divergent but morphologically similar lineages. In our $r b c \mathrm{~L}$ phylogeny, $H$. pinnatifida and $H$. silviae were sister lineages with high support (99/1.00). These results led us to conclude that these entities corresponded to three different species, treated here as Halymenia ignifera sp. nov., Halymenia pinnatifida sp. nov. and Halymenia silviae sp. nov.

\section{Halymenia ignifera C.A.A.Azevedo, Cassano \& M.C.Oliveira sp. nov.}

Figs 3-16

DIAGNOSIS: Thallus with blades pinnately or palmately branched up to three orders, with rare surface proliferations mainly restricted to proximal regions and surface spines on distal regions. Marginal branchlets throughout or concentrated at basal region. 
Blades up to $640 \mu \mathrm{m}$ thick at base. 1-2 cell layers at inner cortex. Longitudinal filaments concentrated at outer medulla at basal region.

Holotype: Brazil, Rio Grande do Norte State, Rio do Fogo City, Rio do Fogo Beach. 515'56”S, 35²3'05’W. Drift material. (SPF 57817). GenBank KT807817 (COI-5P) and KT807829 (rbcL).

ETyMOLOGY: The epithet ignifera refers to Rio do Fogo Beach (= River of Fire Beach), the type locality; - ignifera, "bearing fire" or "containing fire".

DISTRIBUTION: northeastern and southeastern Brazil.

Misapplied name for Brazil: Halymenia floresia sensu Taylor (1960, p. 418), CâmaraNeto (1971, p. 147), Oliveira-Filho (1977, p. 80), Guimarães (1990), Nunes (2005, p. 164, Fig. 184).

\section{Morphology}

Plants were erect, up to $55 \mathrm{~cm}$ high, mucilaginous, pinkish in color, ligulate blade, without midrib and arose from a small discoid holdfast approximately $2 \mathrm{~mm}$ in diameter. Basal region cuneate originated from a little differentiated stipe that was compressed-cylindrical in shape near the holdfast, 1.5-4.0 mm width. Main axes ranged from $2.0-5.0 \mathrm{~cm}$ wide in the basal regions to $0.5 \mathrm{~cm}$ wide at the apex, and were pinnately or palmately branched up to 3 orders, with distally tapering branches. Secondorder branches were up to $6.0 \mathrm{~cm}$ long. Main axis with long and pinnately branched surface proliferations, especially at the proximal region, on both surfaces, reaching 9.5 cm long. Spine-like surface proliferations were present in the upper third of the blade, and marginal ones occurred in the basal region in some specimens. Marginal branchlets were abundant throughout thalli in some specimens, or common in the proximal region, but rare and shorter in the distal region in others. 
In transverse section, thalli were $125-270 \mu \mathrm{m}$ thick in the apical region, 350-460 $\mu \mathrm{m}$ in the middle and $420-640 \mu \mathrm{m}$ in the basal region. Outer cortex with ellipsoidal cortical cells, arranged in 1-3 cell layers, measuring $7.5-12.5 \times 5.0-7.5 \mu \mathrm{m}$ in the apical region, $10.0-15.0 \times 5.0-15.0 \mu \mathrm{m}$ in the middle and $10.0-17.5 \times 5.0-7.5 \mu \mathrm{m}$ in the basal region. Inner cortex with 1-2 layers of rounded or slightly elongated cells, 17.5-25 $\mu \mathrm{m}$ wide throughout the thallus. Medulla with anticlinal filaments, $7.5-12.5$ $\mu \mathrm{m}$ in diameter in the apical and middle regions, and 7.5-17.5 $\mu \mathrm{m}$ in diameter in the basal region. Medulla was lax in the apical region, denser in the middle region, and densely filled with anticlinal and intertwined filaments in the basal region. Longitudinal filaments, $7.5-10 \mu \mathrm{m}$ in diameter were also present between inner cortex and medulla in the basal region. Ganglionic cells were present throughout the thallus. Stellate cells connected inner cortex cells and medullary filaments, $15-22.5 \mu \mathrm{m}$ in diameter.

Auxiliary cell ampullae were sub-globular in shape, bushy and expanded with branched ampullary filaments. Lowermost cells of the ampullary filaments were cylindrical, elongated. Auxiliary cell was intercalary in the ampullary filament. Mature cystocarps were subspherical, totally immersed in thallus, disposed in the apical and middle regions, 85-132.5 $\mu \mathrm{m}$ in diameter, presenting two gonimolobes. Pericarp 180$230 \mu \mathrm{m}$ in diameter. Cells between carposporangia and ampullary filaments with thickened walls. Tetrasporangia in outer cortex in the apical regions of the blade, cruciate, measuring $15-20 \times 10 \mu \mathrm{m}$.

\section{Halymenia pinnatifida C.A.A.Azevedo, Cassano \& M.C.Oliveira sp. nov.}

Figs 17-26

DiAGNOSIS: Thallus with ligulate blades, pinnately branched up to three orders. Surface proliferations distributed throughout. Abundant marginal proliferations and spine-like 
branchlets throughout. Blades up to $1275 \mu \mathrm{m}$ thick at base. 1-2 cell layers at inner cortex. Longitudinal filaments concentrated at outer medulla at basal region.

HolotyPE: Brazil, Rio Grande do Norte State, Rio do Fogo City, Rio do Fogo Beach. 5¹5’56”S, 35²3’05”W. Drift material. (SPF 57871). GenBank KT807811 (COI-5P) and KT807828 (rbcL).

ETYMOLOGY: The epithet refers to abundant pinnately arranged branchlets throughout the thallus; - pinnatifida, pinnately cleft (Stearn 1973).

DISTRIBUTION: northeastern Brazil.

Misapplied name for Brazil: Halymenia floresia sensu Taylor (1960, p. 418), CâmaraNeto (1971, p. 147), Oliveira-Filho (1977, p. 80), Guimarães (1990).

\section{Morphology}

Plants were erect, up to $26 \mathrm{~cm}$ in height, mucilaginous, pinkish in color, ligulate blade, without midrib and arose from a discoid holdfast approximately $5 \mathrm{~mm}$ in diameter. Basal region cuneate originated from a little differentiated stipe that was compressedcylindrical near holdfast, $2-3 \mathrm{~mm}$ width. Main axes ranged from $4.0 \mathrm{~cm}$ wide in the basal region and $0.5 \mathrm{~cm}$ wide at the apex, and were pinnately branched up to 3 orders, with distally tapering branches. Main axis presented long surface proliferations that reached $5.0 \mathrm{~cm}$ in height in the middle region and $0.5 \mathrm{~cm}$ in height in the apical region. Proliferations and spine-like marginal branchlets were very abundant throughout the thalli, in proximal and distal regions.

In transverse section, thalli were $110-140 \mu \mathrm{m}$ thick in the apical region, $290-870$ $\mu \mathrm{m}$ in the middle and $975-1275 \mu \mathrm{m}$ in the basal region. Outer cortex with ellipsoidal or rectangular cells, arranged in 1-2 cell layers, measuring 7.5-10.0 x 2.5-5.0 $\mu \mathrm{m}$ in the apical region, $7.5-12.5 \times 5.0-7.5 \mu \mathrm{m}$ in the middle and $10.0-20.0 \times 5.0-7.5 \mu \mathrm{m}$ in the 
basal region. Inner cortex with 1-2 cell layers of rounded or slightly elongated cells parallel to the cortex, 15.0-25.0 $\mu \mathrm{m}$ wide at both apical and middle regions, and 22.5$30.0 \mu \mathrm{m}$ wide in the basal region. Medulla with anticlinal filaments, $5.0-10.0 \mu \mathrm{m}$ in diameter in the apical region, $10.0-15.0 \mu \mathrm{m}$ in diameter in the middle region and 7.5$17.5 \mu \mathrm{m}$ in diameter in the basal region. Medulla was lax in the apical region, denser in the middle and densely filled with anticlinal and intertwined filaments in the basal region. Longitudinal filaments $7.5-10.0 \mu \mathrm{m}$ in diameter were also present between medulla and inner cortex, in the basal region. Few ganglionic cells were present throughout the thalli. Stellate cells connected inner cortex cells and medullary filaments. Tetrasporangia in outer cortex, numerous in the apical region and less abundant in the middle region, cruciate, $15.0-25.0 \times 12.5-17.5 \mu \mathrm{m}$.

\section{Halymenia silviae C.A.A.Azevedo, Cassano \& M.C.Oliveira sp. nov.}

Figs 27-39

DiAGNOSIS: Thallus with blades foliose, lobate, cleft or irregularly branched with broad base. Surface proliferations irregularly distributed. Margins slightly dentate. 1-2 cell layers at inner cortex, inner cortex cells $7.5-25 \mu \mathrm{m}$ in diameter.

HolotyPe: Brazil, Bahia State, Prado City, Corumbau Beach. 1654’05’S, 3907’10’W. Drift material. (SPF 57875). GenBank KT807814 (COI-5P).

ETYMology: The epithet honors Dr. Silvia Maria Pita de Beauclair Guimarães, a Brazilian phycologist, for her significant contributions to the knowledge of the Halymeniales from Brazil.

DISTRIBUTION: northeastern Brazil.

Misapplied name for Brazil: Halymenia pseudofloresii sensu Joly et al. (1967, p. 176, Pl. 1, Fig. 3 and Pl. 2, Fig. 6), Oliveira-Filho (1977, p. 81), Guimarães (1990). 


\section{Morphology}

Plants were erect, up to $39 \mathrm{~cm}$ in height, pinkish in color, mucilaginous, broad, foliose and lobate blade, without midrib and arose from a discoid holdfast approximately $2 \mathrm{~mm}$ in diameter. Basal region cuneate originated from a compressed stipe up to $5 \mathrm{~mm}$ in height and $2 \mathrm{~mm}$ width. Fronds expanded rapidly from the basal to the middle region, reached up $12 \mathrm{~cm}$ width, and then narrowed toward the apex. Some thalli presented long lateral branches up to $7 \mathrm{~cm}$ long and $1 \mathrm{~cm}$ wide, tapering, pinnately arranged. Long surface proliferations were present. Surfaces presented no rugosities. Margins were slightly undulated and somewhat dentate. Branchlets were absent.

In transverse section, thalli were $142-280 \mu \mathrm{m}$ thick in the apical region, 180-410 $\mu \mathrm{m}$ in the middle and 460-790 $\mu \mathrm{m}$ in the basal region. Outer cortex with ellipsoidal cells arranged in 1-2 cell layers, measuring 7.5-15.0 x 5.0-7.5 $\mu \mathrm{m}$ in both apical and middle regions, and 10.0-20.0 x 5.0-7.5 $\mu \mathrm{m}$ in the basal region. Inner cortex with 1-2 cell layers of rounded and slightly elongated cells $7.5-22.5 \mu \mathrm{m}$ wide in the apical region, 12.5-25.0 $\mu \mathrm{m}$ wide in the middle and 17.5-27.5 $\mu \mathrm{m}$ wide in the basal region. Medulla with anticlinal filaments $7.5-12.5 \mu \mathrm{m}$ in diameter in the apical region, $10.0-15.0 \mu \mathrm{m}$ in diameter in the middle and 7.5-20.0 $\mu \mathrm{m}$ in diameter in the basal region. Medulla was lax in the apical region, denser in the middle and densely filled with anticlinal and intertwined filaments in the basal region. Few ganglionic cells were present throughout the thalli. Stellate cells connected inner cortical cells and medullary filaments.

Auxiliary cell ampullae were spherical in shape, $50-65 \mu \mathrm{m}$ in diameter, very bushy and numerous in the apical region. Auxiliary cells were intercalary in the ampullary filament. Cystocarps subspherical, totally immersed in thallus, disposed in the apical and middle regions, $237.5 \mu \mathrm{m}$ in diameter and presenting two gonimolobes. 
Fusion cell was transversely elongated, $24 \mu \mathrm{m}$ height and $6 \mu \mathrm{m}$ wide. Tetrasporangia in outer cortex, abundant in the apical and middle regions, measuring 17.5-22.5 x 10.0$12.5 \mu \mathrm{m}$.

\section{Key to the species of Halymenia covered in this study}

1a. Branched ligulate foliose blade............................................ 2

1b. Suborbicular, lobate or cleft foliose blade....................................

2a. Surface proliferations or spines absent; margins entire, with occasional spine-like process; inner cortex with 3-4 cell layers. Halymenia floresii

2b. Surface proliferations or spines present; marginal branchlets present; inner cortex with 1-2 cell layers. .3

3a. Branching pattern pinnate or palmate; marginal branchlets throughout or concentrated at basal region; thalli $420-640 \mu \mathrm{m}$ thick at base Halymenia ignifera

3b. Branching pattern pinnate; abundant marginal proliferations and spine-like branchlets throughout; thalli $975-1275 \mu \mathrm{m}$ thick at base Halymenia pinnatifida

4a. Ganglionic cells absent Halymenia brasiliana

4b. Ganglionic cells present. .5

5a. Margins serrate or dentate, with proliferations; inner cortex cells $20-50 \mu \mathrm{m}$ in diameter/width Halymenia pseudofloresii

5b. Margins slightly undulated and somewhat dentate; inner cortex cells $7.5-25 \mu \mathrm{m}$ in diameter/width Halymenia silviae

\section{DISCUSSION}

Our molecular and morphological analyses demonstrated that Brazilian specimens that previously would have been attributed to Halymenia floresii or H. pseudofloresii do not 
correspond to either species and actually constitute three different new species. The phylogenetic analysis included a sequence of $H$. floresii from Portugal (Genbank accession number GQ862071), close to Spain, Cádiz Bay, the type locality of $H$. floresii. It is important to note that this entity corresponds to the same entity occurring at the type locality, as demonstrated by our $r b c \mathrm{~L}$ phylogeny (Fig. 2). In this sense, we can consider that we have a representative of the genuine $H$. floresii in our COI-5P analysis (Fig. 1). In addition, we also include $H$. pseudofloresii from Bermuda, its type locality (Genbank accession numbers GQ862072, GQ862073, GQ862074 and GQ862076).

Considering our COI-5P data, intraspecific divergence values $(0.0-0.5 \%)$ are within the range of $0.0-1.6 \%$ previously reported for Halymeniaceae, while divergences among genetic groups (6.4-11.4\%) are in agreement with values provided by prior studies (3.7-14\%) (Yang \& Kim 2014; Manghisi et al. 2015).

The application of both COI-5P and $r b c \mathrm{~L}$ molecular markers has been considered an effective approach for species discrimination, recognition of cryptic species, and phylogenetic inferences (Kucera \& Saunders 2012; Yang \& Kim 2014). Corroborating the use of COI-5P as a DNA barcode marker, all of the genetic groups obtained with COI-5P data were assigned to distinct lineages in our $r b c \mathrm{~L}$ phylogeny. Regarding $r b c \mathrm{~L}$ interspecific divergences, values presented here (2.8-5.6\%) are within the range of 0.7-9.9\% previously reported for Halymeniaceae (HernándezKantún et al. 2012; Yang et al. 2013; Calderon et al. 2014a; Calderon et al. 2014b; Tan et al. 2015). As in previous studies, our phylogeny shows a clade with moderate to high support that includes the generitype of Halymenia, H. floresii, as well as Gelinaria ulvoidea Sonder and Epiphloea bullosa (Harvey) DeToni, both representing monospecific genera. The possibility of subsuming these two entities into Halymenia 
was mentioned by Yang et al. (2013). However, the genus Halymenia does not correspond to a monophyletic group (Hernández-Kantún et al. 2012; Yang et al. 2013; Kraft \& Saunders 2013; Calderon et al. 2014b) and, consequently, the clarification of phylogenetic relationships within the Halymeniales requires further investigation.

Morphologically, our specimens of both Halymenia ignifera and $H$. pinnatifida agree with descriptions provided by Taylor (1960) and Guimarães (1990) for material identified as $H$. floresii collected on the Brazilian coast. However, when compared to lectotype material of $H$. floresii analyzed by Kawaguchi (2004), both $H$. ignifera and $H$. pinnatifida slightly diverge by: (i) branching up to three orders in Brazilian material, and up to four orders in the type; (ii) presence of surface proliferations that are absent in the type specimens; (iii) 1-2 cell layers in the outer cortex of our material, and 2-3 in the type; (iv) 1-2 cell layers in the inner cortex of our material, and 3-4 in the type. In addition, Kawaguchi (2004) did not mention the presence of longitudinal filaments in the basal region in the lectotype specimens, and it is not possible to visualize it from the pictures provided, which could be a consequence of the rehydrated material used by the author.

The longitudinal filaments observed between the inner cortex and medulla in the basal region of $H$. ignifera and $H$. pinnatifida are somewhat similar to the rhizoidal initial illustrated by Balakrishnan (1961) for Halymenia polydactyla Børgesen, currently a synonym of Sebdenia flabellata (J.Agardh) P.G.Parkinson. However, the rhizoidal initials appear isolated and immersed in the medulla, and not concentrated in the outer medulla as in our material. The same author also observed longitudinal and slender rhizoids among medullary filaments of other species of Halymenia but did not illustrate those. In addition, Chiang (1970) described rhizoidal filaments in Pachymenia carnosa (J.Agardh) J.Agardh as long, non-septate filaments that grow in all directions and fuse 
with cortical cells, which get slightly enlarged and whose cytoplasm becomes denser. We did not observe fusion of longitudinal filaments with cortical cells. De Clerck et al. (2005a, 2005b) illustrated rhizoidal filaments as dense longitudinal filaments that completely fill the basal medulla of species of Grateloupia C.Agardh and Phyllymenia J.Agardh. None of the previous descriptions of rhizoidal filaments completely match the structures that we observed in this study; so we opt to call them longitudinal filaments. In his investigation of the marine flora of the Atlantic tropical and subtropical coasts of the Americas, Taylor (1960) considered specimens of $H$. floresii from Caribbean and Brazil and stated that this species has several orders of branching and filiform apical regions. According to Taylor, $H$. pseudofloresii, only collected from Bermuda, does not have a uniform branching pattern and presents a dentate, broad distal region. Taxa named in this study as $H$. ignifera and $H$. pinnatifida corroborate the description by Taylor (1960) for H. floresii in aspects such as thallus height, width at main divisions and presence of marginal branchlets. Taylor (1960), however, stated that he found individuals with few branchlets, but also very bushy specimens. It is possible to note that $H$. pinnatifida has more abundant branchlets than $H$. ignifera. We therefore suspect that Taylor (1960) considered representatives of these two entities as a single species.

In a comparison of $H$. ignifera and $H$. pinnatifida, these lineages differ by: (i) surface proliferations more evenly distributed throughout the thalli in H. pinnatifida; (ii) marginal branchlets much more abundant in $H$. pinnatifida; (iii) thicker thalli in proximal region of $H$. pinnatifida $(975-1275 \mu \mathrm{m})$, in comparison to $H$. ignifera (420$640 \mu \mathrm{m})$. These differences in thallus thickness are consistent especially because in $H$. ignifera we found individuals longer $(55 \mathrm{~cm})$ than in $H$. pinnatifida $(26 \mathrm{~cm})$. 
Our specimens of $H$. silviae agree with descriptions of $H$. pseudofloresii provided by Collins \& Howe (1916), Taylor (1960), Joly et al. (1967) and Guimarães (1990) in the following: (i) general aspect; (ii) stipe size; (iii) thallus height; (iv) width at main divisions; (v) sparse anticlinal medullary filaments; (vi) medullary filaments diameter; and (vii) infrequent ganglionic cells. Some of our specimens have entire margins, but others present somewhat dentate margins and marginal proliferations, described as abundant by Collins \& Howe (1916) and Taylor (1960) for Bermudian material. These numerous marginal branchlets are also reported by Dawes (1974) for $H$. pseudofloresii from Florida. Another difference between Brazilian material and type specimens of $H$. pseudofloresii is the smaller ellipsoidal inner cortical cells (Brazilian material: 7.5-25 $\mu \mathrm{m}$; Type material: $20-50 \mu \mathrm{m})$.

When Halymenia silviae is compared to the foliose Halymenia brasiliana S.M.Guimarães \& M.T.Fujii, the observed divergences are the following: (i) surface with proliferations and without rugosities in the former and surface with rugosities and without proliferations in the latter; (ii) ganglionic cells present in $H$. silviae and absent in H. brasiliana; (iii) inner cortex cells diameter or width smaller in the former (7.5-25 $\mu \mathrm{m}$, and 20-45 $\mu \mathrm{m}$ in H. brasiliana) (Guimarães \& Fujii 1998).

Vegetative construction was quite different according to the thallus portion sectioned in all specimens observed. Blade thickness, cortical cells size and in particular the abundance and diameter of medullary filaments all diminished from proximal to distal regions. Some studies do not specify the thallus region that was observed (Collins \& Howe 1916; Joly et al. 1967; Taylor 1960), which can limit comparisons. We thus advocate that a complete approach of vegetative anatomy of Halymeniales should include observations of three regions of the thallus (apical, middle and basal). 
The genus Halymenia presents mucilaginous to softly cartilaginous thalli; these may be cylindrical or foliose, narrowed or wide fronds, or entire, cleft or branched (Taylor 1960; Guiry \& Guiry 2016). Several authors consider vegetative features more relevant than reproductive ones for species delimitation within Halymenia (Dawson 1954; Abbott 1967; Guimarães \& Fujii 1998; Hernández-Kantún et al. 2012).

Diagnostic criteria include thallus consistency; habit (terete or flattened); thallus size, with particular regard to blade width; branch shape (lanceolate, orbicular or pinnate) and number of orders of branching; presence or absence of a midrib in the basal region; stipe shape and size; presence or absence of marginal proliferations; presence or absence and abundance of papillae or spines on thallus surface; shape of cells in inner cortex; cortex thickness; and presence or absence of ganglionic cells (Dawson 1954; Abbott 1967; Guimarães \& Fujii 1998; Hernández-Kantún et al. 2012)

In summary, the primary vegetative features that are considered diagnostic to the species treated here are the following: habit, branching pattern and orders of branching, presence of surface proliferations or spines, characteristics of blade margins, presence of ganglionic cells, thickness of thalli, number of cell layers in inner cortex and inner cortex cells size (Table 2). All of them have been considered taxonomically informative for species discrimination of Halymenia by previous studies (Guimarães \& Fujii 1998; De Smedt et al. 2001; Hernández-Kantún et al. 2012; Tan et al. 2015).

Regarding reproductive aspects, the general outline of auxiliary cell ampullae described here, i.e. bushy subglobular or spherical ampullas, as well as cystocarps and tetrasporangia features, are in accordance with those that have been mentioned for Halymenia species by Balakrishnan (1961), Chiang (1970), Guimarães \& Fujii (1998) and Kawaguchi (2004). Male reproductive structures and carpogonial branch ampullae were not found in this study, and consequently remain to be described. 
Despite the absence of some reproductive structures, we consider that the observation of vegetative morphology and the use of molecular markers enable us to identify the new species described here. In conclusion, we propose the removal of $H$. floresii and $\mathrm{H}$. pseudofloresii from the Brazilian marine flora and stress that without the use of molecular tools, the morphological divergences described here could be considered as merely a result of morphological plasticity. Our results reinforce the important role of molecular methods in the investigation of red algal diversity.

\section{Acknowledgments}

This study was supported by FAPESP (2011/19.225-7; 2013/11.833-3). We are grateful for the support provided by Gary W. Saunders, Tanya Moore and the Saunders' lab staff during molecular procedures. We thank M. J. Wynne and E.C. Oliveira for helping with Latin nomenclature. We thank M. J. Wynne, two anonymous reviewers and the editor for their significant contributions that substantially improved the manuscript. V. UrreaVictoria is acknowledged for photographic support.

\section{References}

Аввотт I.A. 1967. Studies in some foliose red algae of the Pacific coast. I.

Cryptonemiaceae. Journal of Phycology 3: 139-149.

Аввотт I.A. 1999. Notes on some species of Halymenia in the southwestern Pacific. In Taxonomy of economic seaweeds with reference to some Pacific species. (ed. by I.A. Abbott), pp. 163-172. California Sea Grant College System, La Jolla, California.

AGARDH C.A. 1817. Synopsis algarum Scandinaviae, adjecta dispositione universali algarum. Ex officina Berlingiana, Lundae [Lund]. [i]-xl, [1]-135 pp. 
BALAKRISHNAN M.S. 1961. Studies on Indian Cryptonemiales III. Halymenia C. A. Ag. Journal of the Madras University, Section B 31: 183-217.

Calderon M.S., Boo G.W. \& Boo S.M. 2014a. Morphology and phylogeny of Ramirezia osornoensis gen. \& sp. nov. and Phyllymenia acletoi sp. nov. (Halymeniales, Rhodophyta) from South America. Phycologia 53: 23-36.

Calderon M.S., Boo G.H. \& Boo S.M. 2014b. Neorubra decipiens gen. \& comb. nov. and Phyllymenia lancifolia comb. nov. (Halymeniales, Rhodophyta) from South America. Phycologia 53: 409-422.

CÂMARA-NeTo C. 1971. Primeira contribuição ao inventário das algas marinhas bentônicas do litoral do Rio Grande do Norte. Boletim do Departamento de Oceanografia e Limnologia. Universidade Federal do Rio Grande do Norte 5: 137-154.

ChIANG Y.M. 1970. Morphological studies of red algae of the family Cryptonemiaceae. University of California Publications in Botany 58: 1-95.

CLEMENTE R. 1807. Ensayo sobre las variedades de la vid comun que vegetan en Andalucía, con un índice etimológico y tres listas de plantas en que se caracterizan varias especies nuevas, por Don Simon de Roxas Clemente y Rubio. En la imprenta de Villalpando, Madrid. 324 pp.

COLLINS F.S. \& HowE M.A. 1916. Notes on species of Halymenia. Bulletin of the Torrey Botanical Club 43: 169-182.

DAWES C.J. 1974. Marine algae of the west coast of Florida. University of Miami Press., Coral Gables, Florida. 201 pp.

DAwson E.Y. 1954. Marine red algae of Pacific Mexico Part 2. Cryptonemiales (contd.). Allan Hancock Pacific Expeditions 17: 241-398. 
De Clerck O., Gavio B., FredericQ S., Cocquyt E. \& Coppejans E. $2005 a$.

Systematic reassessment of the red algal genus Phyllymenia (Halymeniaceae, Rhodophyta). European Journal of Phycology 40: 169 - 178.

De Clerck O., Gavio B. \& FredericQ S. 2005b. Systematics of Grateloupia filicina (Halymeniaceae, Rhodophyta), based on $r b c \mathrm{~L}$ sequence analyses and morphological evidence, including the reinstatement of Grateloupia minima and the description of Grateloupia capensis sp. nov. Journal of Phycology 41.

De Smedt G., De Clerck O., Leliaert F., Coppejans E. \& Liao L.M. 2001.

Morphology and systematics of the genus Halymenia C. Agardh (Halymeniales, Rhodophyta) in the Philippines. Nova Hedwigia 73: 293-322.

DICKIE G. 1875. Enumeration of algae collected from Bahia, collected by H.N. Mosely, M.A. naturalist, to H.M.S. "Challenger". Journal of the Linnean Society of London (Botany) 14: 1-377.

Freshwater D.W., FredericQ S., Butler B.S., Hommersand M.H. \& Chase M.W. 1994. A gene phylogeny of the red algae (Rhodophyta) based on plastid $r b c \mathrm{~L}$. Proceedings of the National Academy of Sciences of the United States of America 91: 7281-7285.

GARgIUlo G.M., DE MASI F. \& TRIPODI G. 1986. Structure and reproduction of Halymenia asymmetrica sp. nov. (Rhodophyta) from the Mediterranean Sea. Phycologia 25: 144-151.

GofF L.J. \& MoON D.A. 1993. PCR amplification of nuclear and plastid genes from algal herbarium specimens and algal spores. Journal of Phycology 29: 381-384. GuIMARÃEs S.M.P.B. 1990. Rodofíceas marinhas bentônicas do Estado do Espírito Santo: ordem Cryptonemiales. Universidade de São Paulo. São Paulo. 275 pp. 
GuIMARÃEs S.M.P.B. \& FujII M.T. 1998. Two species of foliose Halymenia

(Halymeniaceae, Rhodophyta) from Brazil. Botanica Marina 41: 495-504.

GUIRY M.D. \& GUIRY G.M. 2016. AlgaeBase. World-wide electronic publication, National University of Ireland, Galway. http://www.algaebase.org, 12 February 2016.

HALL T.A. 1999. BioEdit: a user-friendly biological sequence alignment editor and analysis program for Windows 95/98/NT. Nucleic Acids Symposium Series 41: 95-98.

HERnÁNDEZ-KANTÚn J.J., SHERwOOd A.R., Riosmena-RodRÍGUEZ R., HuiSMAN J.M. \& DE CLERCK O. 2012. Branched Halymenia species (Halymeniaceae, Rhodophyta) in the Indo-Pacific region, including descriptions of Halymenia hawaiiana sp. nov. and H. tondoana sp. nov. European Journal of Phycology 47: 421-432.

HuELSENBECK J.P. \& RoNQUist F.R. 2001. MrBayes: bayesian inference of phylogeny. Biometrics 17: 754-755.

Joly A.B., Ugadim Y., Oliveira Filho E.C. \& Cordeiro Marino M. 1967. Additions to the marine flora of Brazil VI. Boletim da Faculdade de Filosofia, Ciências e Letras da Universidade de São Paulo, Série Botânica 22: 171-194.

KAWAGUCHI S. 2004. Morphological observations of the type and some authentic material of Halymenia floresia (Clemente y Rubio) C. Agardh, with notes on previous reports of this alga. In Taxonomy of economic seaweeds with reference to the Pacific and other locations. (ed. by I.A. Abbott \& K.J. McDermid), pp. 143-156.

KRAFT L.G. \& SAUNDERS G.W. 2013. Systematic investigation of the red algal order Halymeniales (Florideophyceae, Rhodophyta) in Australia. Phycologia 52: 56. 
KUCERA H. \& SAUNDERS G.W. 2012. A survey of Bangiales (Rhodophyta) based on multiple molecular markers reveals cryptic diversity. Journal of Phycology 48: 869-882.

LeWmanomont K. \& Kawaguchi S. 2002. Foliose Halymenia (Halymeniaceae, Cryptonemiales, Rhodophyta) from Thailand. In Taxonomy of economic seaweeds with reference to some Pacific species. (ed. by I.A. Abbott \& K.J. McDermid), pp. 267-277. California Sea Grant College Program, La Jolla, CA. Manghisi A., Morabito M., Boo G.H., Boo S.M., Bonillo C., De Clerck O. \& Le GALL E. 2015. Two novel species of Yonagunia (Halymeniales, Rhodophyta) were uncovered in the South of Madagascar during the Atimo-Vatae Expedition. Cryptogamie, Algologie 36: 199-217.

Milstein D., MedeIRos A.S., OliveIRA E.C. \& OliveIRA M.C. 2012. Will a DNA barcoding approach be useful to identify Porphyra species (Bangiales, Rhodophyta)? Journal of Applied Phycology 24: 837-845.

NuNES J.M.C. 2005. Rodofíceas marinhas bentônicas do estado da Bahia. Universidade de São Paulo, São Paulo. 410 pp.

OliveIRA FiLHO E.C. 1977. Algas marinhas bentônicas do Brasil. Instituto de Biociências. Universidade de São Paulo, São Paulo. 406 pp.

PosADA D. \& CRANDALL K.A. 1998. Modeltest: testing the model of DNA substitution. Bioinformatics 14: 817-818.

SAundERS G.W. \& MCDEVIT D.C. 2012. Methods for DNA barcoding photosynthetic protists emphasizing the macroalgae and diatoms. Methods in Molecular Biology 858: 207 -222. 
SAUNDERS G.W. \& MoORE T.E. 2013. Refinements for the amplification and sequencing of red algal DNA barcode and RedToL phylogenetic markers: a summary of current primers, profiles and strategies. Algae 28: 31-43.

SCHNEIDER C.W. 2003. An annotated checklist and bibliography of the marine macroalgae of the Bermuda Islands. Nova Hedwigia 76: 275-361.

SCHNEIDER C.W., LANE C.E. \& SAunders G.W. 2010. Notes on the marine algae of the Bermudas. 11. More additions to the benthic flora and a phylogenetic assessment of Halymenia pseudofloresii (Halymeniales, Rhodophyta) from its type locality. Phycologia 49: 154-168.

Stamatakis A., Hoover P. \& Rougemont J. 2008. A rapid bootstrap algorithm for the RAxML web-servers. Systematic Biology 75: 758-771.

STEARN W.T. 1973. Botanical latin. history, grammar, syntax, terminology and vocabulary. David \& Charles, Newton Abbott. 566 pp.

Tamura K., Peterson D., Peterson N., Stecher G., Nei M. \& Kumar S. 2011. MEGA5: Molecular evolutionary genetics analysis using maximum likelihood, evolutionary distance, and maximum parsimony methods. Molecular Biology and Evolution 28: 2731-2739.

TAN P.L., LiM P.E., Lin S.M., Phang S.M., Draisma S.G.A. \& LiAO L.M. 2015. Foliose Halymenia species (Halymeniaceae, Rhodophyta) from Southeast Asia, including a new species, Halymenia malaysiana sp. nov. Botanica Marina 58: 203-217.

TAYLOR W.R. 1960. Marine algae of the eastern tropical and subtropical coasts of the Americas. The University of Michigan Press, Ann Arbor. 870 pp. 
THIERS B. continuously updated. Index Herbariorum: A global directory of public herbaria and associated staff. http://sweetgum.nybg.org/science/ih/, 04 November 2015.

YANG M.Y., HAN E.G. \& KIM M.S. 2013. Molecular identification of Grateloupia elliptica and G. lanceolata (Rhodophyta) inferred from plastid $r b c \mathrm{~L}$ and mitochondrial COI genes sequence data. Genes \& Genomics 35: 239-246.

YANG M.Y. \& KIM M.S. 2014. Taxonomy of Grateloupia (Halymeniales, Rhodophyta) by DNA barcode marker analysis and a description of Pachymeniopsis volvita sp. nov. Journal of Applied Phycology 27: 1373-1384. 
Fig. 1. Relationships among Brazilian Halymenia based on COI-5P Neighbor-joining. Numbers at nodes correspond to bootstrap support for 1000 replicates. Values below 50 are not shown.

Fig. 2. Phylogeny of Halymeniaceae inferred from $r b c \mathrm{~L}$ molecular marker. Numbers at nodes correspond respectively to bootstrap support for Maximum Likelihood and Posterior Probabilities for Bayesian Inference analyses. Values under 50 are not shown. Sequences in bold were generated in this study.

Figs 3-16. Halymenia ignifera sp. nov. Vegetative and reproductive morphology.

Fig. 3. General aspect of holotype specimen (SPF 57817). Scale bar: $5 \mathrm{~cm}$.

Fig. 4. General aspect of pinnately branched specimen (SPF 57865). Scale bar: $5 \mathrm{~cm}$. Fig. 5. General aspect of palmately branched specimen (SPF 57866). Scale bar: $5 \mathrm{~cm}$. Fig. 6. Detail of a second order branch palmately branched (SPF 57866). Scale bar: 2 $\mathrm{cm}$.

Fig. 7. Detail of proximal region. Stipe and holdfast not visible. Arrows indicate abundant surface proliferations (SPF57784). Scale bar: $2 \mathrm{~cm}$.

Fig. 8. Transverse section in apical blade portion showing thin cortex and lax medulla. Arrows indicate anticlinal medullary filaments (SPF 57815). Scale bar: $50 \mu \mathrm{m}$.

Fig. 9. Transverse section in mid blade showing thin cortex and lax medulla. Arrows indicate stellate cells connecting inner cortex cells and medullary filaments (SPF 57817). Scale bar: $100 \mu \mathrm{m}$.

Fig. 10. Transverse section in mid blade showing ganglionic cell (arrow) (SPF57784). Scale bar: $300 \mu \mathrm{m}$. 
Fig. 11. Transverse section in mid blade showing ganglionic cell (arrow) and stellate cell (arrowhead) (SPF57784). Scale bar: $50 \mu \mathrm{m}$.

Fig. 12. Transverse section in basal blade portion. Arrows indicate longitudinal filaments concentrated in outer medulla while arrowhead indicates intertwined medullary filaments (SPF 57815). Scale bar: $50 \mu \mathrm{m}$.

Fig. 13. Cup-shaped, flat, expanded and dense auxiliary cell ampulla in apical portion of blade. Arrow indicates an ampullar filament (SPF 57817). Scale bar: $50 \mu \mathrm{m}$.

Fig. 14. Transverse section in apical blade portion showing totally embedded cystocarp. Arrow indicates carposporophyte and arrowhead indicates cells with thickened wall between carposporangia and ampullar filaments (SPF 57817). Scale bar: $100 \mu \mathrm{m}$.

Fig. 15. Transverse section in mid blade showing mature cystocarp. Arrow indicates carposporophyte and arrowhead indicates surrounding filaments that correspond to the pericarp (SPF 57817). Scale bar: $100 \mu \mathrm{m}$.

Fig. 16. Transverse section in mid blade showing a mature cruciate tetrasporangia (arrow) (SPF 57815). Scale bar: $50 \mu \mathrm{m}$.

Figs 17-26. Halymenia pinnatifida sp. nov. Vegetative and reproductive morphology.

Fig. 17. General aspect of holotype specimen (SPF 57871). Scale bar: $5 \mathrm{~cm}$.

Fig. 18. General aspect (SPF 57872). Scale bar: $5 \mathrm{~cm}$.

Fig. 19. Transverse section in apical blade portion showing thin cortex and lax medulla (SPF 57872). Scale bar: $100 \mu \mathrm{m}$.

Fig. 20. Squash preparation in apical blade portion showing ganglionic cell (SPF 57871). Scale bar: $50 \mu \mathrm{m}$.

Fig. 21. Transverse section in mid blade showing thin cortex and lax medulla (SPF 57872). Scale bar: $300 \mu \mathrm{m}$. 
Fig. 22. Transverse section in mid blade showing stellate cell (arrow) (SPF 57871). Scale bar: $50 \mu \mathrm{m}$.

Fig. 23. Transverse section in basal portion of blade. Arrows indicate longitudinal filaments concentrated in outer medulla (SPF 57872). Scale bar: $50 \mu \mathrm{m}$.

Fig. 24. Squash preparation in middle of blade showing immature tetrasporangia (arrow) (SPF 57871). Scale bar: $50 \mu \mathrm{m}$.

Fig. 25. Squash preparation in middle of blade showing immature tetrasporangia (arrow) (SPF 57871). Scale bar: $50 \mu \mathrm{m}$.

Fig. 26. Squash preparation in middle of blade showing mature cruciate tetrasporangia (arrow) (SPF 57871). Scale bar: $50 \mu \mathrm{m}$.

Figs 27-39. Halymenia silviae sp. nov. Vegetative and reproductive morphology.

Fig. 27. General aspect of holotype specimen (SPF 57875). Scale bar: $2 \mathrm{~cm}$.

Fig. 28. General aspect (SPF 57814). Scale bar: $2 \mathrm{~cm}$.

Fig. 29. Transverse section in apical portion of blade showing thin cortex and lax medulla (SPF 57875). Scale bar: $50 \mu \mathrm{m}$.

Fig. 30. Transverse section in mid blade showing thin cortex and lax medulla. Arrowhead and arrows indicate inner cortex cells and stellate cells, respectively (SPF 57875). Scale bar: $50 \mu \mathrm{m}$.

Fig. 31. Transverse section in mid blade showing ganglionic cell (arrow) (SPF 57814). Scale bar: $50 \mu \mathrm{m}$.

Fig. 32. Transverse section (damaged by $\mathrm{HCl}$ ) in mid blade showing ganglionic filaments (arrows) and medullary filaments (arrowheads) (SPF 57814). Scale bar: 50 $\mu \mathrm{m}$. 
Fig. 33. Transverse section (damaged by $\mathrm{HCl}$ ) in mid blade showing ganglionic cell (arrow) and stellate cells (arrowheads) (SPF 57814). Scale bar: $50 \mu \mathrm{m}$.

Fig. 34. Transverse section in basal blade portion showing thin cortex and intertwined medullary filaments (SPF 57873). Scale bar: $300 \mu \mathrm{m}$.

Fig. 35. Transverse section in apical portion of blade showing cup-shaped and dense auxiliary cell ampulla. Arrow indicates auxiliary cell and arrowhead indicates ampullary filaments (SPF 57873). Scale bar: $50 \mu \mathrm{m}$.

Fig. 36. Transverse section in mid blade showing developing carposporophyte. Arrow, arrowhead and double-arrow indicate fusion cell, gonimoblast initial and pericarp filament, respectively (SPF 57873). Scale bar: $300 \mu \mathrm{m}$.

Fig. 37. Transverse section in mid blade showing mature totally immersed cystocarp. Arrow indicates carposporophyte and arrowhead indicates connecting filament attached to auxiliary cell (SPF 57873). Scale bar: $300 \mu \mathrm{m}$.

Fig. 38. Transverse section in mid blade showing immature tetrasporangia (arrow) immersed in outer cortex (SPF 57875). Scale bar: $50 \mu \mathrm{m}$.

Fig. 39. Transverse section in mid blade showing cruciate-decussate tetrasporangia (arrow) immersed in outer cortex. Arrowhead indicates inner cortex cells (SPF 57875). Scale bar: $50 \mu \mathrm{m}$. 
Table 1. Divergences expressed as p-distance percentages values for lineages from Brazil and sequences from specimens collected at type localities. The lower left figures correspond to COI-5P values, while the upper right figures are $r b c \mathrm{~L}$ values.

\begin{tabular}{lccccc}
\hline & $\mathbf{1}$ & $\mathbf{2}$ & $\mathbf{3}$ & $\mathbf{4}$ & $\mathbf{5}$ \\
\hline 1. Halymenia floresii Portugal & - & 3.0 & 4.2 & 5.4 & 4.7 \\
2. Halymenia pseudofloresii Bermuda & $7.4-7.5$ & - & 4.0 & 5.2 & 4.5 \\
3. Halymenia ignifera sp. nov. & $8.7-9.0$ & $6.4-6.8$ & - & 5.6 & 4.9 \\
4. Halymenia pinnatifida sp. nov. & 11.1 & $9.7-9.9$ & $10.5-11.0$ & - & 2.8 \\
5. Halymenia silviae sp. nov. & $10.6-11.1$ & $9.0-9.5$ & $9.8-10.9$ & $11.0-11.4$ & - \\
\hline
\end{tabular}


Table 2. Comparison of vegetative aspects among authentic H. floresii and H. pseudofloresii and species described in this study.

\begin{tabular}{|c|c|c|c|c|c|c|}
\hline \multirow{2}{*}{ Vegetative aspect } & \multicolumn{6}{|c|}{ Species } \\
\hline & H. floresii & H. pseudofloresii & H. brasiliana & H. ignifera sp. nov. & H. pinnatifida sp. nov. & H. silviae sp. nov. \\
\hline \multirow[t]{3}{*}{ Habit } & Ligulate foliose & Suborbicular, ovate, & Suborbicular, elliptic or & Ligulate foliose & Ligulate foliose & Foliose, lobate or cleft \\
\hline & Blade & lobate or irregular & irregularly lobed foliose & blade & blade & blade \\
\hline & & foliose blade & blade & & & \\
\hline \multirow[t]{2}{*}{ Branching pattern } & Irregular or pinnate, & Irregular & Some plants laciniate & Pinnate or palmate, & Pinnate, & Irregular \\
\hline & up to $3-4$ orders & - & - & up to 3 orders & up to 3 orders & - \\
\hline Stipe shape and & Cylindrical & Not determined & Little differentiated, & Little differentiated, & Little differentiated, & Compressed \\
\hline \multirow[t]{2}{*}{ size } & 3-5 mm height & 5-10 mm height & compressed, few mm long & compressed-cylindrical near & compressed-cylindrical near & $5 \mathrm{~mm}$ height \\
\hline & width not determined & $1-2 \mathrm{~mm}$ thick & & holdfast, with $1.5-4 \mathrm{~mm}$ width & holdfast, with $2-3 \mathrm{~mm}$ width & $2 \mathrm{~mm}$ width \\
\hline Surface proliferations & Absent & Not determined & Absent & Few and mainly restricted & Present at proximal & Surface proliferations \\
\hline \multirow[t]{2}{*}{ or spines } & & & & to proximal region. & and distal regions & present \\
\hline & & & & Surface spines on distal region & & \\
\hline \multirow[t]{3}{*}{ Margins } & Mostly entire, with & Serrate or dentate & Undulated, with or & Marginal branchlets & Abundant marginal & Margins slightly \\
\hline & occasional spine-like & and with proliferations & without irregularities & throughout or concentrated & proliferations and spine-like & undulated and somewhat \\
\hline & Process & & & at basal region & branchlets througout & dentate \\
\hline Ganglionic cells & Present & Few and inconspicous & Absent & Few, but present througout & Few, but present througout & Few, but present througout \\
\hline Thalli height (cm) & Not determined & 30 & 60 & 55 & 26 & 39 \\
\hline Thalli thickness $(\mu \mathrm{m})$ & & $50-450^{*}$ & $200-1400^{*}$ & & & \\
\hline Apical & Not determined & & & $125-210$ & $110-140$ & $142-280$ \\
\hline Middle & Not determined & & & $350-460$ & $290-870$ & $180-410$ \\
\hline
\end{tabular}


Basal

Number of cell layers

Not determined

Not determined

at inner cortex

Inner cortex cells $(\mu \mathrm{m})$

diameter or width

Longitudinal filaments

Not determined

Present

20-640

$975-1275$

$460-790$

at basal medulla

References
$1-2$ 
Table S1. Collection details and GenBank accession numbers of samples included in this study.

\begin{tabular}{|c|c|c|c|c|}
\hline \multirow{2}{*}{ Voucher } & \multirow{2}{*}{ Species } & \multirow{2}{*}{ Collection Data } & \multicolumn{2}{|c|}{ GenBank } \\
\hline & & & COI-5P & $r b c \mathbf{L}$ \\
\hline SPF 57817 & H. ignifera & $\begin{array}{l}\text { Rio do Fogo Beach, Rio do Fogo, RN, Brazil } \\
\left(5^{\circ} 15^{\prime} 56^{\prime \prime} \text {; } 35^{\circ} 23^{\prime} 05^{\prime \prime}\right) .13 J a n .2013 \text {, drift material, female } \\
\text { gametophyte, leg. C.A.A. Azevedo and R.F. Menezes }\end{array}$ & KT807817 & KT807829 \\
\hline SPF 57815 & H. ignifera & $\begin{array}{l}\text { Rio do Fogo Beach, Rio do Fogo, RN, Brazil } \\
\left(5^{\circ} 15^{\prime} 56^{\prime \prime} \text {; } 35^{\circ} 23^{\prime} 05^{\prime \prime}\right) . \text { 13Jan.2013, drift material, } \\
\text { tetrasporophyte, leg. C.A.A. Azevedo and R.F. Menezes }\end{array}$ & KT807808 & KT807826 \\
\hline SPF 57784 & H. ignifera & $\begin{array}{l}\text { Itaoca Beach, Itapemirim, ES, Brazil ( } 20^{\circ} 54^{\prime} 19^{\prime \prime} \text { S; } \\
\left.40^{\circ} 46^{\prime} 41^{\prime \prime W}\right) .06 \text { May2012, drift material, infertile, } \\
\text { leg. B. Torrano-Silva, C. Iha and F. Nauer }\end{array}$ & KT807819 & KT807830 \\
\hline SPF 57865 & H. ignifera & $\begin{array}{l}\text { Rio do Fogo Beach, Rio do Fogo, RN, Brazil } \\
\left(5^{\circ} 15^{\prime} 56^{\prime \prime S} ; 35^{\circ} 23^{\prime} 05^{\prime \prime W}\right) .13 J a n .2013 \text {, drift material, } \\
\text { leg. C.A.A. Azevedo and R.F. Menezes }\end{array}$ & KT807810 & - \\
\hline SPF 57866 & H. ignifera & $\begin{array}{l}\text { Rio do Fogo Beach, Rio do Fogo, RN, Brazil } \\
\left(5^{\circ} 15^{\prime} 56^{\prime \prime S} ; 35^{\circ} 23^{\prime} 05^{\prime \prime W}\right) .13 J a n .2013 \text {, drift material, } \\
\text { leg. C.A.A. Azevedo and R.F. Menezes }\end{array}$ & KT807815 & - \\
\hline SPF 57867 & H. ignifera & $\begin{array}{l}\text { Rio do Fogo Beach, Rio do Fogo, RN, Brazil } \\
\left(5^{\circ} 15^{\prime} 56^{\prime \prime S} ; 35^{\circ} 23^{\prime} 05^{\prime \prime W}\right) .13 J a n .2013 \text {, drift material, } \\
\text { leg. C.A.A. Azevedo and R.F. Menezes }\end{array}$ & KT807821 & - \\
\hline SPF 57868 & H. ignifera & $\begin{array}{l}\text { Rio do Fogo Beach, Rio do Fogo, RN, Brazil } \\
\left(5^{\circ} 15^{\prime} 56^{\prime \prime S} ; 35^{\circ} 23^{\prime} 05^{\prime \prime W}\right) .13 J a n .2013 \text {, drift material, } \\
\text { leg. C.A.A. Azevedo and R.F. Menezes }\end{array}$ & KT807824 & - \\
\hline SPF 57869 & H. ignifera & $\begin{array}{l}\text { Rio do Fogo Beach, Rio do Fogo, RN, Brazil } \\
\left(5^{\circ} 15^{\prime} 56 " \mathrm{~S} ; 35^{\circ} 23^{\prime} 05^{\prime \prime W}\right) .13 J a n .2013 \text {, drift material, } \\
\text { leg. C.A.A. Azevedo and R.F. Menezes }\end{array}$ & KT807825 & - \\
\hline SPF 57870 & H. ignifera & $\begin{array}{l}\text { Ponta Grossa Beach, Icapuí, CE, Brazil (4³7'35"S; } \\
\text { 37²2'53"W). 27Apr.2013, drift material, leg. C.A.A. } \\
\text { Azevedo and T. Vieira-Pinto }\end{array}$ & KT807813 & - \\
\hline SPF 57871 & H. pinnatifida & $\begin{array}{l}\text { Rio do Fogo Beach, Rio do Fogo, RN, Brazil } \\
\left(5^{\circ} 15^{\prime} 56^{\prime \prime} \text {; } 35^{\circ} 23^{\prime} 05^{\prime \prime W}\right) .13 J a n .2013 \text {, drift material, } \\
\text { tetrasporophyte, leg. C.A.A. Azevedo and R.F. Menezes }\end{array}$ & KT807811 & KT807828 \\
\hline SPF 57872 & H. pinnatifida & $\begin{array}{l}\text { Rio do Fogo Beach, Rio do Fogo, RN, Brazil } \\
\left(5^{\circ} 15^{\prime} 56^{\prime \prime} \text {; } 35^{\circ} 23^{\prime} 05^{\prime W}\right) .13 J a n .2013 \text {, drift material, } \\
\text { tetrasporophyte, leg. C.A.A. Azevedo and R.F. Menezes }\end{array}$ & KT807816 & - \\
\hline SPF 57814 & H. silviae & $\begin{array}{l}\text { Rio do Fogo Beach, Rio do Fogo, RN, Brazil } \\
\left(5^{\circ} 15^{\prime} 56 " \mathrm{~S} ; 35^{\circ} 23^{\prime} 05^{\prime \prime} \text { ). } 13 \mathrm{Jan} .2013 \text {, drift material, }\right. \\
\text { infertile, leg. C.A.A. Azevedo and R.F. Menezes }\end{array}$ & KT807809 & KT807827 \\
\hline
\end{tabular}




\begin{tabular}{|c|c|c|c|c|}
\hline SPF 57802 & H. silviae & $\begin{array}{l}\text { Munguba Beach, Paracuru, CE, Brazil ( } 3^{\circ} 24^{\prime} 28^{\prime \prime S} \text {; } \\
39^{\circ} 01^{\prime} 57^{\prime W} \text { ). } 24 \text { Apr.2013, sandy substratum, leg. } \\
\text { C.A.A. Azevedo, T. Vieira-Pinto and B. Torrano-Silva }\end{array}$ & KT807823 & - \\
\hline SPF 57873 & H. silviae & $\begin{array}{l}\text { Rio do Fogo Beach, Rio do Fogo, RN, Brazil } \\
\left(5^{\circ} 15^{\prime} 56^{\prime \prime S} ; 35^{\circ} 23^{\prime} 05^{\prime \prime W}\right) .13 J a n .2013 \text {, drift material, female } \\
\text { gametophyte, leg. C.A.A. Azevedo and R.F. Menezes }\end{array}$ & KT807818 & - \\
\hline SPF 57813 & H. silviae & $\begin{array}{l}\text { Ponta Verde Beach, Maceió, AL, Brazil (9³9'54"S; } \\
35^{\circ} 41^{\prime} 42^{\prime \prime} \text { W). 10Mar.2013, drift material, leg. C.A.A. } \\
\text { Azevedo, T. Vieira-Pinto and B. Torrano-Silva }\end{array}$ & KT807812 & - \\
\hline SPF 57874 & H. silviae & $\begin{array}{l}\text { Pontal do Peba Beach, Piaçabuçu, AL, Brazil } \\
\left(10^{\circ} 21^{\prime} 28^{\prime \prime} \text {; } 36^{\circ} 17^{\prime} 44^{\prime \prime W}\right) .11 \text { Mar.2013, drift material, } \\
\text { leg. C.A.A. Azevedo, T. Vieira-Pinto and B. Torrano-Silva }\end{array}$ & KT807820 & - \\
\hline SPF 57875 & H. silviae & $\begin{array}{l}\text { Corumbau Beach, Prado, BA, Brazil ( } 16^{\circ} 54^{\prime} 05^{\prime \prime} \text {; } \\
\left.39^{\circ} 07^{\prime} 10^{\prime \prime W}\right) .13 \text { May2014, leg. B. Torrano-Silva, } \\
\text { J. Pires and A.S. Santos }\end{array}$ & KT807814 & - \\
\hline SPF 57876 & H. silviae & $\begin{array}{l}\text { Corumbau Beach, Prado, BA, Brazil (16 } 54^{\prime} 05^{\prime \prime S} \text {; } \\
\left.39^{\circ} 07^{\prime} 10^{\prime \prime W}\right) .13 \text { May2014, leg. B. Torrano-Silva, } \\
\text { J. Pires and A.S. Santos }\end{array}$ & KT807822 & - \\
\hline
\end{tabular}

SPF: Universidade de São Paulo, São Paulo, Brazil. Herbarium Codes according to "Index Herbariuorum. Part I. The herbaria of the world" (http://sweetgum.nybg.org/ih/). 


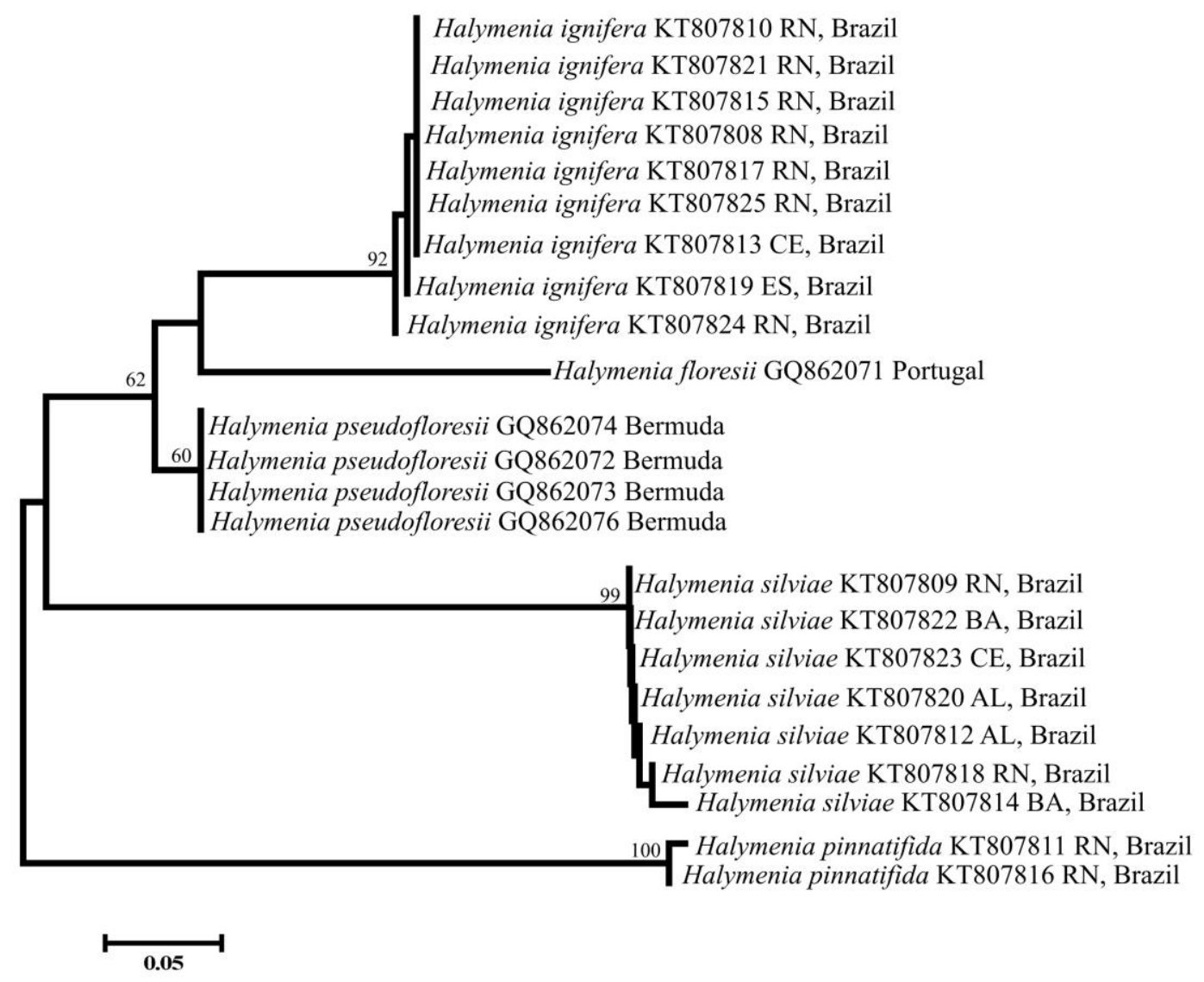




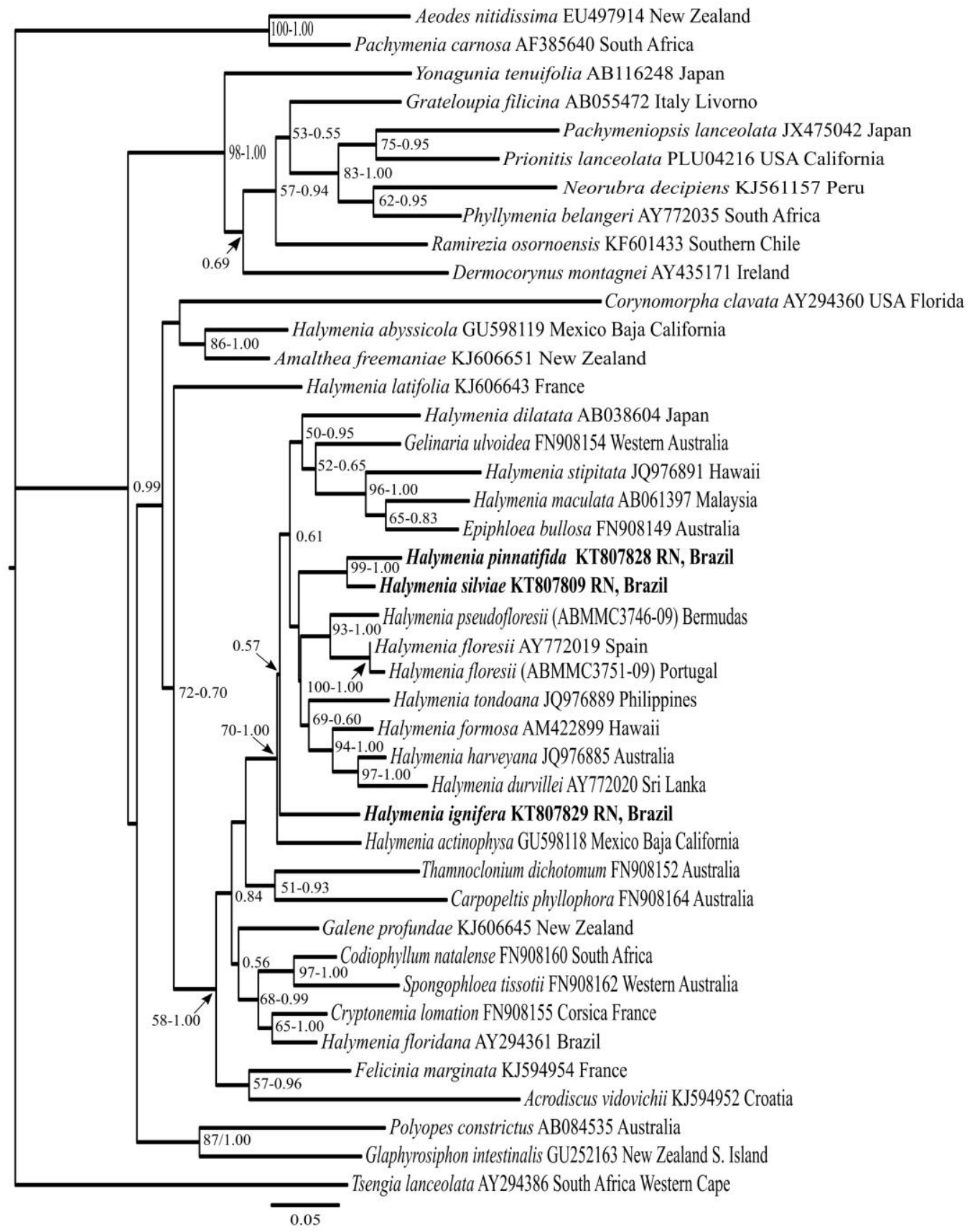




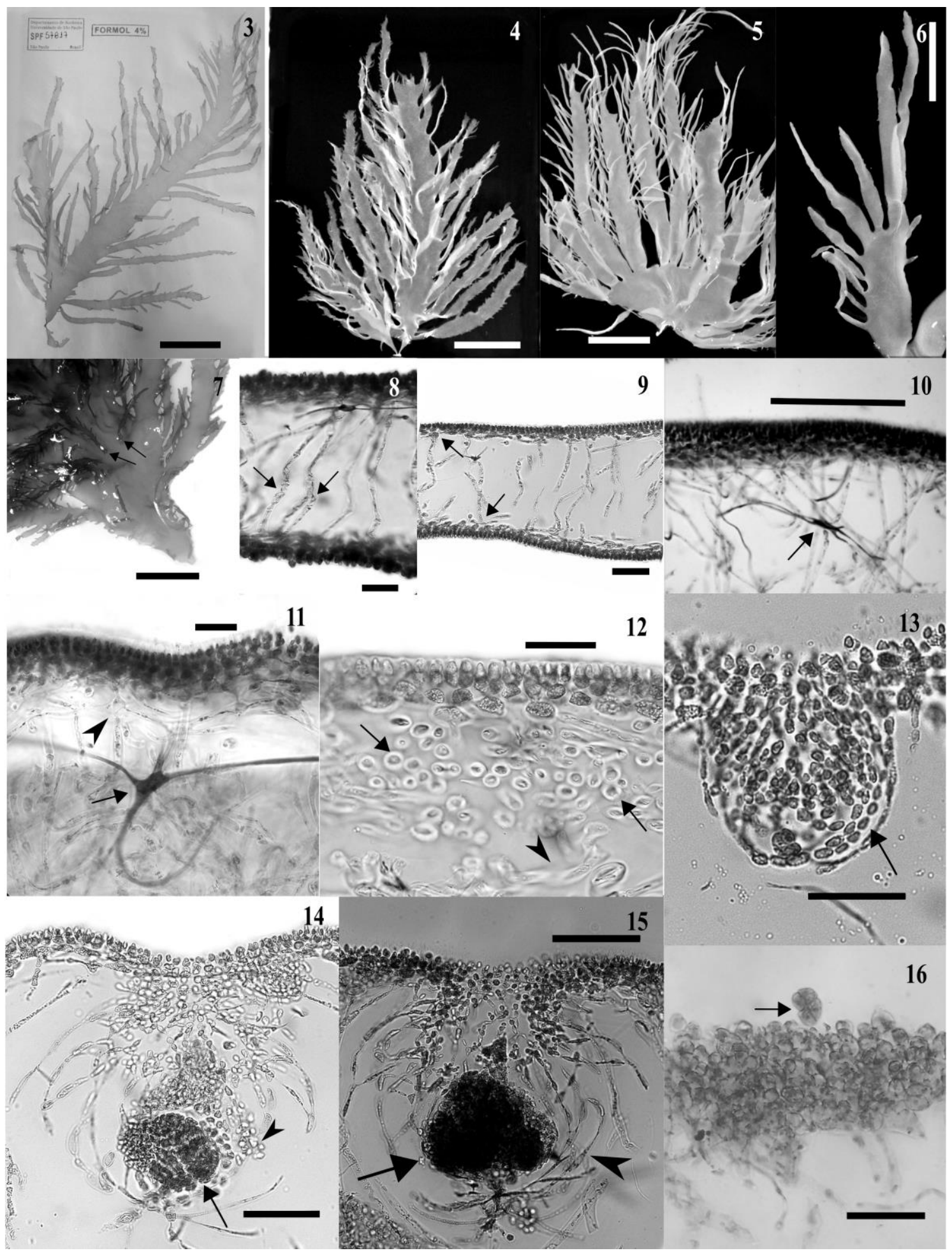




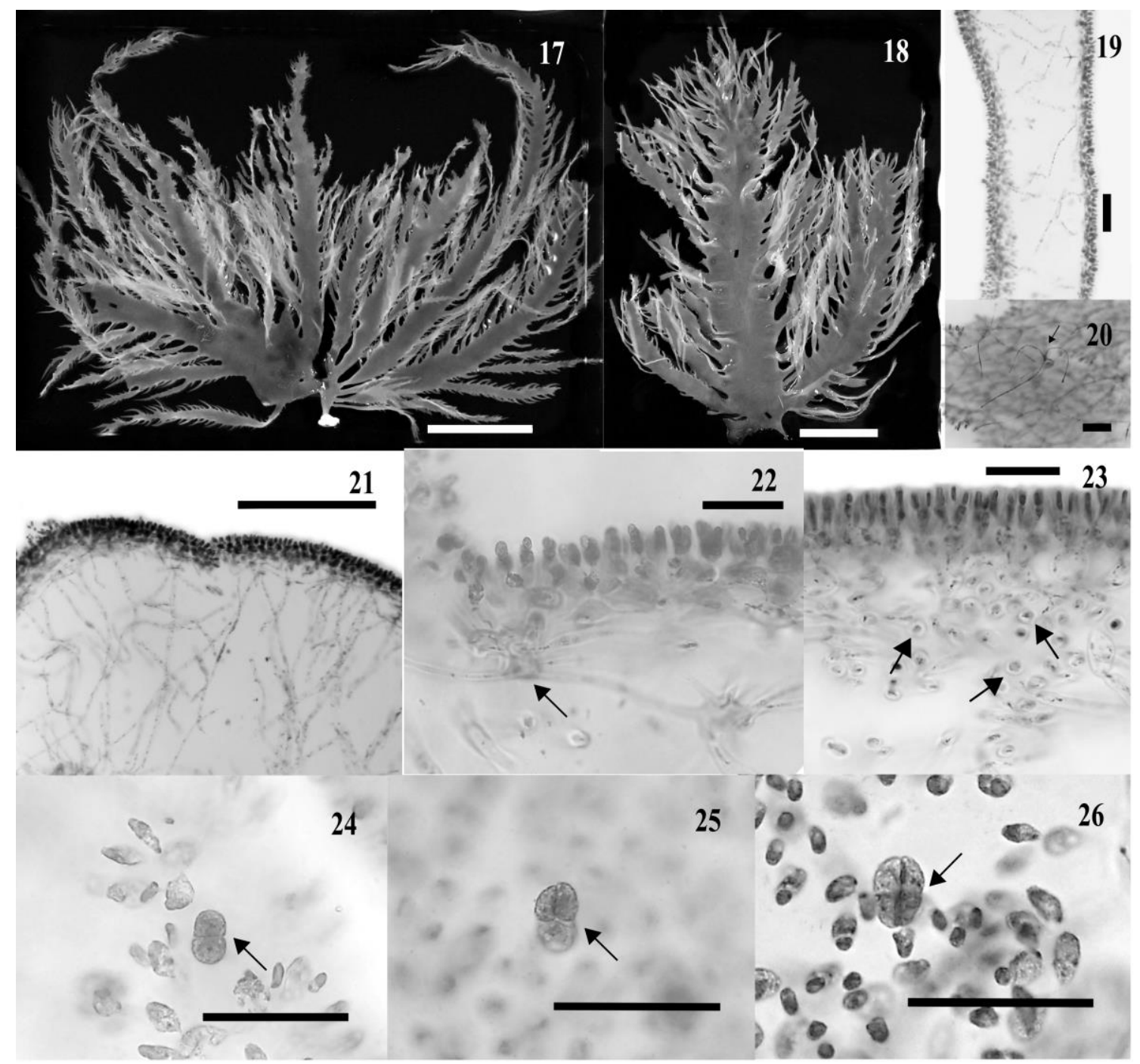



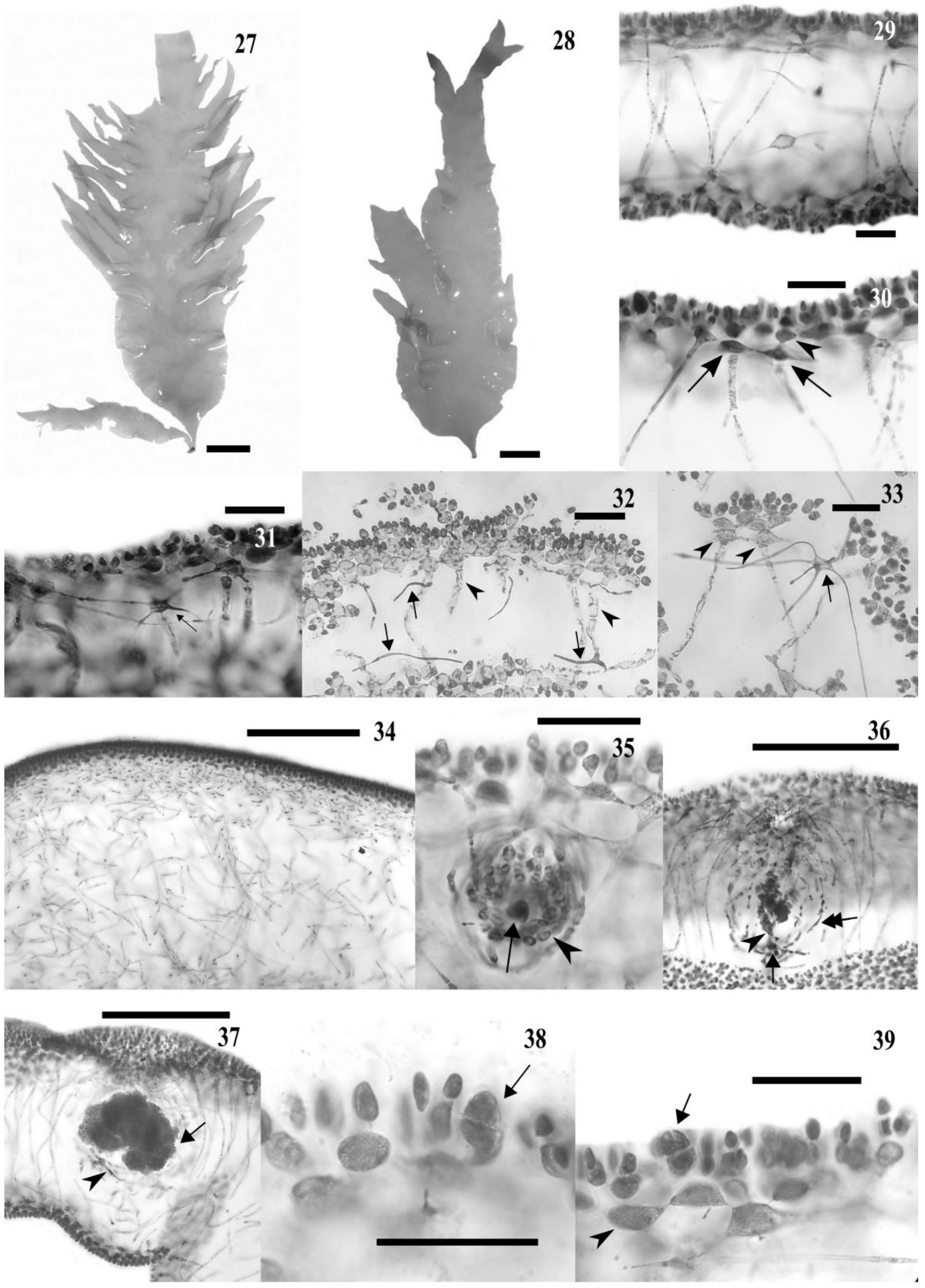


\section{ANEXO IV}

Manuscrito submetido ao periódico Phycologia. 


\title{
DETECTING THE NON-NATIVE GRATELOUPIA TURUTURU \\ (HALYMENIALES, RHODOPHYTA) IN SOUTHERN BRAZIL
}

\author{
Carolina Angélica AraúJo de Azevedo ${ }^{1}$ *, VAléria Cassano $^{1}$, Paulo Antunes \\ HORTA JÚNIOR $^{2}$, MANUELA BERNARDES BATISTA ${ }^{2}$ \\ AND MARIANA CABRAL DE OLIVEIRA ${ }^{1}$
}

${ }^{1}$ Laboratório de Algas Marinhas Édson José de Paula, Departamento de Botânica, Instituto de Biociências, Universidade de São Paulo, R. do Matão 277, 05508-090 São Paulo, SP, Brazil

${ }^{2}$ Laboratório de Ficologia, Departamento de Botânica, Centro de Ciências Biológicas, Universidade Federal de Santa Catarina, Campus de Trindade, 88010-970

Florianópolis, SC, Brazil

GRATELOUPIA TURUTURU IN BRAZIL

ABSTRACT: Grateloupia turuturu is a Pacific native species with invasive behavior which leads to a wide distribution around the world. This study reports collections of fertile tetrasporophytes and female gametophytes of $G$. turuturu at Southern Brazilian coast and constitutes its first record for Southwestern Atlantic. The identity of $G$. turuturu was confirmed through molecular (COI-5P and $r b c \mathrm{~L}$ markers) and morphological assessments. Putative paths of introduction are discussed.

KEY WORDS: Brazilian coast, COI-5P, Grateloupia turuturu, non-native marine species, $r b c \mathrm{~L}$.

\footnotetext{
*Corresponding author (caaazevedo@ hotmail.com)
} 
Grateloupia turuturu Yamada, a Pacific native species, is regarded the fifth most dangerous invasive seaweed in a global perspective (Nyberg \& Wallentinus 2005). In USA (Rhode Island), Portugal, France (Brittany) and Mexican Pacific coast, G. turuturu spread rapidly and displaced native algae and invertebrate species (Harlin \& YallalardBohnsack 2001; Simon et al. 2001; Araújo et al. 2011; Aguilar-Rosas et al. 2013). On the other hand, reports from Tasmania and New Zealand do not mention negative effects of $G$. turuturu, perhaps because they detected the alga just after introduction (Saunders \& Withall 2006; D'Archino et al. 2007). Nonetheless, this species can apparently occur harmlessly in Lagoon of Venice, Italy (Cecere et al. 2011), or even coexist with a similar autochthonous species $G$. lanceola in the northwestern Iberian Peninsula (Barreiro et al. 2006).

Features of G. turuturu that allow this species to be invasive are its ability to occupy sheltered and exposed habitats, to colonize natural and artificial substrates, to tolerate heavy metal and oxidative stress, and a wide range of temperature, salinity, light intensity and trophic conditions (Simon et al. 2001; Bertocci et al. 2015; Liu \& Pang 2010). In addition, fertile specimens can be found throughout the year (Harlin \& Yallalard-Bohnsack 2001). Putative paths of G. turuturu invasions include ballast water, fouling of ships and aquaculture activities (Hewitt et al. 2007).

Torrano-Silva et al. (2010) summarized the knowledge on three non-indigenous seaweeds found in Santa Catarina State in the south of Brazil. Anotrichium yagii (Okamura) Baldock was probably introduced through maritime traffic, apparently with no ecological damages. Kappaphycus alvarezii (Doty) Doty ex P.C. Silva was intentionally introduced and has been cultivated under controlled conditions. 
Cladophora corallicola $\mathrm{B} \emptyset$ rgesen is a species with uncertain origin and treated by the authors as cryptogenic.

In this study, five individuals of $G$. turuturu were obtained in the intertidal zone of Santa Catarina State (Table S1). DNA was extracted according to Saunders \& McDevit (2012), and sequences were generated for mitochondrial DNA barcode COI$5 \mathrm{P}$ and chloroplast-encoded $r b c \mathrm{~L}$ following protocols described in Freshwater et al. (1994) and Saunders \& Moore (2013). The alignment included $33 r b c L$ sequences (1,258 nucleotides), of which five were new sequences from Brazil and the remaining sequences of Halymeniaceae were from GenBank. A Maximum Likelihood analyses was performed at the web-server RaxML Blackbox $(\mathrm{GTR}+\mathrm{G}+\mathrm{I}$, partitioned by codon position) with 1,000 Bootstrap replicates (Stamatakis et al. 2008). We conducted morphological studies in samples stored in $4 \%$ formalin seawater or in herbarium specimens. Handmade cross-sections images were captured with a Leica DFC 420 mounted in a Leica DM 4000B microscope (Leica Microsystems, Wetzlar, Germany).

Sequences for COI-5P region for three samples match G. turuturu sequences in BOLD Database (http://www.boldsystems.org) with 100\% identity. The $r b c$ L tree (Fig. 1) shows the five Brazilian samples inserted in a clade with $G$. turuturu sequences from worldwide, including the type locality (Muroran, Japan). Our samples showed 0.0 $0.8 \%$ intraspecific divergence compared to other G. turuturu $r b c \mathrm{~L}$ sequences, and diverged $0.2-0.6 \%$ from the type locality sample. These values agree with $r b c \mathrm{~L}$ intraspecific divergences reported by Gavio \& Fredericq (2002) and Mateo-Cid et al. (2005).

Morphologically, thalli were pinkish or reddish, delicate and slippery, lightly undulate, $5.5-15.5 \mathrm{~cm}$ height, 1.1-6 cm width. Fronds presented a cuneate base, attached to the substratum by a discoid holdfast, $1-2 \mathrm{~mm}$ in diameter, from which arose a 
cylindrical stipe 4-5 mm long (Fig. 2). Lanceolate blades were irregularly branched, $145-350 \mu \mathrm{m}$ thick at middle region. Marginal proliferations were present at basal and middle regions in some specimens, but were absent in others. In transverse section, the cortex had approximately 3-5 cell layers, with a conspicuous transition to the medulla (Figs. 3, 4). Outer cortical cells were roundish or cylindrical, 5-7.5 $\mu \mathrm{m}$ in diameter, and medulla consisted of loose filaments, 2.5-5 $\mu \mathrm{m}$ in diameter. Medullary filaments were more numerous on basal region, becoming sparser on younger portions. Tetrasporangia were cruciate-decussate, 15-32.5 $\mu \mathrm{m}$ in height and 12.5-25 $\mu \mathrm{m}$ in diameter (Fig. 5). Auxiliary cell ampulla consisted of an oval auxiliary cell approximately $11 \mu \mathrm{m}$ in broader axis, and 2-3 unbranched ampullary filaments, up to 10 cells long (Fig. 6). Mature cystocarps were 77.5-105 $\mu \mathrm{m}$ in diameter (Fig. 7). Vegetative and reproductive features of our samples agreed with descriptions and illustrations of G. turuturu (Gavio \& Fredericq 2002; Bárbara \& Cremades 2004; Verlaque et al. 2005; D'Archino et al. 2007; Figueroa et al. 2007).

Grateloupia turuturu was reported for Espírito Santo coast by Guimarães (2006), based only on morphological traits, but according to the author this record was a misidentification (personal communication). Therefore, this study constitutes the first molecular and morphological assessment of the species for the Brazilian coast.

Our results confirm that Grateloupia turuturu has reached the Southwestern Atlantic. Putative paths for its introduction include proximity to aquaculture facilities and to shipping ports (Bárbara \& Cremades 2004; Araújo et al. 2011). Santa Catarina coast presents both conditions. The Pacific oyster Crassostrea gigas Thunberg, 1793 was introduced in the region for aquaculture purposes in 1987 (Melo et al. 2010). However, since 1998 seeds used at cultures are only produced by the Laboratory of Marine Mollusks at the Federal University of Santa Catarina (Melo et al. 2010). 
Considering that our first record of Grateloupia turuturu is from 2011, it is unlikely that the oyster cultivation is a path for this particular case.

The coast of Santa Catarina State presents four harbours, including Itajaí, which is the second largest harbour in Brazil. Historically, the harbour has shown higher values for export than for import (http://www.portoitajai.com.br/novo/estatisticas/ searched on July, 02, 2014). A high export activity is associated with high ballast water discharge (Micael et al. 2014). However, hull fouling is a more likely vector for seaweeds, once the absence of light inside ballasts can affect the viability of carried organisms (Williams \& Smith 2007).

Grateloupia turuturu was detected on the Brazilian coast only after application of molecular approaches, which highlights the usefulness of the molecular tools for revealing the presence of non-indigenous organisms. Until now, only sparse and rare individuals have been found, and there is no available information about effects of $G$. turuturu over native assemblages in Santa Catarina. The absence of previous data for this species in the region and the few individuals found indicate that we detected a recent introduction of $G$. turuturu. Its well-known aggressive behavior reinforces the need of monitoring programs and control measures to avoid the spread of the species along the Brazilian coast.

\section{ACKNOWLEDGEMENTS}

We are grateful for the support from FAPESP for C.A.A.A. and M.C.O. (2011-19225-7; 2013-11833-3). M.C.O., P.A.H.J. and M.B.B. thank for support by CAPES and CNPq, and also to CAPES/PNADB 2338000071/2010-61 and CAPES/PROTAX 562336/20109. We would like to thank Gary W. Saunders, Tanya Moore and the Saunders' lab staff 
for the support during molecular procedures. Dr. Silvia Maria Pita de Beauclair

Guimarães and Dr. Mutue Toyota Fujjii assisted on morphological studies.

\section{REFERENCES}

Aguilar-Rosas L.E., NúÑEZ-Cebreroa F. \& Aguilar-Rosas C.V. 2013. Introduced marine macroalgae in the Port of Ensenada, Baja California, Mexico: Biological contamination. Procedia Environmental Sciences 18: 836-843.

Araújo R., Violante J., Pereira R., Abreu H., Arenas F. \& Sousa-Pinto I. 2011. Distribution and population dynamics of the introduced seaweed Grateloupia turuturu (Halymeniaceae, Rhodophyta) along the Portuguese coast. Phycologia 50: $392-402$.

BÁRBARA I. \& CREMADES J. 2004. Grateloupia lanceola versus Grateloupia turuturu (Gigartinales, Rhodophyta) en la Península Ibérica. Anales del Jardín Botánico de Madrid 61: 103-118.

BARREIRo R., Quintela M., BÁRBARA I. \& CREMADES J. 2006. RAPD differentiation of Grateloupia lanceola and the invasive Grateloupia turuturu (Gigartinales, Rhodophyta) in the Iberian Peninsula. Phycologia 45: 213-217.

Bertocci I., Godino J.D., Freitas C., Incera M., AraúJo R., Bio A., Arenas F., SousA-Pinto I., ReIS P.A. \& DomíngueZ R. 2015. The regime of climaterelated disturbance and nutrient enrichment modulate macroalgal invasions in rockpools. Biological Invasions 17: 133-147.

Cecere E., Moro I., Wolf M.A., Petrocelli A., Verlaque M. \& Sfriso A. 2011. The introduced seaweed Grateloupia turuturu (Rhodophyta, Halymeniales) in two Mediterranean transitional water systems. Botanica Marina 54: 23-33. 
D'ArChino R., NELSON W.A. \& ZuCCARELLO G.C. 2007. Invasive marine red alga introduced to New Zealand waters: First record of Grateloupia turuturu (Halymeniaceae, Rhodophyta). New Zealand Journal of Marine and Freshwater Research 41: 35-42.

Figueroa F.L., Korbee N., De Clerck O., BÁRbara I. \& Gall E.A.R. 2007. Characterization of Grateloupia lanceola (Halymeniales, Rhodophyta), an obscure foliose Grateloupia from the Iberian Peninsula, based on morphology, comparative sequence analysis and mycosporine-like amino acid composition. European Journal of Phycology 42: 231-242.

Freshwater D.W., FredericQ S., Butler B.S., Hommersand M.H. \& Chase M.W. 1994. A gene phylogeny of the red algae (Rhodophyta) based on plastid $r b c \mathrm{~L}$. Proceedings of the National Academy of Sciences of the United States of America 91: 7281-7285.

GAVIO B. \& FREDERICQ S. 2002. Grateloupia turuturu (Halymeniaceae, Rhodophyta) is the correct name of the non-native species in the Atlantic known as Grateloupia doryphora. European Journal of Phycology 37: 349-359.

GuimarÃES S.M.P.B. 2006. A revised checklist of benthic marine Rhodophyta from the State of Espírito Santo, Brazil. Boletim do Instituto de Botânica 17: 143-194.

HARLIN M.M. \& YALLALARD-BOHNSACK M. 2001. Seasonal dynamics and recruitment strategies of the invasive seaweed Grateloupia doryphora (Halymeniaceae, Rhodophyta) in Narragansett Bay and Rhode Island Sound, Rhode Island, USA. Phycologia 40: 468-474.

HewitT C.L., CAMPBELl M.L. \& SCHAFFELKE B. 2007. Introductions of seaweeds: accidental transfer pathways and mechanisms. Botanica Marina 59: 326-337. 
LiU F. \& PANG S.J. 2010. Stress tolerance and antioxidant enzymatic activities in the metabolisms of the reactive oxygen species in two intertidal red algae Grateloupia turuturu and Palmaria palmata. Journal of Experimental Marine Biology and Ecology 382: 82-87.

Mateo-Cid L.E., Mendoza-GonzÁlez A.C., Gavio B. \& FredericQ S. 2005. Grateloupia huertana sp. nov. (Halymeniaceae, Rhodophyta), a peculiar new prostrate species from tropical Pacific Mexico. Phycologia 44: 4-16.

Melo C.M.R., Silva F.C., Gomes C.H.A.M., Solé-Cava A.M. \& LaZoski C. 2010. Crassostrea gigas in natural oyster banks in southern Brazil. Biological Invasions 12: 441-449.

MiCAEL J., PARENTE M.I. \& CostA A.C. 2014. Tracking macroalgae introductions in North Atlantic oceanic islands. Helgoland Marine Research 68: 209-219.

NyBERG C.D. \& WALLENTINUS I. 2005. Can species traits be used to predict marine macroalgal introductions? Biological Invasions 7: 265-279.

SAUNDERS G.W. \& WiTHALL R.D. 2006. Collections of the invasive species Grateloupia turuturu (Halymeniales, Rhodophyta) from Tasmania, Australia. Phycologia 45: 711-714.

SAUNDERS G.W. \& MCDEVIT D.C. 2012. Methods for DNA barcoding photosynthetic protists emphasizing the macroalgae and diatoms. Methods in Molecular Biology 858: 207 -222.

SAUNDERS G.W. \& MoORE T.E. 2013. Refinements for the amplification and sequencing of red algal DNA barcode and RedToL phylogenetic markers: a summary of current primers, profiles and strategies. Algae 28: 31-43.

Simon C., GALl E.A.R. \& DeSlandes E. 2001. Expansion of the red alga Grateloupia doryphora along the coasts of Brittany (France). Hydrobiologia 443: 23-29. 
Stamatakis A., Hoover P. \& Rougemont J. 2008. A Rapid Bootstrap Algorithm for the RAxML Web-Servers. Systematic Biology 75: 758-771.

TorRano-Silva B.N., Amancio C.E. \& OliveIRA-Filho E.C. 2010. Exotic Marine Macroalgae on the Brazilian Coast: A Revision. Oecologia Australis 14: 403414.

VERLAQUe M., BRANNOCK P.M., Komatsu T., Villalard-BOHNSACK M. \& MARSTON M. 2005. The genus Grateloupia C. Agardh (Halymeniaceae, Rhodophyta) in the Thau Lagoon (France, Mediterranean): a case study of marine plurispecific introductions. Phycologia 44: 477 - 496.

WiLliams S. \& SMith J. 2007. A Global Review of the Distribution, Taxonomy, and Impacts of Introduced Seaweeds. The Annual Review of Ecology, Evolution, and Systematics 38: 327-359. 
Fig. 1. Best-scoring Maximum Likelihood tree constructed with $r b c \mathrm{~L}$ sequences. Numbers on nodes represent bootstrap support for 1000 replicates. For sequences generated by this study (marked in bold), taxon labels correspond to herbarium numbers. For the remaining sequences GenBank accession numbers and places of collection are indicated. Type locality for G. turuturu is marked by *.

Figs. 2-7. Grateloupia turuturu. Vegetative and reproductive morphology.

Fig. 2. Habitat of tetrasporophyte specimen (SPF 57787). Scale bar: $2 \mathrm{~cm}$.

Fig. 3. Transverse section on basal blade showing cortex and loose filamentous medulla (SPF 57787). Scale bar: $100 \mu \mathrm{m}$.

Fig. 4. Transverse section in the middle of blade showing cortical cells. Arrows indicate expanded inner cortical cells. (FLOR 56607). Scale bar: $50 \mu \mathrm{m}$.

Fig. 5. Transverse section in the middle of blade showing mature cruciate-decussate tetrasporangia (SPF 57787). Scale bar: $50 \mu \mathrm{m}$.

Fig. 6. Transverse section in the apical portion of blade showing auxiliary cell ampulla. Arrow indicates auxiliary cell while arrow heads indicate ampullary filaments. (FLOR 56607). Scale bar: $50 \mu \mathrm{m}$.

Fig. 7. Transverse section in the apical portion of blade showing mature cystocarp. Arrow indicates carposporangia. (FLOR 56607). Scale bar: $50 \mu \mathrm{m}$. 


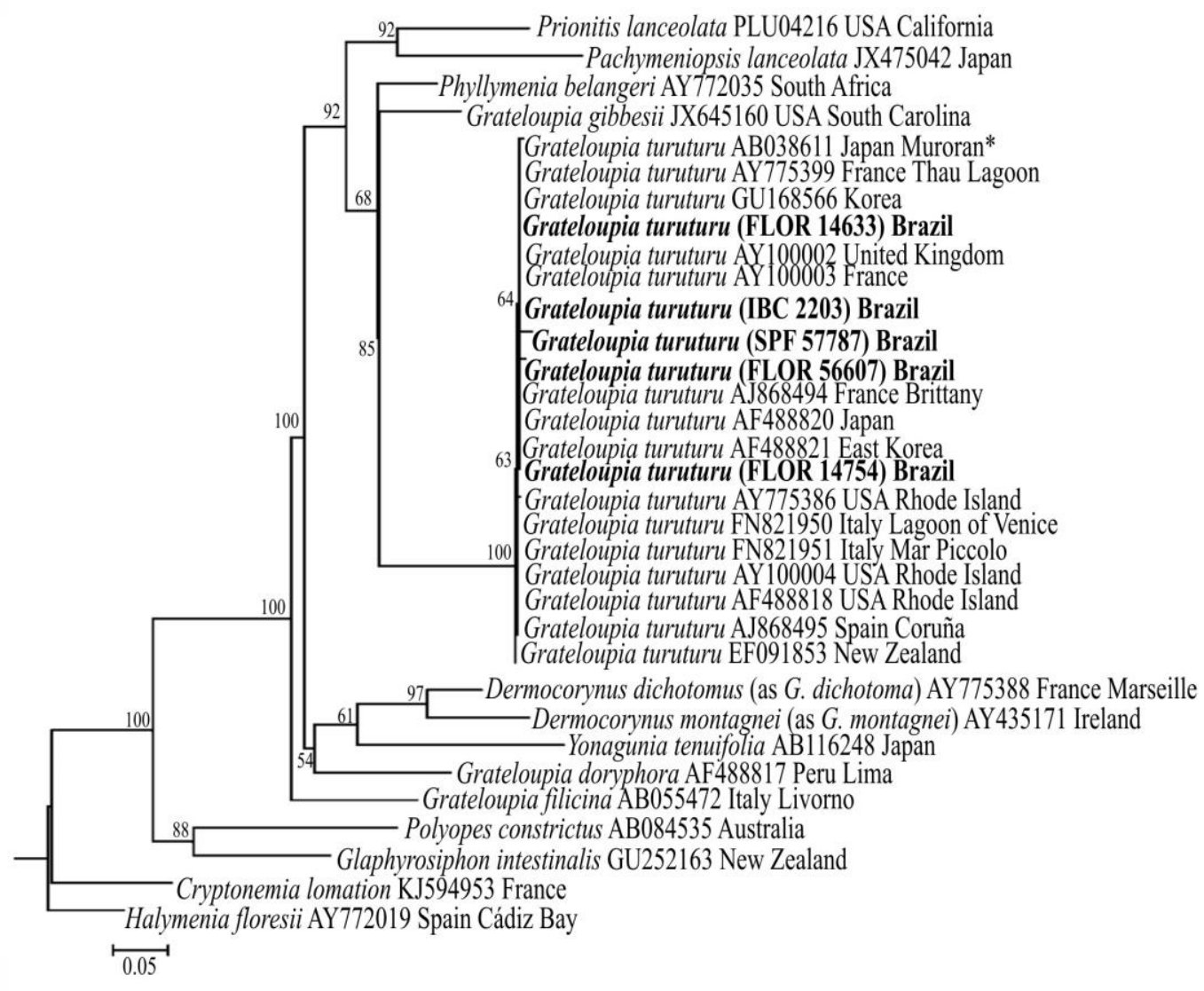




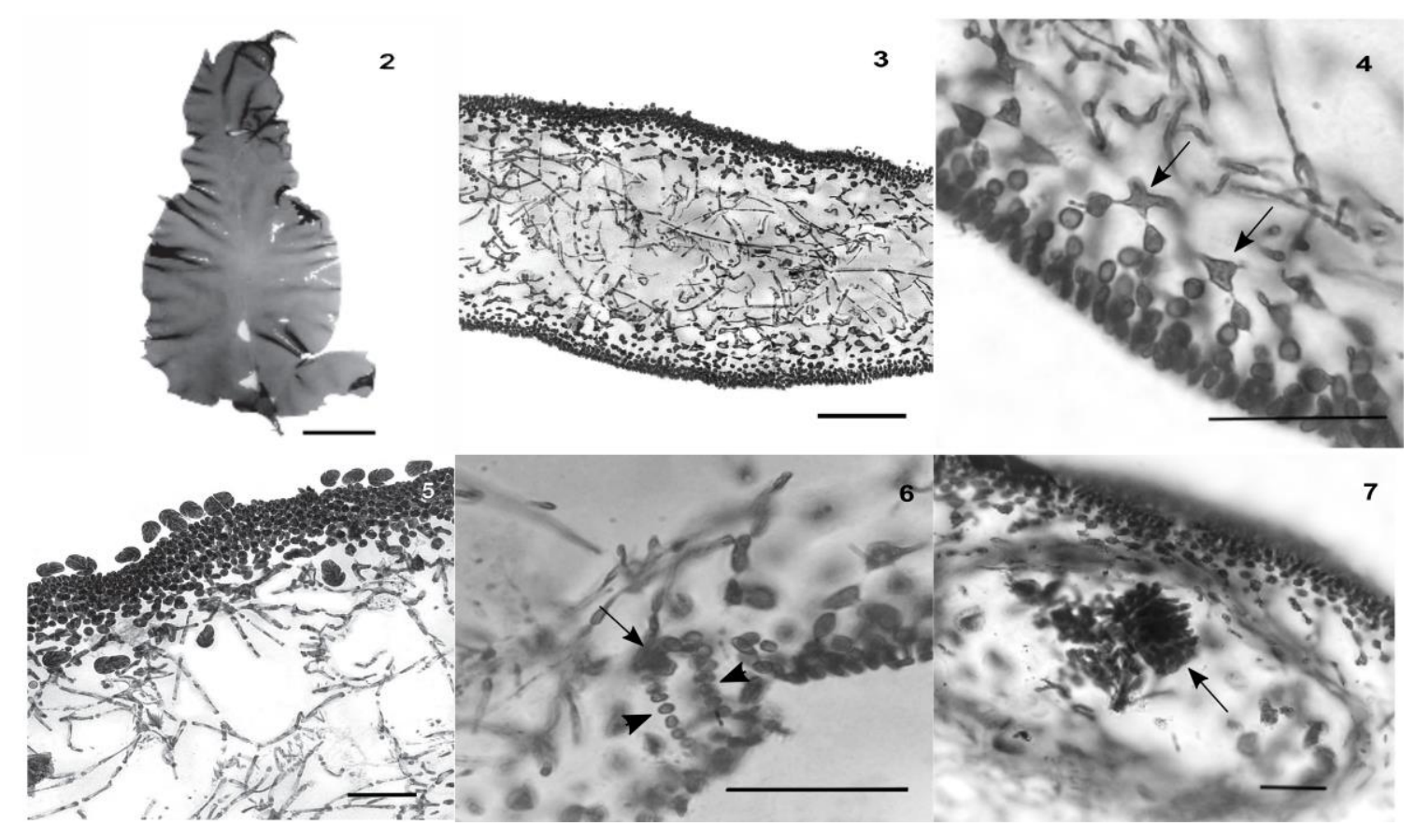


Table S1. Samples of Grateloupia turuturu used in this study. SC: Santa Catarina; n.s.: not sequenced.

Collection data

GenBank

Code

COI-5P $\quad r b c \mathrm{~L}$

SPF 57787

Armação Beach, Florianópolis, SC, Brazil (-

KP976170 KP976173

274'00”S; -48³0’04’'O), 26 Feb. 2012,

tetrasporophyte, leg. C.A.A. Azevedo, B. Torrano-

Silva, F. Nauer, M.N. Sissini.

IBC 2203

Armação Beach, Florianópolis, SC, Brazil (-

n.s.

KP976174

2744'57"S; -48²9'59"O), 30 Jan. 2011, infertile,

leg. P. Horta.

FLOR 14633

Saquinho Beach, Florianópolis, SC, Brazil (-

KP976172

KP976177

27080’31'S; -48 53'64”O), 13 Sep. 2011, infertile,

leg. M.B. Batista.

FLOR 14754

Saquinho Beach, Florianópolis, SC, Brazil (-

n.s.

KP976176

2780’31’S; -4853’64”O), 13 Sep. 2011,

tetrasporophyte, leg. M.B. Batista.

FLOR 56607

Armação Beach, Florianópolis, SC, Brazil (-

KP976171

KP976175

2744'57"S; -48²9'59"O), 30 Jan. 2011, female

gametophyte, leg. M.B. Batista.

FLOR: Universidade Federal de Santa Catarina, Florianópolis, Brazil. SPF: Universidade de São Paulo, São Paulo, Brazil. Herbarium Codes according to "Index Herbariuorum. Part I. The herbaria of the world" (http://sweetgum.nybg.org/ih/). 